\title{
Alinhamento de Seqüências Biológicas
}

Rogério THEOdoRo DE BRITO

\author{
DisSERTAÇÃO APRESENTADA \\ $\mathrm{AO}$ \\ Instituto de Matemática e EstatísticA \\ DA \\ UNIVERSIDADE DE SÃO PAULO \\ PARA \\ OBTENÇÃO DO GRAU \\ DE \\ Mestre em CiênCia da ComputaÇÃo
}

Orientador: Prof. Dr. José Augusto Ramos Soares

Durante a elaboração deste trabalho, o autor recebeu apoio financeiro do CNPq. 


\section{Alinhamento de Seqüências Biológicas}

Este exemplar corresponde à redação final

da dissertação devidamente corrigida e defendida por Rogério Theodoro de Brito e aprovada pela comissão julgadora.

São Paulo, 25 de setembro de 2003.

Banca examinadora:

- Prof. Dr. José Augusto Ramos Soares (orientador, IME/USP)

- Prof. Dr. João Meidanis (IC/Unicamp)

- Prof. Dr. Alair Pereira do Lago (IME/USP) 



\section{Agradecimentos}

Esta dissertação, assim como é o caso de qualquer outro trabalho de longa duração, não poderia se concretizar sem o auxílio direto ou indireto de uma grande quantidade de pessoas.

A mais óbvia das influências neste trabalho é aquela do Prof. José Augusto. Considerome alguém de muita sorte por ter tido o privilégio de poder estudar sob sua orientação desde os meus primeiros passos na Universidade de São Paulo (há quase uma década-desde as primeiras disciplinas que cursei e desde os estudos de Iniciação Científica).

Com suas admiráveis habilidades de observar de maneira clara e simples tudo aquilo que parece enigmático e contorcido, com sempre elegantes soluções e com suas sábias e sempre lúcidas palavras sobre todos assuntos de que pudemos tratar em nossas reuniões semanais, tive a oportunidade de refletir sobre variados aspectos não apenas de Ciência da Computação, mas também de áreas tão diversas que incluíam até mesmo política e relacionamentos humanos. Com toda certeza, procurarei carregar comigo seus ensinamentos pelo restante de minha vida.

Também foram responsáveis por esta dissertação os professores do IME/USP e, mais especificamente, os professores do Departamento de Ciência da Computação pela educação de altíssima qualidade oferecida no Instituto.

Naturalmente, todos os amigos que fiz dentro e fora do Instituto tornaram a escrita deste trabalho muito mais fácil do que ela seria se eu não pudesse contar com seu apoio. Obrigado aos amigos Alexandre Lymberopoulos, Renata Oliveira, Fábio Martinez, Adriano Rodrigues, Glauber Cintra, Claus Matsushigue, Francisco Elói, Said Adi, João Marcelo (J), Paulo Nuin, Roseli Silva e a todos os outros colegas que, por minha falha memória, não me lembrei de citar, mas que me ajudaram em todos os momentos de dificuldade e com quem eu pude compartilhar as alegrias de nossa convivência.

Um agradecimento especialíssimo deve ser feito aqui a todos os meus familiares e, em particular, a meus pais, João e Márcia, que são para mim muito mais do que tudo aquilo que eu conseguiria descrever em palavras pelo restante de minha vida.

Um agradecimento também a Priscila Paiero, que me é um exemplo de dedicação, perseverança e amor, além de ser uma fonte inesgotável de alegria.

É mais do que devido também um agradecimento a todos os funcionários do Instituto, que sempre com muito entusiasmo realizaram trabalhos imprescindíveis para meus estudos.

Agradeço também aos professores da Banca Examinadora, por aceitarem acompanhar meu trabalho e pelas diversas sugestões para sua melhoria.

Agradeço ainda ao CNPq e à Comissão de Bolsas do IME/USP pelo apoio financeiro, indispensável para este trabalho.

Um muito obrigado a todos vocês. 

Ao meu Orientador, que me ensinou sobre Ciência, $e$ aos meus Pais, que me ensinaram sobre a Vida. 



\section{Resumo}

Uma das tarefas mais básicas em Biologia Computacional é fazer a comparação de sequiências de espécies que estejam em estudo. Uma das maneiras de fazer a comparação é pela construção de um alinhamento das seqüências de interesse.

Alinhamentos de seqüências biológicas são ferramentas que, além de serem usadas para análise de regiões conservadas e de regiões que sofreram mutações em seqüências homólogas, também servem como ponto de partida para outras aplicações em Biologia Computacional, como o estudo de estruturas secundárias de proteínas e a construção de árvores filogenéticas.

$\mathrm{Na}$ dissertação procuramos abranger os resultados teóricos conhecidos mais importantes sobre alinhamentos de seqüências. Nela apresentamos, inicialmente, uma introdução ao conceito de alinhamentos de seqüências e aos algoritmos básicos para a busca de alinhamentos ótimos. Mostramos também que, em geral, o problema de encontrar um alinhamento ótimo de várias seqüências é NP-difícil e, além disso, exibimos dois algoritmos de aproximação para o problema. Finalmente, damos uma descrição de modelos estatísticos chamados Modelos de Markov de Estados Ocultos (em inglês, Hidden Markov Models), que possuem amplas aplicações e que podem ser usados para a construção de alinhamentos de várias seqüências.

Nosso objetivo com a dissertação é fazer uma discussão em língua portuguesa que seja detalhada, unificada, clara e bastante acessível de aspectos computacionais do problema de busca de alinhamentos que figuram apenas em artigos científicos e que são freqüentemente omitidos em livros-texto. 



\section{Abstract}

One of the most fundamental tasks in Computational Biology is to perform the comparison of sequences of species in study. One of the ways of doing such comparison is by constructing an alignment of the sequences of interest.

Alignments of biological sequences are tools that, besides being used for analysis of conserved and mutated regions in homologous sequences, are also useful as a starting point for other applications in Computational Biology, like the study of secondary structures of proteins and the construction of phylogenetic trees.

In this dissertation, we were concerned with covering the most important known theoretical results about sequence alignments. Initially, we present an introduction to the concept of sequence alignment and to the basic algorithms for finding optimum alignments. We also show that, in general, the problem of finding an optimum multiple sequence alignment is NP-hard and we also show two approximation algorithms for the problem. Finally, we give a description of statistical models called Hidden Markov Models, that have many applications and that can be used in the construction of multiple sequence alignments.

Our goal with this dissertation is to make available in Portuguese a detailed, unified, clear and accessible discussion of selected computational aspects of the problem that are only available in scientific articles and that are frequently omitted in textbooks. 



\section{Sumário}

1 Alinhamentos de Seqüências 1

1.1 Introdução . . . . . . . . . . . . . . . . . . . . . . . 1

1.2 Objetivo desta Dissertação . . . . . . . . . . . . . . . . . 2

1.3 Definições . . . . . . . . . . . . . . . . . . . . . . 2

1.3.1 Alfabetos, Símbolos e Seqüências . . . . . . . . . . . . . . 2

1.3.2 Alinhamentos . . . . . . . . . . . . . . . . . . 3

1.4 Alinhamentos de Pares de Seqüências . . . . . . . . . . . . . . 3

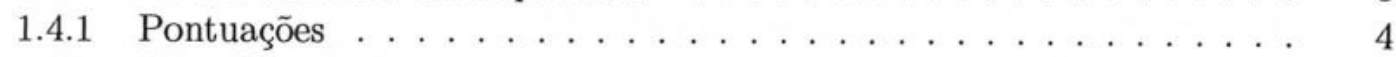

1.4.2 Formalização do Problema . . . . . . . . . . . . . . . . . . 8

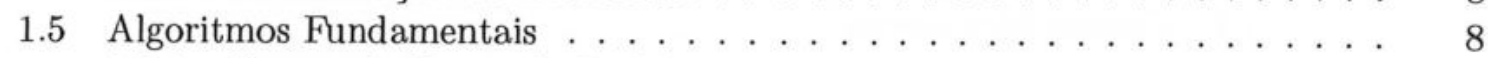

1.5.1 Espaço de Busca do Problema . . . . . . . . . . . . . . . . . . 9

1.5.2 Algoritmo Recursivo para o Problema . . . . . . . . . . . . . . 10

1.5.3 Propriedades do Problema . . . . . . . . . . . . . . . . . . 12

1.5.4 Algoritmo de Programação Dinâmica . . . . . . . . . . . . . . . . . . . . . 13

1.5.5 Método Alternativo de Programação Dinâmica . . . . . . . . . . . . 17

1.6 Método de Economia de Espaço (Hirschberg) . . . . . . . . . . . . . . . . 20

1.6.1 Calculando $d(s, t)$ em Espaço Linear . . . . . . . . . . . . . . . 21

1.6.2 Calculando um Alinhamento Ótimo em Espaço Linear . . . . . . . . 22

1.7 Método de Economia de Tempo (Quatro Russos) . . . . . . . . . . . . . . . 29

1.8 Variantes do Problema . . . . . . . . . . . . . . . . . . . . . 35

1.8.1 Alinhamentos Globais e Similaridade . . . . . . . . . . . . . . . . 35

1.8.2 Alinhamentos Semiglobais . . . . . . . . . . . . . . . . . . . . . 38

1.8.3 Alinhamentos Locais . . . . . . . . . . . . . . . . . . . . . . . . . . . . . . 39

1.8.4 Interpretação Estatística de Similaridades . . . . . . . . . . . . . . . 41

2 Alinhamentos de Várias Seqüências $\quad 45$

2.1 Introdução . . . . . . . . . . . . . . . . . . . . . . . . 45

2.2 Formulação do Problema . . . . . . . . . . . . . . . . . . . . 46

2.2.1 Pontuação de Colunas e Pontuação SP . . . . . . . . . . . . . . . . . 47

2.3 Projeções de Alinhamentos e Interpretação Geométrica . . . . . . . . . . . . . 49

2.3.1 Interpretação Geométrica para Duas Seqüências . . . . . . . . . . 50

2.3 .2 Caso de Várias Seqüências . . . . . . . . . . . . . . . . . . . . 53

2.4 Algoritmo de Programação Dinâmica . . . . . . . . . . . . . . . . . . 55

2.4.1 Análise de Complexidade . . . . . . . . . . . . . . . 57

2.4 .2 Comentários Gerais . . . . . . . . . . . . . . . . . 58

2.5 Método de Carrillo-Lipman . . . . . . . . . . . . . . . . . . . 59

2.5 .1 Motivação . . . . . . . . . . . . . . . . . . . . . 59 
2.5 .2 Interpretação Geométrica . . . . . . . . . . . . . . . . 60

2.5.3 Caminho Ótimo e Projeções de Alinhamentos . . . . . . . . . . . . . 61

2.5 .4 Algoritmo . . . . . . . . . . . . . . . . . . 66

2.5 .5 Análise de Complexidade . . . . . . . . . . . . . 68

3 Complexidade do Problema AVS $\quad 71$

3.1 Introdução . . . . . . . . . . . . . . . . . . . . . . . . . . . 71

3.2 O Problema AVS é NP-difícil (Wang e Jiang) . . . . . . . . . . . . . . 74

3.3 O Problema AVS é NP-difícil (Just) . . . . . . . . . . . . . . . . . . 79

3.3.1 O Problema AVS e Alguns Problemas Relacionados . . . . . . . . . 81

3.3 .2 Redução . . . . . . . . . . . . . . . . . . . . 83

4 Algoritmos de Aproximação $\quad 91$

4.1 Introdução . . . . . . . . . . . . . . . . . . . . . . . . . . . . . . 91

4.2 Junção de Alinhamentos . . . . . . . . . . . . . . . . . . . . . . . . . . . . . . . . . . . . . . . . . .

4.2 .1 O Algoritmo JunTA . . . . . . . . . . . . . . . . . . . . . . 93

4.2 .2 Análise de Complexidade . . . . . . . . . . . . . . . . 93

4.2 .3 Comentários Gerais . . . . . . . . . . . . . . . . . . . . . 94

4.3 Algoritmo de Aproximação de Gusfield . . . . . . . . . . . . . . . . . . . . . . . . . 95

4.3.1 Razão de Aproximação . . . . . . . . . . . . . . . . . . . 97

4.3 .2 Comentários Gerais . . . . . . . . . . . . . . . . . . 98

4.4 Algoritmo de $l$-Estrelas . . . . . . . . . . . . . . . . . . . . . 99

4.4 .1 Definições . . . . . . . . . . . . . . . . . . . 100

4.4.2 Custo de Comunicação de Grafos e $l$-Estrelas . . . . . . . . . . 101

4.4.3 Conjuntos Balanceados de $(2 l-1)$-Estrelas . . . . . . . . . . 106

5 Modelos de Markov de Estados Ocultos $\mathbf{1 1 5}$

5.1 Introdução . . . . . . . . . . . . . . . . . . . . . . . . 115

5.2 Cadeias de Markov . . . . . . . . . . . . . . . . . . . . . . . 117

5.2.1 Estimação de Parâmetros . . . . . . . . . . . . . . . . . . . . . . 119

5.3 Modelos de Markov de Estados Ocultos . . . . . . . . . . . . . . . . . . . 122

5.3.1 Cassino Ocasionalmente Desonesto . . . . . . . . . . . . . . . . 124

5.4 Problemas Básicos de MMEOs . . . . . . . . . . . . . . . . . . . . . . . . 124

5.4.1 Problema 1: Problema de Avaliação . . . . . . . . . . . . . . 126

5.4.2 Problema 2: Problema de Decodificação . . . . . . . . . . . . . . . 129

5.4.3 Problema 3: Problema de Treinamento . . . . . . . . . . . . . . . . 134

5.5 MMEOs de Perfil de Seqüências . . . . . . . . . . . . . . . . . . . . . . 144

5.5.1 Blocos de Alinhamentos e pMMEOs . . . . . . . . . . . . . . . 145

5.5.2 Tratamento de Inserções e de Remoções de Caracteres . . . . . . . . 146

5.6 Alinhamento de Sequiências e MMEOs . . . . . . . . . . . . . . . . . 153 


\section{Lista de Figuras}

1.1 Alinhamento entre TAgGTCA e TAGCTA . . . . . . . . . . . . . . 4

1.2 Alinhamento ótimo entre TAGGTCA e TAGCTA . . . . . . . . . . . . . 4

1.3 Alinhamentos ótimos com e sem colunas só com espaços . . . . . . . . . . . 9 9

1.4 Preenchimento da matriz a pelo Algoritmo Dist . . . . . . . . . . . . 15

1.5 Preenchimento da matriz a pelo Algoritmo Dist-Rev . . . . . . . . . . . 18

1.6 Esquema genérico de um $t$-bloco . . . . . . . . . . . . . . . . 30

1.7 Matriz PAM $250 \ldots \ldots \ldots \ldots \ldots \ldots \ldots \ldots$

2.1 Alinhamento de várias seqüências . . . . . . . . . . . . . . . . . . 46

2.2 Alinhamento ótimo com projeção que não é alinhamento ótimo . . . . . . . 50

2.3 Grafo em forma de reticulado para duas seqüências . . . . . . . . . . . . . 51

2.4 Grafo em forma de reticulado para três seqüências . . . . . . . . . . . 55

2.5 Um alinhamento entre seqüências duas-a-duas "similares" . . . . . . . . . . 60

2.6 Caminho associado a um alinhamento e sua projeção . . . . . . . . . . . . 62

2.7 Simulação de vetor inicializado com vetores não inicializados . . . . . . . 68

3.1 Alinhamento gerado a partir de grafo . . . . . . . . . . . . . . . . 84

4.1 Uma 4-estrela com 10 vértices . . . . . . . . . . . . . . . . . . . . . . . . 100

4.2 Uma 3-estrela de 9-vértices e uma configuração derivada da 3-estrela . . . . 106

5.1 Grafo de transições da cadeia de Markov para previsão de tempo . . . . . . 118

5.2 Grafo de transições para um MMEO para um cassino . . . . . . . . . . . 125

5.3 Modelagem de um bloco de um alinhamento . . . . . . . . . . . . . . . . . 146

5.4 O esquema geral de um pMMEO . . . . . . . . . . . . . . . . . . . . . . 149

5.5 Um alinhamento antes e depois da inclusão de uma seqüência . . . . . . . . 154 


\section{Lista de Algoritmos}

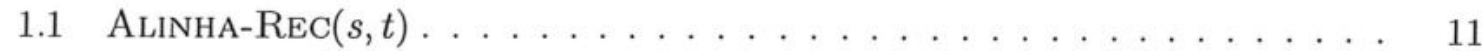

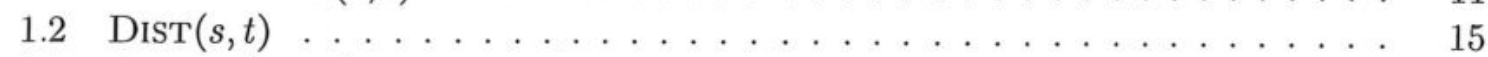

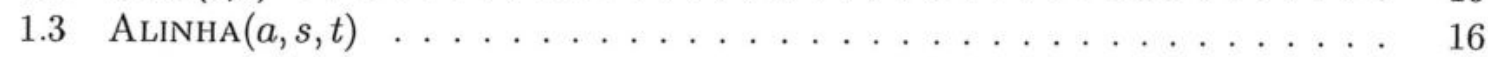

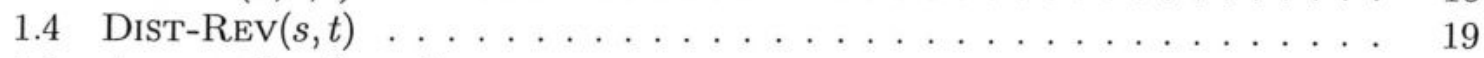

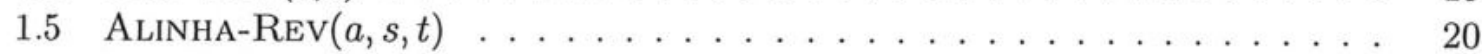

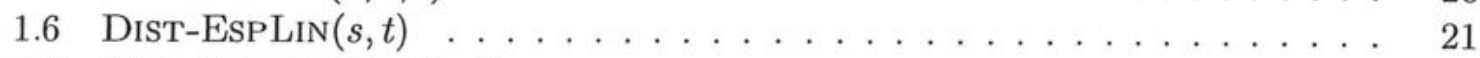

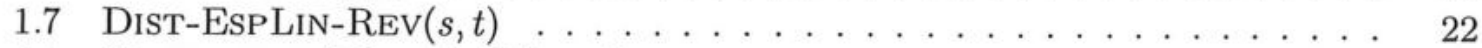

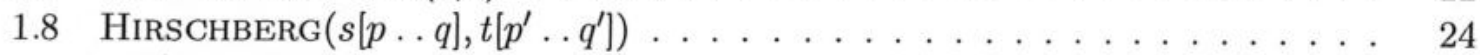

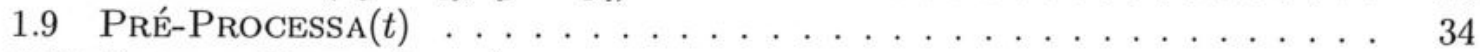

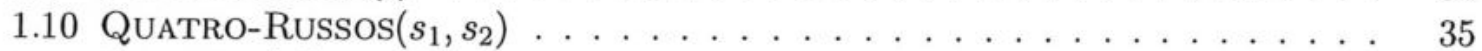

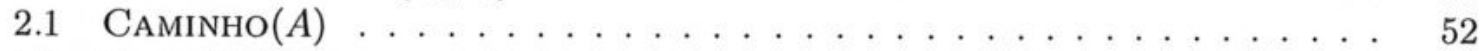

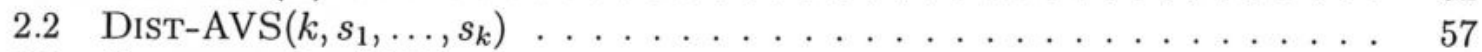

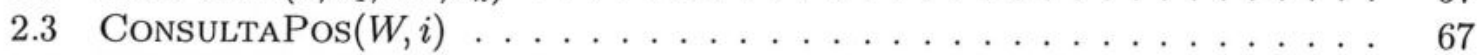

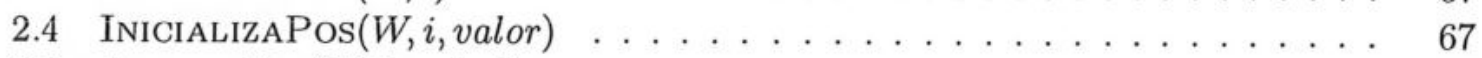

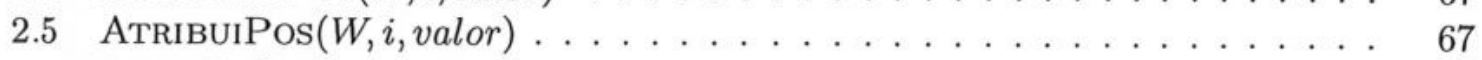

$2.6 \operatorname{DiST-CL}\left(k, s_{1}, \ldots, s_{k}, U\right) \ldots \ldots \ldots \ldots \ldots \ldots$

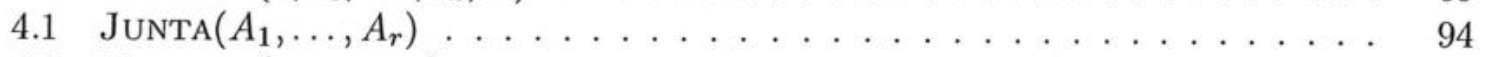

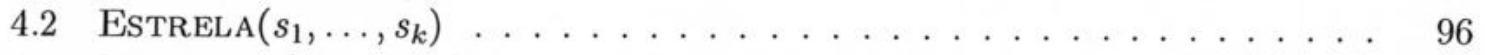

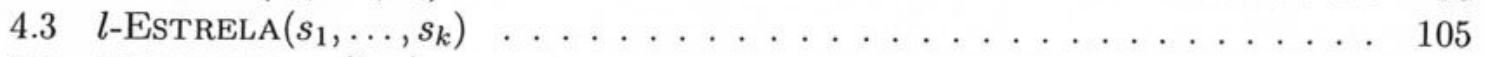

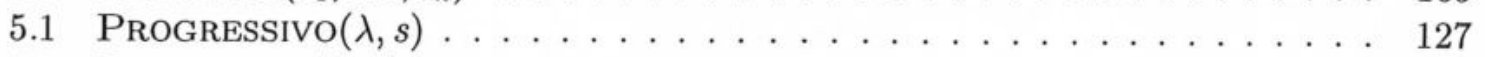

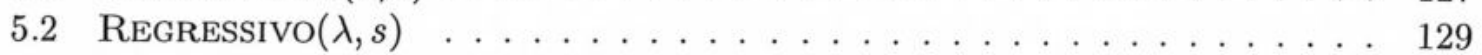

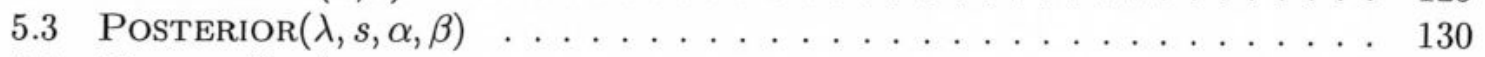

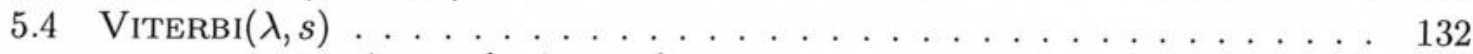

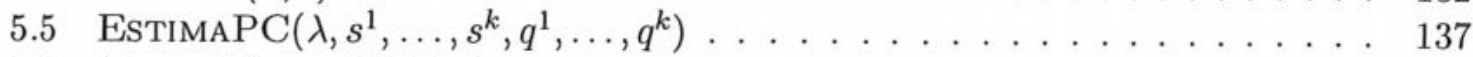

5.6 Baum-Welch $(Q, \Sigma, s) \ldots \ldots \ldots \ldots \ldots \ldots \ldots \ldots \ldots$

5.7 BAum-WeLch-VS $\left(Q, \Sigma, s^{1}, \ldots, s^{k}\right) \ldots \ldots \ldots \ldots \ldots \ldots \ldots \ldots$

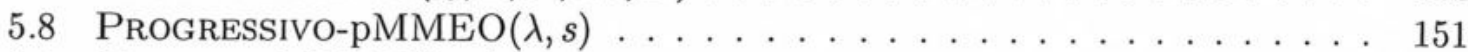

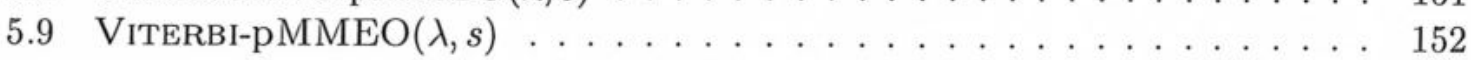




\section{Capítulo 1}

\section{Alinhamentos de Seqüências}

"Nada em Biologia faz sentido exceto à luz da Evolução"

- T. Dobzhansky (1900-1975)

\subsection{Introdução}

No estudo de evolução e de funções de moléculas biológicas é comum a necessidade de comparar moléculas de várias espécies ou seres. Por exemplo, poderíamos estar interessados em conhecer quais são as relações de parentesco entre o HIV presente em uma dada pessoa e as cepas de HIV para as quais se sabe da eficácia ou ineficácia de determinadas drogas antes de prescrever um coquetel de AIDS. Dessa maneira, drogas que não fossem úteis para o tratamento da pessoa não seriam prescritas ou seriam substituídas. Com isso, o tratamento poderia ser mais bem sucedido, resultando também em uma possível redução de recursos destinados à compra de medicamentos e em uma diminuição dos efeitos colaterais das drogas sofridos pelo paciente.

Em geral, as moléculas que se consideram nesse tipo de estudo são moléculas de DNA, de RNA e de proteínas. Como tais moléculas são polímeros que podem ser representadas de maneira fácil por uma seqüência de caracteres, comparar as moléculas resume-se, na prática, a fazer uma comparação das seqüências correspondentes.

Uma maneira de fazer a comparação de seqüências é computar um alinhamento entre as sequiências correspondentes às moléculas de interesse (ou fragmentos dessas moléculas). Intuitivamente falando, um alinhamento é uma maneira de inserir espaços nas seqüências de modo que todas fiquem com mesmo comprimento, para possibilitar uma fácil comparação.

O problema de encontrar alinhamentos entre seqüências ocupa uma posição de destaque em Biologia Computacional: alinhamentos são usados para comparações de seqüências, para construção de árvores evolutivas ("árvores filogenéticas") e para predição de estrutura secundária de moléculas de RNA e de proteínas. Além disso, encontrar alinhamentos é, por si só, um problema de interesse em Ciência da Computação, com aplicações em Processamento de Texto, dentre outras áreas. 


\subsection{Objetivo desta Dissertação}

Reunimos neste trabalho alguns resultados computacionais que tratam de aspectos variados do problema de alinhamento de seqüências biológicas.

Os algoritmos são aqui apresentados por uma descrição simples e intuitiva de seu funcionamento, com justificativas de correção e análises de complexidade de tempo e de espaço. Além disso, os algoritmos são apresentados em forma de pseudo-código de alto nível. $\mathrm{Na}$ discussão dos algoritmos, procuramos dar um tratamento unificado de vários aspectos, incluindo de notação, de definições e, por vezes, de métodos de demonstrações.

Acreditamos que a exposição dos tópicos seja clara, simples e detalhada, abordando aspectos que, em geral, são omitidos em outros textos. Muitas vezes, a exploração desses detalhes evidenciou imprecisões em várias publicações.

Nossa pretensão é que este texto possa servir como material atualizado de apoio para cursos introdutórios de Biologia Computacional e, também, como uma referência em português a respeito de alguns tópicos cuja bibliografia somente pode ser encontrada em língua estrangeira.

\subsection{Definições}

Nesta seção, daremos algumas definições a fim de estabelecer a linguagem utilizada e de fixar a notação. Outras definições serão dadas no momento em que forem necessárias.

\subsubsection{Alfabetos, Símbolos e Seqüências}

Um alfabeto $\Sigma$ é um conjunto finito e não-vazio. Um elemento $\sigma \in \Sigma$ é chamado caractere ou símbolo. Uma seqüência $s$ sobre o alfabeto $\Sigma$ é uma seqüência $s=\left(\sigma_{1}, \sigma_{2}, \ldots, \sigma_{n}\right) \in \Sigma^{n}$, onde $n \geq 0$ é um inteiro. Por conveniência e simplicidade, denotaremos $s$ por $\sigma_{1} \sigma_{2} \cdots \sigma_{n}$ apenas. Se $s=\sigma_{1} \sigma_{2} \cdots \sigma_{n}$, definimos o comprimento $|s|$ de $s$ por $|s|=n$. Se $n=0$ (e, portanto, $|s|=0$ ), então $s$ é chamada seqüência vazia e é denotada por $\varepsilon$. Se $n \geq 0$ é um inteiro e $\sigma \in \Sigma$, então denotamos por $\sigma^{n}$ a seqüência de comprimento $n$ cujos caracteres são todos iguais a $\sigma$. O conjunto de todas as seqüências sobre o alfabeto $\Sigma$ é denotado por $\Sigma^{*}$, enquanto o conjunto de todas as seqüências não-vazias sobre $\Sigma$ é denotado por $\Sigma^{+}$.

Um segmento $s[i \ldots j]$ de uma seqüência $s$, para $i \leq j$, é a seqüência definida por $s[i \ldots j]=\sigma_{i} \sigma_{i+1} \cdots \sigma_{j}$. Se $i>j$, definimos $s[i \ldots j]=\varepsilon$. Por comodidade, denotaremos o caso particular em que $j=i$ por $s[i]$ simplesmente, isto é, $s[i]=s[i \ldots i]$. Nesse caso, claramente $s[i]=\sigma_{i}$. Freqüentemente usaremos esta notação com colchetes em descrições de algoritmos para fazer referência aos símbolos de $s$.

Uma subseqüência $s^{\prime}$ de $s$ é uma seqüência $s^{\prime}=\sigma_{i_{1}} \sigma_{i_{2}} \cdots \sigma_{i_{m}}$ em que $\left\{i_{1}, i_{2}, \ldots, i_{m}\right\} \subseteq$ $\{1,2, \ldots, n\}$ e $i_{1}<i_{2}<\cdots<i_{m}$. Nesse caso, também dizemos que $s$ é uma superseqüência de $s^{\prime}$. É importante observar que, enquanto um segmento de $s$ é uma série de caracteres consecutivos de $s$, uma subseqüência pode ser constituída de caracteres que não necessariamente estejam consecutivos em $s$.

Se $\Sigma$ é um alfabeto tal que $\sqcup \notin \Sigma$, denotamos por $\Sigma^{\prime}$ o alfabeto $\Sigma^{\prime}=\Sigma \cup\{u\}$. O símbolo $\sqcup$ é tratado como especial e é chamado caractere branco ou espaço.

Em nosso texto, freqüentemente supomos que $\Sigma=\{A, C, G, T\}$ é o alfabeto correspondente a bases nitrogenadas (ou simplesmente bases) presentes em seqüências de DNA e que seqüências sobre $\Sigma$ são fragmentos (ou trechos) de DNA de alguma espécie em análise ou 
que $\Sigma$ é o alfabeto correspondente ao conjunto de aminoácidos e que uma seqüência sobre $\Sigma$ é uma proteína (ou fragmento de uma proteína).

Embora esses dois alfabetos sejam usados com grande freqüência, eles não são os únicos alfabetos usados em Biologia Molecular. Por exemplo, um terceiro alfabeto, chamado alfabeto genético estendido IUPAC, é uma extensão do alfabeto de 4 símbolos usado para representar bases de DNA. Sua utilidade é expressar o fato de uma determinada posição de uma sequiência ser ocupada por alguma base que não seja completamente conhecida. Essa necessidade surge durante o seqüenciamento de bases, pois, no processo, pode haver ambigüidade de leitura de uma base que ocupa uma determinada posição. O alfabeto IUPAC possui um caractere correspondente a cada possibilidade de leitura para a base: ele consiste de um símbolo para cada subconjunto não-vazio de $\{\mathrm{A}, \mathrm{C}, \mathrm{G}, \mathrm{T}\}$ (e, portanto, possui $15=2^{4}-1$ símbolos).

Em todo caso, os algoritmos que estudaremos são genéricos e, via de regra, independem dos alfabetos utilizados.

\subsubsection{Alinhamentos}

Sejam $k$ um inteiro positivo e $s_{1}, s_{2}, \ldots, s_{k}$ seqüências sobre um alfabeto $\Sigma$, com $\left|s_{i}\right|=n_{i}$, para $i=1, \ldots, k$. Um alinhamento $A$ de $s_{1}, s_{2}, \ldots, s_{k}$ é uma matriz $A=\left(A_{i j}\right)$ de dimensões $k \times n$ com entradas de $\Sigma^{\prime}=\Sigma \cup\{\cup\}\left(\right.$ e $\left.n \geq \max _{i=1}^{k}\left\{n_{i}\right\}\right)$ tal que a linha $A_{i}$ do alinhamento $A$ consista exatamente da seqüência $s_{i}$ com possíveis espaços (e apenas espaços) inseridos entre os caracteres de $s_{i}$.

Podemos deixar a definição acima mais precisa reescrevendo-a como: um alinhamento $A$ de $s_{1}, s_{2}, \ldots, s_{k}$ é uma matriz $A=\left(A_{i j}\right)$ de dimensões $k \times n$ com entradas em $\Sigma^{\prime}$ tal que, para cada $i$, existe um conjunto $J_{i}=\left\{j_{1}, j_{2}, \ldots, j_{n_{i}}\right\} \subseteq\{1,2, \ldots, n\}$, com $j_{1}<j_{2}<\cdots<j_{n_{i}}$ e tal que $A_{i j_{1}} A_{i j_{2}} \cdots A_{i j_{n_{i}}}=s_{i}$ e tal que para todo $j \in\{1,2, \ldots, n\}-J_{i}$, temos $A_{i j}=\sqcup$.

Dizemos que dois caracteres $s_{i}[j]$ e $s_{i^{\prime}}\left[j^{\prime}\right]$ estão alinhados em $A$ se $s_{i}[j]$ e $s_{i^{\prime}}\left[j^{\prime}\right]$ estão na mesma coluna de $A$.

Seja $A=\left(A_{i j}\right)$ um alinhamento de $s_{1}, s_{2}, \ldots, s_{k}$. Uma lacuna (em inglês gap) de $s_{i}$ no alinhamento $A$ é qualquer segmento não-vazio maximal de $A_{i}$ composto apenas de espaços, isto é, uma lacuna de $s_{i}$ em $A$ é um segmento $A_{i}\left[j \ldots j^{\prime}\right]$ de $A_{i}$ tal que:

- $j \leq j^{\prime}$

- todos os símbolos de $A_{i}\left[j \ldots j^{\prime}\right]$ são ч;

- não é possível estender $A_{i}\left[j \ldots j^{\prime}\right]$ em $A_{i}$ por meio de espaços em branco, ou seja, $j=1$ ou $A_{i}[j-1] \neq$ ч e $j^{\prime}=n$ ou $A_{i}\left[j^{\prime}+1\right] \neq$ ง.

Sejam $s_{1}, s_{2}, \ldots, s_{k}$ seqüências sobre um alfabeto $\Sigma$. Denotamos por $\mathcal{A}_{s_{1}, s_{2}, \ldots, s_{k}}$ o conjunto de alinhamentos entre as seqüências $s_{1}, s_{2}, \ldots, s_{k}$.

\subsection{Alinhamentos de Pares de Seqüências}

Neste capítulo, focalizamos nossa atenção a alinhamentos de apenas duas seqüências, embora boa parte dos conceitos que discutimos aplique-se também a alinhamentos de um número arbitrário de seqüências. Alinhamentos de várias seqüências é o tópico do Capítulo 2 . 
Como dissemos anteriormente, alinhamentos são uma maneira de realizar comparações entre seqüências. Para efeito de ilustração, consideremos as seqüências TAGGTCA e TAGCTA. Um alinhamento entre elas é mostrado na Figura 1.1.

TAGGTCA

பบบபบபบTAGCTA

Figura 1.1: Um alinhamento entre TAGGTCA e TAGCTA.

Uma breve inspeção das sequiências logo nos convence de que elas são "parecidas", embora o alinhamento da Figura 1.1 "deixe a desejar" e não ressalte este fato. Um alinhamento "melhor" entre as seqüências poderia ser o alinhamento ilustrado na Figura 1.2.

TAGGTCA

TAGCT $_{\sqcup} A$

Figura 1.2: Outro alinhamento ("melhor") entre TAGGTCA e TAGCTA.

O segundo alinhamento deixa mais evidente que as seqüências têm muito em comum e que suas únicas diferenças são uma base $\mathrm{G}$ na primeira seqüência ocupando o lugar de uma base $\mathrm{C}$ na segunda seqüência e a penúltima base (um C) da primeira seqüência, que não está presente na segunda seqüência.

Os eventos de substituição, remoção e inserção de caracteres como mostrados acima possuem interpretação biológica durante o processo evolutivo de seqüências, em que bases podem ser substituídas, inseridas ou removidas de seqüências. Um outro tipo de evento, chamado reversão ou inversão, corresponde à substituição de um segmento $s_{1}$ de uma seqüência $s=s_{0} s_{1} s_{2}$ pelo segmento $s_{1}^{-1}$ de modo a obter a seqüência $s^{\prime}=s_{0} s_{1}^{-1} s_{2}$, onde $s_{1}^{-1}$ é o segmento reverso de $s_{1}$ (i.e., os caracteres de $s_{1}^{-1}$ são os caracteres de $s_{1}$ "lidos na ordem contrária"). Reversões geralmente não são levadàs em consideração ao procurarmos alinhamentos ${ }^{1}$.

Naturalmente, estamos interessados em alinhamentos que exponham da melhor forma possível a estrutura das seqüências consideradas, evidenciando suas similaridades e diferenças e permitindo, assim, uma fácil comparação. Isso traduz nossa impressão de que o alinhamento da Figura 1.2 é "melhor" do que aquele da Figura 1.1.

De um modo geral, para comparar alinhamentos, atribuímos um "conceito de qualidade" ou "pontuação" para cada alinhamento. Baseando-nos nesse critério, estamos interessados em escolher o melhor ${ }^{2}$ alinhamento entre as seqüências dadas, como veremos a seguir.

\subsubsection{Pontuações}

Para maior comodidade com a notação, neste capítulo em particular, vamos supor que as seqüências a serem alinhadas sejam $s$ e $t$, com $|s|=m$ e $|t|=n$. As linhas de um

\footnotetext{
${ }^{1}$ É possível tratar de inversões nas comparações feitas em forma de alinhamentos, mas a modelagem para esta situação mais geral é bem mais complicada do que a feita para alinhamentos em que os únicos eventos possíveis são substituições, remoções e inserções de caracteres. Além disso, os algoritmos que levam em consideração as inversões possuem complexidade bem maior do que a dos algoritmos tradicionais para o problema $\left[\mathrm{LKM}^{+} 02\right]$.

${ }^{2} \mathrm{Ou}$ um melhor alinhamento, no caso de haver vários com a mesma pontuação.
} 
alinhamento $A$ entre $s$ e $t$ serão denotadas por $s^{\prime}$ e $t^{\prime}$, de forma que $s^{\prime}$ corresponda à seqüência $s$ com possíveis espaços inseridos e com o mesmo valendo para $t^{\prime}$ em relação a $t$. O comprimento do alinhamento $A$ será denotado por $l$, isto é, $l=\left|s^{\prime}\right|=\left|t^{\prime}\right|$.

Uma maneira usual de atribuir pontuações a alinhamentos de duas seqüências é dada pela estratégia de, a cada coluna de um alinhamento, associar uma pontuação e definir a pontuação do alinhamento como sendo a soma das pontuações de suas colunas. Detalhamos nas seções seguintes o processo usado para pontuar um alinhamento.

\subsubsection{Matrizes de Pontuação}

Para determinarmos a pontuação de um alinhamento $A$ de duas seqüências $s$ e $t$ sobre um alfabeto $\Sigma$, usamos uma função auxiliar $p: \Sigma^{\prime} \times \Sigma^{\prime} \rightarrow \mathbb{Q}$ que a cada par de símbolos $(\sigma, \rho)$ de $\Sigma^{\prime}=\Sigma \cup\{\sqcup\}$ associe uma pontuação $p(\sigma, \rho)$ de alinharmos $\sigma$ e $\rho$. Uma tal função é chamada função de pontuação de símbolos de $\Sigma^{\prime}$ ou, simplesmente, função de pontuação. As funções de pontuação são geralmente representadas por matrizes (com linhas e colunas indexadas por $\left.\Sigma^{\prime}\right)$ e, por este motivo, as função são também chamadas matrizes de pontuação.

Usando a matriz de pontuação $p$, definimos a pontuação ou custo $c_{p}(A)$ do alinhamento $A$ entre $s$ e $t$ como

$$
c_{p}(A)=\sum_{j=1}^{l} p\left(s^{\prime}[j], t^{\prime}[j]\right) .
$$

Quando a matriz de pontuação $p$ estiver clara pelo contexto, denotaremos $c_{p}(A)$ por $c(A)$ apenas.

Note-se que, da maneira acima, a pontuação $c_{p}$ pode ser observada como uma extensão de $p$ a alinhamentos de comprimento arbitrário, se considerarmos um par de símbolos $(\sigma, \rho)$ como sendo um alinhamento de comprimento 1 (reciprocamente, podemos interpretar $p$ como sendo a restrição de $c_{p}$ a alinhamentos de comprimento unitário). Por esse motivo, não faremos grande distinção entre $p$ e $c_{p}$ e, além disso, cometeremos com freqüência abusos de notação como

$$
c(A)=\sum_{j=1}^{l} c\left(s^{\prime}[j], t^{\prime}[j]\right)
$$

ou dizer que $c$ é a matriz de pontuação.

A maneira de atribuir pontuações a alinhamentos como soma das pontuações de suas colunas faz sentido do ponto de vista biológico. Por exemplo, a mutação de uma determinada base a outras bases nem sempre ocorre com a mesma probabilidade. As mutações entre bases podem ser de dois tipos: transições ou transversões. As bases nitrogenadas são divididas em duas classes: purinas (A e G) e pirimidinas (C e T). Uma transição é uma mudança entre bases de mesma classe, enquanto uma transversão é uma mudança entre bases de classes diferentes. Devido à composição das bases, transições ocorrem geralmente com mais freqüência do que transversões [GL99] e, dependendo do tipo de estudo realizado, a matriz de pontuação utilizada pode penalizar com maior pontuação os pares de bases que sejam de tipos diferentes.

Uma importante propriedade da pontuação dos alinhamentos, na forma definida, é ser aditiva no seguinte sentido: se um alinhamento $A$ é decomposto em dois outros alinhamentos, digamos $A_{E}$ e $A_{D}$, de forma que $A=\left(A_{E}: A_{D}\right)$, onde : denota a concatenação de $A_{E}$ com $A_{D}$, então temos que $c(A)=c\left(A_{E}\right)+c\left(A_{D}\right)$ e isto pode ser visto lembrando-nos de que a pontuação $c(A)$ é definida como sendo a soma das pontuações das colunas de $A$ 
(e, portanto, das pontuações das colunas de $A_{E}$ com as pontuações das colunas de $A_{D}$ ). Deixamos esse fato registrado em destaque para referências futuras.

Fato 1.1 (Aditividade da Pontuação). A pontuação de alinhamentos é aditiva.

\subsubsection{Métricas}

Uma importante classe de matrizes de pontuação é a classe das métricas, conceito que definimos a seguir.

Definição 1.1 (Métrica). Uma métrica é uma função $d: M \times M \rightarrow \mathbb{Q} \geq 0$ definida sobre um conjunto não-vazio qualquer $M$ que satisfaça, para todo $x, y, z \in M$,

i. $d(x, y) \geq 0$

ii. $d(x, y)=0 \Longleftrightarrow x=y$;

iii. $d(x, y)=d(y, x)$ (simetria);

iv. $d(x, y) \leq d(x, z)+d(z, y)$ (desigualdade triangular).

Para os nossos propósitos, trabalharemos principalmente com matrizes de pontuação que sejam métricas, a menos de menção em contrário. Se a matriz de pontuação $c$ é uma métrica, então definimos a distância $d(s, t)$ entre as seqüências $s$ e $t$ como

$$
d(s, t)=\min _{A \in \mathcal{A}_{s, t}}\{c(A)\},
$$

onde $\mathcal{A}_{s, t}$ é o conjunto de alinhamentos de $s$ e $t$. Em outras palavras, a distância entre duas seqüências $s$ e $t$ é definida como a menor pontuação de um alinhamento entre $s$ e $t$.

Um alinhamento $A$ entre duas seqüências $s$ e $t$ é dito ótimo se sua pontuação é mínima.

Uma importante propriedade da função $d$ definida acima é que o fato de que $d$ "herda" de $c$ as quatro propriedades de métricas. Isso está provado na proposição seguinte.

Proposição 1.2 (Métrica sobre $\Sigma^{*}$ ). Sejam $\Sigma$ um alfabeto fixado, c uma matriz de pontuação sobre $\Sigma^{\prime}$ que seja uma métrica e $s$ e $t$ seqüências sobre $\Sigma$. Então, a função d definida por $d=\min _{A \in \mathcal{A}_{s, t}}\{c(A)\}$ é uma métrica sobre o conjunto $\Sigma^{*}$.

Prova: Vamos verificar a validade para $d$ de cada um dos axiomas de métrica.

Como $c(\sigma, \rho) \geq 0$ para todo $(\sigma, \rho) \in \Sigma^{\prime} \times \Sigma^{\prime}$, então $c(A) \geq 0$ para todo alinhamento $A$ de $s$ e $t$ e, daí, $d(s, t) \geq 0$. Como $c(\sigma, \rho)=c(\rho, \sigma)$, temos que $d(s, t)=d(t, s)$. Obviamente, se $s=t$, então um possível alinhamento $A$ entre $s$ e $t$ é o alinhamento que alinha símbolos de mesmo índice de $s$ e $t$ (isto é, $s[j]$ com $t[j]$ ) e $A$ possui custo $c(A)=0$, donde segue que $d(s, t)=0$. Por outro lado, se $d(s, t)=0$, então existe um alinhamento $A$ de $s$ e $t$ tal que $c(A)=0$. Mas como $c(A)$ é soma de parcelas não-negativas resultando 0 , cada uma das parcelas é 0 e, como $c$ é uma métrica, cada coluna de $A$ possui símbolos idênticos. Disso segue que $d(s, t)=0 \Longleftrightarrow s=t$.

Resta-nos mostrar que a distância $d$ satisfaz à desigualdade triangular, isto é, que para quaisquer seqüências $s, t, u \in \Sigma^{*}$, temos $d(s, t) \leq d(s, u)+d(u, t)$.

Sejam $A^{\prime}$ um alinhamento ótimo entre $s$ e $u$ e $A^{\prime \prime}$ um alinhamento ótimo entre $u$ e $t$. Vamos descrever um alinhamento $A$ entre $s$ e $t$ a partir de $A^{\prime}$ e $A^{\prime \prime}$ tal que $d(s, t) \leq c(A) \leq$ $d(s, u)+d(u, t)$, de onde segue o resultado. Sem perda de generalidade, podemos supor que na primeira linha de $A^{\prime}$ estão os caracteres de $s$ e que os caracteres de $u$ estão na 
segunda linha. Da mesma maneira, supomos que os caracteres de $u$ e de $t$ estão na primeira e segunda linhas de $A^{\prime \prime}$, respectivamente.

Seja $u=u[1] \cdots u[l]$, onde $l=|u|$ é o comprimento de $u$ e sejam $j_{1}^{\prime}, \ldots, j_{l}^{\prime}$ as colunas de $A^{\prime}$ em que os caracteres $u[1], \ldots, u[l]$ aparecem, com $j_{0}^{\prime}=0$ por definição. Consideremos a divisão de $A^{\prime}$ em blocos de colunas consecutivas de forma que o bloco $A_{i}^{\prime}$ consista das colunas de $j_{i-1}^{\prime}+1$ até a coluna $j_{i}^{\prime}$, para $i=1, \ldots, l$ e o bloco $A_{l+1}^{\prime}$ consista das colunas restantes (possivelmente, este último bloco é vazio).

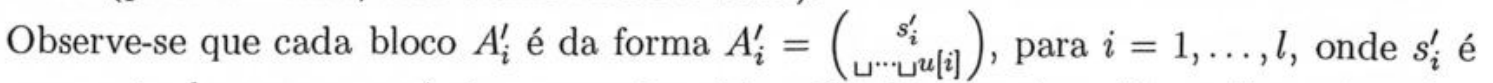
um segmento de $s$ com possíveis espaços inseridos. Intuitivamente, o bloco $A_{i}^{\prime}$ consiste das colunas de $A^{\prime}$ que contém a lacuna anterior ao caractere $u[i]$ seguida da coluna que contém o caractere $u[i]$. O bloco $A_{l+1}^{\prime}$ é da forma $A_{l+1}^{\prime}=\left(\begin{array}{c}s_{l+1}^{\prime} \\ u_{\bullet \cup}^{\prime}\end{array}\right)$ e, intuitivamente, contém as colunas de $A^{\prime}$ restantes, que não pertencem a nenhum outro bloco (isto ocorre quando $A^{\prime}$ não termina em uma coluna com um caractere de $u$ ).

De maneira análoga, podemos particionar o alinhamento $A^{\prime \prime}$ em $l+1$ blocos de colunas, como feito acima, de forma que o bloco $A_{i}^{\prime \prime}$ seja da forma $A_{i}^{\prime \prime}=\left(\begin{array}{c}\sqcup \cdot \cdots u[i] \\ t_{i}^{\prime}\end{array}\right)$, para $i=1, \ldots, l$ e $A_{l+1}^{\prime \prime}=\left(\begin{array}{c}\sqcup \cdots \sqcup \\ t_{l+1}^{\prime} \cdots\end{array}\right)$, em que $t_{i}^{\prime}$ são segmentos de $t^{\prime}$, para todo $i=1, \ldots, l+1$.

$\mathrm{O}$ alinhamento $A$ entre $s$ e $t$ também consistirá de $l+1$ blocos de colunas, da seguinte maneira:

- se o bloco $A_{i}^{\prime}$ tem o mesmo comprimento que o bloco $A_{i}^{\prime \prime}$, então definimos $A_{i}=\left(\begin{array}{c}s_{i}^{\prime} \\ t_{i}^{\prime}\end{array}\right)$;

- se um bloco é maior que o outro, então inserimos colunas com espaços (isto é, da forma $\left(\begin{array}{l}u \\ \sqcup\end{array}\right)$ ) no início do bloco mais curto em uma quantidade suficiente para que os blocos tenham o mesmo tamanho e definimos $A_{i}$ da mesma maneira que no caso anterior.

Com os blocos $A_{i}$ definidos da forma acima, é fácil ver que $c(A) \leq c\left(A^{\prime}\right)+c\left(A^{\prime \prime}\right)=$ $d(s, u)+d(u, t)$, por verificação de que, para cada bloco $A_{i} \operatorname{temos} c\left(A_{i}\right) \leq c\left(A_{i}^{\prime}\right)+c\left(A_{i}^{\prime \prime}\right)$. Isso conclui a prova da proposição.

\subsubsection{Distância de Edição}

Dentre as métricas, uma que merece destaque é aquela derivada a partir da matriz de pontuação zero-ou-um, isto é, quando $c(\sigma, \rho)=0$ para $\sigma=\rho$ e $c(\sigma, \rho)=1$ para $\sigma \neq \rho$. É bastante simples de ver que $c$ satisfaz aos axiomas de métrica. Nesse caso, a distância $d(s, t)$, derivada de $c$, é chamada distância de Levenshtein ou distância de edição.

A título de exemplo, a distância de edição das seqüências da Figura 1.2 é 2 e o alinhamento da figura nos mostra quais são as operações de edição (inserções, remoções ou trocas de caracteres) envolvidas.

A distância de edição entre seqüências pode ser definida, alternativamente, como o número de operações de edição necessárias para transformar uma seqüência em outra. No caso geral em que as operações não têm custos uniformes, a definição é similar, com a diferença de que em vez de número de transformações minimiza-se o custo da seqüência de transformações.

Observe-se que essa definição coincide com a definição de que a distância é a pontuação do alinhamento de menor custo (quando o custo de operações elementares é dado e satisfaz à desigualdade triangular). 
Em linhas gerais, a justificativa para isso (e que faz a "ponte" entre as duas definições) é notar que um alinhamento entre duas seqüências codifica uma seqüência de operações de transformação entre as seqüências alinhadas. Além disso, como a função de custo de operações de edição satisfaz à desigualdade triangular, segue que duas operações de edição incidentes em uma posição fixada de uma seqüência (por exemplo, mudar um caractere de $s$ de A para T e, depois, mudar este mesmo caractere de T para G) não é melhor (em relação a custo) do que realizar apenas uma operação (no exemplo, a mudança direta de A para G). Observe-se que alinhamentos entre seqüências representam no máximo uma operação de edição por caractere/coluna, mas, pelo fato exposto acima, é suficiente observar este tipo de transformações de seqüências para encontrar uma seqüência de operações de menor custo.

Embora parecida à primeira vista com a distância de Hamming ${ }^{3}$, a distância de edição de duas seqüências é bastante diferente. A distância de Hamming só está definida para seqüências de mesmo comprimento, enquanto a distância de edição está definida para quaisquer pares de seqüências. Na verdade, até para seqüências $s$ e $t$ de mesmo comprimento, a distância de Hamming $d_{H}(s, t)$ de $s$ e $t$ pode ser arbitrariamente diferente da distância de edição $d_{L}(s, t)$ : por exemplo, se $s=(\mathrm{TA})^{k}$ e $t=(\mathrm{AT})^{k}$, para algum inteiro $k \geq 1$, então $d_{H}(s, t)=2 k$ (os caracteres de mesmo índice em $s$ e em $t$ são sempre diferentes), enquanto

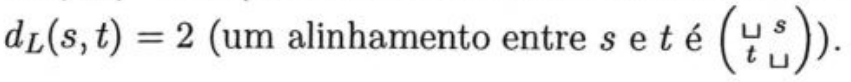

\subsubsection{Formalização do Problema}

Até o momento, nossa discussão apenas tangenciou o problema de encontrar alinhamentos de duas seqüências. Nesta seção, vamos cuidar da formalização do problema.

Observe-se que, conforme dito anteriormente, a pontuação de um alinhamento é definida como a soma das pontuações de suas colunas. Intuitivamente, se a matriz de pontuação $c$ atribui "pontuação baixa" a caracteres "semelhantes" de $\Sigma^{\prime}$ e "pontuação alta" a caracteres "diferentes" de $\Sigma^{\prime}$, então os alinhamentos de maior interesse são aqueles de "pequena pontuação".

Isso motiva a definição do problema de encontrar alinhamentos entre duas seqüuencias como um problema de otimização, formulado de acordo com o enunciado abaixo.

Problema 1.1 (Alinhamento de Pares de Seqüências (APS)). Dadas duas seqüências $s$ e $t$ sobre um alfabeto $\Sigma$ e fixada uma matriz de pontuação $c$ satisfazendo os axiomas de métrica, encontrar um alinhamento $A^{*}$ de $s$ e $t$ cuja pontuação $c\left(A^{*}\right)$ seja mínima.

É claro que o Problema APS é um problema de otimização limitado, já que, por $c$ ser uma métrica, todo alinhamento possui custo não-negativo. Assim, fixada uma instância do Problema APS, sempre há um alinhamento que é solução do problema.

Nas próximas seções, estudamos algumas propriedades do Problema APS e algoritmos que podem ser usados para resolvê-lo.

\subsection{Algoritmos Fundamentais}

Uma característica útil da função objetivo usada pelo Problema APS é o fato de podermos nos preocupar apenas com alinhamentos que não possuam colunas compostas apenas

\footnotetext{
${ }^{3} \mathrm{~A}$ distância de Hamming $d_{H}(s, t)$ de duas seqüências $s, t \in \Sigma^{n}$ é definida como o número de posições em que $s$ e $t$ diferem [Ham80]. Equivalentemente, se $d_{01}(\cdot, \cdot)$ é a métrica zero-ou-um, então $d_{H}(s, t)=$ $\sum_{j=1}^{n} d_{01}(s[j], t[j])$.
} 
por espaços, uma vez que para cada alinhamento $A$ que tenha alguma coluna composta só por espaços, existe um alinhamento $A^{\prime}$ sem colunas que só tenham espaços e tal que $c(A)=c\left(A^{\prime}\right)$.

De fato, o alinhamento $A^{\prime}$ pode ser obtido a partir de $A$ removendo-se, de $A$, todas as colunas compostas apenas por espaços. Pela forma como a pontuação de um alinhamento é definida e pela pontuação de uma coluna que só tenha espaços ser 0 (pois a matriz de pontuação $c$ é uma métrica e $c(\lrcorner, \sqcup)=0)$, segue que $c\left(A^{\prime}\right)=c(A)$. Logo, se $A$ é um alinhamento ótimo, $A^{\prime}$ também é ótimo. Para facilitar a linguagem, damos abaixo uma definição.

Definição 1.2 (Alinhamento Livre de Colunas em Branco). Um alinhamento que não possua colunas cujos símbolos sejam apenas espaços é dito livre de colunas em branco.

Os comentários acima são uma demonstração para o fato enunciado abaixo.

Fato 1.3. Sempre existe um alinhamento ótimo livre de colunas em branco.

$$
A=\begin{aligned}
& \mathrm{A}_{\sqcup} \mathrm{CT} \\
& \mathrm{A}_{\sqcup} \mathrm{GT}
\end{aligned} \quad A^{\prime}=\begin{aligned}
& \mathrm{ACT} \\
& \mathrm{AGT}
\end{aligned}
$$

Figura 1.3: Na busca de alinhamentos ótimos, podemos restringir nossa atenção a alinhamentos que não possuem colunas só com espaços. Os alinhamentos acima possuem mesma pontuação.

Por esse motivo, vamos, de agora em diante, supor que todos os nossos alinhamentos sejam livres de colunas em branco, exceto quando explicitamente indicado.

\subsubsection{Espaço de Busca do Problema}

Uma possível estratégia para resolver o Problema APS poderia ser gerar exaustivamente todos os alinhamentos entre $s$ e $t$ e fornecer como saída um que minimize a função objetivo c. Essa estratégia, embora bastante simples do ponto de vista conceitual, não é prática a menos que as seqüências $s$ e $t$ sejam muito pequenas. Isso ocorre porque o número de alinhamentos entre duas seqüências cresce muito rapidamente conforme o tamanho das seqüências aumenta, até mesmo se ignorarmos os alinhamentos livres de colunas em branco.

Para duas seqüências $s$ e $t$ com $|s|=m$ e $|t|=n$, o número de alinhamentos em que há $i$ caracteres de $s$ alinhados a $i$ caracteres de $t$ é

$$
\left(\begin{array}{c}
m+n-i \\
m-i, n-i, i
\end{array}\right)=\frac{(m+n-i) !}{(m-i) !(n-i) ! i !} .
$$

Uma justificativa para esse cálculo será dada na Seção 2.3.1 do Capítulo 2. Com alguma análise, é possível ver que o número de alinhamentos cresce exponencialmente em relação ao tamanho das seqüências alinhadas, conforme passamos a fazer. Para o caso em que $m=n$, o número total $N(n)$ de alinhamentos entre $s$ e $t$ é dado por

$$
N(n)=\sum_{i=0}^{n}\left(\begin{array}{c}
2 n-i \\
n-i, n-i, i
\end{array}\right) .
$$


Usando a aproximação de Stirling para $n$ vemos que apenas o termo correspondente a $i=0$ no somatório anterior é $\left(\begin{array}{c}2 n \\ n\end{array}\right) \sim 2^{2 n} / \sqrt{\pi n}=4^{n} / \sqrt{\pi n}$, onde $f \sim g$ significa $f(n) / g(n) \rightarrow 1$, quando $n \rightarrow \infty$. Disso podemos concluir que o número $N(n)$ de alinhamentos para duas seqüências de tamanho $n$ cada é

$$
N(n)=\sum_{i=0}^{n}\left(\begin{array}{c}
2 n-i \\
n-i, n-i, i
\end{array}\right)=\Omega\left(4^{n} / \sqrt{n}\right),
$$

o que nos diz que o número de alinhamentos entre seqüências é uma grandeza exponencial nos tamanhos das seqüências a alinhar.

A título de curiosidade, abaixo está uma tabela que mostra o crescimento do número $N(n)$.

\begin{tabular}{c|ccccccccccc}
$n$ & 0 & 1 & 2 & 3 & 4 & 5 & 6 & 7 & 8 & 9 & 10 \\
\hline$N(n)$ & 1 & 3 & 13 & 63 & 321 & 1683 & 8989 & 48639 & 265729 & 1462563 & 8097453
\end{tabular}

Portanto, qualquer algoritmo para o Problema APS que opere examinando de forma exaustiva todos alinhamentos e devolva um de menor pontuação é intrinsecamente lento (ainda que cada alinhamento possa ser examinado em tempo $O(1)$ ). Fica evidente a conclusão de que a estratégia mais simples não é aceitável e naturalmente nos surge a pergunta: "É possível encontrar um alinhamento ótimo entre duas seqüências em menos tempo?". Conforme veremos nas próximas seções, apesar de possuir um espaço de busca "grande", o Problema APS possui boas características, de forma que a resposta à pergunta é sim.

\subsubsection{Algoritmo Recursivo para o Problema}

Seja $A$ um alinhamento entre $s$ e $t$ e consideremos uma decomposição de $A$ da forma $A=\left(A^{\prime}: A^{\prime \prime}\right)$ em que $A^{\prime \prime}$ seja a última coluna de $A$. Então, há apenas três possibilidades para a coluna $A^{\prime \prime}$ :

- o último símbolo de $s$ está alinhado a um espaço em $A^{\prime \prime}$, isto é, $A^{\prime \prime}=\left(\begin{array}{c}s[m] \\ \square\end{array}\right)$;

- o último símbolo de $s$ está alinhado ao último símbolo de $t$ em $A^{\prime \prime}$, isto é, $A^{\prime \prime}=\left(\begin{array}{c}s[m] \\ t[n]\end{array}\right)$;

- o último símbolo de $t$ está alinhado a um espaço em $A^{\prime \prime}$, isto é, $A^{\prime \prime}=\left(\begin{array}{c}\sqcup \\ t[n]\end{array}\right)$.

Por não considerarmos em branco, essas são todas as possibilidades para $A^{\prime \prime}$. Além disso, como a função objetivo do Problema APS é aditiva, o custo de $A$ pode facilmente ser calculado a partir de $A^{\prime}$ e de $A^{\prime \prime}$.

Essas observações nos sugerem uma solução recursiva para o problema, descrita no Algoritmo Alinha-Rec.

A base da recursão do Algoritmo Alinha-Rec corresponde aos casos em que alguma seqüência deve ser alinhada à seqüência vazia, ou seja, quando $s=\varepsilon$ ou $t=\varepsilon$. Como os alinhamentos em que estamos interessados não possuem colunas em branco, existe apenas um possível alinhamento para qualquer caso da base da recursão, que o Algoritmo ALINHA-REC determina diretamente. No caso geral, o algoritmo examina todas as possibilidades para decidir qual é a de menor pontuação, para produzir um alinhamento ótimo como resposta. 


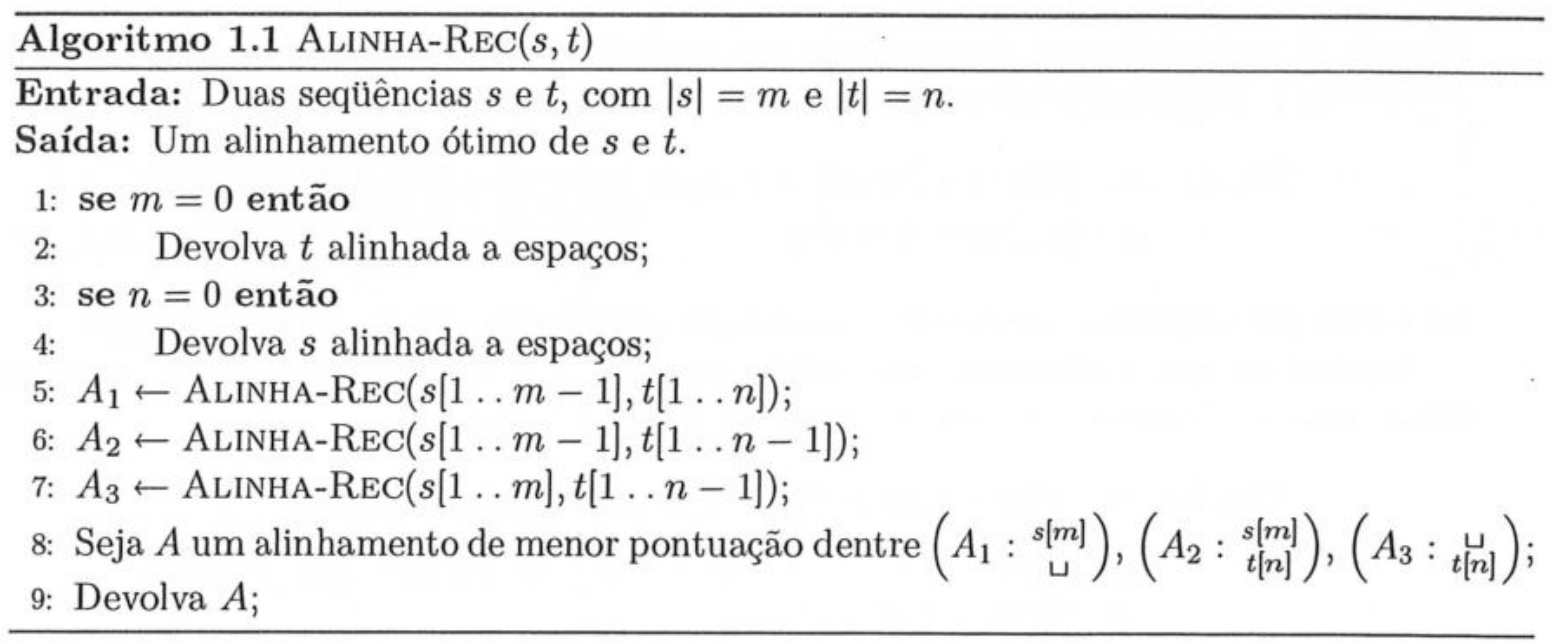

\subsubsection{Análise de Complexidade}

Infelizmente, o Algoritmo ALINHA-REC não é um algoritmo prático, pois ele pode executar um número exponencial de operações em relação ao tamanho de sua entrada. Para ver isso, seja $T(m, n)$ o tempo gasto pelo algoritmo para seqüências $s$ e $t$ com $m=|s|$ e $n=|t|$. É claro, portanto, que o tempo gasto pelo algoritmo satisfaz à recorrência:

$$
T(m, n)= \begin{cases}c n+d, & \text { se } m=0 \\ c m+d, & \text { se } n=0 \\ T(m-1, n)+T(m-1, n-1)+T(m, n-1)+e, & \text { se } m>0 \text { e } n>0\end{cases}
$$

onde $c, d$ e $e$ são constantes positivas apropriadas, relativas a várias operações - como alinhar um caractere a um espaço, fazer chamadas de função e calcular mínimo de conjuntos de 3 elementos (todas são operações que podem ser feitas em tempo $O(1)$ ).

Estamos interessados em encontrar um limite inferior para o número de operações do Algoritmo Alinha-REC. Para mostrar que o número de operações realizadas pelo algoritmo não é polinomial, vamos mostrar que, no caso particular em que $m=n$, temos $T(m, n)=$ $T(n, n) \geq 3^{n} d=\Omega\left(3^{n}\right)$.

Antes de procedermos à demonstração desse fato, vamos provar o seguinte lema.

Lema 1.4. Para a função $T$ definida acima, temos que $T(n, n-1) \geq T(n-1, n-1)$ e que $T(n-1, n) \geq T(n-1, n-1)$, para todo $n>1$.

Prova: Ambas desigualdades são verificadas de maneira simples. Observemos inicialmente que, se $c, d$ e $e$ são constantes positivas, então $T(m, n)$ é não-negativa para todo $m \geq 0$ e $n \geq 0$. Além disso, se $m>0$ e $n-1>0$, então pela definição da Recorrência (1.2), $T(m, n-1)=T(m-1, n-1)+T(m-1, n-2)+T(m, n-2)+e \geq T(m-1, n-1)$, já que tanto $T$ quanto $e$ são não-negativos. De maneira análoga podemos concluir que $T(m-1, n) \geq T(m-1, n-1)$, se $m-1>0$ e $n>0$. Logo, para $m>1$ e $n>1$, temos $T(m, n-1) \geq T(m-1, n-1)$ e $T(m-1, n) \geq T(m-1, n-1)$. O resultado desejado segue diretamente no caso particular em que $m=n>1$.

Proposição 1.5. A função $T(n, n)$ definida acima é tal que $T(n, n) \geq 3^{n} d$, para $n \geq 0$. 
Prova: A proposição será demonstrada por indução. Para $n=0$, temos que $T(0,0)=d \geq$ $1 \cdot d=3^{0} d$ e, portanto, a afirmação é verdadeira. Para $n=1$, temos que

$$
\begin{aligned}
T(1,1) & =T(0,1)+T(0,0)+T(1,0)+e=(c+d)+d+(c+d)+e \\
& =2 c+3 d+e \geq 3^{1} d
\end{aligned}
$$

e a afirmação também é verdadeira, concluindo a demonstração da base de indução.

Supondo-se que a afirmação seja válida para $n-1 \geq 0$, mostremos que ela também é válida para $n$. Como $n>0$, pela definição de $T(n, n)$, temos

$$
\begin{aligned}
T(n, n) & =T(n-1, n)+T(n-1, n-1)+T(n, n-1)+e \\
& \geq T(n-1, n-1)+T(n-1, n-1)+T(n-1, n-1)+e \\
& =3 T(n-1, n-1)+e,
\end{aligned}
$$

onde a desigualdade decorre do lema. Mas pela hipótese de indução,

$$
\begin{aligned}
T(n, n) & \geq 3\left(3^{n-1} d\right)+e=3^{n} d+e \\
& \geq 3^{n} d,
\end{aligned}
$$

uma vez que $e \geq 0$.

Assim para todo inteiro $n \geq 0$, temos $T(n, n) \geq 3^{n} d$, o que conclui a prova da proposição.

Da proposição acima, concluímos que $T(n, n)=\Omega\left(3^{n}\right)$ e que, então, o número de operações realizadas pelo Algoritmo Alinha-Rec não é polinomial. No caso particular em que as constantes da Recorrência (1.2) são $c=0, d=1$ e $e=0$, é simples de ver que a função $T$ nos dá o número de alinhamentos entre uma seqüência de tamanho $m$ e uma seqüência de tamanho $n$. Fazendo-se uma aproximação de $N(n)=T(n, n)$ de maneira mais cautelosa [Wat95], é possível mostrar que $N(n)=T(n, n) \sim(1+\sqrt{2})^{2 n+1} n^{-1 / 2}$.

\subsubsection{Propriedades do Problema}

Apesar de o Algoritmo Alinha-Rec não ser eficiente, ele nos mostra algumas características do Problema APS. Duas características do problema são de importância para o projeto de algoritmos eficientes. São elas:

- Propriedade das Subsoluções Ótimas. A propriedade das subsoluções ótimas para o Problema APS pode ser enunciada como: "Se $A$ é um alinhamento ótimo entre $s$ e $t$ e $A=\left(A^{\prime}: A^{\prime \prime}\right)$, de forma que $A^{\prime \prime}$ seja a última coluna de $A$, então $A^{\prime}$ é um alinhamento ótimo dos segmentos de $s$ e $t$ alinhados em $A^{\prime}$." De fato, esta propriedade é válida para o Problema APS pois, se houvesse um alinhamento $A^{\prime \prime \prime}$ dos segmentos de $s$ e $t$ presentes em $A^{\prime}$ e que tivesse $c\left(A^{\prime \prime \prime}\right)<c\left(A^{\prime}\right)$ (isto é, se $A^{\prime}$ não fosse um alinhamento ótimo), então o alinhamento $\left(A^{\prime \prime \prime}: A^{\prime \prime}\right)$ teria pontuação $c\left(A^{\prime \prime \prime}\right)+c\left(A^{\prime \prime}\right)<$ $c\left(A^{\prime}\right)+c\left(A^{\prime \prime}\right)=c(A)$, o que contradiria o fato de $A$ ser um alinhamento ótimo (de pontuação mínima) entre $s$ e $t$. Observe-se que, para a argumentação, é de importância a propriedade aditiva da pontuação de alinhamentos.

A propriedade das subsoluções ótimas nos indica que a busca por alinhamentos ótimos pode ser feita de maneira recursiva (para seqüências $s$ e $t$, primeiro determinamos $A^{\prime}$ e, depois, determinamos $A^{\prime \prime}$ ). Juntando-se a essa propriedade o fato de que para 
a última coluna de um alinhamento existem apenas três possibilidades, temos uma demonstração de que o Algoritmo Alinha-REC está correto, sempre encontrando um alinhamento de pontuação mínima entre $s$ e $t$.

- Propriedade dos Subproblemas Comuns. O Problema APS é tal que, ao procurarmos um alinhamento ótimo entre $s$ e $t$ por sua formulação recursiva, nós nos deparamos várias vezes com o problema de encontrar um alinhamento ótimo entre segmentos de sua entrada. Isso fica evidente ao analisarmos as chamadas recursivas do Algoritmo Alinha-Rec. Por exemplo, ao computar um alinhamento ótimo entre $s$ e $t$ por meio de uma chamada $\operatorname{Alinha-\operatorname {ReC}}(s, t)$, um alinhamento ótimo entre $s[1 \ldots m-1]$ e $t[1 \ldots n-1]$ é calculado mais de uma vez: uma das vezes ocorre em uma chamada recursiva Alinha-ReC $(s[1 \ldots m-1], t[1 \ldots n])$, uma vez por execução direta do algoritmo e uma vez pela chamada recursiva $\operatorname{Alinha-ReC}(s[1 \ldots m], t[1 \ldots n-1])$. É fácil ver que este argumento se aplica de maneira geral e que o Algoritmo ALINHA-REC desnecessariamente realiza várias vezes algumas computações.

Problemas que, como o Problema APS, apresentam as duas características acima podem ser resolvidos através de uma técnica chamada programação dinâmica [CLR90]. Explorando as características do APS listadas acima (usando um algoritmo de programação dinâmica) é possível resolver o Problema APS de forma muito mais eficiente do que por meio do Algoritmo ALINHA-REC.

\subsubsection{Algoritmo de Programação Dinâmica}

Dada uma entrada para um problema que satisfaça as duas propriedades acima, um algoritmo baseado no paradigma de programação dinâmica opera resolvendo progressivamente subproblemas do problema original (geralmente, em ordem crescente de tamanho dos subproblemas) e armazenando as soluções de cada subproblema em uma tabela para um possível uso posterior. A idéia é evitar que algum subproblema seja resolvido (desnecessariamente) mais de uma vez. Uma interpretação alternativa de um algoritmo de programação dinâmica pode ser como uma maneira de executar os passos de um algoritmo recursivo em uma ordem conveniente, usando uma tabela para manter as soluções dos subproblemas já resolvidos por chamadas recursivas do algoritmo.

Por exemplo, no caso do Problema APS, um algoritmo de programação dinâmica pode ser interpretado como uma ordenação adequada dos passos do Algoritmo Alinha-Rec de forma que os alinhamentos obtidos por cada chamada recursiva (como, por exemplo, Alinha-ReC $(s[1 \ldots 3], t[1 \ldots 4]))$ sejam armazenados em uma tabela.

Ao longo de um algoritmo de programação dinâmica, tentam-se estender soluções ótimas de subproblemas a uma solução ótima de um subproblema maior, fazendo uso da Propriedade das Subsoluções Ótimas, e prosseguindo até que uma solução ótima do problema original seja encontrada.

Um algoritmo de programação dinâmica para o Problema APS foi publicado em 1970 por Needleman e Wunsch [NW70], embora haja relatos de que suas idéias principais fizessem parte do folclore dos pesquisadores da época. O algoritmo, muito modificado desde então por vários pesquisadores, foi melhorado em relação à complexidade de tempo e de espaço [Hir75] e também adaptado para outros problemas, sendo que uma das adaptações mais importantes e populares é a desenvolvida por Smith e Waterman em 1981, para computar alinhamentos locais [SW81]. O algoritmo que veremos possui sua origem incerta e foi provavelmente descoberto independentemente por diversos pesquisadores [SM97]. 


\subsubsection{Etapas do Algoritmo}

Bem como vários algoritmos de programação dinâmica, o algoritmo de programação dinâmica para o Problema APS opera em duas etapas. Na primeira etapa, a distância entre as seqüências de entrada é calculada e, na segunda, um alinhamento ótimo (i.e., de pontuação igual à distância entre as seqüências) é determinado. Vamos à descrição de cada etapa. Para nossas considerações, supomos que o alfabeto $\Sigma$ e que a matriz de pontuação $c$ estejam fixados, como no enunciado do Problema APS.

1.5.4.1.1 Etapa 1: Cálculo da Distância Na primeira etapa, para seqüências $s$ e $t$ de comprimentos $|s|=m$ e $|t|=n$, uma matriz $a$ de dimensões $(m+1) \times(n+1)$, indexada por $\{0, \ldots, m\}$ e $\{0, \ldots, n\}$, é preenchida com as pontuações de alinhamentos ótimos de prefixos de $s$ com prefixos de $t$, de forma que a posição $(i, j)$ de $a$ contenha a pontuação de um alinhamento ótimo de $s[1 \ldots i]$ e $t[1 \ldots j]$, isto é, de modo que $a[i, j]=d(s[1 \ldots i], t[1 \ldots j])$, para $0 \leq i \leq m$ e $0 \leq j \leq n$. É claro que a distância $d(s, t)=d(s[1 \ldots m], t[1 \ldots n])$ está na posição $a[m, n]$.

Conforme mencionamos, o algoritmo tenta "estender" soluções já calculadas para problemas de maior tamanho (ele opera "de baixo para cima").

Pela definição da matriz $a$, a linha $i=0$ é tal que $a[0, j]=d(s[1 \ldots 0], t[1 \ldots j])=$ $d(\varepsilon, t[1 \ldots j])$, para $0 \leq j \leq n$. Como os alinhamentos que consideramos são livres de colunas em branco, a única possibilidade de um alinhamento entre a seqüência vazia e $t[1 \ldots j]$ é o alinhamento em que cada caractere de $t[1 \ldots j]$ fica alinhado a um espaço. Naturalmente, como este alinhamento é único, ele é trivialmente um alinhamento ótimo e seu custo é $a[0, j]=\sum_{k=1}^{j} c(\sqcup, t[k])$. Em outras palavras, temos que $a[0, j]=a[0, j-1]+c(\sqcup, t[j])$, para todo $j=1, \ldots, n$ e $a[0,0]=0$. Essa é a forma de preenchimento da linha $i=0$ da matriz. $\mathrm{O}$ mesmo argumento vale para ver que a coluna $j=0$ deve ser preenchida de acordo com a relação de recorrência $a[i, 0]=a[i-1,0]+c(s[i]$, ப); para todo $i=1, \ldots, m$.

Naturalmente, como há apenas 3 possibilidades para a última coluna de um alinhamento e o Problema APS satisfaz à Propriedade das Subsoluções Ótimas, sabemos que um alinhamento ótimo entre $s[1 \ldots i]$ e $t[1 \ldots j]$ pode ser obtido a partir de um alinhamento ótimo de $s[1 \ldots i-1]$ e $t[1 \ldots j]$ justaposto com $\left(\begin{array}{c}s[i] \\ \sqcup\end{array}\right)$ ou de um alinhamento ótimo de $s[1 \ldots i-1]$ e $t[1 \ldots j-1]$ justaposto com $\left(\begin{array}{c}s[i] \\ t[j\end{array}\right)$ ou de um alinhamento ótimo de $s[1 \ldots i]$ e $t[1 \ldots j-1]$ justaposto com $(\underset{t[j]}{\lfloor})$, dependendo de qual possuir a menor pontuação. Em termos da matriz $a$, isso fica:

$$
a[i, j]=\min \left\{\begin{array}{c}
a[i-1, j]+c(s[i], \sqcup), \\
a[i-1, j-1]+c(s[i], t[j]), \\
a[i, j-1]+c(\sqcup, t[j])
\end{array}\right\},
$$

para $i>0$ e $j>0$.

Para preenchermos a matriz a com o algoritmo, devemos escolher uma ordem conveniente para que o cálculo de $a[i, j]$ seja feito apenas após $a[i-1, j], a[i-1, j-1]$ e $a[i, j-1]$ estarem definidos. Uma possibilidade para isso é preencher a matriz $a$ linha a linha, a partir da linha de índice 0 e, para cada $i$ fixado, em ordem de $j$ crescente $^{4}$.

Um algoritmo que implementa as idéias acima é o Algoritmo DisT.

Como um comentário a parte, algumas implementações do Algoritmo Dist são feitas com a suposição de que existe uma constante $g$ tal que $c(\sqcup, \sigma)=g$ para todo $\sigma \in \Sigma$. Em

\footnotetext{
${ }^{4}$ Outra possibilidade para preenchimento de $a$ é fazer os cálculos coluna a coluna, a partir da coluna 0 e, para $j$ fixado, fazer o preenchimento com $i$ variando de 0 a $m$.
} 


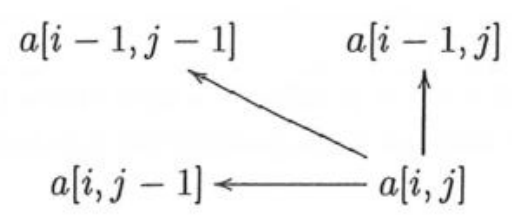

Figura 1.4: Para preencher a entrada $a[i, j]$, o Algoritmo Dist precisa de 3 outras entradas: $a[i-1, j], a[i-1, j-1]$ e $a[i, j-1]$.

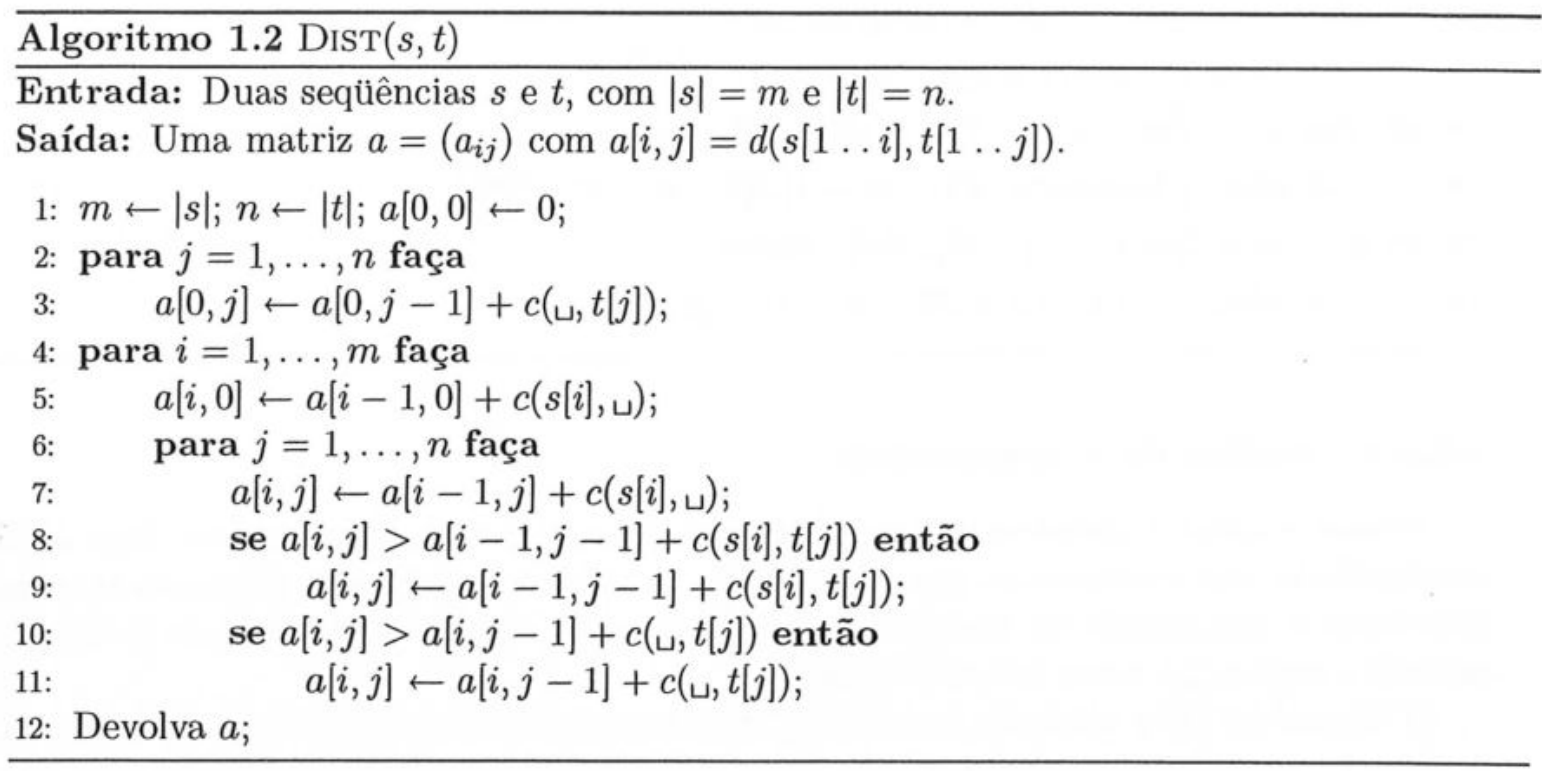

particular, nesse caso, a primeira linha de $a$ pode ser preenchida com $a[0, j]=g \cdot j$ e, a primeira coluna, com $a[i, 0]=g \cdot i$. É comum referir-se a uma tal matriz de pontuação como matriz de custos lineares para lacunas.

1.5.4.1.2 Etapa 2: Cálculo de um Alinhamento Ótimo Até aqui, apenas o cálculo da pontuação de um alinhamento ótimo (distância entre seqüências) foi efetuado. Terminado esse pré-processamento, podemos usar a tabela $a$ resultante da primeira etapa para construir os alinhamentos ótimos.

A construção de um alinhamento ótimo é feita observando-se qual (ou quais, se estivermos interessados em vários alinhamentos ótimos) das pontuações dentre $a[m-1, n]$, $a[m-1, n-1]$ e $a[m, n-1]$ produziu a pontuação $a[m, n]$ (correspondente à pontuação ótima de todos os $m$ caracteres de $s$ alinhados a todos os $n$ caracteres de $t$ ) e decidindo, portanto, qual é a última coluna de um alinhamento ótimo.

Desta forma, supondo-se que $a\left[m^{\prime}, n^{\prime}\right]$ seja a posição dentre as três descritas que produziu a pontuação $a[m, n]$, podemos obter as demais colunas do alinhamento repetindo o processo, usando $\left(m^{\prime}, n^{\prime}\right)$ no lugar de $(m, n)$ e repetir o procedimento de procura de que posição deu origem a $m^{\prime}$ e $n^{\prime}$ até que a posição $(0,0)$ de $a$ seja atingida, momento em que todas as colunas do alinhamento estarão determinadas.

O Algoritmo Alinha contém um resumo dessa discussão. 


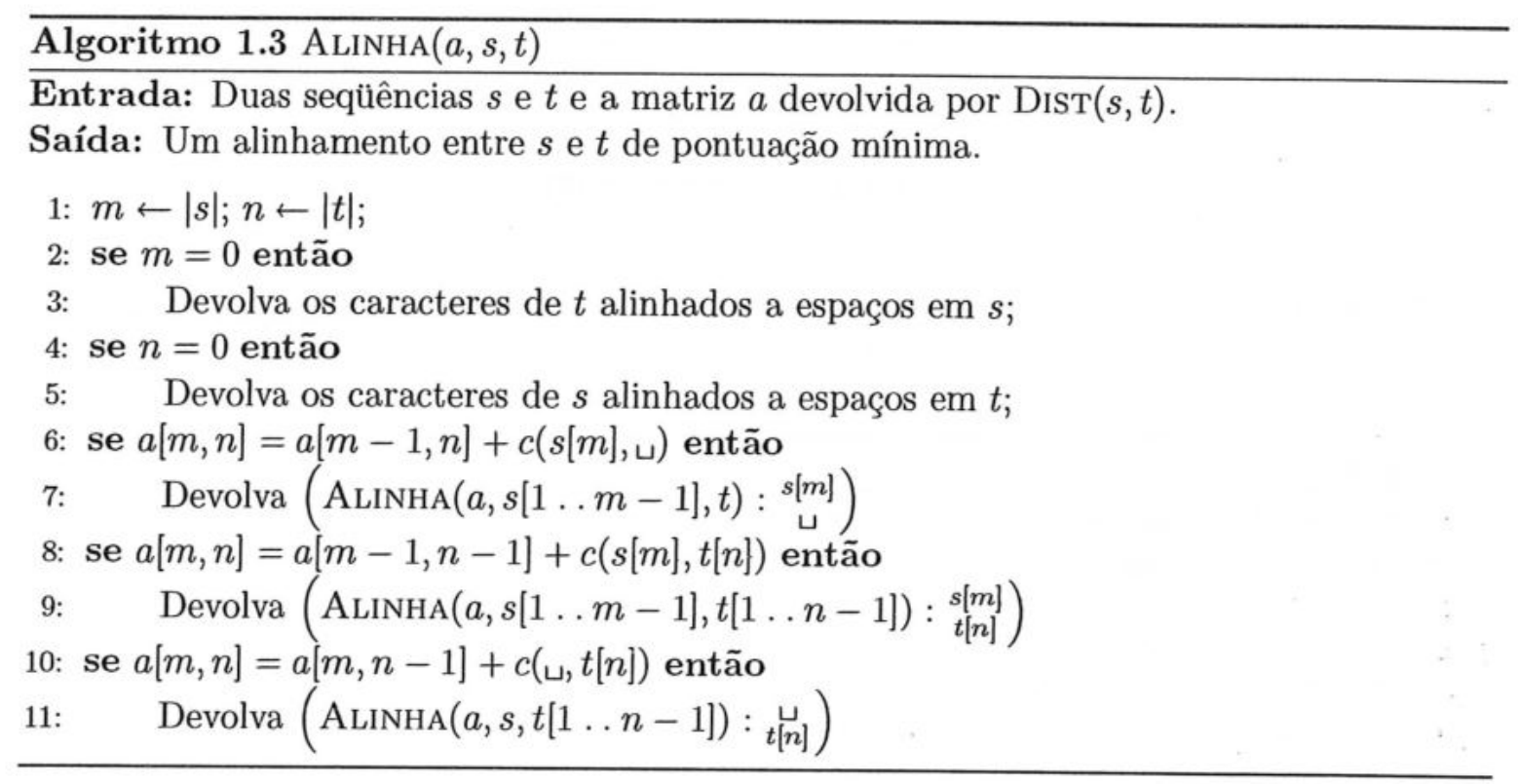

\subsubsection{Análise de Complexidade}

Vamos analisar a complexidade de tempo e de espaço dos algoritmos vistos. Para evitar ambigüidade, convencionamos que, nesta seção, a palavra espaço será utilizada para nos referirmos à quantidade de memória requerida para os algoritmos em vez de designar o caractere espaço (৬) como nas demais seções.

O Algoritmo Dist inicializa a primeira linha da matríz a em tempo $O(n)$ (linhas 2 e 3). A linha 1 é executada em tempo $O(1)$. Após a inicialização, os laços encaixados em $i$ e em $j$ (linhas 4-11) são executados. A parte mais interna desses laços (i.e., cada execução das linhas 7-11) leva tempo constante e são realizadas um total de $O(m n)$ iterações. Ao longo do algoritmo, a linha 5 é executada um total de $m$ vezes e, como cada execução dela toma tempo constante, a parcela de tempo total do algoritmo referente a sua execução é $O(m)$. Disso podemos concluir que o algoritmo leva tempo $O(1)+O(n)+O(m)+O(m n)=O(m n)$.

O espaço usado pelo algoritmo ${ }^{5}$ é $O(1)$, uma vez que os recursos de memória empregados são, basicamente, as variáveis de controle do algoritmo (que são $i, j, m$ e $n$ ) e que ocupam espaço $O(1)$, a matriz de pontuação $c$, que tem também tamanho $O(1)$ (pois o alfabeto está fixado) e a matriz $a$, de tamanho $(m+1) \times(n+1)$, que faz parte da resposta devolvida por DisT.

O outro algoritmo, Alinha, opera em tempo e espaço lineares no tamanho das seqüências $s$ e $t$. Para nos convencermos da complexidade de tempo, basta ver que cada coluna do alinhamento construído como solução requer que, no máximo, 3 posições da matriz $a$ sejam analisadas (vide linhas 6-11). Como cada um dos testes é feito em tempo constante, a determinação de uma coluna qualquer do alinhamento final toma tempo $O(1)$. Ademais, todos os alinhamentos que consideramos (i.e., livres de colunas em branco) possuem comprimento máximo de $m+n$ colunas. Daí, concluímos que o Algoritmo Alinha leva tempo $O(m+n)$.

Para o espaço usado pelo Algoritmo Alinha, observemos que, excetuando-se a matriz $a$

\footnotetext{
${ }^{5}$ Para a análise de espaço de nossos algoritmos, usamos a prática comum [Pap94] de não considerar na complexidade o espaço usado para resposta dos algoritmos (i.e., os algoritmos são modelados como máquinas de Turing de Entrada e Saída).
} 
e o alinhamento produzido como resposta (que usa espaço $O(m+n)$ ), tudo o que é necessário é armazenar as variáveis de controle do algoritmo que totalizam espaço $O(1)$ e a pilha de recursão do algoritmo, que tem tamanho $O(m+n)$ (porque uma chamada recursiva é feita para determinar cada coluna do alinhamento). Isso justifica a afirmação de o Algoritmo Alinha usar espaço $O(m+n)$.

É importante ver que, apesar de ambos os Algoritmos Dist e Alinha terem complexidades individuais de espaço de $O(1)$ e $O(m+n)$, respectivamente, uma implementação natural para encontrar um alinhamento ótimo de $s$ e $t$ opera primeiro fazendo uma chamada a DisT, depois armazenando $a$ e, por fim, fazendo uma chamada a ALinHA, de forma que este método usa espaço $O(m n)$ como um todo.

Como um comentário adicional, embora tenhamos descrito algoritmos para o Problema APS usando espaço (total) quadrático, é possível realizar todo o procedimento em espaço $O(m+n)$, mantendo ainda a complexidade de tempo assintótica de $O(m n)$, conforme veremos na Seção 1.6.

\subsubsection{Método Alternativo de Programação Dinâmica}

Uma característica do método anterior de programação dinâmica para encontrar alinhamentos é que a construção do alinhamento propriamente dito no Algoritmo AlinHa é feita iniciando-se pela entrada $a[m, n]$ (que corresponde, intuitivamente, ao fim do alinhamento) até atingir a entrada $a[0,0]$, isto é, as colunas do alinhamento são obtidas na ordem inversa àquela em que elas aparecem no alinhamento. O Algoritmo AlinHA obtém a ordem correta de impressão por meio de uma pilha (explicitamente programada ou obtida por meio da pilha de recursão).

Existe, todavia, uma maneira de mudar a ordem de obtenção das colunas do alinhamento. Essa ordem, na realidade, é determinada pelo conteúdo da matriz $a$, gerado pelo Algoritmo Dist. Nesta seção, mostramos uma versão alternativa dos Algoritmos DisT e Alinha que constroem o alinhamento ótimo sem necessitar de uma pilha. Além de bastante enriquecedoras do ponto de vista didático, as versões que apresentamos servem como subrotina para a construção de alinhamentos ótimos em espaço linear (vide Seção 1.6) e para um método de alinhamento de várias seqüências (vide Seção 2.5).

Conforme dissemos no parágrafo acima, a obtenção das colunas do alinhamento-solução está atrelada à forma de preenchimento da matriz $a$ e, em nossas novas versões dos algoritmos, vamos alterá-la. No Algoritmo DisT, as entradas correspondem à distância entre prefixos de $s$ e de $t$, isto é, a posição $a[i, j]$ era tal que $a[i, j]=d(s[1 \ldots i], t[1 \ldots j])$.

Podemos, entretanto, querer preencher $a$ com distâncias entre sufixos de $s$ e de $t$. Essa maneira de preencher $a$ equivale a tentarmos observar os alinhamentos de maneira "contrária" a como fizemos na discussão precedente ao Algoritmo AlinHA-REC: lá, estudamos as possibilidades para a última coluna de um alinhamento; aqui, consideramos as possibilidades para a primeira coluna de um alinhamento. As três possibilidades para a primeira coluna $A^{\prime}$ de um alinhamento $A=\left(A^{\prime}: A^{\prime \prime}\right)$ de $s$ e $t$ são:

- o primeiro símbolo de $s$ alinhado a um espaço em $t: A^{\prime}=\left(\begin{array}{c}s[1] \\ \sqcup\end{array}\right)$;

- o primeiro símbolo de $s$ alinhado ao primeiro símbolo de $t: A^{\prime}=\left(\begin{array}{l}s[1] \\ t[1]\end{array}\right)$;

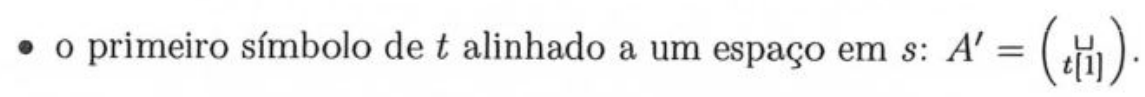


Essas possibilidades são exaustivas.

De uma maneira geral, um alinhamento ótimo entre o sufixo $s[i+1 \ldots m]$ de $s$ e o sufixo $t[j+1 \ldots n]$ de $t$ pode ser obtido através de uma das três possibilidades seguintes:

- $A=\left(\begin{array}{c}s[i+1] \\ \sqcup\end{array}: \operatorname{opt}\left(\begin{array}{c}s[i+2 \ldots m] \\ t[j+1 \ldots n]\end{array}\right)\right)$;

- $A=\left(\begin{array}{l}s[i+1] \\ t[j+1]\end{array}: \operatorname{opt}\left(\begin{array}{l}s[i+2 \ldots m] \\ t[j+2 \ldots n]\end{array}\right)\right)$;

- $A=\left(\begin{array}{c}\dot{u} \\ t[j+1]\end{array}: \operatorname{opt}\left(\begin{array}{c}s[i+1 \ldots m] \\ t[j+2 \ldots n]\end{array}\right)\right)$,

onde $\operatorname{opt}(x, y)$ denota um alinhamento ótimo entre as sequiências $x$ e $y$.

Podemos, então, preencher $a$ de modo que $a[i, j]=d(s[i+1 \ldots m], t[j+1 \ldots n])$, para $i=0, \ldots, m$ e $j=0, \ldots, n$. De acordo com essa nova maneira de preenchimento, $a[i, j]$ é a distância entre o sufixo de $s$ de tamanho $m-(i+1)+1=m-i$ e o sufixo de $t$ de tamanho $n-(j+1)+1=n-j$. Em particular, de acordo com o novo esquema de preenchimento, $a[m, n]=d(s[m+1 \ldots m], t[n+1 \ldots n])=d(\varepsilon, \varepsilon)=0$ e $a[0,0]=d(s[0+1 \ldots m], t[0+1 \ldots n])=$ $d(s, t)$. Logo, quando a matriz a contém distâncias entre sufixos de $s$ e $t$ (em vez de prefixos), a distância entre as seqüências fica armazenada em $a[0,0]$.

Como em um método de programação dinâmica consideramos as instâncias do problema em ordem não-decrescente de tamanho, a nova versão do Algoritmo Dist, o Algoritmo DIST-REV, preenche a matriz $a$ iniciando pela entrada $a[m, n]$ até preencher a entrada $a[0,0]$.

Por argumentos análogos aos usados para o Algoritmo Dist, temos que, para a linha $i=m$ da matriz, $a[m, j]=d(s[m+1 \ldots m], t[j+1 \ldots n])=d(\varepsilon, t[j+1 \ldots n])$, de onde segue que $a[m, j]=\sum_{k=j+1}^{n} c(\sqcup, t[k])$, para todo $j=0, \ldots, n$. Logo, a linha $m$ da matriz pode ser preenchida de acordo com a recorrência $a[m, j]=a[m, j+1]+c(\sqcup, t[j+1])$, para $j=n-1, \ldots, 0$ e $a[m, n]=0$. Pelo mesmo raciocínio, é simples de ver que a coluna $j=n$ deve ser preenchida de acordo com a recorrência $a[i, n]=a[i+1, n]+c(s[i+1]$, $)$, para $i=m-1, \ldots, 0$.

No caso geral, o preenchimento da matriz $a$ é dado por:

$$
a[i, j]=\min \left\{\begin{array}{c}
c(s[i+1],\lrcorner)+a[i+1, j], \\
c(s[i+1], t[j+1])+a[i+1, j+1], \\
c(\lrcorner, t[j+1])+a[i, j+1]
\end{array}\right\},
$$

para $i<m$ e $j<n$. Graficamente, a dependência entre as posições de $a$ é representada de acordo com a Figura 1.5. É importante observar que, da mesma forma em que uma posição

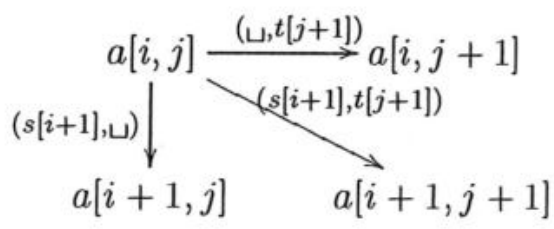

Figura 1.5: Bem como o Algoritmo Dist, o Algoritmo Dist-Rev precisa consultar o conteúdo de 3 posições para preencher cada posição da matriz.

da matriz de programação dinâmica do Algoritmo Dist dava origem ao valor de outra (por 
meio do cálculo de mínimo que determinava o valor desta segunda posição) e elas duas, juntas, determinavam uma coluna do alinhamento ótimo (fato explorado pelo Algoritmo ALINHA), o mesmo acontece com as posições da matriz de programação dinâmica calculada pelo Algoritmo DisT-Rev.

Um resumo de nossa discussão está presente no pseudo-código do Algoritmo DisT-REV, exibido adiante.

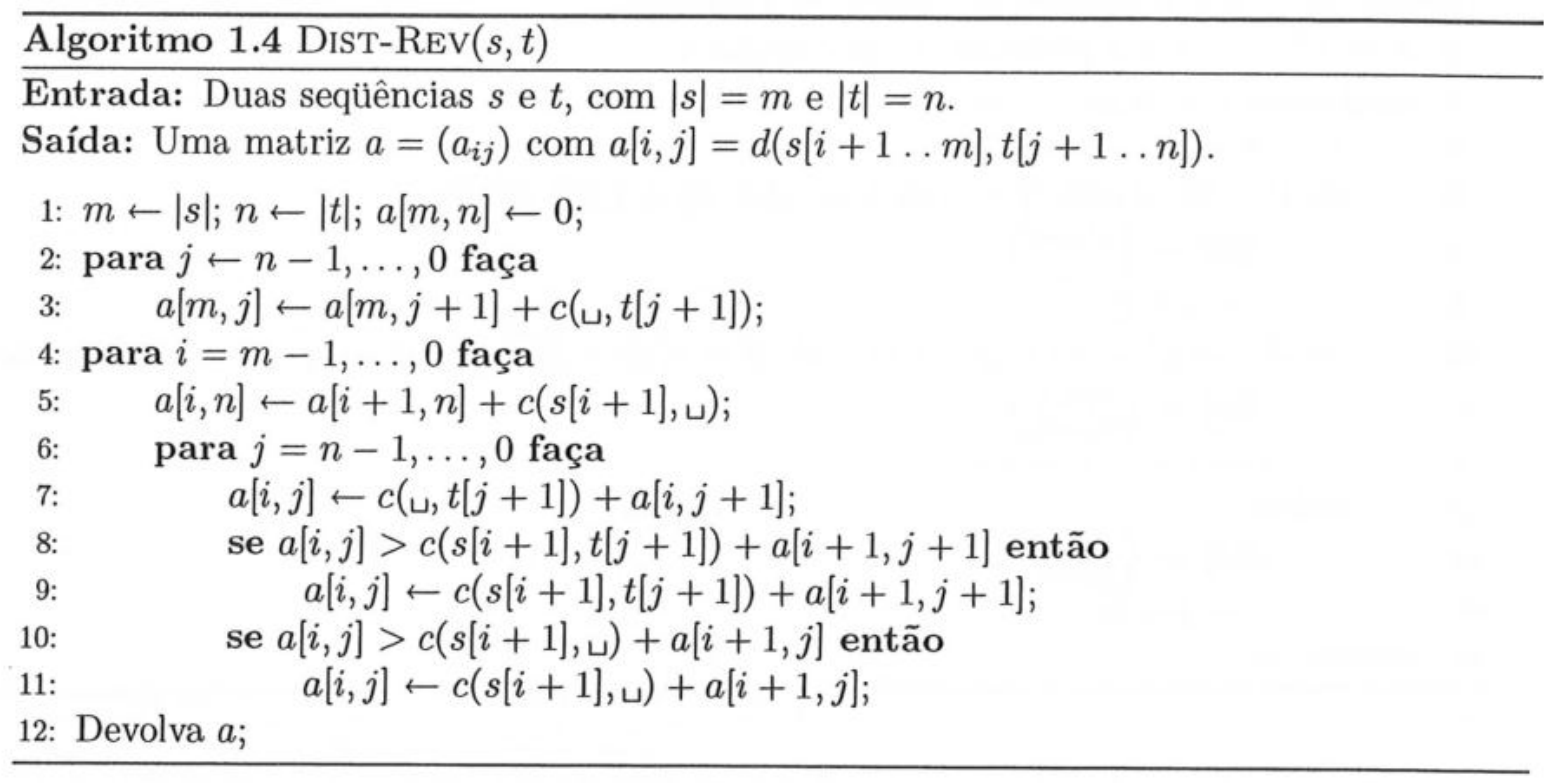

Com a nova forma de preencher a matriz de programação dinâmica, a obtenção de um alinhamento ótimo fica um pouco simplificada em relação àquela do Algoritmo ALINHA, já que não precisamos manter uma pilha para o cálculo do alinhamento ótimo, pois as colunas são determinadas na ordem direta. A nova versão do Algoritmo Alinha será chamada Alinha-Rev.

O Algoritmo Alinha-Rev parte da posição $a[0,0]$ de $a$ e prossegue até atingir a entrada $a[m, n]$, encontrando, a cada passo, dentre as três possibilidades, qual par coluna e restante de alinhamento possui menor custo, a fim de escolher qual é a próxima coluna do alinhamento ótimo (no caso de empates, a escolha da coluna pode ser feita de maneira arbitrária; na implementação, o Algoritmo AlinHA-Rev privilegia alinhamentos entre caracteres de $s$ e espaços em $t$ ).

O Algoritmo Alinha-Rev está descrito no pseudo-código em uma versão iterativa. É claro que uma versão recursiva dele também pode ser desenvolvida, como foi feito para o algoritmo tradicional (o par Alinha e Dist).

\subsubsection{Análise de Complexidade}

Os Algoritmos Dist-Rev e Alinha-Rev operam conjuntamente e produzem um alinhamento entre $s$ e $t$ de pontuação mínima (a justificativa aqui para a afirmação é novamente dada pelas propriedades mencionadas na Seção 1.5.3). De maneira similar ao Algoritmo Dist, o Algoritmo Dist-Rev tem complexidade de tempo $O(m n)$, essencialmente devido ao preenchimento da matriz de programação dinâmica $a$ e complexidade de espaço $O(1)$, porque apenas variáveis de controle do algoritmo são usadas.

Bem como o Algoritmo Alinha, o Algoritmo Alinha-Rev determina cada coluna do alinhamento ótimo em tempo $O(1)$ e, como o alinhamento possui $O(m+n)$ colunas no pior 


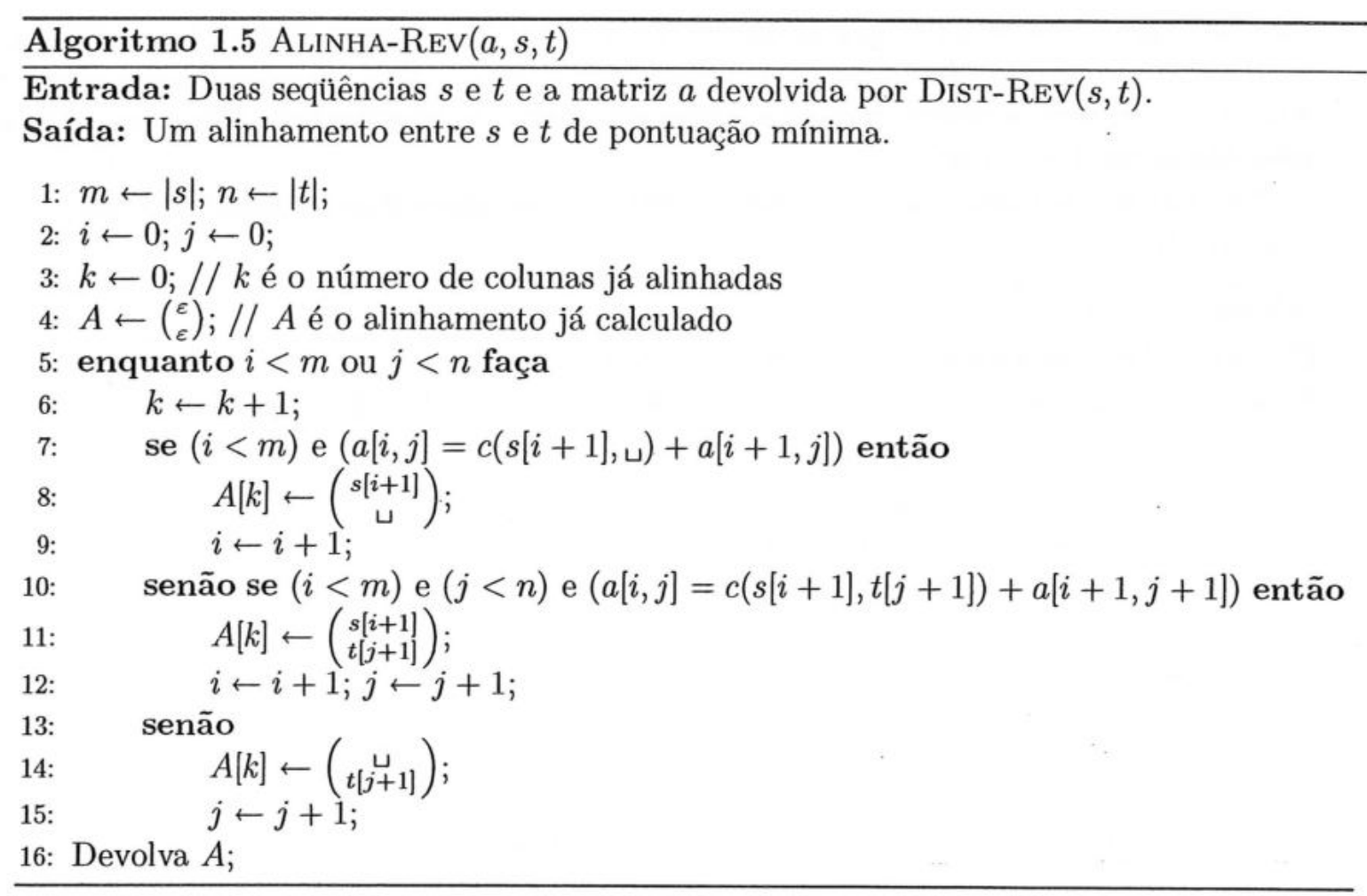

caso, o tempo usado é $O(m+n)$. Além disso, o Algoritmo Alinha-Rev opera em espaço $O(1)$, não contando o espaço requerido para a matriz $a$ (que, para este algoritmo, faz parte da entrada) e o espaço requerido para o alinhamento-resposta (que é $O(m+n)$, conforme já dissemos).

O mesmo comentário feito para o par de Algoritmos Alinha e Dist em relação a como um algoritmo composto por Alinha e por DisT pode ser escrito para encontrar um alinhamento ótimo em espaço $O(m n)$ vale aqui para os Algoritmos Alinha-Rev e DisT-REV (por causa do armazenamento intermediário da matriz a).

Logo, por meio dos algoritmos alternativos, é possível, dadas duas seqüências $s$ e $t$ de tamanhos $|s|=m$ e $|t|=n$, encontrar um alinhamento de custo mínimo em tempo e espaço $O(m n)$.

Veremos, na próxima seção, como é possível realizar toda operação em espaço linear (i.e., $O(m+n))$ e ainda manter a complexidade de tempo quadrática.

\subsection{Método de Economia de Espaço (Hirschberg)}

De acordo com o que já vimos, sabemos que o Problema APS pode ser resolvido em tempo e espaço $O(m n)$. Em Ciência da Computação, estamos freqüentemente interessados não apenas em encontrar algoritmos que resolvam problemas, mas também em algoritmos eficientes, principalmente em relação a espaço e a tempo. Nesta seção, veremos como podemos reduzir o espaço suficiente para encontrar um alinhamento ótimo de um par de seqüências. 


\subsubsection{Calculando $d(s, t)$ em Espaço Linear}

Se estivermos interessados apenas na distância entre $s$ e $t$, podemos reduzir facilmente o espaço suficiente para computar $d(s, t)$ observando que, no Algoritmo Dist, as linhas da matriz $a$ são sucessivamente preenchidas e que, pela Recorrência (1.3), uma dada linha depende apenas da linha anterior (isto é, a $i$-ésima linha de $a$ depende apenas da linha de índice $i-1$, para $i=1, \ldots, n)$. Isso significa que podemos calcular $d(s, t)$ mantendo duas linhas de $a$ apenas: a linha sendo computada e a linha anterior. Na realidade, com uma análise mais cuidadosa da relação de recorrência, é possível ver que tudo pode ser feito com menos espaço ainda: como cada posição de $a$ só depende de posições que estejam na linha anterior e em colunas anteriores (incluindo a coluna da posição em cálculo), é possível fazer todas as contas com o espaço de uma linha mais duas variáveis auxiliares. Essa idéia está apresentada no Algoritmo DisT-EspLin. Com isso, reduzimos o espaço total das variáveis de controle mais o espaço para a resposta de $O(m n)$ para $O(n)$.

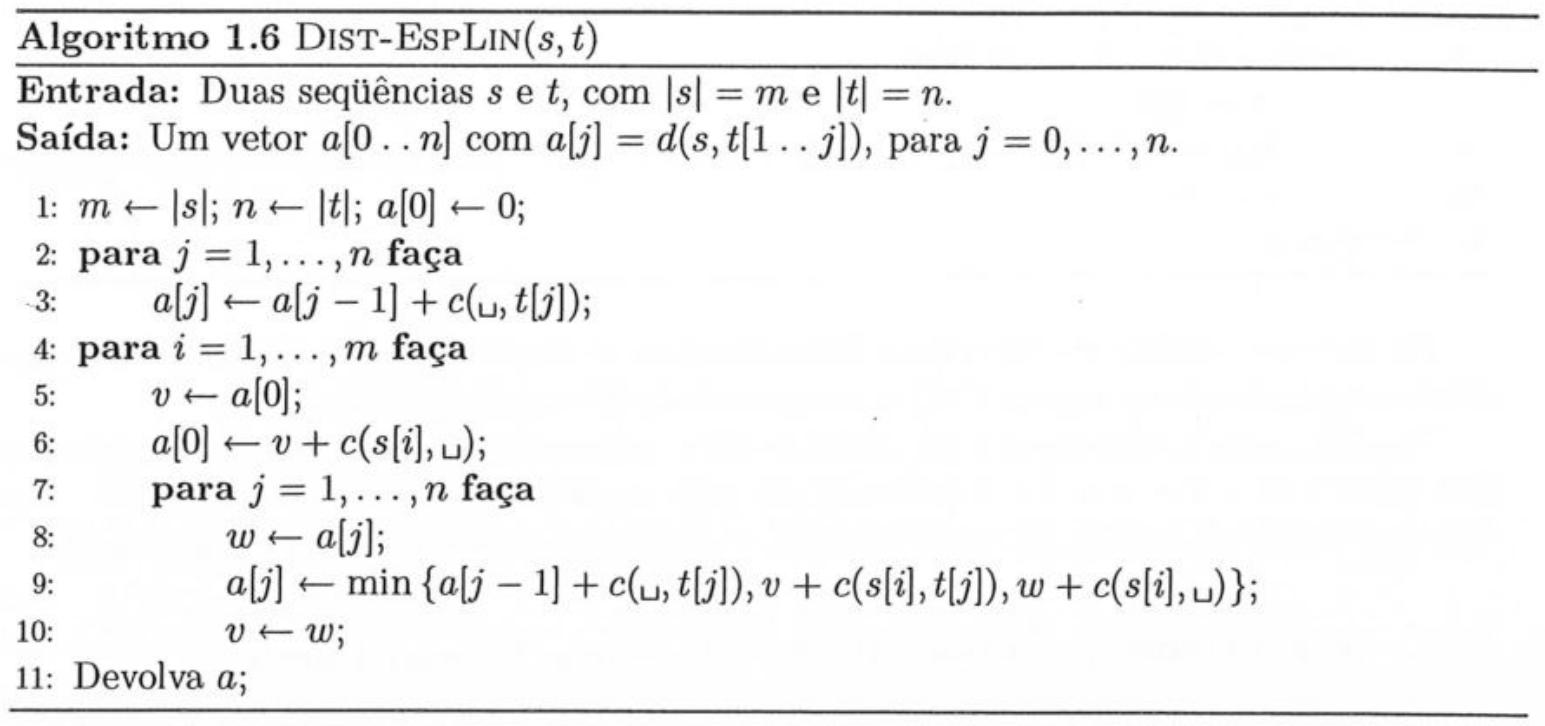

No algoritmo, $v$ e $w$ são os valores correspondentes, respectivamente, às colunas $j-1 \mathrm{e}$ $j$ da linha anterior.

Após a execução do Algoritmo Dist-Esplin, o vetor a contém as distâncias entre a seqüência $s$ inteira e todos os prefixos de $t$ (inclusive o prefixo vazio). Em particular, $a[n]$ contém $d(s, t)$, que era nosso objetivo.

Vamos agora fazer uma breve análise de complexidade do Algoritmo Dist-EspLin. Analisemos primeiro o tempo. No primeiro laço, $O(n)$ operações são executadas, sendo cada uma delas de tempo constante. Nos laços encaixados temos um total de $O(m n)$ iterações, cada uma de tempo constante. Logo, o tempo total consumido pelo algoritmo é $O(n)+O(m n)=O(m n)$.

Quanto ao espaço, podemos notar que o algoritmo usa apenas o vetor $a$ e as variáveis $m, n, i, j, v$ e $w$, excluindo-se, naturalmente, as variáveis de entrada. É interessante notar que o tamanho do vetor de saída é igual a $|t|+1=n+1$, isto é, o tamanho do vetor de saída é determinado pelo tamanho do segundo argumento de DisT-EspLin, o que significa que o espaço usado para a execução do algoritmo é $O(1)$ (fora o tamanho da solução, que é $O(n))$ e, portanto, as modificações feitas resultam em um consumo (total) linear de espaço, como afirmamos no início da seção.

Naturalmente, podemos aplicar as mesmas idéias de redução de espaço (tendo em mente 
a Recorrência (1.4)) ao Algoritmo Dist-Rev para obter o algoritmo que chamamos de Dist-EspLin-Rev, que computa um vetor, digamos, $b[0 \ldots n]$ de forma que $b[j]$ seja a distância entre $s$ e o sufixo de $t$ de tamanho $n-j$, isto é, $b[j]=d(s, t[j+1 \ldots n])$, para $j=0, \ldots, n$. Nesse caso, é claro que $b[0]=d(s, t[1 \ldots n])=d(s, t)$.

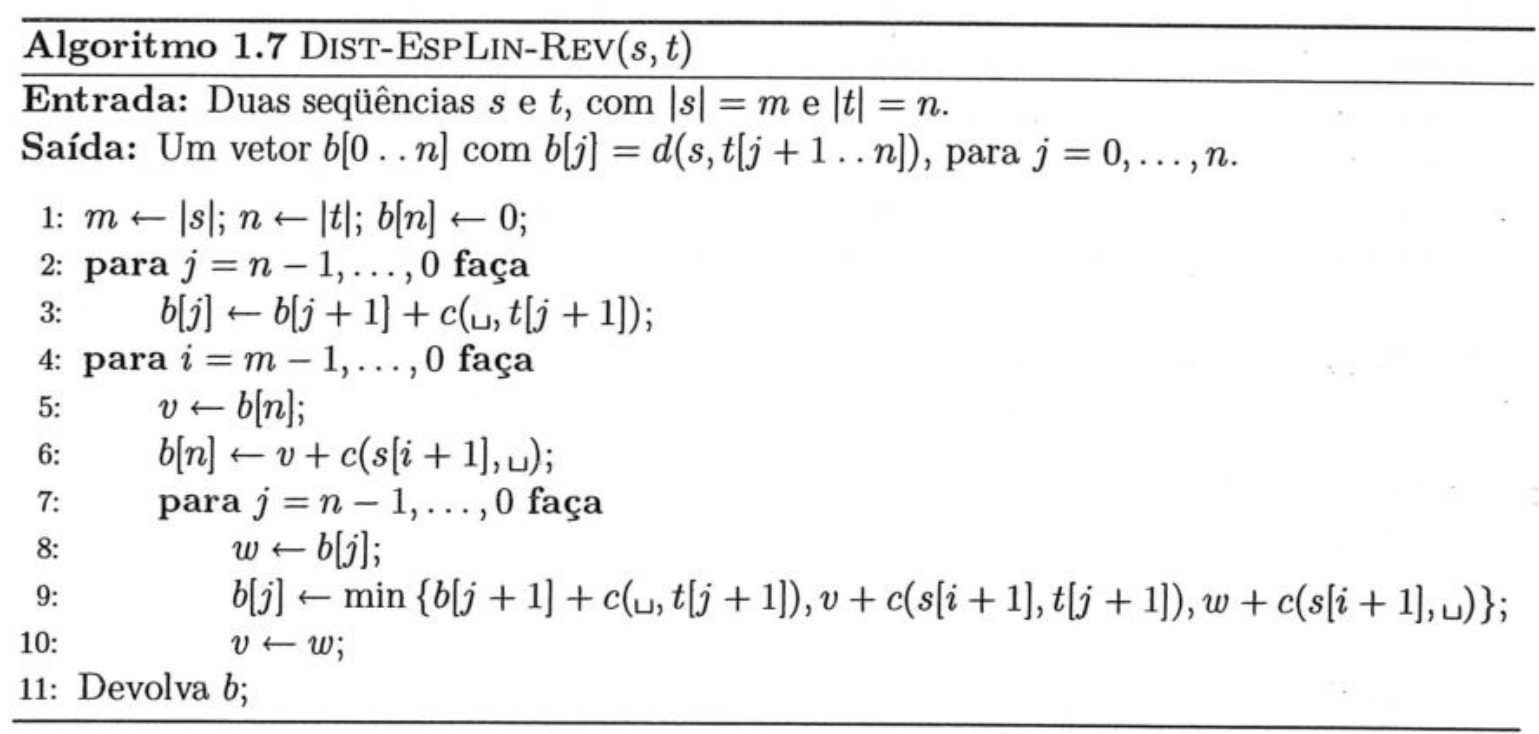

De maneira similar ao Algoritmo Dist-EspLin, o Algoritmo Dist-EspLin-Rev apresenta complexidade de espaço $O(1)$ e complexidade de tempo $O(m n)$.

Também para o Algoritmo DisT-EspLin-Rev, o tamanho do vetor de resposta (no caso, b) é igual a $|t|+1=n+1$ e é determinado pelo segundo argumento de DisT-REv. Esse fato será usado na análise de complexidade do algoritmo apresentado na próxima seção.

\subsubsection{Calculando um Alinhamento Ótimo em Espaço Linear}

Os Algoritmos Dist-EspLin e Dist-EspLin-Rev são duas soluções ao problema de encontrar a distância $d(s, t)$ em espaço linear e a elaboração de ambos é relativamente imediata após contemplar as Recorrências (1.3) e (1.4), que definem suas respectivas matrizes (ou vetores) de programação dinâmica. Uma situação mais complicada é encontrar não só a distância, mas também um alinhamento ótimo em espaço linear. Uma engenhosa solução para este problema foi proposta em 1975 por Hirschberg [Hir75]. Sua descrição original foi para o Problema de Subseqüência Comum de Maior Comprimento ${ }^{6}$; posteriormente, o método foi adaptado para o Problema APS [MM88].

A essência da solução proposta por Hirschberg é a aplicação de um método geral chamado Método da Divisão e Conquista. Um algoritmo baseado nesse método é geralmente recursivo e opera em três etapas:

1. Divisão: uma instância do problema é dividida em sub-instâncias do mesmo problema;

2. Conquista: o algoritmo é usado recursivamente para resolver cada uma das subinstâncias;

\footnotetext{
${ }^{6}$ O Problema da Subseqüência Comum de Maior Comprimento (SC-MÁx) é: dadas duas seqüências $s$ e $t$ sobre um mesmo alfabeto, encontrar uma subseqüência comum a $s$ e a $t$ de comprimento máximo.
} 
3. Combinação: as soluções obtidas na etapa de conquista são combinadas para produzir uma solução para o problema original;

Descrevemos agora como esse método pode ser aplicado para resolver o Problema APS em espaço linear.

Seja $A^{*}$ um alinhamento ótimo entre $s$ e $t, \operatorname{com}|s|=m$ e $|t|=n$ e fixemos um inteiro $i$ entre 1 e $m$. Há duas possibilidades para o alinhamento de $s[i]$ em $A^{*}$ :

1. o caractere $s[i]$ está alinhado a um caractere $t[j]$ de $t$, para algum $j=1, \ldots, n$;

2. o caractere $s[i]$ está alinhado a um espaço em $t$, com o espaço ocorrendo entre os caracteres $t[j]$ e $t[j+1]$, para algum $j=0, \ldots, n$.

Em nossa notação para a segunda possibilidade, o caso $j=0$ corresponde, evidentemente, a $s[i]$ estar alinhado a um espaço antes de qualquer caractere de $t$; simetricamente, $j=n$ equivale a dizer que $s[i]$ está alinhado a um espaço após todos os caracteres de $t$. É importante ressaltar que $j$ varia em intervalos diferentes nas duas possibilidades acima.

Se o primeiro caso ocorre, então $A^{*}$ pode ser dividido em três partes, sendo a primeira um alinhamento $A^{\prime}$ entre $s[1 \ldots i-1]$ e $t[1 \ldots j-1]$, a segunda, uma coluna contendo $s[i]$ alinhado a $t[j]$ e, a terceira, um alinhamento $A^{\prime \prime}$ entre $s[i+1 \ldots m]$ e $t[j+1 \ldots n]$. Ademais, como $A^{*}$ é um alinhamento ótimo por hipótese, pelo Fato 1.1, sabemos que tanto $A^{\prime}$ quanto $A^{\prime \prime}$ são alinhamentos ótimos. Uma situação análoga ocorre se $s[i]$ precisar ser alinhado a um espaço em $t$. Em resumo, mais precisa dos dois casos nas fórmulas abaixo:

- no primeiro caso, $A^{*}=\left(A^{\prime}: \begin{array}{c}s[i] \\ t[j]\end{array}: A^{\prime \prime}\right)=\left(\operatorname{opt}\left(\begin{array}{c}s[1 \ldots i-1] \\ t[1 \ldots j-1]\end{array}\right): \begin{array}{l}s[i] \\ t[j]\end{array}:\right.$ opt $\left.\left(\begin{array}{c}s[i+1 \ldots m] \\ t[j+1 \ldots n]\end{array}\right)\right)$;

- no segundo caso, $A^{*}=\left(A^{\prime}: \underset{\sqcup}{s[i]}: A^{\prime \prime}\right)=\left(\operatorname{opt}\left(\begin{array}{c}s[1 \ldots i-1] \\ t[1 \ldots j]\end{array}\right):{ }_{\sqcup}^{s[i]}: \operatorname{opt}\left(\begin{array}{c}s[i+1 \ldots m] \\ t[j+1 \ldots n]\end{array}\right)\right)$.

Se fixarmos um valor para o índice $i$, digamos $i=\lfloor(1+m) / 2\rfloor$, então, para construirmos $A^{*}$, basta seguirmos o paradigma de divisão e conquista da seguinte maneira ${ }^{7}$ :

1. Divisão: descobrimos qual dos dois casos ocorre (juntamente com o índice $j$ associado), determinando uma coluna de $A^{*}$ (que sabemos definitivamente conter pelo menos o caractere $s[i])$;

2. Conquista: aplicamos o método recursivamente para os prefixos e os sufixos adequados de $s$ e de $t$ para obter $A^{\prime}$ e $A^{\prime \prime}$;

3. Combinação: concatenamos $A^{\prime}$ com a coluna do passo de divisão e com $A^{\prime \prime}$, nessa ordem, para obter $A^{*}$.

Como pelo menos uma coluna de $A^{*}$ fica determinada no passo de divisão, as instâncias fornecidas ao passo de conquista têm tamanho menor do que o tamanho da instância do problema original (mesmo no caso limite em que alguma das instâncias do passo de conquista tenha tamanho 0$)$.

Como podemos perceber facilmente, a tarefa mais complicada é o passo de divisão. Para descobrir qual dos dois casos ocorre, basta procurar, no primeiro caso, qual é o índice $j=1, \ldots, n$ que minimiza $d(s[1 \ldots i-1], t[1 \ldots j-1])+c(s[i], t[j])+d(s[i+1 \ldots m], t[j+1 \ldots n])$. Depois, basta procurar, para o segundo caso, qual é o índice $j=0, \ldots, n$ que minimiza

\footnotetext{
${ }^{7}$ Para a corretude do algoritmo, a escolha do índice $i$ pode ser arbitrária nos inteiros entre 1 e $m$.
} 
$d(s[1 \ldots i-1], t[1 \ldots j])+c(s[i], \sqcup)+d(s[i+1 \ldots m], t[j+1 \ldots n])$ e, finalmente, escolher para $j$ o melhor valor dentre os dois casos.

Mas essa é uma tarefa em que as funções Dist-EspLin e Dist-EspLin-Rev podem nos ajudar: uma chamada a $\operatorname{DisT-EspLin}(s[1 \ldots i-1], t)$ nos devolve um vetor $a[0 \ldots n]$ tal que $a[j]=d(s[1 \ldots i-1], t[1 \ldots j])$ e uma chamada a Dist-EspLin-Rev $(s[i+1 \ldots m], t)$ nos devolve um vetor $b[0 \ldots n]$ tal que $b[j]=d(s[i+1 \ldots m], t[j+1 \ldots n])$ e estes são exatamente os valores necessários para calcularmos os mínimos descritos acima e decidirmos qual caso ocorre.

O Algoritmo Hirschberg, que deve ser chamado com $\operatorname{Hirschberg}(s[1 \ldots m], t[1 \ldots n])$ para produzir um alinhamento ótimo entre $s$ e $t$, incorpora as idéias recém discutidas.

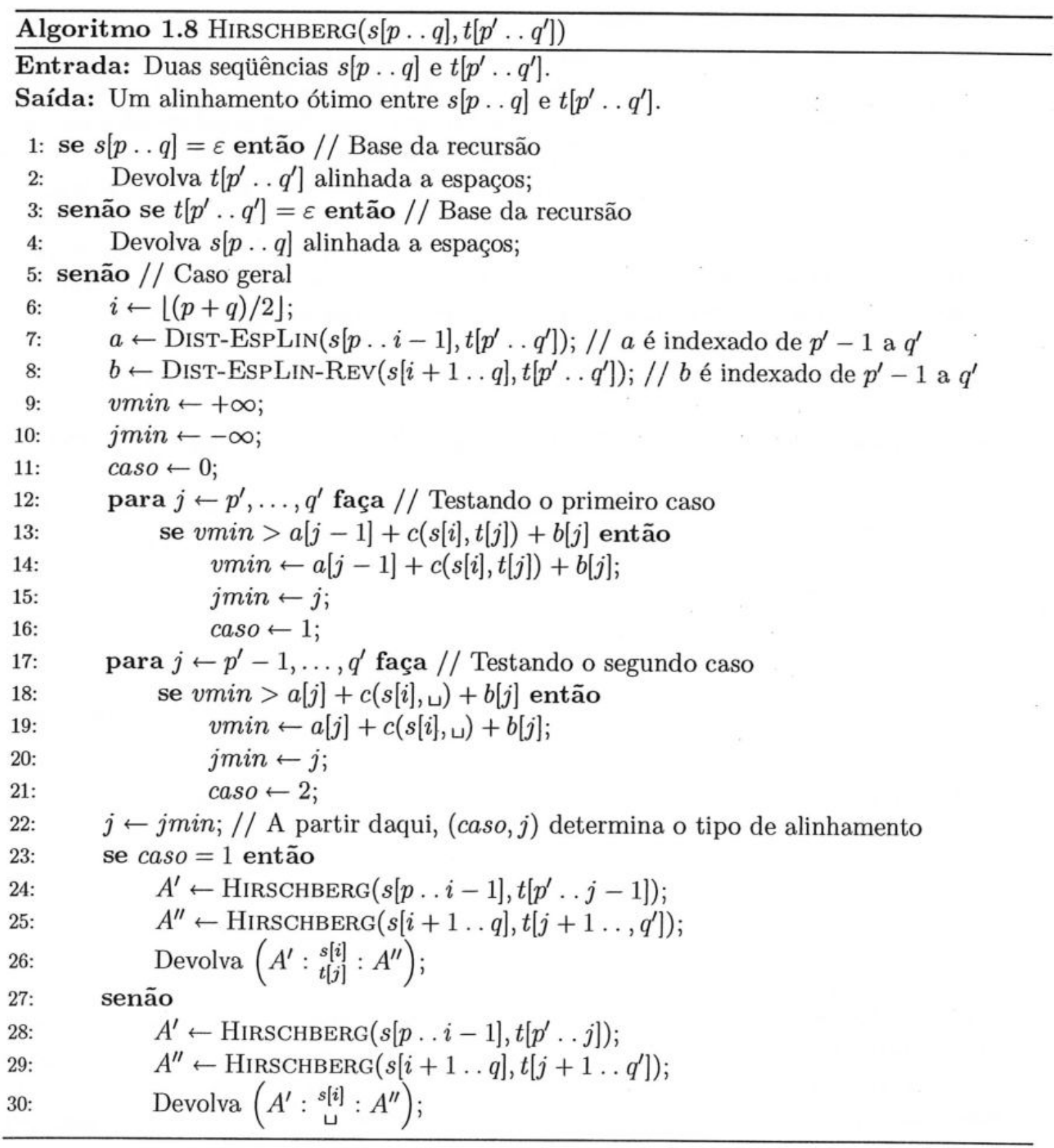




\subsubsection{Análise de Complexidade}

Começamos nossa análise de complexidade verificando que o espaço utilizado pelo Algoritmo HirschBerg é linear.

1.6.2.1.1 Complexidade de Espaço Para cada chamada do algoritmo com parâmetros $s[p \ldots q]$ e $t\left[p^{\prime} \ldots q^{\prime}\right]$ em que ambas seqüências são não-vazias, o espaço usado diretamente por esta chamada (i.e., sem levar em consideração as chamadas recursivas que possam ser feitas) é somente o espaço dos vetores $a$ e $b$ e das demais variáveis temporárias. Os vetores $a$ e $b$ têm, cada, tamanho $\left(q^{\prime}-\left(p^{\prime}-1\right)\right)+1=\left(q^{\prime}-p^{\prime}+1\right)+1 \leq n+1$, isto é, os vetores $a$ e $b$, juntos, possuem tamanho $O(n)$. Internamente, as funções DisT-EspLin e DisT-EsPLin-Rev usam, além de suas variáveis de controle, cujo tamanho total é $O(1)$, os próprios vetores a e $b$ (em que as funções devolvem suas respostas). Logo, todo o espaço usado pelo algoritmo até a decisão da possibilidade ótima (i.e., até a linha 22) de alinhamento de $s[i]$ é $O(n)$.

Após o algoritmo decidir a possibilidade de alinhamento de $s[i]$, os vetores $a$ e $b$ não são mais necessários e podem ser reaproveitados para uso em chamadas recursivas. Cada chamada recursiva em que ambas seqüências são não-vazias usa espaço de tamanho menor ou igual ao tamanho do espaço da chamada original. Se os vetores $a$ e $b$ forem alocados inicialmente com tamanho $|t|+1=n+1$ e forem globais, todas as chamadas recursivas decorrentes da chamada HirschBerg $(s[1 \ldots m], t[1 \ldots n])$ podem ser feitas com os mesmos vetores. Esse espaço é de tamanho $O(n)$.

Observe-se também que ao final da execução do algoritmo, temos um alinhamento entre $s$ e $t$ e, para cada coluna, espaço constante é usado (por exemplo, cada coluna do alinhamento pode ocupar uma coluna de uma matriz ou uma célula de uma lista ligada). Como o alinhamento possui tamanho $l \leq m+n$, segue que o espaço para armazenar a solução do algoritmo tem tamanho $O(m+n)$.

Como a cada chamada recursiva do Algoritmo HiRschBerg pelo menos uma coluna do alinhamento fica determinada, isso significa que, para alinhar duas seqüências de tamanhos $m$ e $n$, no máximo $m+n$ chamadas recursivas são feitas (uma vez que nenhuma outra chamada é feita). Como cada chamada ao Algoritmo HiRschberg pode ser feita passandose apenas apontadores para os inícios de $s$ e de $t$ e os índices $p, p^{\prime}, q$ e $q^{\prime}$, segue que o espaço utilizado para cada chamada recursiva é $O(1)$ (outras variáveis de controle podem estar incluídas nessa quantia), o que significa que o espaço total usado para a pilha de recursão do Algoritmo HirschBerg é também $O(m+n)$.

Isso conclui a argumentação de que o Algoritmo HiRschBerg usa espaço linear em sua execução.

1.6.2.1.2 Complexidade de Tempo Para a análise de tempo, vamos supor que os alinhamentos sejam representados, por exemplo, por meio de listas ligadas em que cada célula da lista representa uma coluna do alinhamento e que tanto o início quanto o fim da lista ligada façam parte de nossa estrutura de dados. Com essa estrutura, podemos concatenar os alinhamentos $A^{\prime}$ e $A^{\prime \prime}$ com uma coluna (uma célula da lista ligada) em tempo constante (efeito similar pode ser obtido usando-se um vetor global; vide [SM97]).

O tempo gasto pelo Algoritmo de Hirschberg pode ser descrito por uma recorrência. Seja $T(m, n)$ o tempo gasto pelo algoritmo para encontrar um alinhamento ótimo entre seqüências $s$ e $t$ com comprimentos $m$ e $n$, respectivamente. É importante notar, para a análise de tempo do algoritmo, que o índice $i$ correspondente ao caractere de $s$ a alinhar está aproximadamente na metade de $s$. A recorrência que nos dá $T(m, n)$ pode ser escrita 
como:

$$
T(m, n)= \begin{cases}O(m), & \text { se } n=0 \\ O(n), & \text { se } m=0 \\ O(i n)+O(i n)+T(i-1, j)+T(m-i, n-j), & \text { se } m>0 \text { e } n>0\end{cases}
$$

para algum inteiro $j$ entre 0 e $n$. Nosso interesse é mostrar um limite superior para $T(m, n)$ e, mais do que isso, mostrar que $T(m, n)=O(m n)$. Em nossa análise, vamos mostrar que o limite superior independe do inteiro $j$. Além disso, notando que tanto $i-1=$ $\lfloor(m+1) / 2\rfloor-1 \leq m / 2$ quanto $m-i=\lceil(m-1) / 2\rceil \leq m / 2$, a recorrência pode ser escrita na forma:

$$
T(m, n) \leq \begin{cases}k_{1} m+k_{1}^{\prime}, & \text { se } n=0 \\ k_{2} n+k_{2}^{\prime}, & \text { se } m=0 \\ k_{3} m n+k_{4} n+k_{5}+T(m / 2, j)+T(m / 2, n-j), & \text { se } m>0 \text { e } n>0\end{cases}
$$

para constantes $k_{1}, \ldots, k_{5}, k_{1}^{\prime}, k_{2}^{\prime}$ apropriadas. Desejamos mostrar que existem constantes positivas $k, k^{\prime}, k^{\prime \prime}, k^{\prime \prime \prime}, m_{0}$ e $n_{0}$ para as quais $T(m, n) \leq k m n+k^{\prime} m+k^{\prime \prime} n+k^{\prime \prime \prime}$ para todo $m \geq m_{0}$ e para todo $n \geq n_{0}$. A prova é por indução.

Se $m=0$, então para todo $n$ temos que $T(m, n) \leq k_{2} n+k_{2}^{\prime} \leq k m n+k^{\prime} m+k^{\prime \prime} n+k^{\prime \prime \prime}$ e o limite superior é válido para $m=0$, se $k^{\prime \prime} \geq k_{2}$ e $k^{\prime \prime \prime} \geq k_{2}^{\prime}$. Analogamente, se $n=0$, então para todo $m$ temos que $T(m, n) \leq k_{1} m+k_{1}^{\prime} \leq k m n+k^{\prime} m+k^{\prime \prime} n+k^{\prime \prime \prime}$ e o limite também vale para $n=0$, desde que $k^{\prime} \geq k_{1}$ e $k^{\prime \prime \prime} \geq k_{1}^{\prime}$.

Agora, supondo-se que o limite seja válido para todo $m^{\prime}$ tal que $0<m_{0} \leq m^{\prime}<m$ e para todo $n^{\prime}$ para o qual $0<n_{0} \leq n^{\prime}<n$, mostraremos que o limite também vale para o par $m$ e $n$. Pela definição da recorrência, temos que:

$$
T(m, n) \leq k_{3} m n+k_{4} n+k_{5}+T(m / 2, j)+T(m / 2, n-j) .
$$

Observe-se que, com $m_{0}>0, m / 2<m$. Podemos aplicar a hipótese de indução se tanto $j<n$ quanto $n-j<n$. Isso acontece se $0<j<n$ ou, como $j$ é inteiro, se $1 \leq j \leq n-1$. Se $j$ está no intervalo indicado, podemos aplicar a hipótese de indução e obter

$$
\begin{aligned}
T(m, n) & \leq k_{3} m n+k_{4} n+k_{5}+k \frac{m}{2} j+k^{\prime} \frac{m}{2}+k^{\prime \prime} j+k^{\prime \prime \prime}+k \frac{m}{2}(n-j)+k^{\prime} \frac{m}{2}+k^{\prime \prime}(n-j)+k^{\prime \prime \prime} \\
& =k_{3} m n+k_{4} n+k_{5}+k \frac{m}{2} n+k^{\prime} m+k^{\prime \prime} n+2 k^{\prime \prime \prime} \\
& \leq k_{3} m n+k_{4} m n+k_{5} m n+k \frac{m}{2} n+k^{\prime} m+k^{\prime \prime} n+k^{\prime \prime \prime}+k^{\prime \prime \prime} m n \\
& =\left(k_{3}+k_{4}+k_{5}+k / 2+k^{\prime \prime \prime}\right) m n+k^{\prime} m+k^{\prime \prime} n+k^{\prime \prime \prime} \\
& \leq k m n+k^{\prime} m+k^{\prime \prime} n+k^{\prime \prime \prime}
\end{aligned}
$$

para o par $m$ e $n$, se $2\left(k_{3}+k_{4}+k_{5}+k^{\prime \prime \prime}\right) \leq k$. A justificativa para a segunda desigualdade acima segue do fato de que $m \geq 1$ e $n \geq 1$.

Finalmente, os últimos casos a verificar para concluir a demonstração são quando $j=0$ ou quando $j=n$, uma vez que, se algum deles ocorrer, os termos $T(m / 2,0)$ e $T(m / 2, n)$ aparecem na relação de recorrência e, para o segundo termo, não é possível usar a hipótese de indução. 
Enquanto algum dos casos $j=0$ ou $j=n$ ocorrer nas chamadas recursivas do Algoritmo de Hirschberg, a recorrência será resolvida pelo seu caso geral ${ }^{8}$ e, assim,

$$
\begin{aligned}
T(m, n) & \leq k_{3} m n+k_{4} n+k_{5}+T(m / 2,0)+T(m / 2, n) \\
& =k_{3} m n+k_{4} n+k_{5}+k_{1} m / 2+k_{1}^{\prime}+T(m / 2, n) \\
& \leq k_{3} m n+k_{4} n+k_{5}+k_{1} m / 2+k_{1}^{\prime}+\left[k_{3} \frac{m}{2} n+k_{4} n+k_{5}+T\left(\frac{m}{4}, 0\right)+T\left(\frac{m}{4}, n\right)\right] \\
& =k_{3}\left(m+\frac{m}{2}\right) n+2 k_{4} n+2 k_{5}+k_{1}\left(\frac{m}{2}+\frac{m}{4}\right)+2 k_{1}^{\prime}+T(m / 4, n) \\
& \leq k_{3}\left(m+\frac{m}{2}+\frac{m}{4}\right) n+3 k_{4} n+3 k_{5}+k_{1}\left(\frac{m}{2}+\frac{m}{4}+\frac{m}{8}\right)+3 k_{1}^{\prime}+T(m / 8, n) .
\end{aligned}
$$

Em geral, após a $i$-ésima iteração consecutiva em que $j$ seja 0 ou $n$, o limite superior é:

$$
T(m, n) \leq k_{3} m n\left(\sum_{k=0}^{i-1} \frac{1}{2^{k}}\right)+i k_{4} n+i k_{5}+k_{1} m\left(\sum_{k=1}^{i} \frac{1}{2^{k}}\right)+i k_{1}^{\prime}+T\left(m / 2^{i}, n\right) .
$$

Mas é importante observar que o menor $i$ para o qual $\left\lfloor m / 2^{i}\right\rfloor<1$ causa a base da recorrência relativa a $m=0$ ser usada, que é dada por uma fórmula fechada. Isso ocorre para $i=\lfloor\lg m\rfloor+1$, onde $\lg i$ denota o logaritmo de $m$ na base 2 . As somas geométricas da desigualdade (1.7) são facilmente delimitadas superiormente, porque $\sum_{k=0}^{i-1} 2^{-k} \leq \sum_{k=0}^{\infty} 2^{-k} \leq 2$ e $\sum_{k=1}^{i} 2^{-k} \leq \sum_{k=1}^{\infty} 2^{-k} \leq 1$. Para $i$, um limite superior é $1+\lg m \geq 1+\lfloor\lg m\rfloor=i$. No caso extremo em que $j$ nunca fica entre 1 e $n-1$, a Recorrência (1.7) é tal que

$$
\begin{aligned}
T(m, n) & \leq k_{3} m n\left(\sum_{k=0}^{i-1} \frac{1}{2^{i}}\right)+i k_{4} n+i k_{5}+k_{1} m\left(\sum_{k=1}^{i} \frac{1}{2^{i}}\right)+i k_{1}^{\prime}+T(0, n) \\
& \leq 2 k_{3} m n+k_{4}(1+\lg m) n+k_{5}(1+\lg m)+k_{1} m+k_{1}^{\prime}(1+\lg m)+k_{2} n+k_{2}^{\prime} \\
& \leq\left(2 k_{3}+k_{4}+k_{5}\right) m n+\left(k_{1}+k_{1}^{\prime}\right) m+k_{2} n+k_{2}^{\prime}+k_{4} n+k_{5}+k_{1}^{\prime} \\
& \leq k m n+k^{\prime} m+k^{\prime \prime} n+k^{\prime \prime \prime},
\end{aligned}
$$

e a hipótese de indução é válida também para esse caso, se $\left(2 k_{3}+k_{4}+k_{5}\right) \leq k,\left(k_{1}+k_{1}^{\prime}\right) \leq k^{\prime}$, $k_{2}+k_{4} \leq k^{\prime \prime}$ e $k_{5}+k_{1}^{\prime}+k_{2}^{\prime} \leq k^{\prime \prime \prime}$.

Resta apenas verificar o caso em que após $i \geq 1$ iterações sem ocorrência de $j$ entre 1 e $n-1$, para $i<\lfloor\lg m\rfloor+1$, ocorre um caso em que $0<j<n$. Mas aí, o limite superior em $T(m, n)$ teria dois termos dados em função de $T$ e ambos termos teriam tanto o primeiro argumento menor do que $m$ quanto o segundo argumento menor do que $n$, o que significa que há condições para aplicar a hipótese de indução. Usando a desigualdade (1.7) e a hipótese de indução, temos que:

$$
\begin{aligned}
T(m, n) \leq & 2 k_{3} m n+k_{4}(1+\lg m) n+k_{5}(1+\lg m)+k_{1} m+k_{1}^{\prime}(1+\lg m) \\
& +\left(k \frac{m}{2^{i}} n+k^{\prime} \frac{m}{2^{i}}+k^{\prime \prime} n+k^{\prime \prime \prime}\right) \\
= & \left(2 k_{3}+2 k_{4}+2 k_{5}+k_{1}^{\prime}+\frac{k}{2^{i}}\right) m n+\left(k_{1}+k_{1}^{\prime}+\frac{k^{\prime}}{2^{i}}\right) m+k^{\prime \prime} n+k^{\prime \prime \prime} \\
\leq & k m n+k^{\prime} m+k^{\prime \prime} n+k^{\prime \prime \prime},
\end{aligned}
$$

para o par $m, n$ se $i \geq 1$ e $\lg m \leq m$, isto é, se $m \geq 1$.

Isso tudo conclui a demonstração de que o tempo gasto pelo Algoritmo de Hirschberg é $T(m, n) \leq k m n+k^{\prime} m+k^{\prime \prime} n+k^{\prime \prime \prime}$, ou seja, $T(m, n)=O(m n)$ e que, portanto, o algoritmo roda em tempo quadrático no tamanho de sua entrada.

\footnotetext{
${ }^{8} \mathrm{E}$ podemos supor que $j=0$, pois no outro caso tudo será idêntico.
} 


\subsubsection{Comentários Gerais}

Na realidade, é possível escrever o Algoritmo de Hirschberg de modo que não seja necessário dividir em duas partes as possibilidades para alinhamentos de $s[i]$ a caracteres de t. É possível fazer uma descrição unificada para simplificar o passo de divisão do algoritmo. Definimos um conceito auxiliar antes de mostrarmos como é essa formulação alternativa.

Definição 1.3 (Corte de um Alinhamento). Dados duas seqüências $s$ e $t$ de comprimentos $|s|=m$ e $|t|=n$ e um alinhamento $A$ de $s$ e $t$, dizemos que um par $(i, j)$ de inteiros, com $0 \leq i \leq m$ e $0 \leq j \leq n$ é um corte de $A$ se $A$ puder ser escrito na forma $A=\left(A^{\prime}: A^{\prime \prime}\right)$ $\operatorname{com} A^{\prime}=\left(\begin{array}{l}s[1 \ldots i] \\ t[1 \ldots j]\end{array}\right)$ e $A^{\prime \prime}=\left(\begin{array}{c}s[i+1 \ldots m] \\ t[j+1 \ldots n]\end{array}\right)$.

Exemplo 1.1. Se $s=$ AACGT, $t=$ ACGT e $A=\left(\begin{array}{l}\text { AACGT } \\ A_{\sqcup} C G T\end{array}\right)$, então $(2,1)$ é um corte de $A$, bem como $(1,1)$. No entanto, $(2,2)$ não é um corte de $A$.

Para a formulação alternativa do algoritmo, notamos que em ambas possibilidades para o alinhamento de $s[i]$, o alinhamento ótimo $A^{*}$ construído pelo Algoritmo HirschBerg possui o corte $(i, j)$ e é da forma $A^{*}=\left(\operatorname{opt}\left(\begin{array}{c}s[1 \ldots i] \\ t[1 \ldots j]\end{array}\right): o p t\left(\begin{array}{c}s[i+1 \ldots m] \\ t[j+1 \ldots n]\end{array}\right)\right)$.

Assim, se fixarmos um valor para o índice $i$, digamos $i=\lfloor(m+1) / 2\rfloor$, então, para construir $A$, basta seguir o paradigma da Divisão e Conquista da seguinte maneira:

1. Divisão: descobrimos um inteiro $j$ entre 0 e $n$ tal que $(i, j)$ seja um corte de um alinhamento ótimo;

2. Conquista: aplicamos o método recursivamente para os prefixos e os sufixos adequados de $s$ e de $t$ para obter os subalinhamentos $A^{\prime}$ e $A^{\prime \prime}$;

3. Combinação: concatenamos $A^{\prime} \operatorname{com} A^{\prime \prime}$ para obter $A^{*}$.

Mais uma vez, podemos perceber que a tarefa mais complicada é o passo de divisão, porque $j$ deve ser escolhido de forma que o corte $(i, j)$ seja um corte de um alinhamento ótimo. Para descobrir qual é um inteiro $j$ entre 0 e $n$ que faça $(i, j)$ ser um corte de um alinhamento ótimo, deve-se encontrar $j$ que minimize $d(s[1 \ldots i], t[1 \ldots j])+d(s[i+1 \ldots m], t[j+1 \ldots n])$. Mas essa também é uma tarefa em que as funções Dist-EspLin e Dist-EspLin-Rev podem ajudar: uma chamada a $\operatorname{DisT}-\operatorname{Rev}(s[1 \ldots i], t)$ nos devolve um vetor $a[0 \ldots n]$ tal que $a[j]=d(s[1 \ldots i], t[1 \ldots j])$ e uma chamada a Dist-EspLin-Rev $(s[i+1 \ldots m], t)$ nos devolve um vetor $b[0 \ldots n]$ tal que $b[j]=d(s[i+1 \ldots m], t[j+1 \ldots n])$ e esses são exatamente os valores necessários para calcular o mínimo descrito acima.

Note-se que o algoritmo, dessa maneira, calcula $n$ mínimos para encontrar qual é o valor de $j$ correspondente a um corte de um alinhamento ótimo. Isso é menos do que os $2 n$ mínimos que o Algoritmo Hirschberg realiza. Por outro lado, as bases da recursão devem ser modificadas para essa versão alternativa e tornam-se ligeiramente mais complicadas.

Para garantir que as instâncias passadas a chamadas recursivas do algoritmo variante sempre tenham tamanho menor do que o da instância original, é necessário que $\lfloor(m+1) / 2\rfloor<$ $m$ e que $\lceil(m-1) / 2\rceil<m$, isto é, é suficiente que $(m+1) / 2<m$, ou seja, que $m \geq 2$. Assim, se os casos em que $m<2$ forem tratados na base da recursão (isto é, se $m=0$ ou $m=1$ ), garante-se que chamadas recursivas do algoritmo não serão feitas com instâncias de mesmo tamanho que a original. 


\subsection{Método de Economia de Tempo (Quatro Russos)}

A complexidade de tempo do algoritmo de programação dinâmica pode ser reduzida em casos particulares por meio de uma interessante estratégia conhecida como o Método dos Quatro Russos $^{9}$, que aparentemente não possui divulgação muito ampla.

Originalmente proposto para obter um algoritmo de multiplicação de matrizes booleanas que tivesse complexidade de tempo menor do que a do algoritmo usual de multiplicação de matrizes [AHU74], o método foi adaptado posteriormente para outros problemas, incluindo o problema de cálculo da distância de edição (de Levenshtein) [MP80].

No caso de multiplicação de matrizes booleanas, o Método dos Quatro Russos obtém uma redução do tempo de $\Omega\left(n^{3}\right)$ operações para $O\left(n^{3} / \log n\right)$. Já para o caso de calcular a distância de edição, conforme veremos, é possível reduzir a complexidade de tempo de $\Omega\left(n^{2}\right)$ para $O\left(n^{2} / \log n\right)$.

Descrevemos o método para distância de edição e, embora o interesse na técnica seja principalmente teórico, as idéias contidas no método podem, com modificações, serem usadas em situações práticas, junto com outras técnicas de implementação [Gus97].

Para a exposição do método, supomos que as seqüências $s_{1}$ e $s_{2}$ a serem alinhadas possuam ambas comprimento igual a $n$.

A idéia básica do método é "particionar" a matriz de programação dinâmica em submatrizes de tamanho $t \times t$ e usar estas submatrizes para determinar valores da matriz de programação dinâmica em tempo menor do que o do método básico de programação dinâmica. Chamaremos cada uma dessas submatrizes de dimensões $t \times t$ de um $t$-bloco.

Na realidade, a matriz de programação dinâmica não é exatamente particionada em $t$-blocos, uma vez que a divisão feita pelo método depende de que algumas sobreposições entre os blocos sejam feitas.

Os $t$-blocos são dispostos sobre a matriz $a$, iniciando-se pela célula $a[0,0]$ (que supomos estar no canto superior esquerdo da matriz), de maneira que cada $t$-bloco tenha sua última coluna sobreposta pela primeira coluna do $t$-bloco à sua direita (quando houver) e sua última linha sobreposta pela primeira linha do $t$-bloco que está abaixo (quando houver). Em outras palavras, a matriz $a$ é coberta por $t$-blocos (dispostos em "linhas de $t$-blocos" que cubram a matriz $a$ ) de maneira que dois $t$-blocos que estejam adjacentes compartilhem exatamente uma coluna (se os $t$-blocos estiverem na mesma "linha de $t$-blocos") ou exatamente uma linha (se os $t$-blocos estiverem em uma mesma "coluna de $t$-blocos").

É claro que como cada $t$-bloco tem $t$ colunas e até 2 dessas colunas podem estar compartilhadas com outros $t$-blocos (um à sua direita e outro à sua esquerda), então $t$ deve ser pelo menos 2. Observe-se que se as seqüências possuem tamanho $n$, então a matriz $a$ possui dimensões $(n+1) \times(n+1)$ e que se $n=k(t-1)$ então $a$ pode ser coberta por $k^{2}=\Theta\left(n^{2} / t^{2}\right)$ $t$-blocos.

Uma observação simples de constatar (analisando a Recorrência (1.3), que define a) é que se um $t$-bloco está dividido como na Figura 1.6, então todos os valores do $t$-bloco podem ser completamente determinados por meio do algoritmo de programação dinâmica se $A, B$, $C, D$ e $E$ forem conhecidos (é claro que isso pode ser feito em tempo $O\left(t^{2}\right)$ ). Por esse motivo, podemos dizer que os valores $F$ do $t$-bloco são a imagem de $A, B, C, D$ e $E$ por

\footnotetext{
${ }^{9} \mathrm{~A}$ denominação do método parece ser incorreta segundo Gusfield [Gus97], já que, dos quatro autores originais, apenas um é realmente russo. Em suas palavras: "The idea comes from a paper by four authors, Arlazarov, Dinic, Kronrod, and Faradzev, concerning boolean matrix multiplication. The general idea taken from this paper has come to be known in the West as the Four-Russians technique, even though only one of the authors is Russian."
} 
meio de uma "função de bloco" $F$.

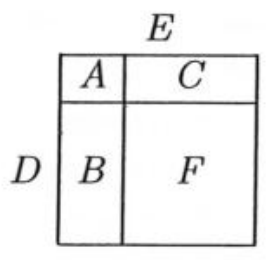

Figura 1.6: Esquema genérico de um $t$-bloco. Os valores da região $F$ do $t$-bloco são função dos valores da posição $A$, da coluna $B$, da linha $C$, e dos segmentos $D=s_{1}[i \ldots i+t-1]$ e $E=s_{2}[j \ldots j+t-1]$. Supomos que $A$ cubra a posição $(i, j)$ da matriz $a$.

$\mathrm{Na}$ realidade, se a matriz a fosse preenchida um $t$-bloco por vez ("linha a linha" de $t$-blocos), então, após um $t$-bloco $b$ qualquer ter todos os seus valores determinados, o $t$ bloco $b^{\prime}$ que está abaixo de $b$ e o $t$-bloco $b^{\prime \prime}$ que está à direita de $b$ já estão com parte dos dados necessários determinados (mais do que isso, $b^{\prime \prime}$ está com todos os dados necessários disponíveis) e isso permite preencher a matriz $a$ um $t$-bloco por vez, linha a linha, para determinar a distância de edição de $s_{1}$ e $s_{2}$.

Como existem $\Theta\left(n^{2} / t^{2}\right)$ blocos a serem preenchidos em $a$, se cada um puder, de alguma maneira, ser preenchido em tempo $O(t)$, então o tempo total para calcular $d\left(s_{1}, s_{2}\right)$ será $O\left(n^{2} / t\right)$ e, se $t=\Theta(\log n)$, então o tempo para calcular $d\left(s_{1}, s_{2}\right)$ será $O\left(n^{2} / \log n\right)$.

Mas como preencher cada $t$-bloco em tempo $O(t)$ ? A idéia chave do Método dos Quatro Russos é de precomputar todos os possíveis subproblemas que podem ocorrer durante a solução de um problema e armazenar suas soluções em uma tabela. Assim, para resolver o problema original, em vez de cada subproblema ser resolvido (possivelmente várias vezes ao longo da execução do algoritmo), a tabela com soluções dọ subproblemas é consultada, acelerando a resolução do problema original.

O Método dos Quatro Russos requer uma seleção cuidadosa de quais subproblemas são resolvidos durante a fase de pré-computação para que sua complexidade de tempo não seja muito grande e inviabilize o uso da estratégia. O ideal é escolher subproblemas que sejam "canônicos" para o problema em questão e que ocorram em pequeno número.

Após uma breve inspeção das interdependências entre os $t$-blocos que cobrem $a$ é fácil ver que as únicas células de um $t$ bloco que devem necessariamente ser calculadas para prosseguir com o cálculo dos próximos $t$-blocos são as células da última linha e da última coluna do $t$-bloco. Como o $t$-bloco possui dimensões $t \times t$, isso significa que apenas 2 vetores de tamanho $t$ deste $t$-bloco são usados por outros $t$-blocos. Conclui-se, pois, que $O(t)$ dados de cada $t$-bloco é que são importantes para as células de $a$ a serem calculadas posteriormente e, portanto, se em uma tabela de pré-computação forem armazenados esses $O(t)$ dados em vez de todos os $O\left(t^{2}\right)$ dados, uma melhoria de tempo pode ser obtida em relação a um algoritmo que calcule todas as células dos $t$-blocos que cobrem $a$.

Mas qual é o tempo gasto com as pré-computações? Cada célula de cada $t$-bloco armazena uma distância de edição que, para seqüências de tamanho $n$ é um inteiro entre 0 e $n$, de que pode-se concluir que há, no máximo, $n+1$ possibilidades para cada célula. Como os valores de cada $t$-bloco ficam totalmente determinados por $A, B, C, D$ e $E$, temos que existem um máximo de $n+1$ possibilidades para $A,(n+1)^{t-1}$ possibilidades para $B$ e $C$ e $L^{t-1}$ possibilidades para $D$ e $E$, isto é, existem $O\left(n^{2 t} L^{2 t}\right)$ possíveis $t$-blocos para as sequiências 
dadas $(L=|\Sigma|$ é constante por considerarmos o alfabeto fixado). Como cada $t$-bloco pode ser computado em tempo $O\left(t^{2}\right)$ por programação dinâmica, a fase de precomputar todos os $t$-blocos pode ser realizada em tempo $O\left(n^{2 t} L^{2 t} t^{2}\right)$. Como $L$ é considerado constante e $t \geq 2$, a complexidade da pré-computação parece ser muito maior do que o tempo gasto pelo algoritmo mais básico e o método não parece ser vantajoso.

Mas um problema com as contas acima é que a contagem de possibilidades para $A$, $B$ e $C$ superestima quantos são os $t$-blocos existentes - como as linhas ou colunas do $t$ bloco contém distâncias de edição, duas células adjacentes em uma linha ou em uma coluna não podem ser totalmente sem relação. De fato, como atesta a proposição abaixo, células adjacentes possuem valores que estão bastante próximos uns dos outros.

Proposição 1.6 (Dependência entre Células Adjacentes). Na matriz de programação dinâmica de distância de edição, duas células adjacentes (em linhas, colunas ou diagonais) possuem valores que diferem de, no máximo, 1.

Prova: Vamos analisar primeiro o caso em que as células adjacentes estejam em uma mesma linha.

Sejam $a[i, j-1]$ e $a[i, j]$ as células em questão. Pela recorrência da distância de edição, é claro que $a[i, j] \leq a[i, j-1]+1$ (a igualdade ocorre no caso em que um espaço em $s_{1}$ é alinhado ao caractere $s_{2}[j]$ em um alinhamento ótimo).

Vejamos agora que $a[i, j-1]-1 \leq a[i, j]$. Existem duas possibilidades para um alinhamento ótimo entre $s_{1}[1 \ldots i]$ e $s_{2}[1 \ldots j]$.

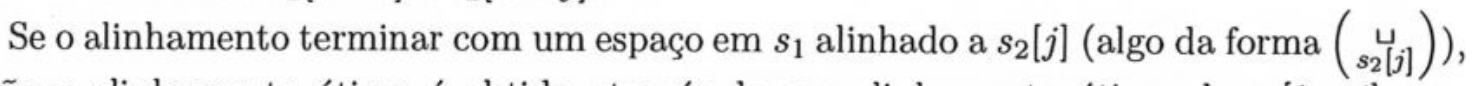
então o alinhamento ótimo é obtido através de um alinhamento ótimo de $s_{1}[1 \ldots i]$ com $s_{2}[1 \ldots j-1]$, cuja pontuação é $a[i, j-1]$, ou seja, $a[i, j]=a[i, j-1]+1$. Como $a[i, j-1]-1 \leq$ $a[i, j-1]+1=a[i, j]$, a desigualdade é verdadeira neste caso.

Seja $A^{*}$ um alinhamento ótimo entre $s_{1}[1 \ldots i]$ e $s_{2}[1 \ldots j]$. Se $A^{*}$ não terminar com um

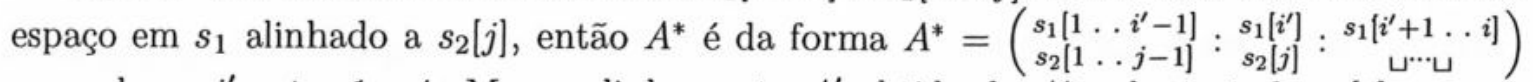
para algum $i^{\prime}$ entre 1 e $i$. Mas o alinhamento $A^{\prime}$ obtido de $A^{*}$ substituindo $s_{2}[j]$ por um espaço é um alinhamento entre $s_{1}[1 \ldots i]$ e $s_{2}[1 \ldots j-1]$ e sua pontuação é no máximo 1 unidade a mais do que o custo de $A^{*}$ (que é $a[i, j]$ ). Assim, $a[i, j-1] \leq c\left(A^{\prime}\right)$ e $c\left(A^{\prime}\right) \leq$ $a[i, j]+1$. Das duas inequações temos que $a[i, j-1]-1 \leq a[i, j]$ e a inequação que desejávamos verificar também é válida nesse caso.

O raciocínio pode ser adaptado para verificar que células adjacentes em uma coluna diferem de, no máximo, uma unidade.

Para o caso de células adjacentes em uma diagonal é trivial que $a[i, j] \leq a[i-1, j-1]+1$, pela definição da recorrência. Vamos agora verificar que $a[i-1, j-1]-1 \leq a[i, j]$. Há três casos a analisar. Se um alinhamento ótimo entre $s_{1}[1 \ldots i]$ e $s_{2}[1 \ldots j]$ termina $\operatorname{com}\left(\begin{array}{l}s_{1}[i] \\ s_{2}[j]\end{array}\right)$, a desigualdade é válida trivialmente. Se um alinhamento ótimo $A^{*}$ não termina com $s_{1}[i]$ alinhado a $s_{2}[j]$ então $A^{*}$ termina com $s_{1}[i]$ alinhado a um espaço ou $s_{2}[j]$ alinhado a um espaço. O argumento é análogo nos dois casos. Vamos analisar aqui quando $s_{2}[j]$ está alinhado a um espaço em $A^{*}$, ou seja, $A^{*}=\left(\begin{array}{c}s_{1}[1 \ldots i] \\ s_{2}[1 \ldots j-1]\end{array}: \underset{s_{2}[j]}{\sqcup}\right)$. Vamos definir $A^{\prime}$ como o alinhamento obtido de $A^{*}$ em que se exclui a última coluna. Então $A^{\prime}$ é um alinhamento ótimo entre $s_{1}[1 \ldots i]$ e $s_{2}[1 \ldots j-1]$ e $A^{\prime}$ possui pontuação exatamente 1 unidade a menos que $A^{*}$, de onde segue $a[i, j-1]=a[i, j]-1$. Mas $a[i-1, j-1]-1 \leq a[i, j-1]$, conforme visto no início da demonstração da proposição. Então $a[i-1, j-1]-1 \leq a[i, j-1] \leq$ $a[i, j-1]+1=a[i, j]$ e a desigualdade é válida. 
Portanto, na matriz de programação dinâmica para distância de edição uma célula difere de suas vizinhas (em qualquer direção) de, no máximo, 1 unidade.

A Proposição 1.6 nos diz que células adjacentes na matriz de programação dinâmica têm seus valores bem próximos umas das outras (por serem relacionadas) e que a contagem que fizemos do número de $t$-blocos ignora este fato (ela considera as células como independentes umas das outras).

Uma decorrência direta da Proposição 1.6 é o fato de que podemos codificar cada linha de um $t$-bloco como um vetor de tamanho $t$ em que a primeira posição do vetor é um número (uma distância) e as demais posições contém os valores $-1,0$ ou +1 , de forma a representar a diferença entre uma célula e a célula anterior na linha. A mesma observação é válida para colunas também.

Essa codificação deixa claro que existem muito menos possíveis $t$-blocos do que calculamos, o que é animador para uso da Estratégia dos Quatro Russos (isso significa menos trabalho feito na fase de pré-computação de subproblemas).

Definição 1.4 (Vetor de Diferença). Um vetor de diferença é um vetor de tamanho $t$ cuja primeira posição tem valor 0 e as demais células são elementos do conjunto $\{-1,0,+1\}$.

O ganho do Método dos Quatro Russos concretiza-se quando vetores de diferença são usados para calcular distância de edição, conforme a proposição a seguir.

Proposição 1.7. Em relação à matriz a, se um t-bloco possui sua primeira célula na posição $(i, j)$ de a, se os segmentos $D$ e $E$ das seqüências $s_{1}$ e $s_{2}$ correspondentes ao $t$-bloco são conhecidos e se os valores de $B$ e $C$ são dados cada um por meio de um vetor de diferenças, mas se o valor de A não é conhecido, então todos os valores da matriz que estão cobertos pelo $t$-bloco podem ser determinados a menos da constante $A$ contida na posição $a[i, j]$.

Prova: A demonstração é uma análise cuidadosa de como o algoritmo de programação dinâmica poderia funcionar se nem todos os dados estivessem disponíveis.

Vamos denotar por $b$ o $t$-bloco com início na posição $(i, j)$. Inicialmente vemos que se o valor $A$ do $t$-bloco (isto é, $a[i, j]$ ) não é conhecido, os valores de $B$ e $C$, dados como vetores de diferença, deixam as distâncias contidas na primeira linha e na primeira coluna de $b$ especificadas a menos da constante (aditiva) $A$. De fato, o valor de $a[i, j+1]$ é igual a $A$ mais o valor da segunda posição de $B, a[i, j+2]$ é igual a $A$ mais a soma dos valores das posições 2 e 3 de $B$ etc. De maneira geral, $a[i, q]$, para $q=j, \ldots, j+t-1$ é igual a $A$ mais a soma dos valores de $B$ da $j$-ésima coluna até a $q$-ésima coluna e todos os valores desta parte de $a$ dependem da mesma constante $A$. O mesmo argumento aplica-se à primeira coluna de $b$ e os valores mais uma vez dependem de maneira cumulativa uns dos outros e também da constante $A$ (igual para todas as células).

Mediante esta inicialização dos valores de $b$ representando distâncias de edição a menos de $A$, os outros valores do $t$-bloco podem ser determinados, porque os segmentos necessários de $s_{1}$ e $s_{2}$ são conhecidos. De fato, se $a[i, j+1]=A+J$ e $a[i+1, j]=A+I$, onde $I$ e $J$ são elementos do conjunto $\{-1,0,+1\}$ que o algoritmo já determinou, então o cálculo de $a[i+1, j+1]$ pode ser realizado pela Recorrência (1.3): como $a[i+1, j+1]=\min \{a[i+$ $\left.1, j]+1, a[i, j+1]+1, a[i, j]+c\left(s_{1}[i], s_{2}[j]\right)\right\}$, então $a[i+1, j+1]=\min \{A+I+1, A+$ $\left.J+1, A+c\left(s_{1}[i], s_{2}[j]\right)\right\}$, isto é, $a[i+1, j+1]=A+\min \left\{I+1, J+1, c\left(s_{1}[i], s_{2}[j]\right)\right\}$ de onde pode-se concluir que o valor de $a[i+1, j+1]$ pode ser determinado a partir de valores disponíveis ao algoritmo a menos da constante $A$. 
Prosseguindo com os cálculos que o algoritmo de programação dinâmica faria (linha a linha e das colunas de menor índice para as colunas de maior índice), todos os valores de $a$ que foram cobertos pelo $t$-bloco $b$ podem ser determinados a menos de $A$, que é uma constante aditiva igual para todas as células de $b$, conforme desejado.

Em particular, todos os valores da última linha e da última coluna do $t$-bloco também ficam determinados pelo método acima. Um conceito útil para a nossa discussão e motivado pela proposição anterior é o de um $t$-bloco canônico.

Definição 1.5 ( $t$-bloco Canônico). Um $t$-bloco canônico é um $t$-bloco cuja primeira posição contém a constante 0 e tal que sua primeira linha e sua primeira coluna são dadas por vetores de diferença.

Outra observação importante que pode ser feita a partir da proposição é que se o $t$ bloco que cobre a posição $(i, j)$ de $a$ for canônico e já tiver sido pré-computado antes de $a$ ser preenchida, então todas as células de $a$ cobertas pelo $t$-bloco podem ter seus valores imediatamente determinados somando-se $A$ ao valor de cada célula do $t$-bloco précomputado. Ademais, como os $t$-blocos são dispostos com sobreposição, o valor $A$ já estará determinado quando o $t$-bloco com início em $(i, j)$ tiver que ser tratado.

Corolário 1.8. Dados dois vetores de diferença (um referente à primeira linha $B$ de um $t$-bloco e outro referente à primeira coluna $C$ ) e os segmentos $D$ e $E$ das seqüências correspondentes, então os vetores de diferença relativos à última linha e à última coluna podem ser computados em tempo $O\left(t^{2}\right)$ para o t-bloco em questão.

Prova: Pelo teorema anterior, sabemos que dados os dois primeiros vetores de diferença (de linha e de coluna), todos os valores do $t$-bloco podem ser determinados a menos de uma constante $A$, igual para todas as células. Também como decorrência imediata da proposição, é fácil de ver que, para calcular os valores da última linha e da última coluna como vetores de diferença, não há prejuízo em supor que a constante $A$ seja igual a 0 .

Assim, um método para determinar os vetores de diferença referentes à última linha e última coluna do $t$-bloco pode ser o seguinte: supor $A=0$, inicializar os valores da primeira linha e da primeira coluna com os valores da distância de edição (deduzidos a partir dos vetores de diferença), usar o algoritmo de programação dinâmica para resolver o problema para o $t$-bloco com as condições iniciais da primeira linha e da primeira coluna e, finalmente, obter os vetores de diferença relativos à última linha e à última coluna do $t$-bloco em questão.

Tudo isto pode ser executado em tempo $O(t)+O\left(t^{2}\right)+O(t)=O\left(t^{2}\right)$, o que conclui a prova do Corolário.

Em suma, o Corolário 1.8 diz que os vetores de diferença correspondentes à última linha e à última coluna de um $t$-bloco canônico podem ser calculados a partir dos vetores de diferença da primeira linha e da primeira coluna do $t$-bloco por um processo de conversão desses dois primeiros vetores de diferença em vetores contendo distâncias, por um cálculo de programação dinâmica e por uma desconversão da última linha e da última coluna em vetores de diferença. Intuitivamente, o cálculo inteiro de um $t$-bloco canônico a partir dos "vetores de diferença iniciais" pode ser visto como uma sucessão conversão/cálculo/desconversão.

O procedimento descrito pelo Corolário 1.8 é adequado para a fase de pré-computação. Para o "preenchimento" de $a$ com $t$-blocos é necessária uma adaptação do processo. A matriz $a$ conterá apenas distâncias nas células que forem preenchidas. A matriz $a$ é inicializada com distâncias de edição em sua primeira linha e primeira coluna. A partir daí, os $t$-blocos são 
processados linha a linha, da esquerda para a direita, da seguinte maneira: a primeira linha e a primeira coluna do $t$-bloco já contém distâncias (inclusive com o valor $A$ determinado no canto superior esquerdo). A partir desses vetores de distância, uma conversão é realizada para transformá-los em vetores de diferenças. Esses vetores são usados, juntamente com os trechos apropriados das seqüências $s_{1}$ e $s_{2}$ como os valores $(B, C, D, E)$ para uma busca na tabela de valores pré-computados. Os valores pré-computados correspondentes à chave $(B, C, D, E)$, que são vetores de diferença, são convertidos em vetores de distância e o valor $A$ é adicionado a cada uma das posições dos vetores de distância, para obter os $O(t)$ valores de $a$ que são cobertos pela última linha e pela última coluna do $t$-bloco. É importante notar que os valores armazenados em $a$ sempre são distâncias e nunca diferenças. Naturalmente, pelo que já discutimos, o processamento feito acima de um $t$-bloco leva tempo $O(t)$.

Apenas os valores da "borda" de um $t$-bloco são necessários para prosseguir com a simulação do Algoritmo Dist, o que significa que só $O(t)$ valores importam (e não todos os $\Omega\left(t^{2}\right)$ valores). Assim, se após a pré-computação de cada $t$-bloco canônico suas duas últimas filas (última linha e última coluna) forem guardadas em uma tabela devidamente organizada (por exemplo, em uma tabela indexada pela quadra $(B, C, D, E)$ ), então a determinação das últimas linha e coluna do $t$-bloco pode ser feita em tempo $O(t)$, se se dispuser de $(B, C, D, E)$ e se fizer uso da tabela de pré-computações. Isso garante que é possível reduzir o tempo por um fator de $t$ a menos do que o algoritmo de programação dinâmica.

Estamos agora em condições de listar o algoritmo que implementa o Método dos Quatro Russos. Ele é apresentado em duas partes, a pré-computação de $t$-blocos (PrÉ-ProcessA) e o preenchimento de $a$ (QUATRO-RUSSOS).

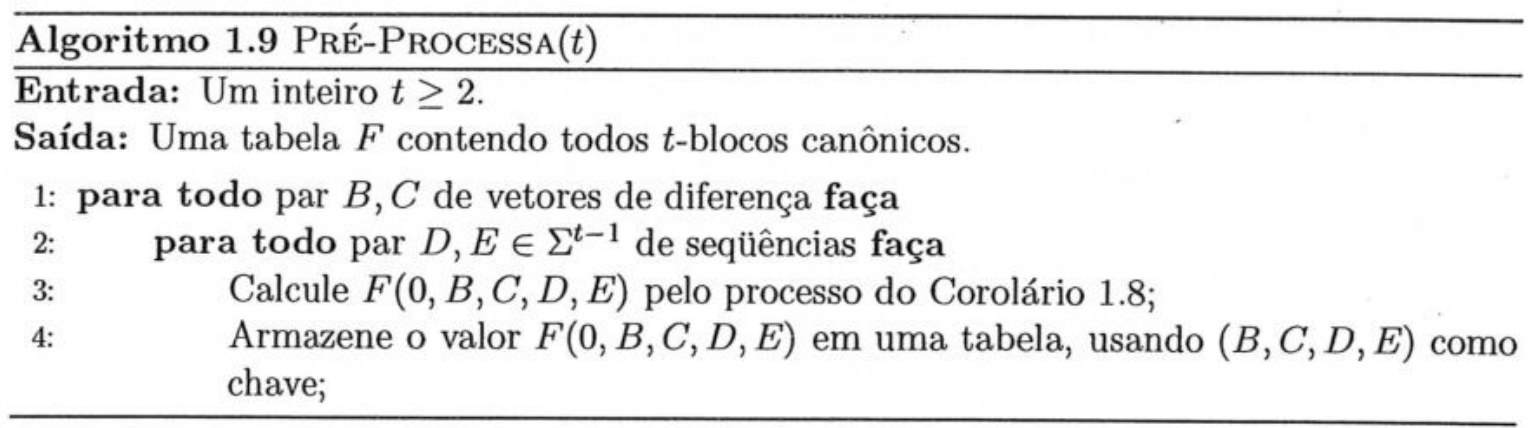

O tempo gasto no pré-processamento do algoritmo é $O\left(3^{2 t} L^{2 t} t^{2}\right)=O\left((3 L)^{2 t} t^{2}\right)$. Já o tempo para o Algoritmo Quatro-Russos é $O\left(n^{2} / t\right)$. Fazendo $t=\left(\log _{3 L} n\right) / 2$, o tempo gasto pelo algoritmo fica $O\left(n(\log n)^{2}\right)+O\left(n^{2} / \log n\right)=O\left(n^{2} / \log n\right)$ e o algoritmo baseado no Método dos Quatro Russos é assintoticamente mais rápido que o algoritmo básico de programação dinâmica.

O método descrito aqui trata somente do cálculo da distância de edição entre $s_{1}$ e $s_{2}$. O artigo original de Masek e Paterson [MP80], que descreve a aplicação do Método dos Quatro Russos ao Problema APS em que a função objetivo é a distância de edição, descreve como obter um alinhamento ótimo em tempo $o\left(n^{2}\right)$.

$\mathrm{O}$ artigo de Masek e Paterson deixou em aberto durante duas décadas a questão de como aplicar com complexidade $o\left(n^{2}\right)$ o Método dos Quatro Russos para distâncias que não fossem a distância de edição. Recentemente, um artigo de Crochemore, Landau e Ziv-Ukelson [CLZU02] mostra como aplicar as idéias de uma fase de pré-computação de subproblemas ao problema do cálculo de distância entre seqüências para métricas em geral ainda em tempo $O\left(n^{2} / \log n\right)$. 


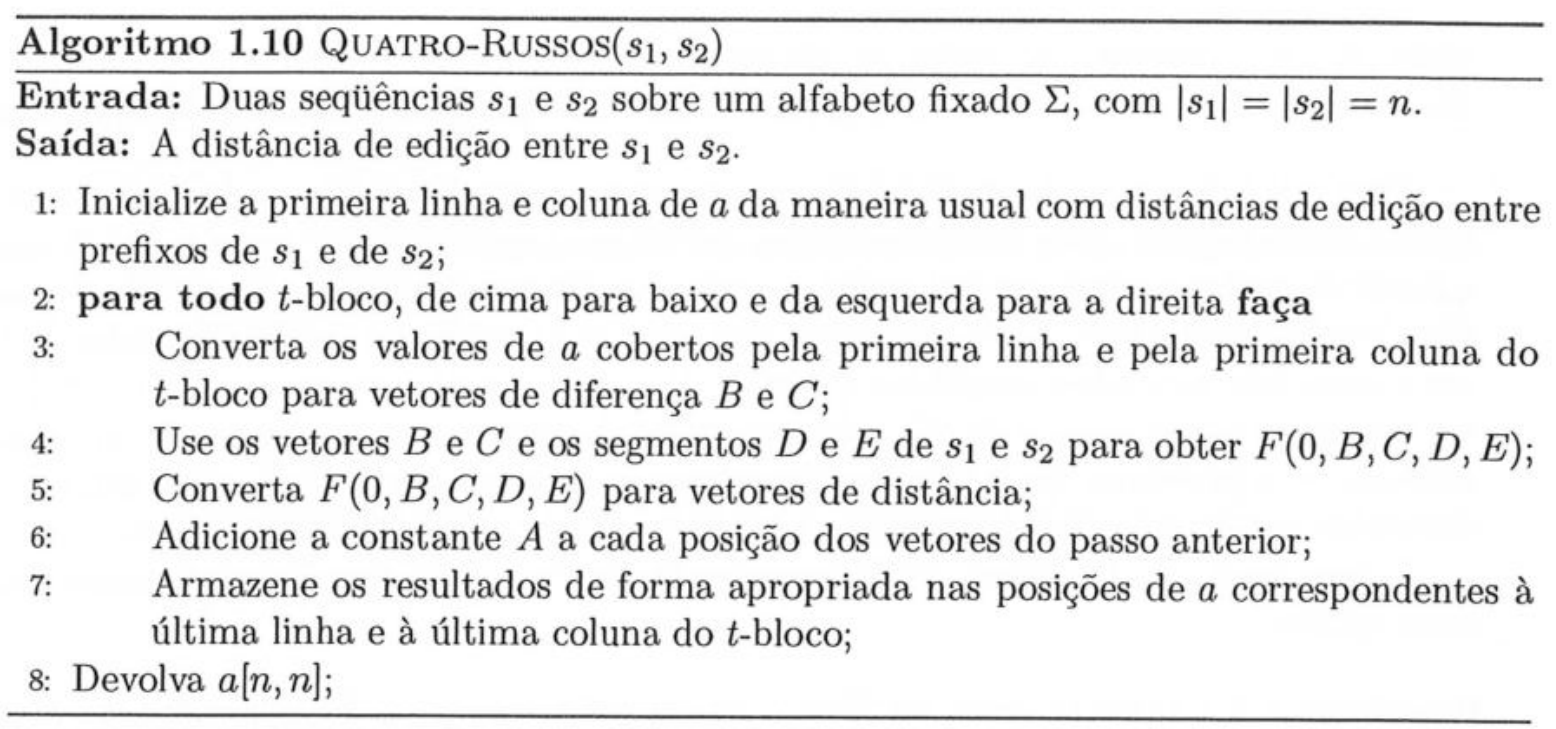

\subsection{Variantes do Problema}

Até agora, concentramos nossa atenção ao Problema 1.1, que é uma das formas de modelar matematicamente o problema de comparação de duas seqüências. Há, entretanto, outras maneiras de modelar o problema e nesta seção mostramos brevemente algumas de suas variantes mais populares. Apesar de nosso enfoque nos próximos capítulos ainda ser o Problema 1.1 (e algumas de suas extensões diretas), existem variantes de grande importância prática do Problema 1.1 e que estão intimamente relacionadas ao material já visto.

\subsubsection{Alinhamentos Globais e Similaridade}

Conforme vimos anteriormente, o Problema 1.1 a respeito de distâncias entre seqüências de acordo com uma matriz de pontuação $c$ pode ser formulado de duas maneiras equivalentes: uma em que busca-se encontrar uma sequiência de operações de edição (em que cada operação tem um custo determinado por $c$ ) de custo mínimo que transforme uma seqüência de caracteres na outra e a outra em que é definido um custo para cada possível alinhamento entre duas seqüências e define-se a distância entre as seqüências como a pontuação do alinhamento de menor custo.

Já vimos que as duas maneiras de formular o problema são equivalentes no sentido de que alinhamentos ótimos (se a pontuação é aditiva) determinam seqüências de operações de edição de custo mínimo e vice-versa.

A maneira de formular o problema como a pontuação de um alinhamento, porém, fica com algumas diferenças importantes se a função $c: \Sigma^{\prime} \times \Sigma^{\prime} \rightarrow \mathbb{Q}$ atribuir pontuações "altas" a caracteres "parecidos" de $\Sigma^{\prime}$ e pontuações "baixas" a caracteres "diferentes" de $\Sigma^{\prime}$. Nessa situação, para escolher os "melhores" alinhamentos, estamos interessados nos alinhamentos que, segundo a função $c$, possuam as maiores pontuações. Isso motiva a definição de um importante conceito para duas seqüências, a similaridade.

Definição 1.6 (Similaridade). Dadas duas seqüências $s$ e $t$ sobre $\Sigma$, definimos a similaridade $\operatorname{sim}(s, t)$ de $s$ e $t$ como

$$
\operatorname{sim}(s, t)=\max _{A \in \mathcal{A}_{s, t}}\{c(A)\},
$$


onde $\mathcal{A}_{s, t}$ é o conjunto de todos os alinhamentos entre $s$ e $t$ e $c(A)$ é a pontuação do alinhamento $A$, definida da maneira habitual como soma das pontuações de suas colunas.

Para que a definição de similaridade faça sentido, é costumeiro supor que $c(\sqcup, \sqcup)=0$ ou que os alinhamentos sejam livres de colunas em branco (caso contrário, se $c(\sqcup, \sqcup)>0$, então a partir de qualquer alinhamento poder-se-iam obter alinhamentos de custo arbitrariamente grande pela simples inserção de colunas só com espaços e o problema ficaria ilimitado) ${ }^{10}$. Em casos onde seja necessário considerar matrizes de pontuação para as quais $c(\sqcup, \sqcup) \neq 0$, pode ser necessário tratar apenas de alinhamentos livres de colunas em branco, para contornar a situação de o problema ser ilimitado. Nesse caso, o conjunto $\mathcal{A}_{s, t}$ é finito (seu número de elementos é dado pela Fórmula (1.1)) e a similaridade de $s$ e $t$ está bem definida.

A nova versão do Problema APS, denominada aqui por APS-SIM, é formalmente enunciada abaixo.

Problema 1.2 (Alinhamento de Pares de Seqüências, para Similaridade). Dadas duas seqüências $s$ e $t$ sobre um alfabeto $\Sigma$ e fixada uma matriz de pontuação $c$, encontrar um alinhamento $A$ de $s$ e t cuja pontuação $c(A)$ seja máxima.

Essa versão do Problema APS é bastante usada na prática [SM97, DEKM98, Fue97]. É de especial interesse o caso em que a matriz de pontuação possui valores negativos (para "penalizar" determinados encontros de caracteres em um alinhamento). Essa possibilidade faz o Problema APS-Sim ter propriedades diferentes das do Problema APS.

É freqüente o uso de matrizes especiais para o Problema APS-SıM, obtidas empiricamente por métodos estatísticos. Esse é o caso das matrizes PAM e das matrizes BLOSUM, vastamente usadas para alinhamentos de seqüências de aminoácidos [SM97, DEKM98].

Em algumas situações, é possível mostrar [SM97] que, se a matriz de pontuação $c$ usada no Problema APS-Sim estiver relacionada a uma matriz $c^{\prime}$ que seja uma métrica por meio das equações

$$
\begin{aligned}
& c(\sigma, \rho)=M-c^{\prime}(\sigma, \rho), \text { para } \sigma, \rho \in \Sigma \mathrm{e} \\
& c(\sqcup, \sigma)=\frac{M}{2}-c^{\prime}(\sqcup, \sigma), \text { para todo } \sigma \in \Sigma,
\end{aligned}
$$

para uma constante $M$, então os Problemas APS e APS-Sım possuem uma dualidade, no sentido de que

$$
\operatorname{sim}(s, t)+d(s, t)=\frac{M}{2}(|s|+|t|),
$$

para as sequiências $s$ e $t$.

Observe-se que nem todas as funções de interesse prático estão relacionadas da forma acima. Para constatar isso, vamos definir um problema bem conhecido em Ciência da Computação, o Problema da Subseqüência Comum de Maior Comprimento (abreviado daqui por diante por SC-Máx).

Problema 1.3 (Subseqüência Comum de Maior Comprimento). Dadas duas seqüências $s$ e $t$ sobre um alfabeto $\Sigma$, encontrar uma subseqüência $w$ de $s$ e de $t$ que possua comprimento máximo.

\footnotetext{
${ }^{10}$ Observe-se que não há esse inconveniente no Problema 1.1 se $c$ satisfaz aos axiomas de métrica, porque $c(\mathrm{u}, \mathrm{u})=0$ é automaticamente satisfeito e o problema é sempre limitado, conforme já observamos.
} 
O Problema SC-MÁx é um problema bem estudado em Ciência da Computação e possui várias aplicações práticas. Uma delas é encontrada no utilitário diff do sistema operacional Unix, que encontra as linhas diferentes (as "diferenças" - daí seu nome) entre dois arquivos dados como argumentos, efetivamente encontrando uma seqüência de operações de edição que transformam o primeiro arquivo no segundo.

Para este propósito, o comando diff interpreta cada linha dos arquivos como se fosse um caractere em um alfabeto (em outras palavras, cada arquivo é interpretado como se fosse uma seqüência sobre o alfabeto $\Sigma^{*}$, onde $\Sigma$ é o alfabeto ASCII). O utilitário patch opera em conjunto com o utilitário diff e recebe como entrada a lista de diferenças produzidas pelo diff e realiza as operações estipuladas pela entrada para converter o primeiro arquivo no segundo.

Por sua importância, vários algoritmos eficientes foram estudados e desenvolvidos para resolver o Problema SC-Máx e problemas relacionados (como o Problema da Subseqüência Crescente de Maior Comprimento) [Gus97].

O Problema SC-Máx pode ser visto como um caso particular do problema de alinhamentos com similaridade como função objetivo. Se penalizarmos com pontuação 0 colunas indesejadas (aquelas que emparelham caracteres diferentes, incluindo colunas com um caractere e um espaço) e pontuarmos com 1 as colunas com caracteres iguais com (que, intuitivamente, são as colunas do tipo desejado), então é relativamente simples de ver que um alinhamento ótimo (de pontuação máxima) entre $s$ e $t$ fornece uma subsequiência comum a $s$ e a $t$ que possui comprimento máximo: uma subseqüência comum de maior comprimento é dada pelas colunas do alinhamento ótimo que possuírem o mesmo caractere em ambas as seqüências. É claro então que o Problema SC-MÁx pode ser visto como um problema de alinhamento em que a função objetivo é a similaridade.

Um problema de alinhamento que é o "dual" do SC-MÁx (como pode ficar claro a partir do caso do comando diff) é o Problema APS em que a função objetivo $d$ é a distância de edição e em que substituições não são permitidas (apenas permitimos remoções e inserções de símbolos $)^{11}$. Para esses dois problemas, não vale que $\operatorname{sim}(s, t)+d(s, t)=M(|s|+|t|) / 2$ : basta observar o caso em que $s=(\mathrm{AT})^{k}$ e $t=(\mathrm{TA})^{k}$ para, digamos, $k=4$. O motivo disso é que as matrizes de pontuação usadas nos dois problemas não se relacionam de acordo com a hipótese do teorema. Entretanto, um resultado similar pode ser mostrado: denotando por $l(s, t)$ o comprimento de uma subseqüência de maior comprimento entre $s$ e $t$ e por $d(s, t)$ a distância entre $s$ e $t$ sem permitir substituições, então

$$
l(s, t)+\frac{d(s, t)}{2}=\frac{(|s|+|t|)}{2} .
$$

Uma justificativa para esse fato pode ser dada notando-se que um alinhamento ótimo que tenha pontuação $l(s, t)$ possui $|s|-l(s, t)$ caracteres de $s$ alinhados a espaços e $|l|-l(s, t)$ caracteres de $t$ alinhados a espaços. Por outro lado, a distância $d(s, t)$ em que substituições não são permitidas é tal que $d(s, t)=(|s|-l(s, t))+(|l|-l(s, t))=|s|+|t|-2 l(s, t)$ pois, para $d(s, t)$ ser menor, $s$ e $t$ deveriam ter mais caracteres em comum, isto é, $l(s, t)$ maior, de onde segue o fato de que $l(s, t)+d(s, t) / 2=(|s|+|t|) / 2$.

Esses fatos mostram que os Problemas APS e APS-Sıм têm relações importantes; entretanto, mostraremos que há situações para as quais eles se comportam de maneira eminentemente distinta.

\footnotetext{
${ }^{11}$ Essa distância é, às vezes, chamada distância simples de Levenshtein, em contraste com a distância generalizada de Levenshtein (distância de edição comum), em que substituições são permitidas [Hir97].
} 
Algoritmicamente, o Problema APS-Sim também pode ser resolvido pela estratégia de programação dinâmica. A forma como a função $\operatorname{sim}(s, t)$ é definida garante propriedades importantes como a aditividade da função, a existência de subsoluções ótimas e a existência de subproblemas comuns, da mesma maneira como ocorre com o Problema APS, em que distâncias são usadas. Os mesmos argumentos usados para aquele caso podem ser adaptados com pequenas modificações (e.g., troca de mínimo por máximo) para provar as propriedades da nova versão do problema.

Por compartilhar características tão parecidas com as do Problema APS, não é surpreendente que o Problema APS-Sim possa ser resolvido por algoritmos que podem ser obtidos dos Algoritmos Dist e Alinha pela simples troca dos cálculos de mínimo por cálculos de máximo.

Isso mostra que o Problema APS-Sım pode ser resolvido em tempo e espaço $O(m n)$ para seqüências $s$ e $t$ de tamanhos $m$ e $n$, respectivamente ${ }^{12}$. Uma adaptação parecida com a troca de mínimos por máximos pode ser feita ao algoritmo de Hirschberg para resolver o Problema 1.2 em espaço linear.

\subsubsection{Alinhamentos Semiglobais}

Todos os alinhamentos que consideramos até aqui são chamados alinhamentos globais, porque procuram comparar as seqüências de entrada como um todo. Nesta seção, mostramos uma variante do problema em que outro tipo de alinhamentos são procurados, os alinhamentos semiglobais.

Esse problema é formulado em termos de similaridade em vez de distâncias (cujo motivo justificamos após definir o problema).

Nos problemas vistos até o momento, a pontuação de uma lacuna é proporcional ao seu comprimento. Por exemplo, se uma lacuna possui $l$ espaços consecutivos e a pontuação de alinhar um caractere a um espaço é $g$, então a pontuação da lacuna é $l \cdot g$. É comum supor que a pontuação de um espaço com um caractere de $\Sigma$ seja uma constante $g<0$ (vide [SM97, DEKM98]).

Em algumas situações práticas, por outro lado, esse esquema de pontuação pode não ser desejado. Um caso em que isso acontece é quando sabe-se que as seqüências $s$ e $t$ que se quer comparar não são semelhantes por inteiro, mas apenas partes delas é que são. Isso ocorre em problemas práticos como no rearranjo de fragmentos de DNA, em que é necessário encontrar um alinhamento entre um sufixo de $s$ e um prefixo de $t$. Em outras palavras, deseja-se encontrar uma fatoração de $s$ e de $t$ na forma $s=s^{\prime \prime} s^{\prime}$ e $t=t^{\prime} t^{\prime \prime}$ de maneira que $s^{\prime}$ e $t^{\prime}$ tenham similaridade maior possível. Naturalmente, o sufixo $s^{\prime}$ e o prefixo $t^{\prime}$ são ambos desconhecidos.

Uma maneira de resolver o problema é analisar alinhamentos entre $s$ e $t$ que tenham a

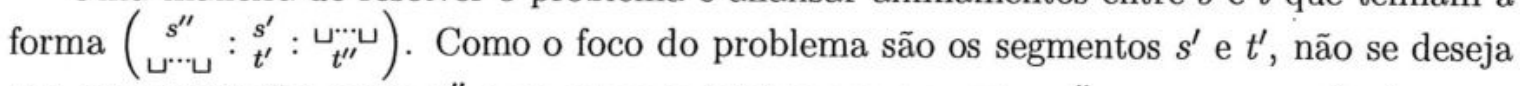
que as pontuações entre $s^{\prime \prime}$ e os espaços iniciais em $t$ e entre $t^{\prime \prime}$ e os espaços finais em $s$ interfiram na escolha de alinhamentos que "alinhem bem" um sufixo de $s$ com um prefixo de $t$.

A estratégia para encontrar um alinhamento ótimo entre um sufixo de $s$ e um prefixo de $t$ pode então atribuir pontuação 0 aos espaços que ocorrem nas extremidades dos alinhamentos (mas apenas a esses espaços).

\footnotetext{
${ }^{12}$ Em particular, isso significa que o Problema SC-MÁx pode ser resolvido em tempo e espaço $O(m n)$ mas existem algoritmos mais eficientes para o SC-Máx [Hir97].
} 
Formalmente, o Problema de Alinhamentos Semiglobais é definido como

Problema 1.4 (Alinhamento Semiglobal). Dadas duas seqüências $s$ e $t$ sobre um mesmo alfabeto $\Sigma$, encontrar um sufixo $s^{\prime}$ de $s$ e um prefixo $t^{\prime}$ de $t$ de modo que $\operatorname{sim}\left(s^{\prime}, t^{\prime}\right)$ seja máxima.

Observe-se que os alinhamentos procurados no Problema 1.2 envolviam as seqüências $s$ e $t$ como um todo, enquanto no Problema 1.4, o interesse é nos alinhamentos de parte de $s$ com parte de $t$, mas não necessariamente das seqüências inteiras. Essa é a justificativa para as nomenclaturas "alinhamentos globais" e "alinhamentos semiglobais" dadas aos Problemas 1.2 e 1.4 .

Uma justificativa de porque o Problema 1.4 é formulado como um problema de maximização em vez de um problema de minimização é porque, no caso de um problema de minimização, o problema admitiria uma solução ótima trivial: se a função de pontuação de caracteres é não-negativa, então todo alinhamento tem também pontuação não-negativa. Mas, nesse caso, uma fatoração trivial de $s$ e de $t$ como $s=s \cdot \varepsilon$ e $t=\varepsilon \cdot t$ nos forneceria um alinhamento de pontuação mínima, o alinhamento $\left(\begin{array}{l}\varepsilon \\ \varepsilon\end{array}\right)$.

Ainda que essa situação seja tratada como patológica e descartada em preferência de alinhamentos não-nulos, é simples de ver que o Problema 1.4 teria características bastante diferentes se ele fosse formulado como um problema de minimização: via de regra, alinhamentos curtos tendem a ter pontuações menores do que alinhamentos mais longos quando a função de pontuação de caracteres é uma métrica. Diferentemente, os alinhamentos longos tendem a possuir pontuações maiores do que os mais curtos quando a função de pontuação de caracteres é uma função que atribui pontuações "altas" a "caracteres semelhantes" e pontuações "baixas" a "caracteres diferentes". Isso dá uma indicação intuitiva de que se o Problema 1.4 fosse formulado como um problema de minimização, ele teria características essencialmente diferentes daquelas que ele possui na forma do enunciado 1.4.

O Problema 1.4 pode também ser resolvido por uma adaptação do algoritmo básico de programação dinâmica (o par Dist/Alinha) em tempo e espaço $O(m n)$, onde $m=|s|$ e $n=|t|$.

\subsubsection{Alinhamentos Locais}

Da mesma maneira como para alinhamentos semiglobais, podemos estar interessados em comparar seqüências $s$ e $t$ que globalmente possam não ser muito parecidas, mas que possuam trechos internos (mas não necessariamente sufixos ou prefixos) que tenham similaridade alta.

Problemas como esse ocorrem no estudo evolutivo de espécies. Em particular, é de interesse a descoberta de trechos em seqüências de DNA ou de proteínas de espécies diferentes que tenham grande similaridade. Essas regiões parecidas em seqüências de espécies diferentes podem indicar que as regiões são homólogas (isto é, descendentes de um ancestral comum) e que se mantiveram conservadas ao longo do processo de evolução das espécies.

Especificamente, o problema é o seguinte:

Problema 1.5 (Alinhamento Local). Dadas duas seqüências $s$ e $t$ sobre um mesmo alfabeto $\Sigma$, encontrar um segmento $s^{\prime}$ de $s$ e um segmento $t^{\prime}$ de $t$ de modo que $\operatorname{sim}\left(s^{\prime}, t^{\prime}\right)$ seja máxima.

Para este problema, se $s=x s^{\prime} y$ e $t=w t^{\prime} z$, para seqüências $w, x, y, z \in \Sigma^{*}$, um alinhamento desejado é algo da forma $\left(\begin{array}{c}x \\ w\end{array}: \begin{array}{c}s^{\prime} \\ t^{\prime}\end{array}: \begin{array}{l}y \\ z\end{array}\right)$, em que os segmentos $s^{\prime}$ e $t^{\prime}$ sejam "bem 
parecidos". A quantidade $\operatorname{sim}\left(s^{\prime}, t^{\prime}\right)$ é chamada similaridade local de $s$ e $t$

Um algoritmo para o problema de encontrar alinhamentos locais ótimos pode ser obtido mais uma vez por uma adaptação do algoritmo básico de programação dinâmica, desta vez proposta em 1981 por Smith e Waterman ${ }^{13}$.

O Algoritmo de Smith-Waterman funciona mudando o significado de uma célula $a[i, j]$ da matriz de programação dinâmica: em vez de $a[i, j]$ conter o valor de um melhor alinhamento entre $s[1 \ldots i]$ e $t[1 \ldots j]$, no Algoritmo de Smith-Waterman, a célula $a[i, j]$ denota o valor de um melhor alinhamento entre um sufixo de $s[1 \ldots i]$ e um sufixo de $t[1 \ldots j]$. Em outras palavras, $a[i, j]$ contém a pontuação de um melhor alinhamento de um segmento de $s$ que termine em $s[i]$ e de um segmento de $t$ que termine em $t[j]$.

No Algoritmo de Smith-Waterman, a primeira linha e a primeira coluna de $a$ (correspondentes a $i=0$ ou a $j=0$ ) são inicializadas com zeros. Isso se deve aos únicos alinhamentos entre sufixos de $s[1 \ldots i]$ e $t[1 \ldots 0]=\varepsilon$ serem os alinhamentos que alinham caracteres de um sufixo de $s[1 \ldots i]$ com espaços em $t$ e como $g<0$, um alinhamento local ótimo é o alinhamento entre as seqüências vazias (que são sufixos triviais de $s[1 \ldots i]$ e de $t[1 \ldots 0]$ ). O argumento simétrico aplica-se a alinhamentos entre sufixos de $s[1 \ldots 0]=\varepsilon$ e $t[1 \ldots j]$ para determinar os valores da primeira linha de $a$.

Se $i \geq 1$ e $j \geq 1$, o valor de $a[i, j]$ é o valor de um melhor alinhamento entre sufixos de $s[1 \ldots i]$ e $t[1 \ldots j]$ que pode ser obtido pela melhor das quatro alternativas:

- prolongar um alinhamento ótimo entre sufixos de $s[1 \ldots i-1]$ e de $t[1 \ldots j] \operatorname{com}\left(\begin{array}{c}s[i] \\ \sqcup\end{array}\right)$;

- prolongar um alinhamento ótimo entre sufixos de $s[1 \ldots i-1]$ e de $t[1 \ldots j-1]$ com $\left(\begin{array}{c}s[i] \\ t[j]\end{array}\right)$

- prolongar um alinhamento ótimo entre sufixos de $s[1 \ldots i]$ e de $t[1 \ldots j-1] \operatorname{com}\left(\begin{array}{c}u \\ t[j]\end{array}\right)$;

- considerar o alinhamento entre os sufixos vazios de $s[1 \ldots i]$ e $t[1 \ldots j]$.

É interessante ver que as três primeiras possibilidades são parecidas com aquelas que ocorrem em alinhamentos globais. A última, todavia, não. Como o alinhamento entre seqüências vazias possui pontuação 0, a quarta opção é escolhida quando as demais possuem valor negativo. Isso significa, em particular, que a matriz $a$ do Algoritmo de SmithWaterman possui apenas valores não-negativos.

Com base nas possibilidades descritas, uma recorrência para a entrada $a[i, j]$, para $i>0$ e $j>0$ é:

$$
a[i, j]=\max \left\{\begin{array}{c}
a[i-1, j]+c(s[i], \sqcup), \\
a[i-1, j-1]+c(s[i], t[j]), \\
a[i, j-1]+c(\lrcorner, t[j]), \\
0
\end{array}\right\} .
$$

A similaridade local de $s$ e $t$ fica guardada, então, na célula de $a$ que possuir o maior valor.

\footnotetext{
${ }^{13}$ Aparentemente e de maneira similar ao Algoritmo de Needleman e Wunsch, o Algoritmo de Smith e Waterman foi redescoberto várias vezes em diferentes contextos pela comunidade científica, mas a influência dos artigos relacionando as aplicações de algoritmos de seqüências à Biologia estabeleceu-os de tal forma que os termos "Algoritmo de Needleman e Wunsch" e "Algoritmo de Smith e Waterman" são usados de maneira geral para denominar algoritmos de programação dinâmica para os problemas de alinhamento global e local, respectivamente [SM97].
} 
É fácil de ver também que, de acordo com a Recorrência (1.9), um algoritmo aos moldes do Algoritmo Dist pode ser escrito com as mesmas complexidades de tempo e de espaço. Um alinhamento ótimo entre $s$ e $t$ pode ser obtido a partir da célula de maior valor de $a$ com uso de um algoritmo parecido com o Algoritmo Alinha.

\subsubsection{Interpretação Estatística de Similaridades}

Antes de concluirmos este capítulo, vamos discutir brevemente as idéias por trás de matrizes de substituição como as matrizes PAM e as matrizes BLOSUM, que são construídas estatisticamente e são muito utilizadas para pontuar alinhamentos de seqüências de aminoácidos. O método ilustrado é, todavia, geral e pode ser utilizado também para seqüências de bases.

No processo de evolução das espécies, as moléculas ficam sujeitas a eventos que as modificam, como mutação de resíduos, ou sua remoção ou inserção. É de interesse estudar a freqüência com que esses eventos ocorrem. Por exemplo, podemos querer saber, para um determinado gene, qual é a probabilidade $p_{\mathrm{AT}}$ de uma base A transformar-se em T ou, de uma maneira geral, a probabilidade $p_{\sigma \rho}$ de um resíduo $\sigma$ transformar-se em um resíduo $\rho$.

Note-se que para incluir o caso de inserções e de remoções de resíduos no estudo, é importante tratar de alguma maneira o caso em que $\sigma$ ou $\rho$ seja um espaço.

Considerando um alinhamento como uma relação hipotética de eventos de evolução entre duas seqüências, podemos querer calcular, dadas as probabilidades de substituição de resíduos, a probabilidade de os eventos estipulados pelo alinhamento ocorrerem. Se supusermos que os eventos em posições diferentes dos alinhamentos sejam independentes ${ }^{14}$, então a probabilidade do alinhamento pode ser calculada como o produto das probabilidades das substituições dadas pelas colunas do alinhamento, isto é, se $s$ e $t$ são seqüências sobre um alfabeto $\Sigma$ e se $A$ é um alinhamento de $s$ e $t$ com $l$ colunas, então a probabilidade de $A$ é dada por

$$
\operatorname{Pr}(A)=\prod_{j=1}^{l} p_{A_{1}[j] A_{2}[j]},
$$

onde $A_{1}$ denota a linha de $A$ que contém $s$ e $A_{2}$ denota a linha de $A$ que contém $t$.

Com essa formulação fica claro que há pouco sentido em considerar alinhamentos em que haja espaços emparelhados com espaços (i.e., colunas em branco).

Mas muitas vezes o interesse maior é em saber como um alinhamento se compara a um emparelhamento "ao acaso" de símbolos de $s$ com símbolos de $t$, a fim de saber se o alinhamento dado é significativo ou não do ponto de vista estatístico. Isso pode ser feito comparando-se a probabilidade $p_{\sigma \rho}$ à probabilidade de o par $(\sigma, \rho)$ alinhar-se "ao acaso". Se supusermos que a probabilidade de $\sigma$ ocorrer na família de seqüências em estudo é $q_{\sigma}$, então nosso interesse é em comparar as quantidades $p_{\sigma \rho}$ e $q_{\sigma} q_{\rho}$ através da razão de probabilidades $p_{\sigma \rho} /\left(q_{\sigma} q_{\rho}\right)$. O modelo em que o par de caracteres $(\sigma, \rho)$ ocorre com probabilidade $q_{\sigma} q_{\rho}$ é às vezes chamado modelo nulo (em inglês, null model).

A comparação entre a probabilidade $\operatorname{Pr}(A)$ do alinhamento e a probabilidade $\operatorname{Pr}_{N}(A)$ de os símbolos de $A$ emparelharem-se da maneira dada por $A$ de acordo com o modelo nulo

\footnotetext{
${ }^{14} \mathrm{O}$ que pode não ser uma hipótese muito realista, porque é possível que algum evento evolutivo, digamos uma remoção de resíduos, ocorra e afete uma seqüência de várias posições consecutivas e introduza uma lacuna grande na seqüência.
} 
pode ser feita pelo cálculo de $\operatorname{Pr}(A) / \operatorname{Pr}_{N}(A)$ dado por

$$
\frac{\operatorname{Pr}(A)}{\operatorname{Pr}_{N}(A)}=\prod_{j=1}^{l} \frac{p_{A_{1}[j] A_{2}[j]}}{q_{A_{1}[j]} q_{A_{2}[j]}} .
$$

A razão $\operatorname{Pr}(A) / \operatorname{Pr}_{N}(A)$ pode potencialmente ser muito pequena por ser uma razão de produto de probabilidades (vide Capítulo 5) e, por isso, pode ser vantajoso trabalhar em termos de logaritmos de razão de probabilidades (em inglês, log-odd scores). Nesse caso, a equação fica

$$
\log \frac{\operatorname{Pr}(A)}{\operatorname{Pr}_{N}(A)}=\sum_{j=1}^{l} \log \frac{p_{A_{1}[j] A_{2}[j]}}{q_{A_{1}[j]} q_{A_{2}[j]}} .
$$

Observe-se que cada termo do somatório da Equação (1.11) depende apenas dos símbolos $A_{1}[j]$ e $A_{2}[j]$, isto é, é uma função $c\left(A_{1}[j], A_{2}[j]\right)$ desses símbolos e o logaritmo de razão de probabilidade, quando usado como matriz de pontuação é exatamente a função objetivo calculada pelo algoritmo de programação dinâmica para similaridade (versão de maximização) e, nesse caso, o custo de uma lacuna, se a pontuação de $\sqcup$ com símbolos do alfabeto for uma constante, é linear. Modificações podem ser feitas ao modelo estatístico para dar conta da situação de lacunas com custos afins [DEKM98].

Esse é, em linhas gerais, o procedimento usado para derivar os valores para uma função de pontuação de caracteres, como no caso das matrizes PAM e BLOSUM. Na realidade, matrizes como as matrizes PAM formam, de fato, uma família de matrizes e cada membro dessa família é uma matriz de pontuação adequada para comparar um determinado tipo de alinhamento. No caso das matrizes PAM, cada matriz é apropriada para pontuar alinhamentos de proteínas cujas seqüências estejam a uma certa distância evolutiva.

Cabe aqui dizer que PAM é uma sigla do inglês, que significa Point Accepted Mutations ou Percent Accepted Mutations. Uma mutação aceita é uma mutação gerada entre duas seqüências e que não provocou a extinção do ser que contém a seqüência descendente (sob o ponto de vista filogenético). A sigla PAM é usada para duas finalidades: para designar distâncias evolucionárias e para designar as matrizes de substituição de resíduos [DEKM98, Gus97, Mat01, SM97].

No caso de distâncias, 1 PAM é definida como a distância evolucionária entre duas sequências de proteínas que causa uma média de mudança de $1 \%$ de resíduos entre as seqüências. A matriz PAM 1 é uma matriz proposta por Dayhoff e colegas para comparar seqüências que estejam à distância de 1 PAM [SM97]. A matriz é construída por um processo parecido com o que expusemos, incorporando apenas algumas mudanças ${ }^{15}$. A matriz 1 PAM define um processo estocástico que é uma cadeia de Markov (veja o Capítulo 5 para a definição de cadeia de Markov) e a $i$-ésima matriz PAM, a matriz PAM $i$, é definida essencialmente como a $i$-ésima potência da matriz PAM 1 (na realidade, as matrizes de pontuação são definidas com logaritmos de probabilidades e, por isso, não representam exatamente as matrizes de transição de cadeias de Markov; as matrizes de pontuação são derivadas das matrizes de transição das cadeias de Markov). Maiores detalhes a respeito das matrizes PAM e das matrizes BLOSUM podem ser obtidos nas referências bibliográficas [GK99, DEKM98, SM97].

A título de curiosidade, mostramos a matriz PAM 250, que é adequada para detectar relações evolutivas entre seqüências distantes.

\footnotetext{
${ }^{15}$ Por exemplo, as matrizes PAM só contém pontuações de substituição de aminoácidos, deixando a parte o tratamento de alinhar caracteres ao símbolo $\sqcup$.
} 


\begin{tabular}{|c|c|c|c|c|c|c|c|c|c|c|c|c|c|c|c|c|c|c|c|c|}
\hline & $\mathrm{A}$ & $\mathrm{R}$ & $\mathrm{N}$ & $\mathrm{D}$ & $\mathrm{C}$ & $\mathrm{Q}$ & $\mathrm{E}$ & $\mathrm{G}$ & $\mathrm{H}$ & I & $\mathrm{L}$ & $\mathrm{K}$ & M & $\mathrm{F}$ & $\mathrm{P}$ & $\mathrm{S}$ & $\mathrm{T}$ & W & $\mathrm{Y}$ & $\mathrm{V}$ \\
\hline $\mathrm{A}$ & 2 & & & & & & & & & & & & & & & & & & & \\
\hline $\mathrm{R}$ & -2 & 6 & & & & & & & & & & & & & & & & & & \\
\hline $\mathrm{N}$ & 0 & 0 & 2 & & & & & & & & & & & & & & & & & \\
\hline D & 0 & -1 & 2 & 4 & & & & & & & & & & & & & & & & \\
\hline C & -2 & -4 & -4 & -5 & 12 & & & & & & & & & & & & & & & \\
\hline $\mathrm{Q}$ & 0 & 1 & 1 & 2 & -5 & 4 & & & & & & & & & & & & & & \\
\hline $\mathrm{E}$ & 0 & -1 & 1 & 3 & -5 & 2 & 4 & & & & & & & & & & & & & \\
\hline G & 1 & -3 & 0 & 1 & -3 & -1 & 0 & 5 & & & & & & & & & & & & \\
\hline $\mathrm{H}$ & -1 & 2 & 2 & 1 & -3 & 3 & 1 & -2 & 6 & & & & & & & & & & & \\
\hline I & -1 & -2 & -2 & -2 & -2 & -2 & -2 & -3 & -2 & 5 & & & & & & & & & & \\
\hline $\mathrm{L}$ & -2 & -3 & -3 & -4 & -6 & -2 & -3 & -4 & -2 & 2 & 6 & & & & & & & & & \\
\hline K & -1 & 3 & 1 & 0 & -5 & 1 & 0 & -2 & 0 & -2 & -3 & 5 & & & & & & & & \\
\hline M & -1 & 0 & -2 & -3 & -5 & -1 & -2 & -3 & -2 & 2 & 4 & 0 & 6 & & & & & & & \\
\hline $\mathrm{F}$ & -4 & -4 & -4 & -6 & -4 & -5 & -5 & -5 & -2 & 1 & 2 & -5 & 0 & 9 & & & & & & \\
\hline $\mathrm{P}$ & 1 & 0 & -1 & -1 & -3 & 0 & -1 & -1 & 0 & -2 & -3 & -1 & -2 & -5 & 6 & & & & & \\
\hline S & 1 & 0 & 1 & 0 & 0 & -1 & 0 & 1 & -1 & -1 & -3 & 0 & -2 & -3 & 1 & 2 & & & & \\
\hline $\mathrm{T}$ & 1 & -1 & 0 & 0 & -2 & -1 & 0 & 0 & -1 & 0 & -2 & 0 & -1 & -3 & 0 & 1 & 3 & & & \\
\hline W & -6 & 2 & -4 & -7 & -8 & -5 & -7 & -7 & -3 & -5 & -2 & -3 & -4 & 0 & -6 & -2 & -5 & 17 & & \\
\hline$Y$ & -3 & -4 & -2 & -4 & 0 & -4 & -4 & -5 & 0 & -1 & -1 & -4 & -2 & 7 & -5 & -3 & -3 & 0 & 10 & \\
\hline V & 0 & -2 & -2 & -2 & -2 & -2 & -2 & -1 & -2 & 4 & 2 & -2 & 2 & -1 & -1 & -1 & 0 & -6 & -2 & 4 \\
\hline
\end{tabular}

Figura 1.7: Matriz PAM 250. A matriz de pontuação indica apenas a pontuação entre os 20 aminoácidos. Como a matriz é simétrica, apenas parte dela está representada. Fonte: http://www.infobiogen.fr/doc/tutoriel/SIMIL/similarite.html. 


\section{Capítulo 2}

\section{Alinhamentos de Várias Seqüências}

"One or two homologous sequences whisper... a full multiple alignment shouts out loud"

- Arthur Lesk

\subsection{Introdução}

O Problema APS trata da comparação de duas seqüências apenas. Embora esse seja um problema importante por si só e com várias aplicações (de acordo com o que vimos no final do capítulo anterior), a necessidade de comparar seqüências (em particular, as biológicas) geralmente vai além da comparação de só duas seqüências. Conforme mencionado no Capítulo 1, alinhamentos de seqüências são importantes por causa de sua conexão com vários outros problemas em Biologia Computacional. Um dos problemas que recebe bastante atenção na área é a construção de Árvores Filogenéticas ou Evolucionárias [Gus97]. Nesse problema, faz-se o estudo de algumas espécies e a relação de ascendência e descendência entre as espécies é inferida e representada em um diagrama em forma de árvore (a árvore filogenética).

Atualmente, a disponibilidade em abundância de dados sobre moléculas (moléculas seqüenciadas de DNA ou de proteínas) oferece uma possibilidade adicional para o estudo de árvores filogenéticas em relação aos critérios (por exemplo, morfológicos) usados anteriormente. Os métodos mais usados atualmente para construção de árvores filogenéticas (que incluem os métodos de Máxima Parcimônia e Máxima Verossimilhança [DEKM98, Mat01]) usam como ponto de partida um alinhamento entre as seqüências em estudo para produzirem as árvores. Nessas árvores, as seqüências (que representam, cada, uma unidade taxonômica operacional ou OTU - do inglês operational taxonomic unit) rotulam as folhas das árvores. Naturalmente, o interesse é maior nos casos não-triviais de construção de árvores com mais de duas espécies, isto é, alinhamentos entre mais de duas seqüências são necessários.

Outro uso importante dos alinhamentos é a criação de um modelo para uma família de proteínas. A partir de um alinhamento entre moléculas de proteínas pertencentes a uma dada família (por exemplo, à família das globinas), pode-se criar um modelo estatístico que seja um "resumo" das características da família, sob o aspecto de sua composição bioquímica linear. Um desses modelos é chamado de Modelo de Markov de Estados Ocultos de Perfil das Seqüências (do inglês, profile hidden Markov model) [DEKM98]. Tratamos desses modelos no Capítulo 5. 
As seqüências do alinhamento, por serem usadas para criar o perfil, são chamadas $s e$ qüências de treinamento. Esses modelos são usados, dentre outras coisas, para verificar se uma dada proteína (de que se conhece pouco) pertence ou não à família de proteínas usadas para a construção do modelo. Tais modelos são tão mais fiéis à família ${ }^{1}$ quanto maior o número de seqüências dessa família forem usadas para a construção. É claro, pois, que os alinhamentos de várias seqüências são os mais desejados.

Conectado à aplicação acima, alinhamentos de várias sequiências podem evidenciar características de seqüências (por exemplo, regiões que permanecem conservadas durante o processo evolutivo) que a simples construção de todos alinhamentos de pares de seqüências não ressaltam. Esse é o motivo para a ilustrativa frase de Arthur Lesk que aparece na epígrafe deste capítulo [Gus97].

Como é de se esperar, um alinhamento de várias seqüências é uma generalização natural do conceito de alinhamento de um par de seqüências. Este capítulo trata dessa generalização e de características próprias do caso geral do problema.

\subsection{Formulação do Problema}

Começamos pela definição generalizada de um alinhamento.

Definição 2.1 (Alinhamento). Dados um inteiro $k \geq 2$ e $k$ seqüências $s_{1}, \ldots, s_{k}$ sobre um alfabeto $\Sigma$, com $\sqcup \notin \Sigma$, um alinhamento $A$ de $s_{1}, \ldots, s_{k}$ é uma matriz $A=\left(A_{i, j}\right)$ de dimensões $k \times l, \operatorname{com} l \geq \max \left\{\left|s_{i}\right|\right\}$, com entradas em $\Sigma^{\prime}=\Sigma \cup\{u\}$ de forma que a $i$-ésima linha de $A$ seja obtida a partir da sequiência $s_{i}$ pela possível inserção de caracteres ч.

Por questão de comodidade, definimos $n_{i}=\left|s_{i}\right|$. Também supomos que $\sqcup \notin \Sigma$ para todos nossos alfabetos, a menos de menção contrária.

Um exemplo de alinhamento de várias seqüências está mostrado na Figura 2.1. Nele constam seqüências de nucleotídeos de globinas de algumas espécies. Nosso interesse, bem como no caso de alinhamentos de pares de sequiências, é a obtenção de "bons" alinhamentos. Também como no caso de duas seqüências, é atribuída uma pontuação (ou custo) a cada alinhamento e esse é o parâmetro usado para decisão de quais são os "melhores" alinhamentos.

Oryctolagus cuniculus (K03256)
Homo sapiens (U01317)
Capra hircus (M15387)
Mus musculus (J00413)
Gallus gallus $\beta-\mathrm{A}$ (L17432)
Gallus gallus $\beta$-H (L17432)

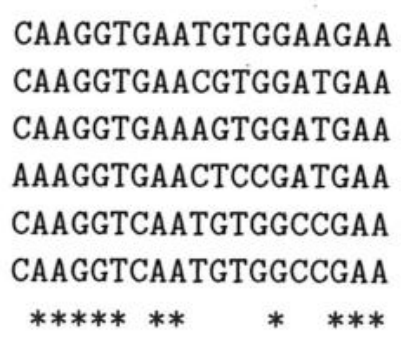

Figura 2.1: Alinhamento de várias seqüências. As seqüências são trechos codificadores de $\beta$-hemoglobinas das espécies indicadas. Os dados foram obtidos do banco de dados mundial chamado GenBank, disponível em http://www.ncbi.nlm.nih.gov/Entrez/ e o alinhamento foi construído pelo programa Clustal W, versão 1.82. Os números ao lado das seqüências correspondem aos números de acesso das seqüências no GenBank. Os asteriscos indicam posições em que os resíduos são totalmente preservados.

\footnotetext{
${ }^{1} \mathrm{E}$ imunes ao "overfitting" dos dados de treinamento.
} 
A atribuição de custos a alinhamentos de várias seqüências pode ser realizada de um número maior de modos do que a feita para duas seqüências (em que essencialmente usamos distâncias ou similaridades). O escopo do texto é limitado ao uso de pontuações aditivas, no sentido do Fato 1.1, de que se um alinhamento $A$ puder ser escrito como $\left(A^{\prime}: A^{\prime \prime}\right)$, então sua pontuação será $c(A)=c\left(A^{\prime}\right)+c\left(A^{\prime \prime}\right)$. Um método usado para definir pontuações aditivas é, como feito para pares de seqüências, atribuir uma pontuação a cada coluna (dependendo do conteúdo da coluna) e tomar como pontuação do alinhamento a soma das pontuações de suas colunas.

A forma geral de pontuação de uma coluna de um alinhamento de $k$ seqüências sobre um alfabeto $\Sigma$ é uma função $c:\left(\Sigma^{\prime}\right)^{k} \rightarrow \mathbb{Q}_{\geq 0}$, chamada função de pontuação ou custo de colunas (similar às funções de pontuação do Capítulo 1).

\subsubsection{Pontuação de Colunas e Pontuação SP}

Algumas características são desejáveis para uma função de pontuação de colunas. Por exemplo, desejamos que elas associem custos "baixos" a colunas que tenham vários caracteres "semelhantes" e que associem custos "altos" a colunas com vários caracteres "diferentes", da mesma maneira como feito para alinhamentos de pares de seqüências.

Outra característica desejável é que a função de pontuação $c$ seja simétrica em seus argumentos, isto é, que o custo $c(\mathcal{C})$ de uma coluna qualquer $\mathcal{C}$ seja igual ao custo $c(\tau(\mathcal{C}))$ de uma permutação $\tau(\mathcal{C})$, para qualquer permutação $\tau$. Em outras palavras, o custo de uma coluna deve ser independente da ordem em que os caracteres aparecem na coluna (mas não dos caracteres propriamente ditos da coluna). Um motivo por que essa característica é desejável é que ela permite que algoritmos sejam escritos sem que haja preocupação com a ordem em que as sequiências $s_{1}, \ldots, s_{k}$ são dadas como entradas.

Finalmente, é desejável, para que seja possível elaborar algoritmos eficientes, que a função $c$ possa ser computada em "pouco" tempo e que os recursos de memória utilizados por ela sejam os menores possíveis.

Uma função bastante usada ${ }^{2}$ para a pontuação de colunas de alinhamentos e que satisfaz às características descritas é a pontuação de Soma de Pares, ou pontuação SP.

Definição 2.2 (Pontuação SP de uma Coluna). Fixada uma função de pontuação de pares de caracteres $c$, definimos a função de pontuação $\mathrm{SP}_{c}:\left(\Sigma^{\prime}\right)^{k} \rightarrow \mathbb{Q}_{\geq 0}$ que mapeia uma coluna $\mathcal{C}$ com $k$ caracteres à sua pontuação $\mathrm{SP}_{c}(\mathcal{C})$ por

$$
\mathrm{SP}_{c}(\mathcal{C})=\sum_{1 \leq i<i^{\prime} \leq k} c\left(\mathcal{C}[i], \mathcal{C}\left[i^{\prime}\right]\right)
$$

onde $\mathcal{C}[i]$ denota o $i$-ésimo caractere da coluna $\mathcal{C}$.

Em palavras, o custo SP de uma coluna é definido como o somatório dos custos de todos os pares de símbolos da coluna. Quando a função $c$ estiver clara pelo contexto, escreveremos $\mathrm{SP}$ apenas em vez de $\mathrm{SP}_{c}$. Por abuso de notação, também escreveremos $c(\mathcal{C})$ para denotar $\mathrm{SP}(\mathcal{C})$, quando não houver confusão.

Por exemplo, se adotarmos a matriz zero-ou-um para pontuação de pares de caracteres, a sétima coluna do alinhamento da Figura 2.1 terá pontuação SP igual a 8.

\footnotetext{
${ }^{2} \mathrm{~A}$ função SP, em alguns contextos, não é a função mais adequada para pontuar colunas de alinhamentos. Especialmente para estudos filogenéticos, ela tem características que não condizem com a intuição [DEKM98, KG99] e pode ser bom usar alguma outra pontuação nesses casos.
} 
Definida como é calculada a pontuação SP para uma coluna, pode-se definir a pontuação SP de um alinhamento.

Definição 2.3 (Pontuação SP de um Alinhamento). A pontuação $\operatorname{SP}(A)$ de um alinhamento $A$ das seqüências $s_{1}, \ldots, s_{k}$ é definida por

$$
\mathrm{SP}(A)=\sum_{j=1}^{l} \operatorname{SP}(A[\cdot, j])=\sum_{j=1}^{l} \sum_{1 \leq i<i^{\prime} \leq k} c\left(A[i, j], A\left[i^{\prime}, j\right]\right),
$$

onde $A[\cdot, j]$ denota a $j$-ésima coluna de $A$ e $l$ é o número de colunas de $A$.

Também como abuso de notação, denotamos o custo $\operatorname{SP}(A)$ de um alinhamento $A$ por $c(A)$ quando não há ambigüidade. Se $s_{1}, \ldots, s_{k}$ são $k$ seqüências sobre um mesmo alfabeto $\Sigma$, definimos o custo $c\left(s_{1}, \ldots, s_{k}\right)$ de alinhar as seqüências como

$$
c\left(s_{1}, \ldots, s_{k}\right)=\min _{A \in \mathcal{\mathcal { A } _ { s _ { 1 } } , \ldots , s _ { k }}}\{c(A)\}
$$

onde $\mathcal{A}_{s_{1}, \ldots, s_{k}}$ é o conjunto de todos alinhamentos entre as $k$ seqüências. O Problema AVS de alinhar várias seqüências com pontuação SP pode então ser definido como

Problema 2.1 (Problema AVS). Dados um inteiro $k \geq 2$ e $k$ seqüências $s_{1}, \ldots, s_{k}$ sobre um alfabeto $\Sigma$ fixado e fixada uma função de pontuação $c: \Sigma^{\prime} \times \Sigma^{\prime} \rightarrow \mathbb{Q}_{\geq 0}$, encontrar um alinhamento $A$ cujo custo $c(A)$ seja igual a $c\left(s_{1}, \ldots, s_{k}\right)$.

Um alinhamento $A$ de $s_{1}, \ldots, s_{k}$ cuja pontuação $c(A)$ seja igual a $c\left(s_{1}, \ldots, s_{k}\right)$ é dito um alinhamento ótimo.

Assim como o Problema APS pôde ser formulado com versões de minimização e maximização, o Problema AVS também pode. No caso de maximização, pode ser conveniente trabalhar com funções de pontuação de coluna que tomem valores em $\mathbb{Q}$ em vez de $\mathbb{Q} \geq 0$. No texto, utilizamos a versão de minimização com distâncias pois elas possuem boas propriedades para nosso estudo (como, por exemplo, permitir a elaboração de algoritmos de aproximação para o Problema AVS).

Em determinadas situações, é conveniente considerar uma formulação generalizada da pontuação SP de um alinhamento, em que um peso $W_{i j}$ seja atribuído a cada par $s_{i}, s_{j}$ de seqüências de forma que a pontuação SP ponderada de uma coluna $\mathcal{C} \in\left(\Sigma^{\prime}\right)^{k}$ seja dada por

$$
\mathrm{SP}_{W}(\mathcal{C})=\sum_{1 \leq i<i^{\prime} \leq k} W_{i j} c\left(\mathcal{C}[i], \mathcal{C}\left[i^{\prime}\right]\right)
$$

e de forma que a pontuação SP ponderada de um alinhamento $A$ seja dada da maneira usual como

$$
\mathrm{SP}_{W}(A)=\sum_{j=1}^{l} \operatorname{SP}_{W}(A[\cdot, j])=\sum_{j=1}^{l} \sum_{1 \leq i<i^{\prime} \leq k} W_{i j} c\left(A[i, j], A\left[i^{\prime}, j\right]\right),
$$

onde mais uma vez $A[\cdot, j]$ denota a $j$-ésima coluna de $A$.

A pontuação SP definida sem pesos pode obviamente ser enquadrada como um caso particular da pontuação SP ponderada se os pesos $W_{i j}$ forem adotados de forma que $W_{i j}=1$ para todo par $i<j$ e $W_{i j}=0$ para os outros casos. 
Um exemplo do interesse em considerar pontuações ponderadas ocorre quando, de alguma forma, sabe-se que algum par de seqüências representa seres que sejam evolutivamente remotos e que, por esse motivo, espera-se que as seqüências sejam biologicamente "pouco alinháveis" e que, portanto, qualquer alinhamento entre esse par de seqüências possua pontuação alta. Para dar menor importância para alinhamentos entre essas sequiências, pode-se adotar um peso menor para esse par de seqüências do que os adotados para os outros pares.

\subsection{Projeções de Alinhamentos e Interpretação Geométrica}

Definição 2.4 (Alinhamento Induzido). Dado um alinhamento $A$ de $k$ seqüências $s_{1}, \ldots, s_{k}$ e um subconjunto $S \subseteq\left\{s_{1}, \ldots, s_{k}\right\}$, definimos o alinhamento induzido em $S$ por $A$ como sendo o alinhamento obtido de $A$ por remoção das seqüências que não estão em $S$ e pela remoção das colunas em branco. O alinhamento induzido em $S$ por $A$ é denotado por $A_{\mid S}$.

O alinhamento $A_{\mid S}$ é também chamado projeção de $A$ na direção de $S$. Para deixar a notação mais simples, ao especificarmos alguma projeção de um alinhamento, denotaremos o conjunto $S$ apenas pelos índices das seqüências pertencentes a ele.

Se o conjunto $S$ possui cardinalidade $k^{\prime}$, dizemos que $A_{\mid S}$ é uma $k^{\prime}$-projeção de $A$ na direção de $S$. O caso particular de maior importância para os algoritmos deste capítulo é o caso em que $|S|=2$. As 2-projeções dão uma maneira alternativa de calcular a pontuação SP de um alinhamento, conforme estabelecido na proposição a seguir.

Proposição 2.1. Para um alinhamento A qualquer, sua pontuação $\mathrm{SP}$ é tal que $\mathrm{SP}(A)=$ $\sum_{i<i^{\prime}} \mathrm{SP}\left(A_{\mid i, i^{\prime}}\right)$, isto é, a pontuação $\mathrm{SP}(A)$ pode ser calculada como a soma das pontuações de todas 2-projeções de $A$.

Prova: Pela definição de pontuação SP, temos que $\mathrm{SP}(A)=\sum_{j=1}^{l} \sum_{i<i^{\prime}} c\left(A[i, j], A\left[i^{\prime}, j\right]\right)$ e, rearranjando os termos do somatório, segue que $\operatorname{SP}(A)=\sum_{i<i^{\prime}} \sum_{j=1}^{l} c\left(A[i, j], A\left[i^{\prime}, j\right]\right)$. Mas para $i$ e $i^{\prime}$ fixados, o termo $\sum_{j=1}^{l} c\left(A[i, j], A\left[i^{\prime}, j\right]\right)$ é o custo do alinhamento entre $s_{i}$ e $s_{i^{\prime}}$ induzido por $A$ mais algumas possíveis colunas em branco. Cada uma dessas colunas possui custo $c(\sqcup, \sqcup)=0$. Em outras palavras, $\sum_{j=1}^{l} c\left(A[i, j], A\left[i^{\prime}, j\right]\right)=\operatorname{SP}\left(A_{\mid i, i^{\prime}}\right)$, de onde segue o resultado.

Na realidade, a proposição acima é válida para toda função de pontuação de colunas $c:\left(\Sigma^{\prime}\right)^{k} \rightarrow \mathbb{Q}_{\geq 0}$ definida segundo o esquema de soma de pares, desde que o custo de alinhamento de dois espaços seja 0 , não importando se a função de custo de pares é ou não uma métrica (isso significa que a proposição é válida também para similaridades—não só para distâncias).

A maneira como a pontuação SP é definida e a afirmação do teorema acima podem nos dar a impressão errada de que 2-projeções de um alinhamento ótimo são também alinhamentos ótimos de 2 seqüências. Isto não é verdade de modo geral, como atesta o exemplo da Figura 2.2. O alinhamento à esquerda na figura é um alinhamento ótimo entre as 4 seqüências, mas a projeção deste alinhamento na direção das seqüências $s_{2}$ e $s_{3}$ é o alinhamento à direita na figura, que não é um alinhamento ótimo entre $s_{2}$ e $s_{3}$.

$\mathrm{O}$ fato de a pontuação SP poder ser calculada como soma de custos de 2-projeções é essencial para alguns algoritmos; em especial, é de extrema importância para o método proposto por Carrillo e Lipman, apresentado na Seção 2.5 . 


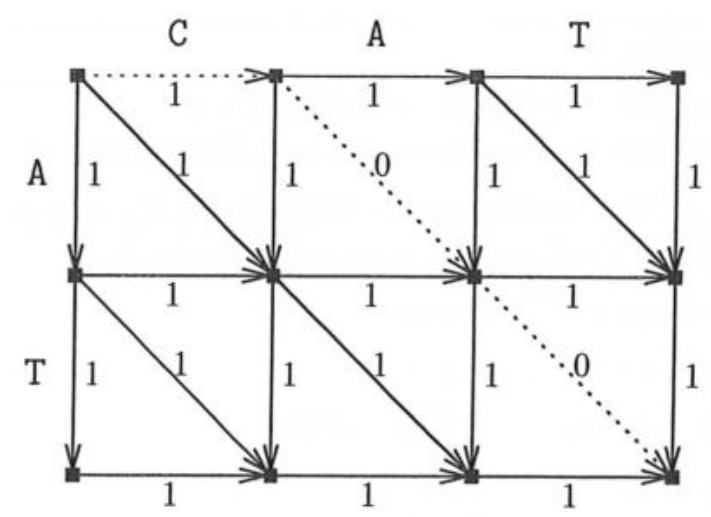

Figura 2.3: O grafo em forma de reticulado para a matriz de programação dinâmica $a$ entre as seqüências $s=\mathrm{AT}$ e $t=\mathrm{CAT}$. O custo de um arco no grafo é igual ao custo da coluna do alinhamento determinada pelos extremos do arco. Um caminho orientado de custo mínimo está indicado com arcos em destaque e corresponde ao alinhamento ( $\left.\begin{array}{l}\mathrm{CAT} \\ \mathrm{CAT}\end{array}\right)$.

$\mathrm{O}$ custo do caminho dirigido, igual à soma dos custos de seus arcos, é igual à soma dos custos das colunas do alinhamento que ele determina e, assim, o custo do caminho dirigido é igual ao custo do alinhamento. O objetivo do Problema APS é encontrar um alinhamento de custo mínimo e isso significa, na formulação em termos de grafos, que um caminho orientado de custo mínimo em $G$, com origem em $(0,0)$ e término em $(m, n)$ é procurado.

O reticulado $G$ é também chamado grafo de edição. Se houver custos associados às arestas (em vez de todos arcos terem custo trivial igual a 1), ele também é chamado grafo de edição com pesos. Um caminho orientado de menor número de arestas (ou de custo mínimo, no caso com pesos) determina um alinhamento ótimo entre as seqüências e, portanto, uma seqüência de custo mínimo de operações de edição para transformar uma seqüência na outra. Por esse motivo, um tal caminho é chamado transcrição de edição de custo mínimo [Gus97, p. 223].

O que o Algoritmo Alinha faz é justamente "converter" um caminho de custo mínimo no grafo (com os arcos do caminho determinados dinamicamente) em um alinhamento. Para isso, o algoritmo observa, a cada passo (partindo do último vértice do caminho, o vértice $(m, n))$, qual foi a dependência entre vértices calculada pelo Algoritmo Dist para obter menor custo no alinhamento global.

Dizemos que um caminho orientado qualquer de $(0,0)$ a $(m, n)$ em $G$, que ao ser percorrido produz um alinhamento, é um caminho associado ao alinhamento.

A tarefa contrária à do Algoritmo AlinhA, isto é, "converter" um alinhamento a um caminho orientado no grafo, também é possível. Os caminhos que consideramos partem do vértice $(0,0)$ e terminam no vértice $(m, n)$. Se $A$ é um alinhamento qualquer entre $s$ e $t$ com comprimento $l$ (i.e., $A$ possui $l$ colunas), então podemos construir um caminho $P_{A}=v_{0} \rightarrow v_{1} \rightarrow \cdots \rightarrow v_{l}$ de forma que "seguindo os arcos de $P_{A}$ " possamos reconstruir $A$. O Algoritmo Caminho constrói um caminho $P_{A}$ associado ao alinhamento $A$.

Observe-se que se $A$ é um alinhamento livre de colunas em branco e que se $A^{\prime}$ é um alinhamento obtido de $A$ por inserção de colunas em branco, então $\operatorname{CAminho}(A)=\operatorname{CAminho}\left(A^{\prime}\right)$. Basta, então, para tratar de todos os possíveis caminhos, restringir a atenção apenas aos alinhamentos livres de colunas em branco.

O Algoritmo CAminho pode ter sua corretude verificada por indução finita. É claro que 


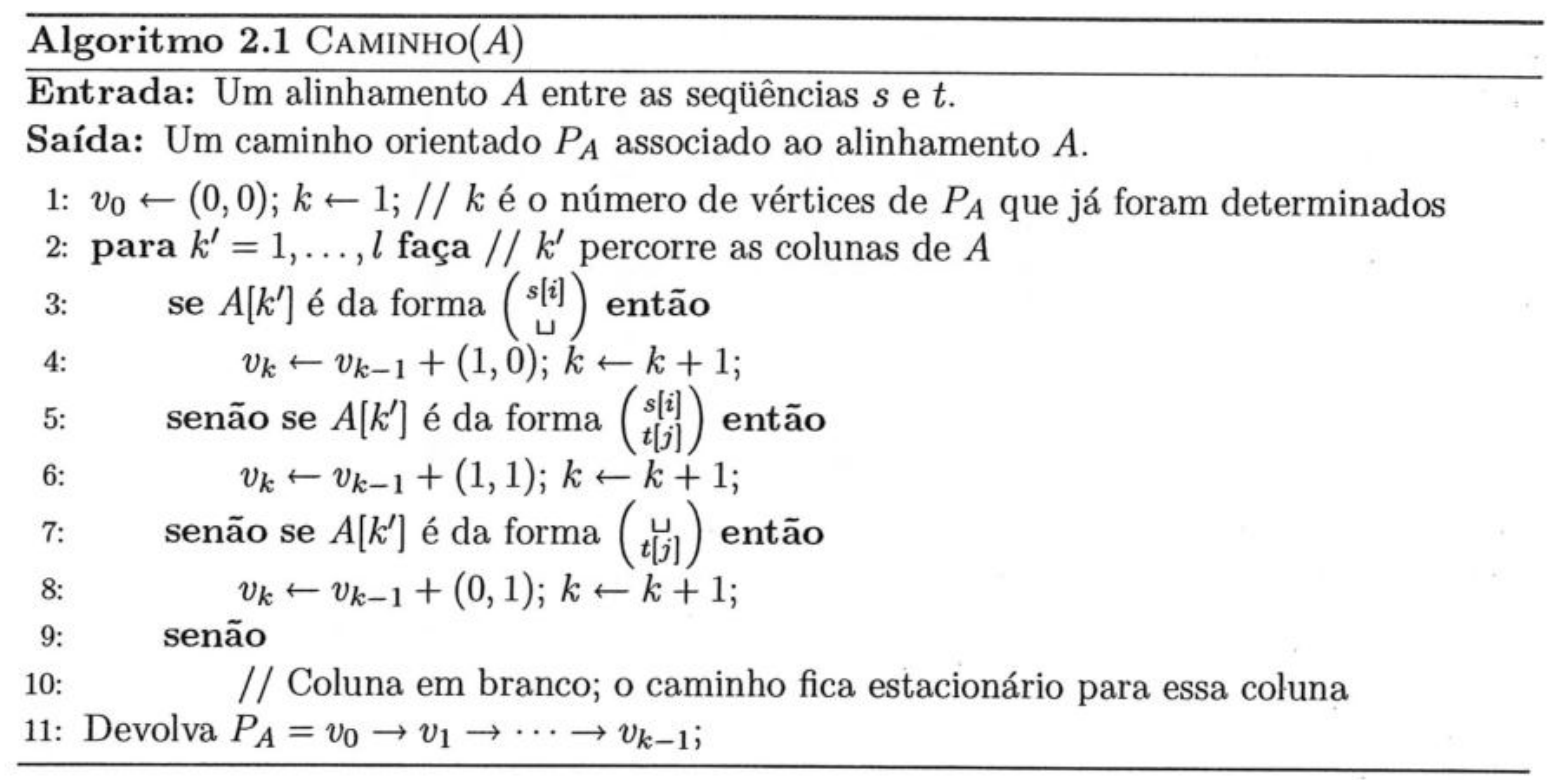

o Algoritmo Caminho toma tempo linear em $l$, onde $l$ é o número de colunas de $A$. Se $A$ é um alinhamento livre de colunas em branco, então $l \leq m+n$ e o algoritmo toma tempo $O(m+n)$.

Sob luz dessa discussão, fica claro que há uma bijeção entre caminhos dirigidos de $G$ e alinhamentos livres de colunas em branco de $s$ e $t$. A bijeção é dada pelos Algoritmos Alinha e Caminho.

Um invariante muito simples do Algoritmo Caminho é que, se em um dado momento de sua execução, o último vértice determinado do caminho foi $v=(i, j)$, então o subalinhamento considerado até aquele ponto alinhava $s[1 \ldots i]$ a $t[1 \ldots j]$. Em outras palavras, se $(i, j)$ é um dos vértices do caminho associado a $A$, então $(i, j)$ é um corte do alinhamento $A$. Mais ainda, se $(i, j)$ é um corte de $A$, então $(i, j)$ é um vértice do caminho $P_{A}$. Essas duas afirmações nos dizem que o caminho associado a $A$ é composto exatamente pelos cortes de $A$ (vide Seção 1.6.2.2).

A relação entre o problema de alinhamentos com o problema de caminhos mínimos em grafos é útil pois, além de permitir uma elegante interpretação geométrica dos alinhamentos e dos algoritmos, também deixa à disposição ferramentas bem estudadas de Teoria de Grafos para resolução do problema (inclusive para o estudo de soluções sub-ótimas).

Agora que conhecemos a bijeção existente entre caminhos orientados e alinhamentos sem colunas em branco, podemos fornecer a justificativa prometida feita na Seção 1.5.1 para o número de alinhamentos existentes entre duas seqüências.

Um alinhamento de maior comprimento entre duas seqüências é aquele em que cada caractere de uma seqüência está alinhado a um espaço na outra seqüência. Nesse caso, se as seqüências $s$ e $t$ possuem respectivamente tamanhos $m$ e $n$, tal alinhamento teria $m+n$ colunas. Por outro lado, um alinhamento de comprimento mínimo é aquele em que o maior número possível de caracteres entre as seqüências estão alinhados e, por conseqüência, um tal alinhamento possui $\max \{m, n\}$ colunas (já que é possível emparelhar no máximo um número de caracteres igual ao comprimento da menor seqüência e os demais caracteres da seqüência mais longa ficarem alinhados a espaços). Em resumo, o maior alinhamento pode ter $m+n$ colunas e o menor, $\max \{m, n\}$. Além disso, qualquer número entre 0 e $\min \{m, n\}$ pode ser o número de pares formados entre caracteres de $s$ e $t$. 
É fácil de ver que, quando o número de emparelhamentos de caracteres de $s$ a caracteres de $t$ fica fixado, o número de emparelhamentos de caracteres de $s$ a espaços fica automaticamente determinado, bem como o número de caracteres de $t$ que ficam alinhados a espaços. Isso ocorre porque se exatamente $i$ caracteres de $s$ forem emparelhados a $i$ caracteres de $t$, então os $m-i$ caracteres de $s$ restantes e os $n-i$ caracteres restantes de $t$ deverão ficar alinhados a espaços.

Ademais, da maneira representada na Figura 2.3, um caractere de $s$ alinhado a um caractere de $t$ é representado como um arco diagonal, um caractere de $s$ alinhado a um espaço em $t$ é representado por um arco vertical e um espaço alinhado a um caractere de $t$ é representado por um arco horizontal. Logo um caminho do vértice $(0,0)$ ao vértice $(m, n)$ pode ser representado por uma sequiência de $D$ 's, $V$ 's e $H$ 's, de forma que cada letra represente um tipo de arco.

Sabemos então que se um caminho orientado de $(0,0)$ a $(m, n)$ possui $i$ arestas diagonais $(D)$, então o número de arestas horizontais $(H)$ será $n-i$ e o número de arestas verticais $(V)$ será $m-i$.

Um caminho de $(0,0)$ a $(m, n)$ pode então ser observado como uma palavra de $i$ caracteres $D, m-i$ caracteres $V$ e $n-i$ caracteres $H$, para cada $i$ fixado. O número de caminhos com $i$ arestas diagonais (e, portanto, o número de alinhamentos de $s$ e $t$ em que há $i$ caracteres de $s$ emparelhados a $i$ caracteres de $t$ ) pode então ser calculado como o número de palavras distintas (anagramas) que possuem $i$ letras $D, m-i$ letras $V$ e $n-i$ letras $H$, que é dado pelo coeficiente multinomial $\left(\begin{array}{c}m+n-i \\ m-i, n-i, i\end{array}\right)$. Como $i$ pode variar entre 0 e $\min \{m, n\}$, segue que o número de alinhamentos entre duas seqüências $s$ e $t$ com comprimentos $|s|=m$ e $|t|=n$ é

$$
\sum_{i=0}^{\min \{m, n\}}\left(\begin{array}{c}
m+n-i \\
m-i, n-i, i
\end{array}\right) .
$$

No caso particular em que ambas seqüências possuem comprimento $n$, temos que o número $N(n)$ de alinhamentos é

$$
N(n)=\sum_{i=0}^{n}\left(\begin{array}{c}
2 n-i \\
n-i, n-i, i
\end{array}\right)
$$

conforme desejávamos argumentar.

\subsubsection{Caso de Várias Seqüências}

No caso de alinhamentos de várias seqüências, as Propriedades de Subsoluções Ótimas e de Subproblemas Comuns também são válidas e podem ser verificadas por argumentos análogos aos usados para o caso de duas seqüências na Seção 1.5.3. Além disso, uma generalização natural do método de programação dinâmica descrito no Capítulo 1 nos fornece um algoritmo para o Problema AVS. Tratamos a partir daqui dessa generalização.

Sejam dadas $k \geq 2$ seqüências $s_{1}, \ldots, s_{k}$. Então, uma coluna qualquer de um alinhamento entre essas seqüências pode ter, em sua $i$-ésima linha, um caractere de $s_{i}$ ou um espaço. A afirmação é obviamente válida para qualquer $i$ entre $1 \mathrm{e} k \mathrm{e}$, se a possibilidade de colunas em branco é excluída, isso significa que há $2^{k}-1$ possibilidades para a coluna. É claro também que esse número é um limite superior no número de possibilidades para a coluna, pois se alguma seqüência já tiver terminado antes dessa coluna, então a posição da coluna que corresponde à sequiência deverá ser preenchida com um espaço. A título de 
ilustração, é interessante verificar que, se $k=2$ seqüências, então há no máximo $2^{2}-1=3$ possibilidades para a última coluna de um alinhamento, conforme esperado.

Um algoritmo de programação dinâmica para o Problema AVS no espírito daquele visto para duas seqüências pode ser elaborado se considerarmos uma matriz $k$-dimensional $a$ em que a posição $a\left[i_{1}, \ldots, i_{k}\right]$ armazena a pontuação mínima de um alinhamento entre os prefixos $s_{1}\left[1 \ldots i_{1}\right], \ldots, s_{k}\left[1 \ldots i_{k}\right]$ das seqüências $s_{1}, \ldots, s_{k}$.

A pontuação $a\left[i_{1}, \ldots, i_{k}\right]$ pode ser calculada considerando todas as possibilidades para a última coluna de um alinhamento de $s_{1}\left[1 \ldots i_{1}\right], \ldots, s_{k}\left[1 \ldots i_{k}\right]$ e escolhendo aquela que minimiza a soma da pontuação SP da coluna com a pontuação ótima de um alinhamento dos prefixos das seqüências que não inclua os caracteres alinhados na coluna. Damos uma descrição formal do algoritmo com mais detalhes na próxima seção. Vamos atentar agora à interpretação geométrica do algoritmo, que vai nos ajudar a escrever o pseudo-código para resolver o Problema APS.

De maneira análoga ao caso de duas seqüências, podemos construir um reticulado $G=(V, A) k$-dimensional para representar o funcionamento do algoritmo de programação dinâmica. Se o comprimento da seqüência $s_{i}$ é representado por $\left|s_{i}\right|=n_{i}$, então definimos o conjunto de vértices $V$ de $G$ por $V=\left\{0, \ldots, n_{1}\right\} \times \cdots \times\left\{0, \ldots, n_{k}\right\}$. Da mesma forma como para o caso de dimensão $k=2$, definimos os arcos do reticulado com base nos pares de vértices que representam células da matriz de programação dinâmica que estejam diretamente relacionados do ponto de vista do cálculo do mínimo: dizemos que um vértice $v=\left(v_{1}, \ldots, v_{k}\right)$ depende de um vértice $w=\left(w_{1}, \ldots, w_{k}\right)$ se $a[w]$ é usada no cálculo do mínimo de $a[v]$ e, nesse caso, $(w, v)$ é um arco de $G$.

$\mathrm{O}$ vértice $v$ apenas pode depender de $w$ se cada componente de $v$ for, no máximo, 1 unidade a mais do que o componente de $w$ correspondente e se cada componente de $v$ tiver valor pelo menos igual àquele do componente de $w$ de mesma posição, isto é, $v$ pode depender de $w$ apenas se $v_{i} \leq w_{i}+1$ e se $w_{i} \leq v_{i}$, para todo $i=1, \ldots, k$. Disso segue que $0 \leq v_{i}-w_{i} \leq 1$, para toda coordenada e, portanto, $\overrightarrow{0} \leq v-w \leq \overrightarrow{1}$, onde $\overrightarrow{0}=(0, \ldots, 0)$ é o vetor cujos componentes são todos nulos, $\overrightarrow{1}=(1, \ldots, 1)$ é o vetor com componentes iguais a 1 e o símbolo $\leq$ é interpretado componente a componente. Como os vetores $v$ e $w$ possuem coordenadas inteiras e cada coordenada está compreendida entre 0 e 1 , o vetor diferença $b=v-w$ é um vetor binário. É claro que, pela definição de $b, v=w+b$. As posições em que $b$ possui 1 são aquelas posições da possibilidade para a última coluna de um alinhamento de $s_{1}\left[1 \ldots v_{1}\right], \ldots, s_{k}\left[1 \ldots v_{k}\right]$ que possuem caracteres das seqüências, enquanto as posições de $b$ que têm 0 são aquelas em que um espaço está presente.

Pela forma como definimos dependência entre vértices de $G$, não é possível ter $b=\overrightarrow{0}$, porque este caso equivaleria a considerar a última coluna de um alinhamento contendo só espaços, isto é, uma coluna em branco e esse é um caso excluído. Evidentemente, em todos os outros casos as colunas representadas por um vetor binário não são colunas em branco.

Definimos o conjunto de $\operatorname{arcos} A$ do reticulado $G$ como o conjunto dos pares ordenados de vértices de $G$ cujo vértice de destino dependa do vértice de origem, isto é, o conjunto de arcos de $G$ é o conjunto de todos os elementos da forma $(w, v) \in V^{2}$ em que $w \leq v$ e $v-w \in\{0,1\}^{k} \backslash\{\overrightarrow{0}\}$.

É claro que se um vértice $v$ está em alguma região do reticulado em que algum de seus componentes seja 0 , então $v$ depende de menos do que $2^{k}-1$ outros vértices, uma vez que todos os vértices de que $v$ depende têm esse tal componente fixado e igual a 0 . Isso pode ser expressado de uma maneira concisa observando que se o vértice $v$ depende de um vértice $w=v-b$, então como $\overrightarrow{0} \leq w=v-b$, temos que o vetor binário $b$ é tal que $b \leq v$, isto é, apenas vetores $b \in\{0,1\}^{k} \backslash\{\overrightarrow{0}\}$ que satisfaçam $b \leq v$ é que podem ser diferença de $v$ e de 
algum vértice de que $v$ dependa. Em particular, se $v$ tem alguma determinada coordenada igual a 0 , então essa coordenada em $b$ só pode ser 0 .

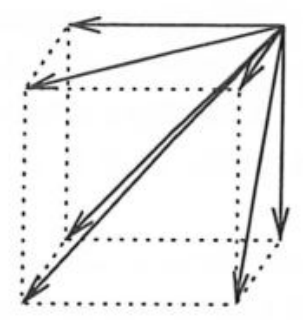

Figura 2.4: Dependências de um vértice em um reticulado de programação dinâmica para 3 seqüências. Os arcos em destaque são vetores binários. O vértice de origem dos arcos é o vértice que depende dos demais. O custo dos arcos depende das seqüências a alinhar (que não estão exibidas) e é igual à pontuação da coluna que o arco representa.

\subsection{Algoritmo de Programação Dinâmica}

Apresentamos nesta seção uma descrição mais detalhada do algoritmo de programação dinâmica para o Problema AVS, que chamamos DisT-AVS. Em cada iteração, o algoritmo testa qual das colunas pode ser concatenada a um alinhamento ótimo para um subproblema a fim de obter uma solução para um subproblema maior.

A matriz $a$ preenchida pelo Algoritmo DisT-AVS tem $k$ dimensões e sua $i$-ésima dimensão é indexada de 0 ao comprimento $n_{i}$ da $i$-ésima seqüência da entrada. A idéia por trás da matriz $a$ é representar o reticulado $G$. Nele, um caminho dirigido de $\overrightarrow{0}=(0, \ldots, 0)$ a $\vec{n}=\left(n_{1}, \ldots, n_{k}\right)$ é procurado. A entrada $a\left[i_{1}, \ldots, i_{k}\right]$ contém o custo de um alinhamento ótimo entre os prefixos $s_{1}\left[1 \ldots i_{1}\right], \ldots, s_{k}\left[1 \ldots i_{k}\right]$.

A entrada $a[0, \ldots, 0]$ é inicializada com 0 pois há apenas um alinhamento entre as seqüências vazias (que, por conseqüência, é ótimo) e o custo deste alinhamento é 0 . As demais entradas de $a$ são preenchidas de acordo com os valores mínimos derivados de suas dependências, da maneira discutida na seção anterior.

A interpretação geométrica de uma entrada $a\left[i_{1}, \ldots, i_{k}\right]$ é simples: um caminho orientado qualquer de $\overrightarrow{0}$ a um vértice $\left(i_{1}, \ldots, i_{k}\right)$ corresponde a um alinhamento das seqüências em que $i_{1}$ caracteres de $s_{1}$ estão alinhados a $i_{2}$ caracteres de $s_{2}, i_{3}$ caracteres de $s_{3}$ e assim por diante até $i_{k}$ caracteres de $s_{k}$. A entrada $a\left[i_{1}, \ldots, i_{k}\right]$ armazena o custo do melhor caminho de $\overrightarrow{0}$ a $\left(i_{1}, \ldots, i_{k}\right)$. Da mesma forma como para duas seqüências, cada vértice de um caminho orientado de $\overrightarrow{0}$ a $\vec{n}$ é um corte do alinhamento associado a esse caminho.

Mas conhecendo o caminho de $\overrightarrow{0}$ até um vértice $v$ e as seqüências de entrada, é possível dizer qual é a última coluna do alinhamento associado ao caminho? A resposta é naturalmente "sim" e a coluna pode ser obtida notando-se que como o caminho chegou até o vértice $\left(v_{1}, \ldots, v_{k}\right)$, então o alinhamento compreende até os caracteres $s_{1}\left[v_{1}\right], \ldots, s_{k}\left[v_{k}\right]$. É claro que, embora todos estes caracteres façam parte do alinhamento, pode ocorrer que nem todos ocupem a última coluna, por causa da ocorrência de espaços. Mas se conhecemos a penúltima coluna (e, por conseqüência, qual é o penúltimo vértice $w$ do caminho-porque as coordenadas de $w$ são dadas pelas quantidades de caracteres das seqüências que foram alinhadas até a penúltima coluna), descobrir qual é a última coluna do alinhamento é simples: supondo-se que $w=\left(w_{1}, \ldots, w_{k}\right)$, temos que se para alguma coordenada $w_{i}=v_{i}$, então sabemos que o alinhamento até a última coluna possui, na $i$-ésima linha, o mesmo 
número de caracteres alinhados que o alinhamento possui até sua penúltima coluna, o que significa que a última coluna possui um espaço na $i$-ésima linha. Em outras palavras, se a quantidade de caracteres de uma seqüência permanece constante entre duas colunas de um alinhamento, a última coluna teve de ser preenchida com um espaço para que isso acontecesse. Por outro lado, se $w_{i}=v_{i}-1$, então a última coluna da linha $i$ foi preenchida pelo caractere $s_{i}\left[v_{i}\right]$. Para facilitar a notação, se $v=\left(v_{1}, \ldots, v_{k}\right)$, definimos por $s[v]$ o vetor de caracteres $\left(s_{1}\left[v_{1}\right], \ldots, s_{k}\left[v_{k}\right]\right)$.

Equivalentemente, se os últimos vértices são $w$ e $v$, com $w=v-b$, para algum vetor binário $b \neq 0$, temos que a última coluna do alinhamento pode ser descrita pelo produto coordenada a coordenada $b \otimes s[v]$, onde $0 \otimes \sigma=\sqcup$ e $1 \otimes \sigma=\sigma$ para todo caractere $\sigma \in \Sigma$.

Isso significa que os dois últimos vértices de um caminho associado a um alinhamento determinam por completo a última coluna do alinhamento, ou seja, a última coluna do alinhamento fica determinada pelo último arco do caminho associado ao alinhamento, de forma análoga ao caso de duas seqüências. É claro que o custo SP da última coluna é $\mathrm{SP}(b \otimes s[v])$. $\vec{i} \neq \overrightarrow{0}$,

A fórmula geral para preenchimento das entradas de $a$ é, portanto, $a[\overrightarrow{0}]=0 \mathrm{e}$, para todo

$$
a[\vec{i}]=\min _{\substack{b \in\{0,1\}^{k} \backslash\{\overrightarrow{0}\} \\ b \leq v}}\{a[\vec{i}-b]+\operatorname{SP}(b \otimes s[\vec{i}])\}
$$

Bem como no caso de duas seqüências, aquii também deve-se prestar atenção à ordem de preenchimento da matriz a para que cada entrada a preencher só dependa de entradas previamente calculadas. Para preencher a matriz $a$, podemos percorrer os vértices do reticulado em ordem lexicográfica, que definimos abaixo.

Definição 2.5 (Ordem Lexicográfica). Dados dois vetores $v, w \in \prod_{i=1}^{k}\left\{0, \ldots, n_{i}\right\}$, dizemos que $w$ e $v$ estão em ordem lexicográfica (e denotamos por $w \leq_{L} v$ ) se $w_{i}=v_{i}$, para todo $i=1, \ldots, k$ ou se existe $j$ entre 1 e $k$ para o qual $w_{i}=v_{i}$ para todo $i<j$ e $w_{j}<v_{j}$.

Mais uma vez, uma generalização do caso de duas seqüências funciona para o caso geral: se preenchermos a matriz $a$ com índices em ordem lexicográfica, temos a garantia de que todas entradas preenchidas dependem apenas de entradas já calculadas, como afirma a seguinte proposição.

Proposição 2.2. Se os índices de a são gerados em ordem lexicográfica e v é um dos indices, então todos os índices de que a $[v]$ depende já estão gerados quando a entrada $a[v]$ for preenchida.

Prova: Se o vértice $v$ depende de um vértice $w$, então temos que $v=w+b$, para algum vetor binário $b \neq \overrightarrow{0}$. Mas isto significa que $w \leq v$, ou seja, $w_{i} \leq v_{i}$ para todo $i=1, \ldots, k$. Como $w \neq v$ por hipótese, se $j$ é o menor índice em que $w$ e $v$ diferem, então temos que $w_{i}=v_{i}$, para todo $i<j$ e que $w_{j}<v_{j}$, de onde segue que $w \leq_{L} v$. Logo, um vértice $v$ apenas depende de outros vértices que o precedem na ordem lexicográfica, de onde segue o resultado.

Os vetores $\vec{i}$ correspondentes aos vértices do reticulado podem ser gerados em ordem lexicográfica de $\overrightarrow{0}$ até $\vec{n}$ por meio de um algoritmo que simula o conta-giros (ou hodômetro) de um automóvel, inicializando $\vec{i}$ (um "contador de distância") com todas coordenadas iguais a 0 e "incrementando" $i$ a cada passo, com a restrição que a $j$-ésima coordenada de $\vec{i}$ varia entre 0 e $n_{j}$ (inclusive). 
A geração dos vetores binários pode ser feita sem nenhum problema também em ordem lexicográfica ${ }^{4}$ pelo mesmo procedimento descrito acima, com a particularidade de que cada coordenada varia, evidentemente, entre 0 e 1 como em um contador binário.

O Algoritmo DisT-AVS está descrito em pseudo-código a seguir.

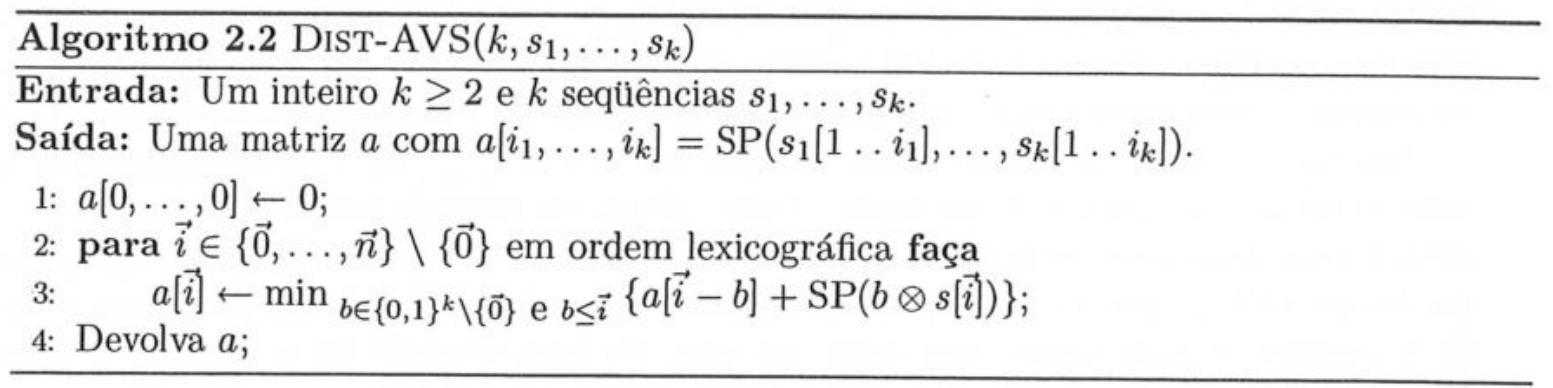

O Algoritmo DiST-AVS foi descrito com cálculo de mínimo empregando a função SP para dar custos para colunas. Todavia, o algoritmo continua válido para qualquer função $c$ que forneça o custo de uma coluna, pois as propriedades importantes (como, por exemplo, a aditividade) independem de qual é a função usada ${ }^{5}$.

A obtenção de um alinhamento ótimo é feita por um algoritmo que, como no caso do Algoritmo Alinha (descrito na página 16) parte da entrada $a[\vec{n}]$ e determina a cada passo qual é a entrada anterior à já obtida e a coluna correspondente usada para conseguir um alinhamento ótimo. Isso pode ser feito essencialmente por reprodução das contas feitas no passo 3 do Algoritmo DiST-AVS (tomando-se o cuidado de verificar quais são os vetores binários válidos).

Essa não é a maneira mais eficiente em relação a tempo para produzir um alinhamento ótimo, porque parte dos cálculos de mínimo realizados por DisT-AVS ficam duplicados ao realizar-se a construção do alinhamento. Uma alternativa que elimina a duplicação (a despeito de um maior uso de memória) é modificar o Algoritmo DisT-AVS para que cada entrada $a[\vec{i}]$ contenha não só o valor de um alinhamento ótimo de prefixos das seqüências, mas também uma indicação (digamos, um ponteiro) para a entrada da matriz cujo valor deu origem a $a[\vec{i}]$ no cálculo de mínimo.

O algoritmo aqui descrito opera encontrando custos de alinhamentos de prefixos das sequiências e a construção do alinhamento ótimo é feita determinando as colunas do alinhamento de "trás para diante" (i.e., primeiro as últimas colunas). Caso seja necessário, as idéias dos Algoritmos Dist-Rev e Alinha-Rev podem ser empregadas para um algoritmo para o Problema AVS.

\subsubsection{Análise de Complexidade}

Procedemos nesta seção à análise de complexidade do algoritmo de programação dinâmica. O mais simples de ser analisado é o espaço consumido pelo algoritmo. Essencialmente, o espaço usado para a saída é o da matriz $k$-dimensional $a$, que contém $\left(n_{1}+1\right) \cdots\left(n_{k}+1\right)$ entradas e que, portanto, ocupa espaço $O\left(\prod_{i=1}^{k}\left(n_{i}+1\right)\right)$, ou, se todas seqüências têm tamanho $n$, espaço ${ }^{6} O\left((n+1)^{k}\right)$.

\footnotetext{
${ }^{4} \mathrm{~A}$ ordem em que os vetores binários são gerados não é importante.

${ }^{5}$ Isso inclui a pontuação SP ponderada.

${ }^{6}$ É importante observar que, como $k$ é uma grandeza variável no problema, a complexidade de espaço do algoritmo não pode ser escrita como $O\left(n^{k}\right)$. Por outro lado, diante da hipótese adicional de que $k \leq n$ é possível mostrar que $(n+1)^{k}=O\left(n^{k}\right)$. A justificativa para a afirmação segue diretamente do fato de que,
} 
Para a execução do algoritmo, as variáveis de controle ocupam espaço total de $O(k)$, o que significa que DisT-AVS tem complexidade de espaço $O(k)$.

Mais uma vez cabe aqui o comentário de que se o objetivo for o cálculo de um alinhamento ótimo das várias seqüências, então a maneira mais direta de realizar as computações é armazenando a matriz de programação dinâmica devolvida por DIST-AVS antes de chamar um algoritmo, digamos, ALINHA-AVS, que construa um alinhamento ótimo com base na matriz $a$. Isso mostra que a complexidade de espaço do Problema AVS é $O\left((n+1)^{k}\right)$.

Em relação ao tempo, o algoritmo executa um laço de $\prod_{i=1}^{k}\left(n_{i}+1\right)$ iterações onde, em cada iteração, um mínimo é calculado. Cada cálculo de mínimo possui no máximo $2^{k}-1$ termos (um para cada vetor binário não-nulo). Cada um dos termos pode ser computado em tempo $O\left(k^{2}\right)$, que é o tempo suficiente para computar a função SP para uma coluna de $k$ posições e para somar este valor ao valor de uma entrada de $a$. Assim, o tempo suficiente para a execução do Algoritmo DisT-AVS é $O\left(2^{k} k^{2} \prod_{i=1}^{k}\left(n_{i}+1\right)\right)$. No caso em que as seqüências possuem tamanho $n$ cada, um limite superior no consumo de tempo pode ser expressado de maneira mais simples como $O\left(2^{k} k^{2}(n+1)^{k}\right)$.

É simples de ver também que a pontuação SP ponderada de uma coluna qualquer pode ser calculada em tempo $O\left(k^{2}\right)$ e que, assim, o Algoritmo DisT-AVS pode calcular alinhamentos ótimos para pontuações ponderadas (supondo-se a matriz $W$ fixada) em tempo $O\left(2^{k} k^{2}(n+1)^{k}\right)$, o mesmo limite superior que para a pontuação SP simples.

É fácil de deduzir um limite inferior trivial para o tempo consumido pelo algoritmo. Observando-se que existem $n^{k}$ entradas da matriz a (que são as entradas cujas coordenadas variam apenas entre 1 e $n$ ) que dependem de exatamente $2^{k}-1$ outras entradas para o cálculo de mínimo, podemos concluir que o tempo usado pelo algoritmo é $\Omega\left(2^{k} n^{k}\right)$, já que pelo menos tempo $\Omega(1)$ é usado para avaliar cada um dos termos do cálculo de mínimo (em que é necessário calcular o custo das colunas - veja a Equação (2.2)) e para preencher cada uma das entradas de $a$.

Mas o Algoritmo DIST-AVS apenas determina a pontuação de um alinhamento ótimo. Determinar algum alinhamento ótimo é uma tarefa que pode ser feita em tempo $O(l k)=$ $O\left(\left(\sum_{i=1}^{k} n_{i}\right) k\right)$, onde $l \leq \sum_{i=1}^{k} n_{i}$ é o comprimento do alinhamento ótimo, se a estratégia de uso de ponteiros for adotada para o Algoritmo DisT-AVS. No caso particular em que as seqüências tenham todas comprimento $n$, esse limite de tempo é $O\left(k^{2} n\right)$.

Assim, o limite inferior na complexidade de tempo do método de programação dinâmica para resolver o Problema AVS deixa evidente que o método só é prático para instâncias pequenas do problema, por causa do crescimento rápido de recursos (memória, tempo) exigidos pelo método, conforme as instâncias crescem de tamanho.

\subsubsection{Comentários Gerais}

Conforme já dissemos, o Problema AVS pode, com a interpretação possibilitada pela modelagem em termos do reticulado, ser formulado como um problema de encontrar um caminho orientado de custo mínimo com origem em $\overrightarrow{0}$ e término em $\vec{n}$ no reticulado.

Dada essa formulação alternativa, algoritmos para encontrar caminhos de custo mínimo em grafos dirigidos podem ser usados para resolver o Problema AVS. Como todos arcos

para $k \leq n$ e $n \geq 1$, temos $[(n+1) / n]^{k}=(1+1 / n)^{k} \leq(1+1 / n)^{n}$, de que a seqüência definida por $(1+1 / n)^{n}$ é crescente e de que, além disso, a seqüência é limitada superiormente por uma constante-é fácil mostrar a partir do desenvolvimento de $(1+1 / n)^{n}$ pela fórmula do Binômio de Newton que 3 é um limite superior para a seqüência [Gui89]. Na prática, a hipótese de que $k \leq n$ pode ser adequada, para casos em que se desejam alinhar "poucas" seqüências que sejam "longas". 
possuem custo não-negativo, um algoritmo que pode ser usado para resolver o problema é o Algoritmo de Dijkstra [AMO93]. Infelizmente, o reticulado possui um grande número de vértices e de arcos em relação ao tamanho da entrada do problema (pelo menos $n^{k}$ vértices e $2^{k} n^{k}$ arcos, para $k$ seqüências de tamanho $n$ ) e o Algoritmo de Dijkstra também pode não ser bom para o Problema APS, porque sua complexidade de tempo de pior caso é $\Omega\left(2^{k} n^{k}\right)$, uma vez que o algoritmo processa cada um dos arcos do grafo e cada arco (uma possibilidade para uma coluna de um alinhamento) é analisado em tempo $\Omega(1)$, o que resulta em uma complexidade de pior caso de $\Omega\left(2^{k} n^{k}\right)$, que é exponencial no tamanho da entrada. No caso mais realista em que uma coluna de $k$ posições é analisada em tempo $\Omega(k)$, vê-se que o Algoritmo de Dijkstra pode não representar ganhos significativos em relação ao algoritmo mais básico de programação dinâmica.

Apesar disso, como o reticulado é acíclico (no sentido de que não há ciclos orientados), é possível tomar vantagem desse fato e descrever um algoritmo para encontrar um caminho de custo mínimo cuja complexidade de tempo de pior caso seja proporcional ao número de arcos do reticulado, que é $2^{k} n^{k}$. Esse algoritmo é, fundamentalmente, o Algoritmo DisT-AVS.

$\mathrm{Na}$ realidade, o que ocorre com o Problema AVS não é uma exclusividade. Existe uma forte relação entre algoritmos de programação dinâmica e o algoritmo para encontrar caminhos de custo mínimo em grafos dirigidos, de maneira que é freqüentemente possível reformular um problema combinatório que admita um algoritmo de programação dinâmica como um problema de encontrar caminhos mínimos (ou máximos) em grafos dirigidos e acíclicos. Essa relação é estabelecida da mesma forma como fizemos para o Problema AVS, associando em alguma ordem adequada os "estágios" da programação dinâmica a vértices de um grafo dirigido e acíclico. No caso do Problema AVS, um estágio equivale à resolução de um subproblema original e o grafo dirigido e acíclico é trivialmente o próprio reticulado.

Um problema combinatório importante que também mostra esta "visão dupla" de resolução (ainda que de maneira não tão clara quanto o Problema AVS) é o Problema da Mochila, que possui formas simples de resolução por programação dinâmica e por reformulação como um problema de caminhos máximos em um grafo dirigido e acíclico [AMO93].

\subsection{Método de Carrillo-Lipman}

Nesta seção, mostramos uma alteração ao método de programação dinâmica que utiliza limites triviais no custo SP de um alinhamento para encontrar um meio de reduzir o tempo suficiente para resolver o Problema AVS.

\subsubsection{Motivação}

Infelizmente, o método de programação dinâmica resolve o Problema AVS, mas ele não é prático para instâncias de mais de algumas poucas seqüências [GKS95] e ele não é "eficiente", no sentido de que tanto o tempo quanto o espaço por ele consumidos não são um polinômio em $k$ e $n_{i}$, para $i=1, \ldots, k$.

Para termos uma idéia de grandeza, se tivermos um computador que execute uma operação a cada picossegundo ${ }^{7}$, poderemos obter um alinhamento ótimo entre 6 seqüências de proteínas em que cada uma possui 100 resíduos com pelo menos $2^{6} 100^{6}=64 \times 10^{12}$ operações, ou seja, aproximadamente 64 segundos (ou pouco mais de um minuto). Se apenas

\footnotetext{
${ }^{7} \mathrm{Um}$ picossegundo é igual a $10^{-12} \mathrm{~s}$. Um computador que executa operações nesse tempo teria uma freqüência aproximadamente igual a 1 Terahertz $=1000 \mathrm{GHz}$.
} 
uma sequiência for acrescentada, o tempo necessário para encontrar um novo alinhamento ótimo pelo método de programação dinâmica será de, pelo menos, $2^{7} 100^{7} \times 10^{-12}=12800$ segundos, que é mais do que 3 horas e meia!

De maneira semelhante, o espaço requerido pelo algoritmo também torna-se proibitivo conforme cresce o número de seqüências que se deseja alinhar.

Qualquer método que "acelere" a construção de alinhamentos ótimos em relação ao algoritmo de programação dinâmica é bem-vindo. Um desses métodos, que tratamos no restante deste capítulo é o método proposto em 1988 por Carrillo e Lipman [CL88] que objetiva diminuir tanto o consumo de memória quanto o consumo de tempo do algoritmo de programação dinâmica.

\subsubsection{Interpretação Geométrica}

O método de Carrillo e Lipman tenta diminuir os recursos de tempo e de espaço para resolver o Problema AVS pelo método de programação dinâmica com uma estratégia básica: como o tempo usado pelo Algoritmo DisT-AVS é proporcional ao número de vértices do reticulado $G$ que são visitados pelo algoritmo, o método procura reduzir o número dos vértices que são analisados para determinar um alinhamento ótimo. O método de CarrilloLipman supõe que a função de pontuação de colunas seja a função SP e usa propriedades de como ela é definida para tentar reduzir o tempo e o espaço.

O método parte da observação que, intuitivamente, ao alinharmos seqüências que tenham aproximadamente o mesmo comprimento e que sejam "parecidas" (em que cada par de seqüências tenha apenas "poucas" trocas, inserções e remoções de caracteres) é de se esperar que um alinhamento ótimo possua "poucos" espaços, principalmente se o custo de lacunas for "alto". Por exemplo, a Figura 2.5 mostra um alinhamento entre as seqüências TAGTCA, AGTCAT e TACTCA, que possuem comprimento $n=6$ e são "parecidas", fato que fica evidente pelo alinhamento entre elas ter somente 3 espaços.

$\mathrm{TAGTCA}_{\sqcup}$

$\triangle A G T C A T$

$\mathrm{TACTCA}_{\sqcup}$

Figura 2.5: Um alinhamento entre seqüências duas-a-duas "similares".

Isso significa, na interpretação geométrica, que o caminho associado a esse alinhamento no reticulado possui "poucos desvios" em relação à diagonal principal do reticulado. A diagonal principal do reticulado é o conjunto de vértices cujas coordenadas têm todas o mesmo valor, isto é, o conjunto dos vértices da forma $(i, \ldots, i)$, para um inteiro $i$ qualquer.

Em outras palavras, é mais plausível que alinhamentos ótimos de seqüências parecidas tenham caminhos associados que passem "longe" de determinados vértices (como os vértices $(0,0, n),(0, n, 0),(n, 0,0)$ etc) pois seria necessário inserir vários espaços no alinhamento para que o caminho correspondente passasse por algum desses vértices (i.e., para que algum desses vértices fosse um corte do alinhamento ótimo), o que provavelmente não é o caso se as seqüências são similares.

De um modo geral, se as seqüências possuem grande similaridade e o custo de lacunas é alto, podemos esperar que os caminhos associados aos alinhamentos ótimos estejam todos contidos em uma região em torno da diagonal principal do reticulado. Assim, basta concentrar nossa atenção aos nós que estão nessa região no algoritmo de programação dinâmica 
para que um caminho ótimo seja encontrado.

O método de Carrillo-Lipman tenta delimitar uma região no reticulado que contenha a diagonal principal e que contenha caminhos ótimos, de forma que o algoritmo de programação dinâmica possa restringir com segurança os seus cálculos a essa região. Naturalmente, como vimos na análise de complexidade do Algoritmo DisT-AVS, o tempo de execução do algoritmo é, dentre outras coisas, proporcional ao número de vértices visitados do reticulado. Quanto mais vértices estiverem fora da região delimitada, mais vértices podem ser descartados pelo algoritmo (evitando serem considerados) e, portanto, menos tempo será suficiente para resolver o Problema AVS.

A região a que a busca será restrita contém todos os nós do reticulado por que passa pelo menos algum caminho com custo entre certos limites. A limitação nos custos dos caminhos é feita de maneira indireta e para calcular esses limitantes, os custos de alinhamentos de cada par das seqüências de entrada são levados em consideração. Em particular, para calcular os limitantes para um reticulado derivado de 3 seqüências $s_{1}, s_{2}$ e $s_{3}$, os custos de alinhamentos ótimos dos pares $\left\{s_{1}, s_{2}\right\},\left\{s_{1}, s_{3}\right\}$ e $\left\{s_{2}, s_{3}\right\}$ são usados. De maneira geral, se $k$ seqüências devem ser alinhadas, então $\left(\begin{array}{c}k \\ 2\end{array}\right)$ limitantes são calculados pelo método.

Na região limitada pelo método de Carrillo e Lipman estão apenas os caminhos cujos custos de todas 2-projeções sejam menores ou iguais aos limites. Naturalmente, os limites são calculados de forma que um alinhamento ótimo sempre lhes satisfaça e, assim, esteja na região (restrita) onde o algoritmo revisado realiza suas buscas.

\subsubsection{Caminho Ótimo e Projeções de Alinhamentos}

Antes de deduzirmos fórmulas para os limitantes dos custos que nos permitirão restringir a região de interesse no reticulado de programação dinâmica, notemos que as projeções de alinhamentos na direção de um par de seqüências também possui uma interpretação geométrica.

Se $s_{1}, \ldots, s_{k}$ são seqüências sobre um alfabeto $\Sigma$ e $A$ é um alinhamento livre de colunas em branco dessas seqüências, sabemos que a $A$ está associado um único caminho orientado $P_{A}$ no reticulado de programação dinâmica e o caminho é uma representação geométrica do alinhamento $A$. De maneira similar, fixadas duas seqüências, $s_{i}$ e $s_{j}$, com $1 \leq i<j \leq k$, a projeção $A_{\mid i, j}$ de $A$ é um alinhamento de $s_{i}$ e $s_{j}$ e, no reticulado indexado apenas por essas seqüências, $A_{\mid i, j}$ pode ser representada por um caminho. Há, na realidade, uma conexão entre o caminho que representa $A_{\mid i, j}$ e $A$ : pela maneira como uma projeção $A_{\mid i, j}$ é definida a partir de um alinhamento $A$, é simples ver que o caminho de $A_{\mid i, j}$ é igual à projeção do caminho de $A$ na direção do plano $i, j$.

De fato, a projeção $A_{\mid i, j}$ de um alinhamento $A$ na direção $i, j$ é definida como o alinhamento obtido de $A$ pela remoção de todas as linhas de $A$ referentes às seqüências que não sejam $s_{i}$ ou $s_{j}$ e pela posterior remoção de colunas em branco. Lembrando-nos de que cada caminho orientado pode ser representado como uma seqüência de vértices, temos que a projeção de um vértice $v=\left(v_{1}, \ldots, v_{i}, \ldots, v_{j}, \ldots, v_{k}\right)$ na direção $i, j$ é igual a $v_{\mid i, j}=\left(v_{i}, v_{j}\right)$ e este vértice, por sua vez, pode ser identificado com o vértice $\left(0, \ldots, 0, v_{i}, 0, \ldots, 0, v_{j}, 0, \ldots, 0\right)$ do reticulado de programação dinâmica em que constam todas as seqüências, isto é, o caminho associado a uma projeção do alinhamento $A$ na direção da seqüências $s_{i}$ e $s_{j}$ é igual à projeção do caminho associado a $A$ na direção do plano relativo a $s_{i}$ e a $s_{j}$. 
Exemplo 2.1. Sejam $s_{1}=\mathrm{AT}, s_{2}=\mathrm{AC}$ e $s_{3}=\mathrm{A}$ e consideremos o alinhamento

$$
A=\left(\begin{array}{c}
\mathrm{AT} \\
\mathrm{AC} \\
\mathrm{A}_{\sqcup}
\end{array}\right)
$$

entre essas três seqüências. O alinhamento $A_{\mid 2,3}$ é igual a $A_{\mid 2,3}=\left(\begin{array}{c}\mathrm{AC} \\ \mathrm{A}_{\sqcup}\end{array}\right)$. O caminho associado a $A$ é $(0,0,0) \rightarrow(1,1,1) \rightarrow(2,2,1)$ e o caminho associado a $A_{\mid 2,3}$ é $(0,0) \rightarrow$ $(1,1) \rightarrow(2,1)$, que pode ser identificado com o caminho $(0,0,0) \rightarrow(0,1,1) \rightarrow(0,2,1)$ no reticulado tridimensional de $s_{1}, s_{2}$ e $s_{3}$ (veja Figura 2.6).

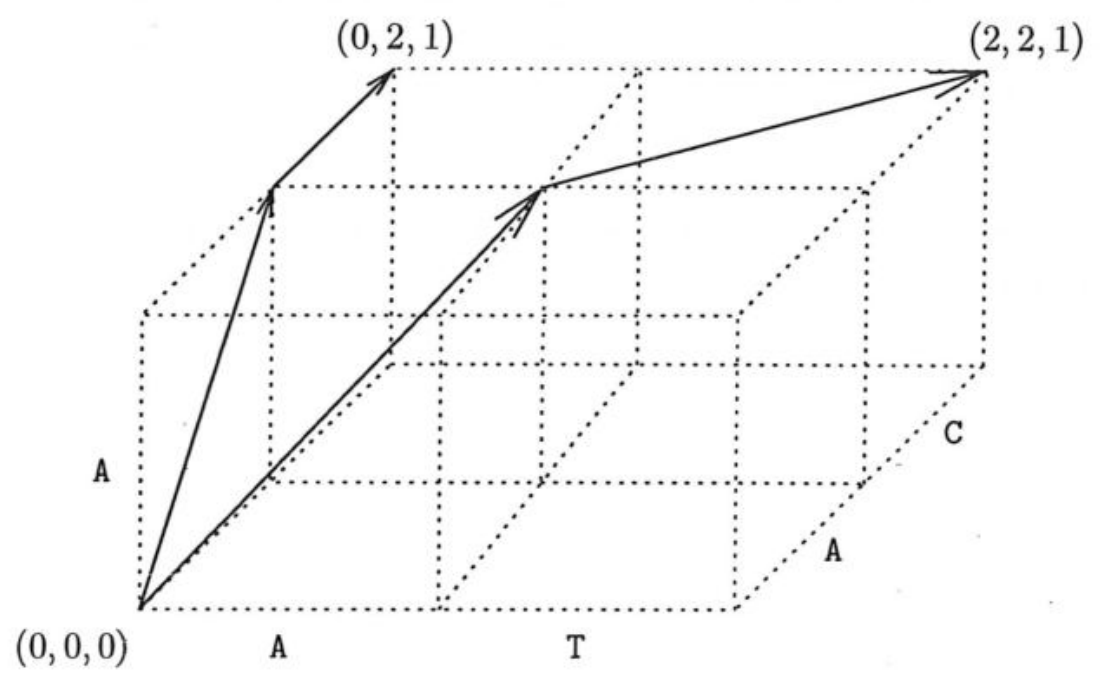

Figura 2.6: Um caminho associado ao alinhamento $A$ de $s_{1}, s_{2}$ e $s_{3}$ e a projeção do caminho na direção do plano $s_{2}$ e $s_{3}$.

Sejam $k \geq 2$ um inteiro e $s_{1}, \ldots, s_{k}$ seqüências sobre um alfabeto $\Sigma$. Dada uma função de pontuação de caracteres $c:\left(\Sigma^{\prime}\right)^{2} \rightarrow \mathbb{Q}_{\geq 0}$, fixemos a função de pontuação de coluna $\mathrm{SP}_{c}$, dada pela Fórmula (2.1). Para simplificar a notação, freqüentemente deixaremos a função $c$ subentendida, escrevendo apenas SP.

Em nossa discussão, se $s$ e $t$ são duas seqüências, $c(s, t)$ é o custo de um alinhamento ótimo entre essas duas seqüências (i.e., o custo de alinhamento ótimo do par de seqüências).

Seja $A$ um alinhamento qualquer de $s_{1}, \ldots, s_{k}$ e seja $A^{*}$ um alinhamento ótimo dessas seqüências. Por definição, como $A^{*}$ é ótimo, temos que $\mathrm{SP}\left(A^{*}\right) \leq \mathrm{SP}(A)$ e, pela Proposição 2.1, isso significa que $\sum_{i<j} c\left(A_{\mid i, j}^{*}\right) \leq \sum_{i<j} c\left(A_{\mid i, j}\right)$, onde $A_{\mid i, j}$ denota a 2-projeção do alinhamento $A$ na direção das seqüências $s_{i}$ e $s_{j}$.

Infelizmente, conforme ilustrado pela Figura 2.2 , o fato de $A^{*}$ ser ótimo não significa que $c\left(A_{\mid i, j}^{*}\right)=c\left(s_{i}, s_{j}\right)$ para todo par de seqüências $s_{i}, s_{j}$, uma vez que podemos ter $c\left(A_{\mid i, j}^{*}\right)>$ $c\left(s_{i}, s_{j}\right)$. O máximo que se pode afirmar é que $c\left(s_{i}, s_{j}\right) \leq c\left(A_{\mid i, j}^{*}\right)$, pois nenhum alinhamento de $s_{i}$ e $s_{j}$ pode ter custo menor do que $c\left(s_{i}, s_{j}\right)$.

Mas nem mesmo é possível afirmar que $c\left(A_{\mid i, j}^{*}\right) \leq c\left(A_{\mid i, j}\right)$, porque a desigualdade pode não valer para todo par de seqüências. É possível que ocorra que $c\left(A_{\mid i, j}\right)<c\left(A_{\mid i, j}^{*}\right)$, isto é, que a projeção de $A$ na direção de $s_{i}$ e $s_{j}$ seja melhor do que a projeção de $A^{*}$ nessa direção. Naturalmente, pela forma como a função SP é definida, não é possível que $A$ seja 
melhor do que $A^{*}$ em todas as direções, pois, nesse caso, $A^{*}$ teria pontuação maior do que a de $A$ e, com isso, $A^{*}$ não seria um alinhamento ótimo. Decorre disso o fato de que se alguma projeção de $A$ for melhor do que a projeção de $A^{*}$ naquela direção, então os custos das demais projeções de $A^{*}$ serão, no todo, menores do que os custos das projeções de $A$, uma "compensação" devido à hipótese de que $\mathrm{SP}\left(A^{*}\right) \leq \mathrm{SP}(A)$.

A discussão dos parágrafos acima significa, intuitivamente, que embora o custo de um alinhamento ótimo $A^{*}$ em alguma projeção possa não ser ótimo, este custo não pode estar "muito longe" do custo de uma projeção de um alinhamento $A$ que seja melhor nessa direção.

Sejam $s$ e $t$ duas seqüências quaisquer. Denotamos por melhor $_{s, t}(i, j)$ o custo do melhor alinhamento de $s$ e $t$ que tenha $(i, j)$ como corte, isto é,

$$
\underset{s, t}{\operatorname{melhor}}(i, j)=\min \left\{c(A): A \in \mathcal{A}_{s, t} \text { e } A \text { possui o corte }(i, j)\right\}
$$

onde $\mathcal{A}_{s, t}$ é o conjunto dos alinhamentos entre $s$ e $t$.

A idéia-chave do método de Carrillo-Lipman é estimar um limite superior digamos, $U_{i, j}$, para cada custo $c\left(A_{i, j}^{*}\right)$ (sendo que, naturalmente, $c\left(A_{\mid i, j}^{*}\right)$ é desconhecido). Se o caminho $P^{*}$ associado a $A^{*}$ passa pelo vértice $v^{*}=\left(v_{1}^{*}, \ldots, v_{k}^{*}\right)$, então a projeção $P_{\mid i, j}^{*}$ deste caminho na direção de $s_{i}$ e $s_{j}$ passa pelo vértice $\left(v_{i}^{*}, v_{j}^{*}\right)$.

Similarmente, se $A$ é um alinhamento qualquer entre as $k$ seqüências e o caminho de $A$ passa por $v=\left(v_{1}, \ldots, v_{k}\right)$, sua projeção na direção de $s_{i}$ e $s_{j}$ passa por $\left(v_{i}, v_{j}\right)$.

Se soubermos que, dentre os caminhos que passam por $\left(v_{i}, v_{j}\right)$, o de menor custo tiver custo maior do que o limite superior $U_{i, j}$ estimado para $c\left(A_{\mid i, j}^{*}\right)$, então sabemos que a projeção $P_{\mid i, j}^{*}$ não passa por $\left(v_{i}, v_{j}\right)$, o que significa que $P^{*}$ não passa por nenhum vértice do reticulado cuja $i$-ésima coordenada seja $v_{i}$ e cuja $j$-ésima coordenada seja $v_{j}$. As entradas da matriz de programação dinâmica correspondentes a esses vértices não precisam, portanto, de serem calculadas para determinar o alinhamento ótimo.

A determinação de melhor $_{s, t}(i, j)$ é relativamente simples. Seja $B$ um alinhamento ótimo de $s$ e $t$ que passe por $(i, j)$. Por um argumento similar ao usado na Seção 1.5.3 sobre a Propriedade das Subsoluções Ótimas do Problema APS, podemos ver que se $B=\left(B^{\prime}: B^{\prime \prime}\right)$, $\operatorname{com} B^{\prime}=\left(\begin{array}{c}s[1 \ldots i] \\ t[1 \ldots j]\end{array}\right)$ e $B^{\prime \prime}=\left(\begin{array}{c}s[i+1 \ldots m] \\ t[j+1 \ldots n]\end{array}\right)$, então $B^{\prime}$ é um alinhamento ótimo entre $s[1 \ldots i]$ e $t[1 \ldots j]$ e $B^{\prime \prime}$ é um alinhamento ótimo entre o restante dessas seqüências ${ }^{8}$. Ademais, o custo de $B^{\prime}$ pode ser facilmente calculado por uma chamada à função Dist definida no Capítulo 1 e o custo de $B^{\prime \prime}$ pode ser calculado por uma chamada a DisT-Rev. Se $a_{s, t}$ e $b_{s, t}$ são respectivamente as matrizes de programação dinâmica devolvidas pelas chamadas $\operatorname{Dist}(s, t)$ e Dist-Rev $(s, t)$, então melhor ${ }_{s, t}(i, j)$ pode ser calculado pela fórmula

$$
\operatorname{melhor}_{s, t}(i, j)=a_{s, t}[i, j]+b_{s, t}[i, j]
$$

para todo $i$ e $j$.

Os limites superiores $U_{i, j}$ podem ser calculados também de maneira simples. Para as seqüências $s_{1}, \ldots, s_{k}$, sejam $A^{*}$ um alinhamento ótimo e $A$ um alinhamento qualquer. Pela definição de $A^{*}$ temos que $\mathrm{SP}\left(A^{*}\right) \leq \mathrm{SP}(A)$, de onde segue, pela Proposição 2.1, que $\sum_{i<j} c\left(A_{\mid i, j}^{*}\right) \leq \sum_{i<j} c\left(A_{\mid i, j}\right)$.

Daí, para duas seqüências fixadas $s_{p}$ e $s_{q}$, com $p<q$, temos que

$$
c\left(A_{\mid p, q}^{*}\right)+\sum_{\substack{(i, j) \neq(p, q) \\ i<j}} c\left(A_{\mid i, j}^{*}\right) \leq c\left(A_{\mid p, q}\right)+\sum_{\substack{(i, j) \neq(p, q) \\ i<j}} c\left(A_{\mid i, j}\right),
$$

${ }^{8}$ Ou seja, $B$ possui o corte $(i, j)$. 
de onde segue que

$$
c\left(A_{\mid p, q}^{*}\right) \leq c\left(A_{\mid p, q}\right)+\sum_{\substack{(i, j) \neq(p, q) \\ i<j}} c\left(A_{\mid i, j}\right)-\sum_{\substack{(i, j) \neq(p, q) \\ i<j}} c\left(A_{\mid i, j}^{*}\right) .
$$

$\mathrm{Na}$ desigualdade acima, o lado direito da inequação poderia ser usado como limitante superior para o custo de uma projeção de $A^{*}$, se não fosse pelo fato de que ele envolve os custos de outras projeções de $A^{*}$, que são desconhecidos.

Pode-se contornar essa dificuldade usando-se que $c\left(s_{i}, s_{j}\right) \leq c\left(A_{\mid i, j}^{*}\right)$, de onde decorre, por soma membro a membro de todas as possibilidades para a inequação que

$$
\sum_{\substack{(i, j) \neq(p, q) \\ i<j}} c\left(s_{i}, s_{j}\right) \leq \sum_{\substack{(i, j) \neq(p, q) \\ i<j}} c\left(A_{\mid i, j}^{*}\right) .
$$

Daí,

$$
-\sum_{\substack{(i, j) \neq(p, q) \\ i<j}} c\left(A_{\mid i, j}^{*}\right) \leq-\sum_{\substack{(i, j) \neq(p, q) \\ i<j}} c\left(s_{i}, s_{j}\right)
$$

e então

$$
\begin{aligned}
c\left(A_{\mid p, q}^{*}\right) & \leq c\left(A_{\mid p, q}\right)+\left[\sum_{\substack{(i, j) \neq(p, q) \\
i<j}} c\left(A_{\mid i, j}\right)-\sum_{\substack{(i, j) \neq(p, q) \\
i<j}} c\left(A_{\mid i, j}^{*}\right)\right] \\
& \leq c\left(A_{\mid p, q}\right)+\left[\sum_{\substack{i, j) \neq(p, q) \\
i<j}} c\left(A_{\mid i, j}\right)-\sum_{\substack{i, j) \neq(p, q) \\
i<j}} c\left(s_{i}, s_{j}\right)\right] .
\end{aligned}
$$

Definindo $U=\sum_{i<j} c\left(A_{\mid i, j}\right)$ e $L=\sum_{i<j} c\left(s_{i}, s_{j}\right)$, a desigualdade (2.4) pode ser reescrita como

$$
\begin{aligned}
c\left(A_{\mid p, q}^{*}\right) & \leq\left[c\left(A_{\mid p, q}\right)+\sum_{\substack{(i, j) \neq(p, q) \\
i<j}} c\left(A_{\mid i, j}\right)\right]-\left[\sum_{\substack{(i, j) \neq(p, q) \\
i<j}} c\left(s_{i}, s_{j}\right)+c\left(s_{p}, s_{q}\right)-c\left(s_{p}, s_{q}\right)\right] \\
& =U-L+c\left(s_{p}, s_{q}\right) .
\end{aligned}
$$

Se definimos $C=U-L$, que é denominada a constante de Carrillo-Lipman para a instância do problema, temos finalmente (após uma mudança de índices) que

$$
c\left(s_{i}, s_{j}\right) \leq c\left(A_{\mid i, j}^{*}\right) \leq c\left(s_{i}, s_{j}\right)+C,
$$

para todo par $i, j$, onde $c\left(s_{i}, s_{j}\right)+C$ é o limitante superior desejado, que depende apenas do alinhamento $A$ e dos custos de alinhamentos ótimos entre as seqüências $s_{1}, \ldots, s_{k}$.

A inequação (2.5) nos diz que embora o custo de uma 2-projeção de um alinhamento ótimo não seja mínimo, ele está no intervalo entre o mínimo e mínimo mais uma constante, o que dá sentido à intuição de que o custo das 2-projeções não pode "estar muito longe" do mínimo. 
Para a obtenção do limite $C$ das inequações, um alinhamento $A$ qualquer foi usado para calcular $U$. Este alinhamento de $s_{1}, \ldots, s_{k}$ pode ser proveniente da aplicação de alguma heurística (como, por exemplo, os alinhamentos obtidos pelo programa Clustal ${ }^{9}$ ) ou de algum algoritmo de aproximação (como, por exemplo, os algoritmos vistos no Capítulo 4). $\mathrm{O}$ alinhamento ótimo $A^{*}$ obtido pelo método de Carrillo-Lipman pode ser interpretado nessas condições como um "refinamento" da solução $A$ obtida por algum outro método.

$\mathrm{Na}$ realidade, embora tenhamos usado um alinhamento para deduzir a inequação (2.5), tudo o que é usado a respeito dele é o seu custo e o alinhamento em si não é utilizado além do cálculo de $U$. Assim, o método de Carrillo-Lipman pode ser usado se dispusermos apenas de um limite superior $U$ no custo de um alinhamento ótimo $A^{*}$ (i.e., um limite $U$ tal que $\left.\mathrm{SP}\left(A^{*}\right) \leq U\right)$.

Apesar de qualquer limite superior poder ser usado no método de Carrillo-Lipman, limites superiores menores são preferidos, uma vez que a constante $C$ fica menor e, assim, o limite superior ditado pela desigualdade (2.5) significa que mais vértices do reticulado de programação dinâmica podem ser descartados.

Mas então, dado um vértice $v$ do reticulado, como decidir se $v$ é um vértice importante para calcular alinhamentos ótimos?

Se $v=\left(v_{1}, \ldots, v_{i}, \ldots, v_{j}, \ldots, v_{k}\right)$ é um vértice pertencente a um caminho associado a um alinhamento ótimo $A^{*}$, então se $i<j$, para as seqüências $s_{i}$ e $s_{j}$, sabemos que $c\left(s_{i}, s_{j}\right) \leq$ melhor $_{s_{i}, s_{j}}\left(v_{i}, v_{j}\right) \leq c\left(A_{\mid i, j}^{*}\right) \leq c\left(s_{i}, s_{j}\right)+C$, onde a primeira desigualdade segue do fato de $c\left(s_{i}, s_{j}\right)$ ser a melhor pontuação possível de alinhamentos de $s_{i}$ e $s_{j}$, a segunda segue do fato de melhor $s_{i}, s_{j}\left(v_{i}, v_{j}\right)$ ser a melhor pontuação possível dentre os alinhamentos de $s_{i}$ e $s_{j}$ que possuem o corte $\left(v_{i}, v_{j}\right)$ e a terceira segue da inequação (2.5). Como o par $(i, j)$ com $i<j$ é genérico, temos que se $v$ é um vértice no caminho ótimo entre as seqüências da entrada, vale que melhor $s_{i}, s_{j}\left(v_{i}, v_{j}\right) \leq c\left(s_{i}, s_{j}\right)+C$ para todas as 2-projeções de $v$.

Caso contrário, se houver um vértice $v$ para o qual existem $i$ e $j$ tais que $c\left(s_{i}, s_{j}\right)+C<$ melhor $_{s_{i}, s_{j}}\left(v_{i}, v_{j}\right)$, então todos os caminhos que passam por $v$ têm projeção na direção de $s_{i}$ e $s_{j}$ com custo maior do que o limite superior no custo da projeção do alinhamento ótimo e, portanto, sabe-se de antemão que o vértice $v$ não é corte de nenhum alinhamento ótimo e pode ser excluído do cálculo de programação dinâmica.

Isso motiva a definição de vértice relevante.

Definição 2.6 (Vértice Relevante). Um vértice $v=\left(v_{1}, \ldots, v_{i}, \ldots, v_{j}, \ldots, v_{k}\right)$ do reticulado de programação dinâmica é dito relevante para calcular um alinhamento ótimo se, para todo par $i, j$ com $1 \leq i<j \leq k$ tivermos que melhor $_{s_{i}, s_{j}}\left(v_{i}, v_{j}\right) \leq c\left(s_{i}, s_{j}\right)+C$.

Em resumo, apenas os vértices relevantes são aqueles que podem fazer parte de um caminho ótimo no reticulado.

Observe-se que não há problemas em restringir os cálculos aos vértices relevantes, uma vez que se $A^{*}$ for um alinhamento ótimo de $s_{1}, \ldots, s_{k}$ e $A$ for um alinhamento qualquer dessas seqüências com pontuação $c(A)=U$, então restringir o cálculo a um vértice relevante $v$ que seja corte de um alinhamento $A^{\prime}$ significa que melhor $s_{i}, s_{j}\left(v_{i}, v_{j}\right) \leq c\left(A_{\mid i, j}^{\prime}\right) \leq c\left(s_{i}, s_{j}\right)+C$ para todo $i<j$, ou seja,

$$
\sum_{i<j} \operatorname{melhor}_{s_{i}, s_{j}}\left(v_{i}, v_{j}\right) \leq \sum_{i<j} c\left(A_{\mid i, j}^{\prime}\right) \leq \sum_{i<j} s\left(s_{i}, s_{j}\right)+\sum_{i<j} C,
$$

\footnotetext{
${ }^{9}$ Disponível em http://www.ebi.ac.uk/clustalw/.
} 
isto é,

$$
c\left(A^{*}\right) \leq C\left(A^{\prime}\right) \leq L+\left(\begin{array}{l}
k \\
2
\end{array}\right) C .
$$

Como aplicamos o método de Carrillo-Lipman para $k \geq 2$ seqüências, sabemos que $\left(\begin{array}{l}k \\ 2\end{array}\right) \geq 1$ e daí é possível ver que o limite superior no custo dos alinhamentos que o método usa ao só verificar vértices relevantes é de pelo menos $L+1 C=L+(U-L)=U$, isto é, o limite superior conhecido no custo $c\left(A^{*}\right)$, o que significa que o método descarta com segurança os vértices do reticulado (de modo que se $U$ for realmente um limite superior no custo de um alinhamento ótimo, então um alinhamento ótimo poderá ser encontrado).

Da inequação (2.6) é possível ver que considerar a constante $C$ muito grande significa que o método de Carrillo-Lipman torna-se menos restritivo em relação aos alinhamentos que ele considera para encontrar o ótimo e, portanto, o método potencialmente emprega mais tempo se $C$ for maior.

De posse dos critérios para avaliar se uma entrada da matriz/vértice do reticulado é relevante para o cálculo do alinhamento ótimo, podemos dar alguns detalhes sobre um algoritmo que implemente o método.

\subsubsection{Algoritmo}

A idéia de usar o Algoritmo DisT-AVS e simplesmente fazer o teste de relevância para cada entrada de $a$ antes do cálculo de mínimo não é boa, porque o algoritmo continuaria percorrendo cada nó do reticulado, em vez de descartar aqueles que não são necessários. $\mathrm{O}$ ideal seria analisar na programação dinâmica apenas os vértices do reticulado que fossem relevantes para um caminho ótimo do vértice $\overrightarrow{0}$ ao vértice $\vec{n}$. Isso pode ser feito da seguinte maneira: começando pelo vértice de origem (que é relevante); analisamos quais são os vértices que dependem dele e que são relevantes e continuamos aplicando o processo a partir destes vértices que são relevantes, construindo assim uma "rede de relevância", até chegar ao vértice terminal do reticulado (que também é relevante).

Para auxiliar a manutenção do conjunto dos vértices relevantes a serem pesquisados, uma estrutura de dados como uma fila pode ser usada, com os vértices relevantes sendo incluídos na fila em ordem lexicográfica assim que forem descobertos. A idéia com a fila é que nela seriam mantidos todos os vértices que se descubra serem relevantes e que devem ser processados pelo algoritmo. O primeiro vértice da fila é o próximo vértice a ser processado (i.e., ter seu valor calculado e seus vértices dependentes determinados). Já sabemos que isso não interfere na corretude da busca por alinhamentos ótimos.

Ao serem retirados da fila, naturalmente, os vértices têm a ordem lexicográfica mantida e, conforme notamos na Proposição 2.2, processar os vértices em ordem lexicográfica garante que as entradas da matriz de programação dinâmica são preenchidas apenas quando todas as entradas de que elas dependem já tiverem sido completamente determinadas.

Observe-se que a fila mantém, é claro, a todo momento, apenas vértices relevantes.

Como a matriz a possui $(n+1)^{k}$ entradas, sua inicialização leva tempo $\Omega\left((n+1)^{k}\right)$ e só a inicialização é responsável por uma grande parcela do tempo do método. Na realidade, a inicialização de todas as células da matriz $a$ poderia até mesmo anular parte dos ganhos que se teria ao se restringir os cálculos de programação dinâmica apenas às células relevantes da matriz se muitas células de $a$ pudessem ser descartadas.

Felizmente, existe um truque de implementação muito útil e engenhoso que serve para simular o acesso a um vetor inicializado sem que a inicialização seja feita explicitamente antes de qualquer acesso. $\mathrm{O}$ truque funciona de forma a inicializar apenas aquelas entradas 
que sejam realmente necessárias [AHU74, Ben00]. O truque é útil para situações como o caso do Algoritmo DisT-CL em que é possível que nem todas as entradas de um vetor (no caso, a matriz a) sejam usadas.

O método para simular o acesso a um vetor inicializado $W$ de $n$ posições é feito usandose um vetor $W^{\prime}$ e uma pilha de apontadores $P$, ambos com o mesmo número $n$ de posições que $W$ possui.

O vetor $W^{\prime}$ é um vetor de pares de campos, onde o campo valor armazena a informação que é desejada (i.e., a informação que seria armazenada em uma posição de $W$ ) e o campo ponteiro aponta para uma posição da pilha de apontadores. O topo da pilha é denotado pela variável $T$ e as posições em uso na pilha são as posições $P[1 \ldots T]$. Os ponteiros armazenados na pilha $P$ são chamados ponteiros de volta (do inglês, backpointers). No início do uso da estrutura, $T=0$ (e $T$ é interpretado como o número de posições de $P$ que estão utilizadas). Veja a representação esquemática na Figura 2.7.

Para verificar se a posição $W^{\prime}[i]$ do vetor está em uso ${ }^{10}$ e, se estiver, para saber seu conteúdo, procede-se da maneira indicada na função ConsultaPos.

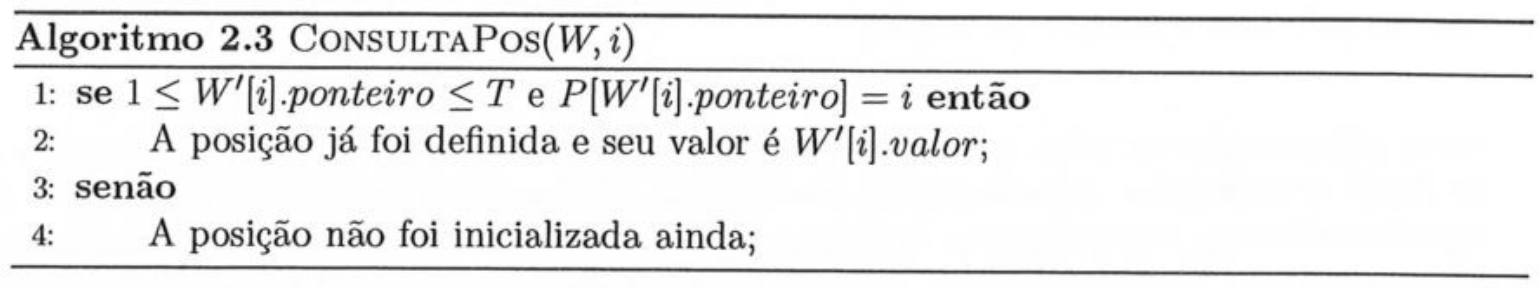

Já para inicializar a posição $i$ do vetor $W^{\prime}$ com o valor valor, pode-se usar o trecho de código da função InicializaPos. A função somente deve ser chamada com posições que estejam previamente não-inicializadas.

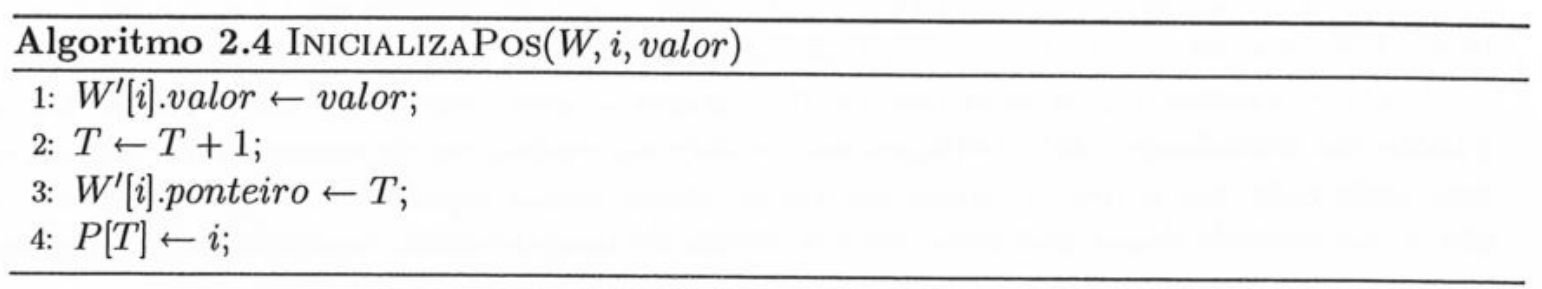

Se a posição $i$ do vetor já tiver sido inicializada, então a chamada ATrIBUIPos $(W, i$, valor $)$ pode ser usada para modificar o conteúdo da posição $i$ de $W^{\prime}$ para valor.

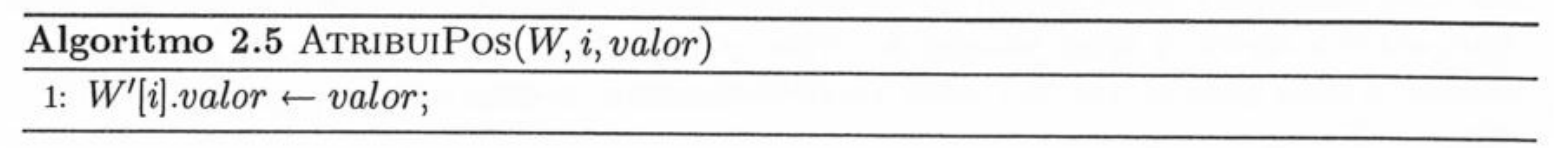

A corretude dessa estrutura de dados pode ser verificada por uma análise das possibilidades dos casos dos valores de $W^{\prime}[i]$.ponteiro e de $P\left[W^{\prime}[i]\right.$.ponteiro]. Veja a ilustração de casos na Figura 2.7.

É relativamente simples de verificar a corretude do funcionamento da estrutura de dados. É necessário verificar que ConsultaPos diz que uma posição está inicializada se e somente se a posição já tiver sido inicializada por INICIALIZAPos.

Se a função ConsultaPos diz que uma posição $i$ de $W^{\prime}$ está inicializada, então é porque $W^{\prime}[i]$.ponteiro contém um índice válido para a pilha $P$ e porque o ponteiro de

\footnotetext{
${ }^{10}$ Isto é, inicializada e com algum valor armazenado.
} 


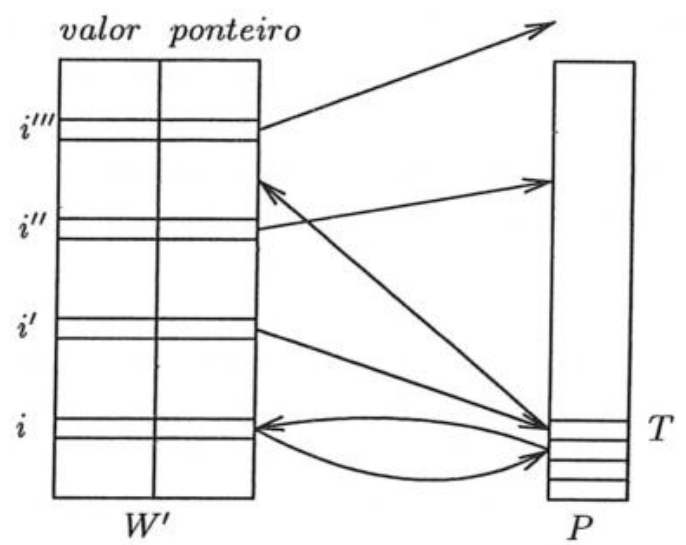

Figura 2.7: A posição $i$ é válida (inicializada) e o ponteiro $P\left[W^{\prime}[i]\right.$.ponteiro $]$ aponta para a posição $i$ de $W^{\prime}$. As outras posições (não inicializadas) podem ser detectadas porque seu campo ponteiro não aponta para uma posição de $P[1 \ldots T]$ ou porque o ponteiro "de volta" não aponta para a posição de origem.

volta armazenado na pilha aponta para a posição $i$ de $W^{\prime}$. Mas na pilha de ponteiros $P$ só ficam armazenados ponteiros para posições de $W^{\prime}$ que forem inicializados por meio de InICIALIZAPos e, naturalmente, nenhuma dessas posições é removida de $P$ por meio das funções (ou seja, "desinicializada"), porque $T$ nunca é decrementado. Logo, se $W^{\prime}[i]$.ponteiro contém uma posição válida da pilha e essa posição aponta para a posição $i$ de $W^{\prime}$, então a posição foi previamente inicializada com a função INICIALIZAPos ${ }^{11}$.

A verificação de que se uma posição tiver sido inicializada por INICIALIzAPos, então ConsultaPos diz que é posição está inicializada é trivial, porque esta é a condição que INICIALIZAPos estabelece e $T$ nunca é decrementado, de forma que a condição não muda.

É muito simples de verificar que tanto o acesso a uma posição da estrutura de dados quanto sua inicialização são operações que podem ser realizadas em espaço $O(1)$. Ademais, para cada valor que se deseja armazenar na estrutura, usa-se espaço $O(1)$ também, de forma que a estrutura de dados tem tanto complexidade de tempo quanto complexidade de espaço igual à de um vetor comum.

No caso de ser necessário representar um vetor multidimensional de $k$ dimensões, o método pode funcionar se as $k$ coordenadas de uma célula da matriz forem armazenadas em uma posição da pilha (sendo suficiente, portanto, tamanho $O(k)$ para representar essa posição) e o acesso a uma posição do vetor pode, então, ser realizada em tempo $O(k)$, enquanto uma posição em um vetor multidimensional comum ocupa espaço $O(1)$ e leva tempo $O(k)$ para ser acessada.

Após essa discussão, apresentamos o Algoritmo DisT-CL, que é um pseudo-código para o método de Carrillo-Lipman.

\subsubsection{Análise de Complexidade}

Para simplificar as análises, vamos adotar como convenção que todas as seqüências sendo alinhadas possuem tamanho igual a $n$. Os limites deduzidos aqui são facilmente adaptados se as seqüências não forem todas do mesmo tamanho.

\footnotetext{
${ }^{11}$ Estamos supondo que todos acessos à estrutura de dados sejam feitos por meio das funções dadas.
} 


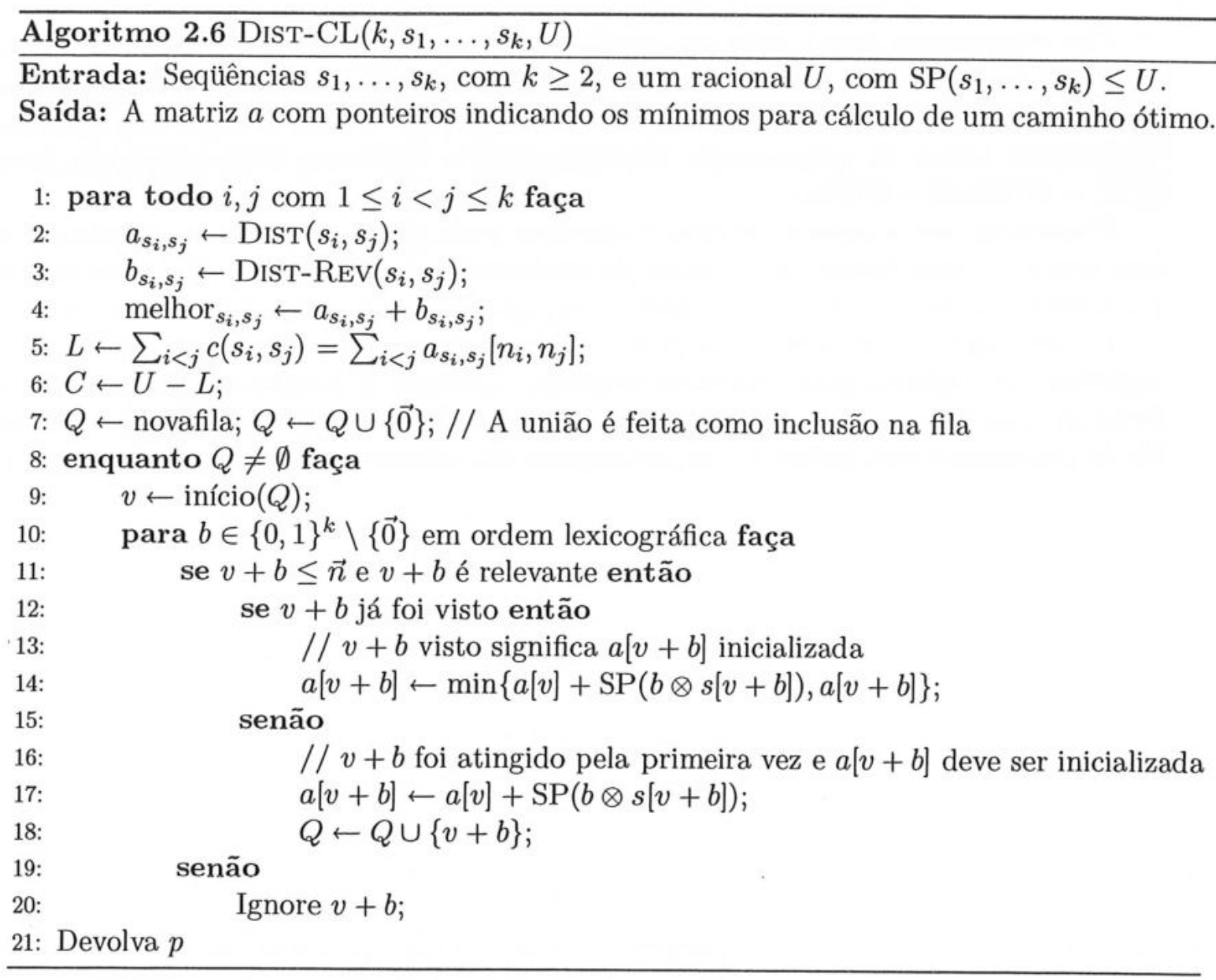

Embora o método de Carrillo-Lipman possa levar a uma redução de tempo para preencher a parte relevante da matriz $a$, não é possível fornecer garantias de que há sempre uma economia de tempo, já que o tempo depende do valor de $U$ passado para o algoritmo (i.e., de quão "longe" o alinhamento $A$ estiver de $A^{*}$ em termos de custo) e, de acordo com a desigualdade (2.6), o algoritmo pode não conseguir descartar muitos vértices se a constante $C$ ou se $k$ forem grandes.

O Algoritmo DiST-CL calcula as matrizes melhor $_{s_{i}, s_{j}}$ para cada par de seqüências da entrada. Cada matriz melhor $s_{i}, s_{j}$ pode ser computada como a soma das matrizes $a_{s_{i}, s_{j}} \mathrm{e}$ $b_{s_{i}, s_{j}}$ em tempo $O\left(n^{2}\right)$. Como existem $\left(\begin{array}{l}k \\ 2\end{array}\right)$ pares de seqüências, o tempo total para este pré-processamento é $\left(\begin{array}{c}k \\ 2\end{array}\right) O\left(n^{2}\right)=O\left(k^{2} n^{2}\right)$. As outras inicializações (cálculo de $L$ e de $C$ ) podem ser feitas em tempo total igual a $O\left(k^{2}\right)$.

O teste de relevância de uma entrada da matriz a pode ser feito também em tempo $O\left(k^{2}\right)$, pois, fixado um vértice $v$, verifica-se, para cada par $1 \leq i<j \leq k$, se melhor $s_{i}, s_{j}\left(v_{i}, v_{j}\right) \leq$ $s\left(s_{i}, s_{j}\right)+C=a_{s_{i}, s_{j}}[n, n]+C$. No pior caso, o algoritmo pode precisar visitar todos os $(n+1)^{k}$ vértices e, para cada vértice $v$, calcular a entrada $a[v]$. Isso significa que, essencialmente, o Algoritmo Dist-CL executa os passos do Algoritmo DisT-AVS, fazendo um passo adicional de verificar a relevância de cada entrada da matriz. Logo, o tempo gasto pelo algoritmo é $O\left(k^{2} n^{2}\right)+O\left((n+1)^{k} k^{2} 2^{k}\right)+O\left((n+1)^{k} k^{2}\right)=O\left((n+1)^{k} k^{2} 2^{k}\right)$, onde o primeiro termo corresponde ao pré-processamento, o segundo ao tempo de preencher todas as células da matriz $a$ e o terceiro, ao teste de relevância das $(n+1)^{k}$ entradas da matriz $a$. 
Um alinhamento ótimo pode ser obtido facilmente se durante os cálculos de mínimo do Algoritmo DisT-CL forem mantidos ponteiros para as posições que resultaram nos valores mínimos. Pode-se determinar o alinhamento em tempo linear, como feito para o algoritmo básico de programação dinâmica para o Problema AVS, isto é, em tempo $O(k l)=O(k(k n))=O\left(k^{2} n\right)$.

Finalmente, em relação ao espaço, o algoritmo pode preencher todas as entradas de $a$ e usar (como no caso básico de programação dinâmica), espaço $O\left((n+1)^{k}\right)$ e mais uma vez o comentário a respeito de complexidade de espaço feito para o algoritmo básico é válido.

É interessante notar a semelhança de funcionamento entre o Algoritmo DisT-CL e o Algoritmo de Dijkstra para caminhos mínimos, incluindo a coleção de nós mantida em forma de uma fila pelos algoritmos (no caso do Algoritmo de Dijkstra, a fila deve ser uma fila de prioridades para garantir o processamento dos vértices em ordem de seus rótulos). 


\section{Capítulo 3}

\section{Complexidade do Problema AVS}

"This solution is gloriously non-deterministic." - E. W. Dijkstra (1930-2002)

\subsection{Introdução}

Nos capítulos anteriores, nossa atenção esteve principalmente voltada para o desenvolvimento e análise de algoritmos para encontrar alinhamentos ótimos. Embora os algoritmos desenvolvidos tenham complexidade polinomial para qualquer número fixado de seqüências, eles tornam-se pouco práticos até mesmo para um pequeno número de sequêencias (dependendo das instâncias a serem resolvidas), ainda que métodos para economia de espaço e de tempo (como o de Carrillo-Lipman) sejam usados [Fue97, GKS95].

Infelizmente, não se conhecem algoritmos ou técnicas que sirvam para resolver os Problemas APS e AVS de maneira exata (isto é, que encontrem alinhamentos que minimizem suas respectivas funções objetivo) e em toda sua generalidade com complexidades de espaço e de tempo de pior caso assintoticamente menores do que as dos algoritmos que já vimos.

É claro que exceção deve ser feita ao considerarmos versões mais restritas dos problemas, que são casos em que pode haver algoritmos que resolvam tais versões em tempo ou espaço menores do que os algoritmos mais gerais.

Há ainda outra classe de algoritmos para os problemas de alinhamentos. Um exemplo de um algoritmo para o Problema APS que opera com complexidade de pior caso igual à dos algoritmos de programação dinâmica, mas que pode requerer menos recursos para grande parte das instâncias é o algoritmo proposto em 1983 por Ukkonen para o problema de alinhar pares de sequiências em que a distância de edição é a função objetivo. O algoritmo tem complexidade de tempo igual a $O(d(s, t) \cdot \min (|s|,|t|))$ e complexidade de espaço igual a $O\left(d(s, t)^{2}\right)$ para encontrar um alinhamento ótimo entre duas seqüências $s$ e $t$. No pior caso, a distância entre duas seqüências de tamanho $n$ é $\Theta(n)$ e este algoritmo exibe também o comportamento quadrático de tempo e espaço do algoritmo básico de programação dinâmica para o Problema APS, embora ele possa ser melhor em situações em que as seqüências sejam "próximas". Se apenas a distância de edição entre as seqüências for desejada, a complexidade de espaço do Algoritmo de Ukkonen pode ser reduzida para $O(d(s, t))$ [Ukk83, Ukk85].

A complexidade de tempo do algoritmo básico de programação dinâmica (inclusive no caso multidimensional) e a necessidade de encontrar rapidamente "bons" alinhamentos para 
aplicações práticas de Biologia levaram ao projeto e uso de algoritmos e heurísticas que não necessariamente encontram alinhamentos ótimos para todas instâncias do problema, mas que rodam em tempo "aceitável na prática" e que devolvem "respostas razoáveis".

Cabe aqui reiterar o comentário de que a modelagem do problema de encontrar alinhamentos não captura todos os aspectos biologicamente significativos (como, por exemplo, similaridades de estruturas secundárias de seqüências de RNA e mutações compensatórias), sendo a modelagem matemática uma simplificação da situação encontrada na prática. Na realidade, até mesmo programas ${ }^{1}$ que empregam várias heurísticas para obter as respostas parecem não satisfazer em vários casos às necessidades que surgem em Biologia e os alinhamentos produzidos como resposta são geralmente inspecionados e modificados manualmente antes do uso. A expressão "respostas razoáveis" deve ser, portanto, interpretada de acordo [HSP00].

Toda a dificuldade em obter algoritmos rápidos para encontrar alinhamentos obviamente nos conduz à pergunta de se é possível, de fato, desenvolver algoritmos que sejam rápidos (mais precisamente, de tempo de execução polinomial no tamanho da entrada) para o Problema AVS. Uma questão um pouco mais ambiciosa é descobrir não apenas se é ou não possível projetar um algoritmo de tempo polinomial para o problema, mas de descobrir quais são os recursos de tempo necessários para um algoritmo qualquer que o resolva.

Embora não saibamos responder às perguntas acima de maneira direta (à semelhança de muitos outros casos, conforme exposto por Garey e Johnson [GJ79, Capítulo 1]), podese mostrar que para uma ampla classe de instâncias, o Problema AVS é pelo menos tão difícil, em termos de complexidade de tempo, quanto outros problemas combinatórios, no sentido de que se houver um algoritmo que resolva o Problema AVS em tempo polinomial para qualquer entrada, então cada um dos problemas de uma grande classe, a classe dos Problemas NP, também admitirá um algoritmo de tempo polinomial.

O presente capítulo possui natureza diferente dos capítulos anteriores: enquanto lá estivemos preocupados com o desenvolvimento de algoritmos, aqui o foco é o problema de alinhamentos em si de uma maneira mais geral e abstrata, independente de quais são os algoritmos usados para resolvê-lo. Nosso objetivo é mostrar a relação entre o Problema AVS e os problemas mais difíceis da classe NP de problemas de decisão, os problemas NP-completos.

Para o estudo da intratabilidade computacional de problemas, é conveniente fazer distinção entre os problemas que podem e os que não podem ser resolvidos por algoritmos de tempo polinomial. Dizemos que um algoritmo que usa tempo polinomial no tamanho de sua entrada é um algoritmo polinomial. Caso a complexidade de tempo de um algoritmo não possa ser limitada por um polinômio, o algoritmo é dito exponencial ${ }^{2}$. Os problemas que admitem um algoritmo polinomial que os resolva são ditos problemas de solução eficiente ou que podem ser resolvidos eficientemente. Caso um problema não admita um algoritmo polinomial, ele é dito um problema intratável. Nesse sentido, a polinomialidade de soluções para um dado problema funciona como o limite para distinguir problemas "fáceis" de problemas "difíceis".

Uma idéia central para estudar a complexidade de problemas é a idéia de redução. Intuitivamente, um problema $\Pi$ reduz-se a um problema $\Pi^{\prime}$ se for possível resolver o problema $\Pi$

\footnotetext{
${ }^{1}$ Como é o caso do Clustal W.

${ }^{2}$ É importante ressaltar que essa nomenclatura, apesar de tradicional, é incorreta, uma vez que se um algoritmo tiver complexidade de tempo superpolinomial, mas subexponencial (como é o caso da função $\left.n^{\log n}=e^{\log ^{2} n}=o\left(e^{n}\right)\right)$ ele será ainda assim chamado de exponencial.
} 
usando-se algum algoritmo que resolva $\Pi^{\prime}$, isto é, se for possível "adaptar" um algoritmo que resolva o problema $\Pi^{\prime}$ para resolver também o problema $\Pi$, de maneira que o problema $\Pi$ possa ser observado como um caso particular do problema $\Pi^{\prime}$, após uma "tradução" (que é a redução). Para efeito do estudo de complexidade dos problemas, queremos que as reduções sejam também algoritmos polinomiais. Dizemos que uma redução cuja complexidade de tempo é limitada superiormente por um polinômio é uma redução polinomial.

Uma classe muito grande de problemas ocupa uma posição de destaque em Ciência da Computação, a classe dos já mencionados problemas NP-completos. Para esses problemas, não se conhecem algoritmos eficientes, mas também não se conhecem provas de que eles sejam intratáveis. De qualquer maneira, esses problemas compartilham a curiosa característica de que todos problemas NP-completos são redutíveis em tempo polinomial a todos outros problemas da classe, o que significa que se um desses problemas puder ser resolvido em tempo polinomial, então todos os demais problemas da classe também poderão e, portanto, em relação à intratabilidade, todos eles são "iguais". Pelo motivo de um grande número de importantes problemas pertencer a esta classe, por terem todos eles essencialmente "a mesma" dificuldade (no sentido de intratabilidade) e por nenhum algoritmo polinomial ser conhecido para nenhum destes problemas (ainda que nenhuma prova de sua complexidade inerente seja conhecida), o máximo que se pode dizer a respeito de tais problemas é que eles são aparentemente intratáveis ${ }^{3}$ [GJ79].

A primeira demonstração de dificuldade (no sentido de NP-completude) do Problema AVS foi publicada em 1994 por Wang e Jiang [WJ94]. A demonstração apresentada naquele artigo, apesar de concisa, restringe-se ao caso de pontuação SP em que a matriz de pontuação não é uma métrica (a matriz atribui pontuação não-nula a pares de caracteres iguais).

Em 2001, Bonizzoni e Vedova mostraram que o Problema AVS, em sua versão de decisão, é NP-completo também para uma matriz de pontuação que satisfaz aos axiomas de métrica [BV01], que era uma questão em aberto até então. Em um artigo posterior [Jus01], Winfried Just mostrou que o problema de alinhar seqüências é NP-difícil para uma ampla classe de matrizes de pontuação (que inclui as matrizes do artigo de Bonizzoni e Vedova). No mesmo artigo, Just mostrou também que existe uma matriz de pontuação para a qual o Problema AVS é MAXSNP-difícil. Essa matriz, no entanto, não é uma métrica (ela atribui pontuação 0 a caracteres diferentes do alfabeto).

Uma questão em aberto sobre o Problema AVS diz respeito ao fato de o problema ser ou não MAXSNP-difícil para matrizes que sejam métricas. Na realidade, não se sabe se o Problema AVS é MAXSNP-difícil para matrizes de pontuação que tenham elementos nulos na diagonal principal e diferentes de zero fora da diagonal, mesmo que a matriz não seja uma métrica [Jus01, Jus02].

Neste capítulo, apresentamos a demonstração de Wang e Jiang, que é simples e estabelece a relação do problema de alinhar seqüências com outro problema que envolve seqüências de caracteres (além de ter sido a primeira demonstração de complexidade do Problema AVS) e a linha geral das várias demonstrações de complexidade do Problema AVS (e de versões mais restritas do problema) e aproximabilidade apresentadas por Just.

Para nossa discussão, supomos que o leitor esteja familiarizado com conceitos básicos de Teoria de Complexidade de Algoritmos. A notação adotada é padrão e pode ser encontrada em diversos livros-texto comuns sobre algoritmos como em [CLR90, Capítulo 36] ou [GJ79].

\footnotetext{
${ }^{3}$ Muitos pesquisadores acreditam que tais problemas necessitam, realmente, de algoritmos exponenciais para serem resolvidos.
} 


\subsection{O Problema AVS é NP-difícil (Wang e Jiang)}

A demonstração de Wang e Jiang de que o Problema AVS é NP-difícil considera a versão de decisão do problema e mostra, efetivamente, que a versão de decisão do Problema AVS é NP-completa e que, portanto, a versão de otimização é NP-difícil. Formalmente, a versão de decisão do Problema AVS é a seguinte:

Problema 3.1 (Problema AVS, versão de decisão). Dadas $k$ seqüências $s_{1}, \ldots, s_{k} e$ dado um inteiro $C$, decidir se existe um alinhamento das seqüências com custo menor ou igual a $C$.

A demonstração dada por Wang e Jiang é feita reduzindo-se o Problema da Superseqüência Comum de Menor Comprimento (em inglês, Shortest Common Supersequence, que abreviamos aqui por SC-Mín) ao Problema AVS.

Para estabelecermos formalmente o Problema SC-Mín, precisamos de uma definição. Dadas $k$ seqüências $s_{1}, \ldots, s_{k}$ sobre um alfabeto $\Sigma$, dizemos que uma seqüência $s \in \Sigma^{*}$ é uma superseqüência de $s_{1}, \ldots, s_{k}$ se, para cada cada seqüênçia $s_{i}=s_{i}[1] \cdots s_{i}\left[n_{i}\right]$, existirem palavras $w_{0}, \ldots, w_{n_{i}} \in \Sigma^{*}$ tais que $s$ seja da forma $s=w_{0} s_{i}[1] w_{1} \ldots s_{i}\left[n_{i}\right] w_{n_{i}}$. Aqui, o comprimento da seqüência $s_{i}$ é $n_{i}=\left|s_{i}\right|$, para $i=1, \ldots, k$. Em palavras, esta definição significa que $s$ é uma superseqüência de $s_{1}, \ldots, s_{k}$ se $s$ contiver cada $s_{i}$ (onde, possivelmente, os caracteres de $s_{i}$ estão espaçados em $s$ por caracteres do alfabeto).

O Problema da Superseqüência Comum de Menor Comprimento pode ser enunciado como $^{4}$ :

Problema 3.2 (Problema SC-Mín, versão de decisão). Dadas $k$ seqüências $s_{1}, \ldots, s_{k}$ $e$ dado um inteiro $L$, decidir se existe uma superseqüência $s$ de $s_{1}, \ldots, s_{k}$ com comprimento no máximo $L$.

O Problema SC-Mín é um problema NP-completo [GJ79] e, para mostrar que o Problema AVS também é NP-completo, basta mostrar uma redução de tempo polinomial do Problema SC-Mín ao Problema AVS, uma vez que, como SC-Mín é NP-completo, todo problema da classe NP reduz-se polinomialmente também a AVS.

Antes de darmos a redução, observemos que:

- se $L<\max \left\{n_{i}\right\}$, a resposta ao SC-Mín é NÃo, uma vez que toda superseqüência $s$ tem comprimento no mínimo igual ao comprimento das seqüências $s_{i}$, isto é, não existe superseqüência de $s_{1}, \ldots, s_{k}$ de comprimento menor que o comprimento da seqüência mais longa;

- se $L \geq \sum n_{i}$, a resposta ao SC-Mín é Sim, uma vez que a seqüência $s=s_{1} s_{2} \cdots s_{k}$, igual à concatenação das seqüências de entrada, é, naturalmente, uma supersequiência das seqüências de entrada e seu comprimento é menor ou igual a $L$.

Assim, para a redução, podemos supor que o inteiro $L$ é tal que $\max \left\{n_{i}\right\} \leq L \leq \sum n_{i}$. Essa hipótese é necessária para que a redução possa ser feita em tempo polinomial. E fácil ver que um algoritmo de redução pode decidir se essa hipótese a respeito de $L$ é válida ou não em tempo linear no tamanho da entrada.

A redução propriamente dita é feita tomando-se uma instância do Problema SC-MíN com $k$ seqüências $S=\left\{s_{1}, \ldots, s_{k}\right\}$ sobre o alfabeto $\{0,1\}$ e um inteiro $L$ (de acordo com

\footnotetext{
${ }^{4}$ Compare com o Problema SC-MÁx, definido no Capítulo 1.
} 
a hipótese acima) e construindo-se $L+1$ instâncias para o Problema AVS. Para facilitar a discussão, definimos como $\|S\|$ o comprimento total das seqüências do multiconjunto $S$, isto é $\|S\|=\sum n_{i}$. Como abuso de linguagem, vamos nos referir ao multiconjunto $S$ como conjunto $S$ apenas.

A $j$-ésima instância do Problema AVS, para $j=0, \ldots, L$, construída a partir da instância do Problema SC-Mín, é dada pelo conjunto de seqüências $S_{j}=S \cup\left\{a^{j}, b^{L-j}\right\}$ e pelo inteiro $C=k\|S\|+(k+1) L$, onde os caracteres $a$ e $b$ são caracteres novos que não pertencem ao alfabeto binário $\{0,1\}$ sobre o qual as seqüências $s_{i}$ são descritas.

A matriz de pontuação $c$ usada para o Problema AVS é:

\begin{tabular}{c|ccccc} 
& 0 & 1 & $a$ & $b$ & ப \\
\hline 0 & 2 & 2 & 1 & 2 & 1 \\
1 & 2 & 2 & 2 & 1 & 1 \\
$a$ & 1 & 2 & 0 & 2 & 1 \\
$b$ & 2 & 1 & 2 & 0 & 1 \\
$\sqcup$ & 1 & 1 & 1 & 1 & 0
\end{tabular}

É importante notar que a matriz $c$, embora simétrica, não satisfaz aos axiomas de métrica pois, por exemplo, $c(0,0)=2>0$.

Cada instância $\left(S_{j}, C\right)$ do Problema AVS possui duas seqüências extras $\left(a^{j}\right.$ e $\left.b^{L-j}\right)$ em relação à instância de SC-Mín e estas duas sequiências juntas possuem comprimento igual a $L$. A concatenação das duas seqüências pode ser interpretada como uma escrita em unário do inteiro $L$. Entretanto, por nossa hipótese de que $L \leq\|S\|$, isso não apresenta um problema à polinomialidade do tamanho de cada instância do Problema AVS (ou mesmo do número de instâncias geradas pela redução, que é $L+1$ ), nem à polinomialidade do número de passos realizados pela redução.

Definido como a redução produz as instâncias do Problema AVS, passamos agora a verificar que a redução mapeia instâncias do Problema SC-Mín cuja resposta é Sim a um conjunto de instâncias para o qual a resposta ao Problema AVS é Sı a pelo menos uma instância e vice-versa. Mais especificamente, vamos mostrar que uma instância $\left(S=\left\{s_{i}\right\}, L\right)$ nas condições acima admite uma superseqüência $s$ de comprimento $L$ se e somente se alguma instância $\left(S_{j}=S \cup\left\{a^{j}, b^{L-j}\right\}, C\right)$ admite um alinhamento com custo no máximo $C$. Disso seguirá o fato de que o Problema AVS com pontuação SP é NP-completo.

Antes da demonstração, entretanto, dependemos de alguns fatos auxiliares.

Lema 3.1 (Pontuação Constante). Seja $A$ um alinhamento das $k+2$ seqüências de $S_{j}$, para algum $j$ em $\{0, \ldots, L\}$. Então, a pontuação do alinhamento $A_{\mid S}$, o alinhamento induzido em $S$ por $A$, é igual a $(k-1)\|S\|$.

Prova: A prova é feita observando-se a pontuação de uma coluna qualquer do alinhamento $A_{\mid S}$. Fixemos uma coluna $\mathcal{C}$ de $A_{\mid S}$. Cada coluna de $A_{\mid S}$ possui $k$ linhas. Em $\mathcal{C}$ não estão presentes caracteres $a$ 's ou $b$ 's, por hipótese, o que significa que os únicos caracteres possivelmente presentes são 0's, 1's ou u's. Suponhamos que $\mathcal{C}$ tenha $r_{0}$ caracteres 0 's, $r_{1}$ 
caracteres 1's e $r_{\sqcup}=k-\left(r_{0}+r_{1}\right)$ caracteres ப's. Sua pontuação SP é igual a

$$
\begin{aligned}
c(\mathcal{C}) & =\left(\begin{array}{c}
r_{0} \\
2
\end{array}\right) c(0,0)+\left(\begin{array}{c}
r_{1} \\
2
\end{array}\right) c(1,1)+\left(\begin{array}{c}
r_{\sqcup} \\
2
\end{array}\right) c(\sqcup, \sqcup)+r_{0} r_{1} c(0,1)+r_{0} r_{\sqcup} c(0, \sqcup)+r_{1} r_{\sqcup} c(1, \sqcup) \\
& =r_{0}\left(r_{0}-1\right)+r_{1}\left(r_{1}-1\right)+2 r_{0} r_{1}+r_{0} r_{\sqcup}+r_{1} r_{\sqcup} \\
& =r_{0}^{2}-r_{0}+r_{1}^{2}-r_{1}+2 r_{0} r_{1}+r_{0} r_{\sqcup}+r_{1} r_{\sqcup} \\
& =\left(r_{0}^{2}+2 r_{0} r_{1}+r_{1}^{2}\right)-\left(r_{0}+r_{1}\right)+r_{\sqcup}\left(r_{0}+r_{1}\right) \\
& =\left(r_{0}+r_{1}\right)^{2}-\left(r_{0}+r_{1}\right)+r_{\sqcup}\left(r_{0}+r_{1}\right) \\
& =\left(r_{0}+r_{1}+r_{\sqcup}-1\right)\left(r_{0}+r_{1}\right) \\
& =(k-1)\left(r_{0}+r_{1}\right) .
\end{aligned}
$$

Logo, a pontuação de uma coluna qualquer de $A_{\mid S}$ é proporcional (com fator de proporcionalidade $k-1$ ) ao número de caracteres de $s_{1}, \ldots, s_{k}$ que estão presentes naquela coluna.

Somando-se as pontuações de todas as colunas, concluímos que a pontuação SP de $A_{\mid S}$ é igual a $(k-1)\|S\|$, uma vez que existem $\|S\|$ caracteres de $s_{1}, \ldots, s_{k}$ em $A_{\mid S}$, de onde segue o resultado enunciado no lema.

Lema 3.2 (Desmembramento de Colunas). Seja $j$ um inteiro fixado entre 0 e $L$ (inclusive) e seja $A$ um alinhamento das seqüências de $S_{j}$. Então existe um alinhamento $A^{\prime}$ de $S_{j}$ de mesma pontuação que $A$ e tal que, em $A^{\prime}$, todas as colunas contenham só caracteres u's, 0's e a's ou só caracteres ч's, 1's e b's.

Prova: Para a demonstração do lema, mostraremos uma operação que chamaremos desmembramento de coluna, que pode ser aplicada às colunas de $A$ que não forem de uma das formas desejadas (isto é, cujos caracteres não sejam apenas u's, 0's e $a$ 's ou u's, 1's e $b$ 's) para obtermos um novo alinhamento em que o número de colunas indesejadas seja 1 a menos do que em $A$ e cuja pontuação seja igual à de $A$. Com a repetição desse processo até que todas colunas sejam de uma das formas desejadas, obtemos o alinhamento $A^{\prime}$ procurado.

A operação de desmembramento de coluna é feita da seguinte forma: seja $\mathcal{C}$ uma coluna genérica de $A$ que contenha uma certa quantidade de caracteres s's, 0 's, 1's, $a$ 's e $b$ 's. A partir dessa coluna, definimos duas outras colunas, $\mathcal{C}^{\prime}$ e $\mathcal{C}^{\prime \prime}$, de forma que $\mathcal{C}^{\prime}$ contenha 0 's nas linhas em que $\mathcal{C}$ tinha 0 's, $a$ 's onde $\mathcal{C}$ tinha $a$ 's e u's nas linhas em que $\mathcal{C}$ tinha u's, 1 's ou $b$ 's. A coluna $\mathcal{C}$ " é definida de maneira "complementar", tendo 1's nas linhas em que $\mathcal{C}$ tinha 1 's, $b$ 's onde $\mathcal{C}$ tinha $b$ 's e u's onde $\mathcal{C}$ tinha u's, 0 's ou $a$ 's. O alinhamento após a operação de desmembramento da coluna é o alinhamento $A$ com a coluna $\mathcal{C}$ substituída pelo par de colunas $\mathcal{C}^{\prime}$ e $\mathcal{C}^{\prime \prime}$.

Vejamos agora que o novo alinhamento possui a mesma pontuação que o alinhamento original $A$ : como as únicas colunas que foram envolvidas no processo de desmembramento são $\mathcal{C}, \mathcal{C}^{\prime}$ e $\mathcal{C}^{\prime \prime}$, as outras colunas permanecem com sua pontuação inalterada e podem ser ignoradas no cálculo da variação da pontuação.

Vamos supor que a coluna $\mathcal{C}$ tivesse $r_{0}$ caracteres $0, r_{1}$ caracteres $1, r_{\sqcup}$ caracteres $\sqcup, r_{a}$ caracteres $a$ e $r_{b}$ caracteres $b$. Observe-se que tanto $r_{a}$ quanto $r_{b}$ são, no máximo, 1 e que, portanto, não é possível que uma coluna tenha um par $a-a$ ou $b-b$ alinhados, embora seja possível que ela tenha um par $a-b$. 
O custo da coluna $\mathcal{C}$ é

$$
\begin{aligned}
c(\mathcal{C})= & \left(\begin{array}{c}
r_{0} \\
2
\end{array}\right) c(0,0)+\left(\begin{array}{c}
r_{1} \\
2
\end{array}\right) c(1,1)+\left(\begin{array}{c}
r_{\sqcup} \\
2
\end{array}\right) c(\sqcup, \sqcup)+\left(\begin{array}{c}
r_{a} \\
2
\end{array}\right) c(a, a)+\left(\begin{array}{c}
r_{b} \\
2
\end{array}\right) c(b, b)+ \\
& \left(r_{0} r_{1} c(0,1)+r_{0} r_{\sqcup} c(0, \sqcup)+r_{0} r_{a} c(0, a)+r_{0} r_{b} c(0, b)\right)+ \\
& \left(r_{1} r_{\sqcup} c(1, \sqcup)+r_{1} r_{a} c(1, a)+r_{1} r_{b} c(1, b)\right)+\left(r_{\sqcup} r_{a} c(a, \sqcup)+r_{\sqcup} r_{b} c(b, \sqcup)\right)+r_{a} r_{b} c(a, b) \\
= & 2\left(\begin{array}{c}
r_{0} \\
2
\end{array}\right)+2\left(\begin{array}{c}
r_{1} \\
2
\end{array}\right)+2 r_{0} r_{1}+r_{0} r_{\sqcup}+r_{0} r_{a}+2 r_{0} r_{b}+ \\
& r_{1} r_{\sqcup}+2 r_{1} r_{a}+r_{1} r_{b}+r_{\sqcup} r_{a}+r_{\sqcup} r_{b}+2 r_{a} r_{b} \\
= & 2\left(\begin{array}{c}
r_{0} \\
2
\end{array}\right)+2\left(\begin{array}{c}
r_{1} \\
2
\end{array}\right)+r_{0}\left(2 r_{1}+r_{\sqcup}+r_{a}+2 r_{b}\right)+r_{1}\left(r_{\sqcup}+2 r_{a}+r_{b}\right)+r_{\sqcup}\left(r_{a}+r_{b}\right)+2 r_{a} r_{b} .
\end{aligned}
$$

Na expansão acima, usamos os fatos de que $c(\sqcup, \sqcup)=0$ e que $\left(\begin{array}{c}r_{a} \\ 2\end{array}\right)=\left(\begin{array}{c}r_{b} \\ 2\end{array}\right)=0$. De maneira similar, o custo da coluna $\mathcal{C}^{\prime}$ é

$$
\begin{aligned}
c\left(\mathcal{C}^{\prime}\right)= & \left(\begin{array}{c}
r_{0} \\
2
\end{array}\right) c(0,0)+\left(\begin{array}{c}
r_{\sqcup}+r_{1}+r_{b} \\
2
\end{array}\right) c(\sqcup, \sqcup)+\left(\begin{array}{c}
r_{a} \\
2
\end{array}\right) c(a, a)+ \\
& r_{0}\left(r_{1}+r_{\sqcup}+r_{b}\right) c(0, \sqcup)+r_{0} r_{a} c(0, a)+\left(r_{1}+r_{\sqcup}+r_{b}\right) r_{a} c(a, \sqcup) \\
= & 2\left(\begin{array}{c}
r_{0} \\
2
\end{array}\right)+r_{0}\left(r_{1}+r_{\sqcup}+r_{b}\right)+r_{0} r_{a}+\left(r_{1}+r_{\sqcup}+r_{b}\right) r_{a} \\
= & 2\left(\begin{array}{c}
r_{0} \\
2
\end{array}\right)+r_{0}\left(r_{1}+r_{\sqcup}+r_{a}+r_{b}\right)+r_{1} r_{a}+r_{\sqcup} r_{a}+r_{a} r_{b},
\end{aligned}
$$

uma vez que a coluna $\mathcal{C}^{\prime}$ possui $r_{\mathrm{L}}+r_{1}+r_{b}$ caracteres ${ }^{\prime}$ 's. Analogamente ao caso de $\mathcal{C}^{\prime}$, o custo da coluna $\mathcal{C}^{\prime \prime}$ é

$$
c\left(\mathcal{C}^{\prime \prime}\right)=2\left(\begin{array}{c}
r_{1} \\
2
\end{array}\right)+r_{0}\left(r_{1}+r_{b}\right)+r_{1}\left(r_{\sqcup}+r_{a}+r_{b}\right)+r_{\sqcup} r_{b}+r_{a} r_{b}
$$

Logo, podemos ver facilmente que $c(\mathcal{C})=c\left(\mathcal{C}^{\prime}\right)+c\left(\mathcal{C}^{\prime \prime}\right)$ e que, portanto, podemos substituir a coluna $\mathcal{C}$ pelo par de colunas $\left(\mathcal{C}^{\prime}, \mathcal{C}^{\prime \prime}\right)$ em $A$ e obter um novo alinhamento de mesma . pontuação.

Repetindo-se o desmembramento de colunas para as colunas de $A$ que não estiverem no formato desejado, podemos concluir que existe um alinhamento $A^{\prime}$ cujas colunas são compostas apenas por u's, 0's e $a$ 's ou apenas por u's, 1's e $b$ 's e que possui a mesma pontuação que o alinhamento $A$ original, conforme desejado.

Lema 3.3. Seja $A$ um alinhamento de $S_{j}=S \cup\left\{a^{j}, b^{L-j}\right\}$ cujas colunas contenham apenas caracteres 0's, a's $e$ u's ou apenas caracteres 1's, b's $e$ ப's. Então, a contribuição das seqüências $a^{j}$ e $b^{L-j}$ à pontuação $\mathrm{SP}$ de $A$ é $\|S\|+(k+1) L+q$, onde $q$ é o número de caracteres 0 's e 1 's que não estão em colunas com a's ou b's.

Prova: Para este lema, vamos proceder de maneira análoga ao Lema 3.1, calculando a pontuação referente a cada coluna e o total referente a todas as colunas.

Seja $\mathcal{C}$ uma coluna de $A$ e suponhamos que esta coluna possua um caractere $a$. Então, pela hipótese, temos que a coluna é composta por $r_{0}$ caracteres 0 's e $r_{\sqcup}$ caracteres ப's nas primeiras $k$ linhas, por 1 caractere $a$ na penúltima linha e por 1 caractere $\sqcup$ na última linha. A contribuição dos dois últimos caracteres à pontuação de $\mathcal{C}$ é, assim, $r_{0} c(0, a)+r_{0} c(0, \sqcup)+$ $r_{\sqcup} c(\sqcup, a)+r_{\sqcup} c(\sqcup, \sqcup)+1 c(a, \sqcup)=(k+1)+r_{0}$. 
Analogamente, se $\mathcal{C}$ é uma coluna de $A$ que possui um caractere $b$, a contribuição das duas últimas linhas de $\mathcal{C}$ à pontuação SP de $\mathcal{C}$ é $(k+1)+r_{1}$, onde $r_{1}$ é a quantidade de 1's em $\mathcal{C}$. É importante observar que as contribuições que calculamos são válidas até mesmo para os casos em que $r_{0}=0$ ou que $r_{1}=0$, porque, nesses casos, as contribuições das últimas linhas à pontuação da coluna é de $(k+1)$.

Logo, somando as contribuições de todas as colunas que contenham caracteres $a$ 's ou $b$ 's, temos que a contribuição total das duas últimas linhas de tais colunas é igual a $(k+$ 1) $L+\|S\|-q$, onde $L=j+(L-j)$ é o número de colunas que contém caracteres $a$ 's ou $b$ 's e $q$ é o número de caracteres 0 's ou 1's que estão em colunas que não contém $a$ 's ou $b$ 's.

Se $\mathcal{C}$ é uma coluna de $A$ de acordo com as hipóteses do lema, que possui 0's, mas que não possui $a$ 's, então $\mathcal{C}$ possui seus dois últimos caracteres sendo u's. Nesse caso, se $\mathcal{C}$ possui $r_{0}$ caracteres 0 's e $r_{\sqcup}$ caracteres $\sqcup$ 's em suas $k$ primeiras linhas, a contribuição das duas últimas linhas à pontuação SP de $\mathcal{C}$ é $2 r_{0} c(0, \sqcup)+2 r_{\sqcup} c(\sqcup, \sqcup)+\left(\begin{array}{l}2 \\ 2\end{array}\right) c(\sqcup, \sqcup)=2 r_{0}$. Analogamente, se $\mathcal{C}$ possui 1's, mas não possui $b$ 's, a contribuição das duas últimas linhas à pontuação de $\mathcal{C}$ é $2 r_{1}$, onde $r_{1}$ é o número de 1's de $\mathcal{C}$.

Assim, a contribuição total das colunas que contém 0's mas que não contém a's ou que contém 1's mas que não contém $b$ 's é igual a $2 q$, onde $q$ é o número de caracteres 0 's ou 1's nestas colunas.

Portanto, a contribuição total das duas últimas linhas à pontuação SP de $A$ é igual a $\|S\|-q+(k+1) L+2 q=\|S\|+(k+1) L+q$, como desejávamos mostrar.

Corolário 3.4. Nas condições do lema anterior, se a contribuição das linhas que contém $a^{j}$ e $b^{L-j}$ à pontuação SP de A é no máximo $\|S\|+(k+1) L$, então todo caractere 0 das seqüências de $S$ está alinhado a um caractere a e todo caractere 1 das seqüências de $S$ está alinhado a um caractere $b$.

Prova: Basta ver que, nesse caso, $q=0$ caracteres das seqüências de $S$ estão fora de colunas que contém um caractere $a$ ou $b$.

Estamos agora prontos para a demonstração do Teorema de Wang e Jiang.

Teorema 3.5 (Wang e Jiang, 1994). O Problema AVS é NP-completo.

Prova: Naturalmente, o Problema AVS está em NP, pois dado um alinhamento (ótimo ou não) $A$, para uma instância de um conjunto $S=\left\{s_{1}, \ldots, s_{k}\right\}$ de seqüências e um inteiro $C$, pode-se decidir se $c(A) \leq C$ em tempo polinomial.

Vamos mostrar agora que a redução do Problema SC-Mín ao Problema AVS (em suas versões de decisão) mapeia instâncias cuja resposta seja SıM a instâncias cuja resposta seja Sim e vice-versa.

Suponhamos que $A$ seja um alinhamento de custo no máximo $C=k\|S\|+(k+1) L$ de $S_{j}=S \cup\left\{a^{j}, b^{L-j}\right\}$, para algum $j$. Pelo Lema 3.2 , podemos supor que as colunas de $A$ sejam organizadas de forma que seus caracteres sejam apenas 0's, $a$ 's e u's ou apenas 1's, $b$ 's e u's. Pelo Lema 3.1 , sabemos que $A_{\mid S}$ possui pontuação exatamente $(k-1)\|S\|$ e que, portanto, a contribuição das seqüências $a^{j}$ e $b^{L-j}$ à pontuação de $A$ é de, no máximo, $C-(k-1)\|S\|=\|S\|+(k+1) L$. Pelo Corolário 3.4, segue que cada 0 deve estar alinhado a um $a$ e cada 1 deve estar alinhado a um $b$ em $A$ e, portanto, não há caractere das seqüências de $S$ que não esteja alinhado a um $a$ ou a um $b$.

Podemos construir uma superseqüência $s$ para as seqüências de $S$ associando um caractere 0 a cada coluna com um caractere $a$ e um caractere 1 a cada coluna com um caractere 
b. A seqüência $s$ assim construída é uma superseqüência das seqüências de $S=\left\{s_{i}\right\}$, já que cada caractere 0 ou 1 de $s_{i}$ corresponde a um caractere 0 ou 1 de $s$. Naturalmente, a seqüência $s$ possui comprimento $j+(L-j)=L$ e $s$ é, portanto, uma solução para o Problema SC-Mín com valor igual a $L$, o que significa que a redução mapeia instâncias do Problema AVS cuja resposta seja Sim a instâncias do Problema SC-Mín com resposta Sim.

Vamos agora proceder à demonstração do outro caso. Seja $s$ uma superseqüência das seqüências de $S$, com $|s|=L$, e seja $j$ o número de 0's de $s$ (de forma que, naturalmente, $L-j$ seja o número de 1's de $s$ ). Consideremos o conjunto $S_{j}=S \cup\left\{a^{j}, b^{L-j}\right\}$. Para cada $s^{\prime} \in S$, consideremos um alinhamento de $s$ e $s^{\prime}$ em que os 0 's de $s^{\prime}$ estejam alinhados apenas a 0 's de $s$ e em que os caracteres 1's de $s^{\prime}$ estejam alinhados a 1's de $s$. Naturalmente, como $\left|s^{\prime}\right| \leq|s|$, podemos ter caracteres de $s$ alinhados a espaços em $s^{\prime}$.

Observe-se que cada um dos $k$ alinhamentos considerados acima possui comprimento exatamente $L$ e que, por construção, em nenhuma coluna desses alinhamentos há pares 0-1 alinhados.

O alinhamento $A$ com pontuação desejada será obtido usando-se a sequiência $s$ como uma espécie de "seqüência guia", da seguinte maneira": a $i$-ésima linha do alinhamento $A$ conterá a seqüência $s_{i}$ (com possíveis espaços inseridos) de forma que a a $l^{\prime}$-ésima coluna do alinhamento $A$ contenha os caracteres que estavam alinhados ao $l^{\prime}$-ésimo caractere de $s$, para todo $1 \leq l^{\prime} \leq L$. As duas últimas linhas do alinhamento $A$ (isto é, as linhas $k+1 \mathrm{e}$ $k+2$ ) conterão um "espelho" de $s$ em forma de $a$ 's e de $b$ 's, da seguinte maneira: nas colunas de $s$ em que havia 0's, a $(k+1)$-ésima linha de $A$ contém $a$ 's (portanto, $j$ caracteres $a$ 's) e espaços nas colunas restantes desta linha; nas colunas de $s$ em que havia 0 's, a $(k+2)$-ésima linha de $A$ contém espaços e, nas colunas em que havia 1's, a linha contém $b$ 's. Note-se que a seqüência $s$ não faz parte de $A$.

Com essa construção, o alinhamento $A$ possui exatamente $L$ colunas e cada uma de suas colunas possui apenas caracteres 0's, $a$ 's e espaços ou 1's, $b$ 's e espaços. Além disso, não há caracteres 0 's em colunas sem $a$ 's ou caracteres 1 's em colunas sem b's. Logo, pelo Lema 3.3, a contribuição referente às sequiências de $a$ 's e $b$ 's à pontuação de $A$ é $(k+1) L+\|S\|$.

Esse alinhamento possui pontuação igual a $(k-1)\|S\|$ pela parte referente às primeiras $k$ seqüências, conforme o Lema 3.1.

Portanto, o alinhamento $A$ obtido pelo método descrito possui pontuação igual a ( $k$ 1) $\|S\|+(k+1) L+\|S\|=k\|S\|+(k+1) L=C$, como desejávamos mostrar.

A idéia básica por trás da redução do Problema SC-Mín ao Problema AVS dada por Wang e Jiang é o fato de que se $s$ é uma superseqüência das seqüências de $S=\left\{s_{i}\right\}$, então $s$ pode ser alinhada a cada seqüência sem que caracteres diferentes fiquem alinhados em uma mesma coluna.

Outro fato a ressaltar é que como $S$ está fixado, $k$ e $\|S\|$ estão também fixados. Assim, a única parte variável no custo $C=k\|S\|+(k+1) L$ de um alinhamento das seqüências de $S$ é o valor $L$.

\subsection{O Problema AVS é NP-difícil (Just)}

Conforme vimos, o Problema AVS é NP-difícil para a matriz de pontuação apresentada por Wang e Jiang. Isso significa que é provável que o Problema AVS não admita

\footnotetext{
${ }^{5}$ Compare essa construção com o método de junção de alinhamentos exibido no Capítulo 4 .
} 
um algoritmo polinomial que o resolva para qualquer instância e para qualquer matriz de pontuação.

Por outro lado, é trivial de constatar que se a matriz identicamente nula for usada para pontuação, então qualquer alinhamento possuirá pontuação igual a zero e, assim, qualquer alinhamento será ótimo, o que significa que, pelo menos para a matriz nula, o problema pode ser resolvido eficientemente. É claro que essa é uma situação degenerada.

A matriz de pontuação usada na demonstração de Wang e Jiang não satisfaz aos axiomas de métrica (pois, como já observamos, $c(0,0)=2 \neq 0$ ) e, por isso, o interesse naquela matriz para o estudo de alinhamentos é menor do que em matrizes que sejam métricas: o fato de a matriz de Wang e Jiang não diferenciar entre o alinhamento de dois caracteres 0's de um alinhamento entre um caractere 0 e um caractere 1 faz dela algo de menor interesse para a escolha dos "melhores" alinhamentos do que uma matriz que diferencie esses dois casos, como, por exemplo, a matriz zero-ou-um usada para definir a distância de edição (Levenshtein).

Os casos da matriz nula e da matriz usada na demonstração de Wang e Jiang indicam que o comportamento do Problema AVS pode variar bastante de acordo com a matriz que for usada para comparar seqüências. Essa diferença de comportamento, aliada ao fato de a matriz de Wang e Jiang não ter uma interpretação simples para uso prático, dá margens à questão de se o Problema AVS poderia ser resolvido por algum algoritmo polinomial (ainda que ele não seja genérico) para alguns casos mais particulares de matriz de pontuação que conduzissem a pontuações que fossem intuitivamente mais próximas das aplicações biológicas e que, por conseqüência, fossem de maior interesse.

Essa dúvida ficou sem uma resposta por pelo menos meia década, quando, então Bonizzoni e Vedova [BV01] exibiram duas matrizes que satisfazem aos axiomas de métrica e para as quais o Problema AVS é NP-difícil, mostrando a possível intratabilidade do problema também para o caso de pontuação por métricas.

O trabalho posterior de Just [Jus01] veio reafirmar que o Problema AVS é aparentemente intratável para cada uma das matrizes de pontuação de uma grande família de matrizes de interesse e não apenas para matrizes que poderiam ser julgadas "artificiais" (como a de Wang e Jiang). As famílias de matrizes apresentadas por Just incluem as matrizes do artigo de Bonizzoni e Vedova, além de outras métricas.

Nesta seção do capítulo, expomos as idéias básicas do artigo de Just. No artigo, a demonstração de que o Problema AVS é NP-difícil é feita em etapas, considerando inicialmente casos restritos do problema (mas, em compensação, usando classes mais amplas de matrizes de pontuação) até demonstrar que o Problema AVS é NP-difícil para cada matriz de uma particular família de matrizes de pontuação. Em todos esses casos, basicamente a mesma redução é usada para mostrar que cada um dos problemas é NP-difícil para sua respectiva classe de matrizes. Mais ainda, uma adaptação da redução é suficiente para mostrar que cada um dos problemas é MAXSNP-difícil para uma matriz particular (que não é uma métrica).

Para esta parte do capítulo, consideramos o Problema AVS com seqüências que tenham todas o mesmo tamanho. Naturalmente, se o problema for intratável para esse caso particular, então o problema mais geral em que as seqüências podem ter tamanhos diferentes também será intratável. 


\subsubsection{O Problema AVS e Alguns Problemas Relacionados}

Freqüentemente, os alinhamentos de interesse em Biologia são alinhamentos que não possuem um grande número de espaços intercalados com caracteres de seqüências ${ }^{6}$ [SM97]. Em vez disso, a preferência é dada a alinhamentos que possuam um menor número de lacunas (ainda que elas sejam possivelmente longas).

Uma razão para essa preferência é a observação de que cada espaço em um alinhamento representa, do ponto de vista evolutivo, um evento de remoção ou de inserção de caracteres nas seqüências (freqüentemente bases nitrogenadas ou aminoácidos, dependendo do tipo de seqüências) e uma hipótese freqüentemente adotada é a de que é mais provável que ocorra um pequeno número de tais eventos (talvez afetando longos trechos de seqüências) do que ocorra um grande número de eventos (cada um afetando um pequeno número de bases ou aminoácidos). Esse é, a propósito, o motivo da freqüente escolha de funções afim para o custo de pontuação de lacunas em alinhamentos (i.e., funções da forma $h+g l$, onde $h$ e $g$ são constantes e $l$ é o comprimento da lacuna).

Um caso extremo da procura por alinhamentos com poucas lacunas é o caso particular do Problema AVS em que nenhuma lacuna interna às seqüências é permitida. Nessa versão restrita do problema, os únicos alinhamentos permitidos são aqueles em que os espaços ocorrem no início ou no fim das seqüências, mas não entre caracteres de uma dada seqüência. Em outras palavras, nessa versão do problema, apenas os alinhamentos em que as seqüências são deslocadas umas em relação às outras são considerados.

Um alinhamento que não apresenta espaços internos às seqüências alinhadas é chamado alinhamento 0-lacuna (do inglês, "gap-0 multiple sequence alignment"). A versão especializada do Problema AVS em que apenas alinhamentos 0-lacuna são permitidos é chamada Problema AVSOL e pode ser enunciada formalmente como:

Problema 3.3 (Problema AVS0L). Dadas $k$ seqüências $s_{1}, \ldots, s_{k}$ sobre um alfabeto $\Sigma e$ fixada uma matriz de pontuação $c$ sobre $\Sigma$, encontrar um alinhamento $A$ de $s_{1}, \ldots, s_{k}$ cuja pontuação $\mathrm{SP}_{c}(A)$ seja mínima e cujos únicos espaços de $A$ ocorram no início ou no fim de cada seqüência.

No Problema AVS0L, obviamente há um menor número de possibilidades para a disposição de espaços em um alinhamento do que no Problema AVS.

Uma versão ainda mais restrita do problema de alinhamentos é a versão do Problema AVSOL em que cada seqüência do alinhamento pode ser deslocada de, no máximo, uma posição em relação à primeira coluna do alinhamento, isto é, em que 0 ou 1 espaço é inserido no início de cada linha.

Um alinhamento 0-lacuna em que há 0 ou 1 espaço no início de cada seqüência é dito um alinhamento 0-1-lacuna (em inglês, "gap-0-1 multiple sequence alignment"). O Problema AVS01L é formulado como:

Problema 3.4 (Problema AVS01L). Dadas $k$ seqüências $s_{1}, \ldots, s_{k}$ sobre um alfabeto $\Sigma$ e fixada uma matriz de pontuação $c$ sobre $\Sigma$, encontrar um alinhamento $A$ de $s_{1}, \ldots, s_{k}$ cuja pontuação $\mathrm{SP}_{c}(A)$ seja mínima e tal que $A$ seja um alinhamento 0-lacuna com, no máximo, 1 espaço no início de cada seqüência.

Observe-se que, nesta nova versão do problema, há relativamente poucos alinhamentos em comparação com a versão geral do Problema AVS: como cada seqüência pode ou não

\footnotetext{
${ }^{6}$ Essa idéia básica é recorrente e é a motivação para métodos como o de Carrillo-Lipman.
} 
ser prefixada por um espaço no alinhamento, temos que, para $k$ seqüências, há exatamente $2^{k}-1$ alinhamentos possíveis, onde o -1 deve-se ao fato de não permitirmos que a coluna inicial do alinhamento seja em branco.

Para apresentarmos o resultado de Just e o argumento básico usado no artigo, vamos definir as classes de matrizes de pontuação a serem usadas. $\mathrm{O}$ alfabeto utilizado daqui em diante é, salvo menção contrária, o alfabeto $\{A, T\}$.

Definição 3.1 (Matriz Genérica). Dizemos que uma matriz de pontuação $M$ sobre o alfabeto $\{\mathrm{A}, \mathrm{T}\}$ é uma matriz genérica se $M$ for da forma

$$
M=\begin{array}{c|ccc} 
& \sqcup & \mathrm{A} & \mathrm{T} \\
\hline \sqcup & x & y & z \\
\mathrm{~A} & y & v_{A} & u \\
\mathrm{~T} & z & u & v_{T}
\end{array},
$$

onde $x, y, z$ são números não-negativos e $u>\max \left\{0, v_{A}, v_{T}\right\}$. Dizemos que uma matriz de pontuação $N$ definida sobre um alfabeto $\Sigma$ contém uma matriz genérica se existem caracteres de $\Sigma$ tal que a restrição de $N$ a estes caracteres (incluindo o espaço) é uma matriz genérica.

Intuitivamente falando, uma matriz é genérica se ela penalizar caracteres emparelhados A-T mais do que emparelhamentos de A-A ou de T-T, o que é uma condição geralmente desejável em aplicações práticas de Biologia.

Algumas classes de matrizes genéricas são importantes para os problemas de alinhamentos. Sejam $\mathcal{M}_{2}$ a classe das matrizes que contêm alguma matriz genérica, $\mathcal{M}_{1}$ a classe das matrizes que contêm uma matriz genérica em que $z>v_{T}$ e $\mathcal{M}$ a classe das matrizes que contêm uma matriz genérica em que $z>v_{T}$ e $y>u$.

É conseqüência imediata da definição das classes de matrizes que $\mathcal{M} \subset \mathcal{M}_{1} \subset \mathcal{M}_{2}$. Além disso, é fácil de ver que cada uma das relações de continência é estrita. As classes de matrizes $\mathcal{M}, \mathcal{M}_{1}$ e $\mathcal{M}_{2}$ abrangem várias matrizes de interesse, incluindo matrizes que são métricas.

Exemplo 3.1 (Distância de Edição). A matriz de pontuação $M_{L}$ que serve como base para definir a distância de edição possui 1's em todas as entradas, com exceção da diagonal principal, onde ela possui 0's e $M_{L}$ é uma matriz genérica. Mais do que isso, $M_{L}$ é tal que $M_{L} \in \mathcal{M}_{1} \subset \mathcal{M}_{2}$, já que $1=u>\max \left\{0, v_{A}, v_{T}\right\}=0$ e $1=z>v_{T}=0$. Por outro lado, $M_{L} \notin \mathcal{M}$, porque $1=y \ngtr u=1$, de onde segue que $M_{L} \in \mathcal{M}_{1} \backslash \mathcal{M}$.

Exemplo 3.2 (Bonizzoni e Vedova, 2001). Outro exemplo de interesse é a matriz

$$
M=\begin{array}{c|ccc} 
& \mathrm{U} & \mathrm{A} & \mathrm{T} \\
\hline \sqcup & 0 & 2 & 1 \\
\mathrm{~A} & 2 & 0 & 1 \\
\mathrm{~T} & 1 & 1 & 0
\end{array} .
$$

É claro que $M$ é tal que $1=u>\max \left\{0, v_{A}, v_{T}\right\}=0,1=z>v_{T}=0$ e $2=y>u=1$, o que significa que $M \in \mathcal{M} \subset \mathcal{M}_{1} \subset \mathcal{M}_{2}$.

A matriz apresentada acima é a matriz usada no artigo de Bonizzoni e Vedova [BV01], sendo que os caracteres A e T acima representam os caracteres $a$ e $b$ daquele artigo, respectivamente. 
Na realidade, o que ocorre com os exemplos acima não é uma surpresa. Se uma matriz $M$ é uma métrica sobre $\{\mathrm{A}, \mathrm{T}, \sqcup\}$, então $x=v_{A}=v_{T}=0$ e $y, z, u>0$, pelos axiomas de métrica (ver Seção 1.4.1.2). $\operatorname{Logo}, u>\max \left\{0, v_{A}, v_{T}\right\}$ e $M$ é automaticamente uma matriz genérica (ou seja, pertence a $\mathcal{M}_{2}$ ). Como, além disso, $z>0=v_{T}$, segue que toda métrica está também em $\mathcal{M}_{1}$.

O resultado principal do artigo de Just afirma a respeito da intratabilidade em potencial dos problemas de alinhamentos para classes de matrizes genéricas e é formalmente o seguinte:

Teorema 3.6 (Just, 2001). Na notação acima:

- para cada matriz de pontuação $M \in \mathcal{M}_{2}$, o Problema AVSO1L é NP-difícil;

- para cada matriz de pontuação $M \in \mathcal{M}_{1}$, o Problema AVSOL é NP-difícil;

- para cada matriz de pontuação $M \in \mathcal{M}$, o Problema AVS é NP-difícil.

\subsubsection{Redução}

A demonstração do Teorema de Just é feita por redução do Problema CorteMáx $(B)$ (definido adiante) a cada um dos três problemas de alinhamentos. As demonstrações das três partes do Teorema 3.6 seguem a mesma idéia básica de como uma instância do Problema CorteMÁx $(B)$ é transformada em instâncias dos problemas de alinhamento e cada demonstração usa fatos das demonstrações anteriores, incluindo a forma geral da função objetivo. A diferença entre as demonstrações é a forma como uma solução de cada um dos problemas de alinhamento é decodificada para obter uma solução do problema CoRTEMÁx $(B)$.

Apresentamos aqui com detalhes como a redução é feita para o Problema AVS01L e referimos o leitor ao artigo de Just [Jus01] para as modificações necessárias à redução para demonstrar a NP-dificuldade dos outros dois problemas de alinhamentos.

Para enunciarmos o Problema CorteMáx $(B)$, que é um problema clássico de Teoria de Grafos, precisamos primeiro do conceito de um corte de um grafo.

Definição 3.2 (Corte de um Grafo). Dados um grafo simples $G=(V, E)$ e uma bipartição de $V$ em $\left(V_{0}, V_{1}\right)$, dizemos que o conjunto $C$ das arestas de $G$ que têm um extremo em $V_{0}$ e outro em $V_{1}$ é um corte de $G$. Também dizemos que $C$ é o corte induzido em $G$ pela bipartição $\left(V_{0}, V_{1}\right)$.

O Problema CoRTeMáx $(B)$ pode, então, ser enunciado como:

Problema 3.5 (Problema CorteMÁx $(B)$ ). Fixado um inteiro $B$ e dado um grafo $G=$ $(V, E)$, com grau no máximo $B$, encontrar um corte de $G$ que tenha cardinalidade máxima.

Uma instância de tamanho $k$ do Problema CorteMáx $(B)$ é um grafo $G=(V, E)$ com grau no máximo $B$ e com $|V|=k$.

O Problema CoRteMÁx $(B)$ definido acima é um caso bastante particular do problema mais geral de partição de grafos [CK00, GJ79]. Entretanto, ele ainda assim é NP-difícil na forma descrita para qualquer inteiro $B \geq 3$.

Fixemos um inteiro $B \geq 3$ para o qual o Problema CorteMáx $(B)$ seja NP-difícil. Dada uma instância $G=(V, E)$ de tamanho $k$ para o Problema CorteMáx $(B)$, com $l=|E|$, e fixada uma enumeração dos vértices e das arestas de $G$ em que $V=\left\{v_{0}, \ldots, v_{k-1}\right\}$ e $E=\left\{e_{0}, \ldots, e_{l-1}\right\}$, vamos definir $k^{2}$ seqüências $t_{0}, \ldots, t_{k^{2}-1}$ sobre o alfabeto $\{\mathrm{A}, \mathrm{T}\}$, de forma que cada uma tenha comprimento $k^{12} l$. 
Intuitivamente, as $k$ primeiras seqüências representam os $k$ vértices de $G$ e as demais $k^{2}-k$ seqüências são "seqüências de preenchimento", cuja função é penalizar alinhamentos indesejados.

As últimas $k^{2}-k$ seqüências consistem apenas de T's, de forma que $t_{i}=\mathrm{T}^{k^{12} l}$, para $k \leq i<k^{2}$. As $k$ primeiras seqüências representam vértices de $G$, com $t_{i}$ representando $v_{i}$. Uma aresta $e_{m}=\left\{v_{h}, v_{i}\right\} \in E$ de $G$, com $h<i$, é representada nas seqüências $t_{h}$ e $t_{i}$ por caracteres $t_{h}[j]$ e $t_{i}[j]$, de forma que, para todo $n$ que satisfaça $0 \leq n<k^{5}$, tenhamos

$$
t_{h}\left[k^{7} l n+k^{7} m+2\right]=t_{i}\left[k^{7} l n+k^{7} m+1\right]=t_{i}\left[k^{7} l n+k^{7} m+3\right]=\mathrm{A}
$$

e todos os outros caracteres de $t_{h}$ e de $t_{i}$ que não representem arestas do grafo sejam iguais a T.

Destacamos duas observações importantes sobre as seqüências definidas acima:

- Vejamos que como $m \leq l-1$ e $n \leq k^{5}-1$, então o maior $j$ possível é $j=k^{7} l\left(k^{5}-\right.$ 1) $+k^{7}(l-1)+3=k^{12} l-k^{7} l+k^{7} l-k^{7}+3=k^{12} l-k^{7}+3 \leq k^{12} l$, para todo $k \geq 2$, o que significa que as seqüências estão bem definidas se $k \geq 2$. Como desejamos usar apenas instâncias do CoRTEMÁx $(B)$ que tenham $k$ suficientemente grande, o fato de adotarmos $k \geq 2$ não é um problema.

- Como $l=O\left(k^{2}\right)$, temos que cada seqüência $t_{i}$ possui comprimento $\left|t_{i}\right|=k^{12} l=$ $k^{12} O\left(k^{2}\right)=O\left(k^{14}\right)$. Como a transformação gera $k^{2}$ seqüências a partir do grafo, segue que um total de $k^{2} O\left(k^{14}\right)=O\left(k^{16}\right)$ caracteres são gerados a partir do grafo, isto é, um número polinomial de caracteres é gerado a partir de uma instância do CorteMáx $(B)$. Naturalmente, devido a isso, todo o processo de geração das seqüências pode ser feito em tempo polinomial.

Um exemplo que ilustra como são as seqüências para arestas $e_{m}=\left\{v_{g}, v_{h}\right\}$ e $e_{m^{\prime}}=$ $\left\{v_{h}, v_{i}\right\}$, com $g<h<i$ e $m<m^{\prime}$ está na Figura 3.1. Nela, $n<n^{\prime}$.

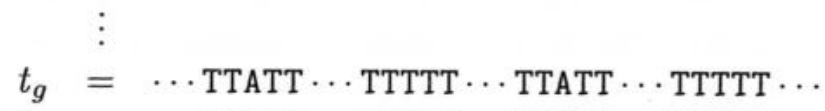

$$
\begin{aligned}
& t_{h}=\cdots \text { TATAT } \cdots \text { TTATT } \cdots \text { TATAT } \cdots \text { TTATT } \cdots \\
& t_{i}=\cdots \text { TTTTT } \cdots \text { ТАТАТ } \cdots \text { ТTTTT } \cdots \text { ТАТАТ } \cdots \\
& \vdots
\end{aligned}
$$

Figura 3.1: Um alinhamento gerado a partir de um grafo. Os símbolos A ficam dispostos sempre agrupados e em formato de triângulo. O fato de as arestas terem um vértice em comum $\left(v_{h}\right)$ reflete-se na seqüência correspondente ao vértice ter tanto trechos da forma "ATA" quanto trechos da forma "TAT".

Conforme ilustrado na figura, se duas seqüências $t_{h}$ e $t_{i}$ são seqüências codificadoras de vértices e se existe uma aresta $e=\left\{v_{h}, v_{i}\right\} \in E$ que liga os vértices correspondentes a essas seqüências, então $t_{h}$ e $t_{i}$ possuem trechos (que se repetem) em que os caracteres A's referentes à aresta estão em trincas, formando "triângulos" no alinhamento. Os A's que fazem parte de uma trinca sempre ocorrem em colunas consecutivas. 
É fácil observar que se $t_{h}$ for deslocada de um caractere para a direita (i.e., se um espaço for inserido em seu início), pares de caracteres A's serão criados entre as seqüências $t_{h}$ e $t_{i}$. $\mathrm{O}$ mesmo continua válido se o espaço for inserido no início de $t_{i}$ em vez de $t_{h}$.

Vista a maneira de codificação de um grafo em uma coleção de seqüências, vejamos o processo de decodificação ${ }^{7}$ de uma solução do Problema AVS01L. A partir de um alinhamento 0-1-lacuna podemos definir uma bipartição $\left(V_{0}, V_{1}\right)$ dos vértices do grafo (e, portanto, definir um corte) de maneira bastante natural: definimos $V_{0}$ como o conjunto dos vértices cujas seqüências codificadoras não tiveram a inserção de um espaço em seu início no alinhamento e $V_{1}$ como o conjunto dos vértices cujas seqüências correspondentes sofreram a inserção de espaço. Dizemos que o corte obtido dessa maneira a partir de um alinhamento 0-1-lacuna é um corte associado ao alinhamento.

Vamos mostrar que para todo $k$ suficientemente grande (i.e., para $k \geq k_{0}$, para algum $k_{0}$ fixado), se $A$ for um alinhamento 0-1-lacuna ótimo das seqüências $t_{0}, \ldots, t_{k^{2}-1}$ em relação a uma matriz genérica fixada de $\mathcal{M}_{2}$ e se $C_{A}$ for o corte associado a $A$, então $C_{A}$ será um corte ótimo para o Problema CorteMáx $(B)$.

Observe-se que isso é suficiente para mostrar que o Problema AVS01L é NP-difícil, pois se existir um algoritmo $\mathcal{A}_{M}$ que resolva o Problema AVS01L em relação à matriz genérica $M \in \mathcal{M}_{2}$, então um algoritmo que resolve o Problema CorteMáx $(B)$ poderá ser obtido da seguinte maneira: se $G$ for uma instância de tamanho $k \geq k_{0}$, então resolva o Problema AVS01L pelo algoritmo $\mathcal{A}_{M}$ com as seqüências derivadas de $G$, obtendo um alinhamento 0-1-lacuna e devolva como resposta o corte associado ao alinhamento $C_{A}$. Caso contrário, sabemos que há um número finito de grafos com menos de $k_{0}$ vértices e grau no máximo $B$ e colocamos as respostas ótimas (pré-computadas) para cada um dos grafos em uma tabela. $\mathrm{O}$ algoritmo para o CoRTEMÁx $(B)$ teria que simplesmente devolver a resposta correspondente ao grafo da entrada (e a busca na tabela pode ser feita em tempo polinomial - constante, pois $k_{0}$ está fixado).

Observe-se que o primeiro dos casos (caso $k \geq k_{0}$ ) toma tempo polinomial no tamanho do grafo $G$ pois, como já mencionamos, as seqüências possuem tamanho polinomial no tamanho de $G$ e a obtenção do corte $C_{A}$ a partir de um alinhamento 0-1-lacuna também pode ser feita em tempo polinomial. Se, além disso, o algoritmo $\mathcal{A}_{M}$ que resolve o Problema AVS01L para a matriz $M$ for um algoritmo polinomial, então o Problema CorteMáx $(B)$ poderá ser resolvido em tempo polinomial.

Por esse motivo, vamos nos preocupar apenas com $k$ suficientemente grande.

Também podemos supor que o número $l$ de arestas do grafo é diferente de zero, pois, caso contrário, todo corte do grafo possui cardinalidade 0 e um corte máximo tem, naturalmente, 0 aresta. Esse é um fato que pode ser verificado facilmente em tempo polinomial pelo algoritmo para resolver o problema CoRTEMÁx $(B)$.

Para concluir a demonstração de que o Problema AVS01L é NP-difícil falta apenas mostrar que se um alinhamento 0-1-lacuna ótimo $A^{*}$ for encontrado, então o corte $C_{A^{*}}$ será também ótimo. Para facilitar a exposição, vamos denotar por $A_{0}$ o alinhamento em que as seqüências $t_{0}, \ldots, t_{k^{2}-1}$ estão alinhadas sem nenhum espaço inserido nas seqüências (sem espaços inclusive em seu início e em seu fim). Assim, a $j$-ésima coluna de $A_{0}$ é composta pelos caracteres $\left(t_{0}[j], t_{1}[j], \ldots, t_{k^{2}-1}[j]\right)$, para $0 \leq j<k^{12} l$. Dizemos que $A_{0}$ é o alinhamento das seqüências não-alinhadas. Naturalmente, $A_{0}$ é um alinhamento 0-1-lacuna.

Também para simplificar a notação, se $C$ é um corte de $G$, denotamos por $c=|C|$ o

${ }^{7}$ A forma de codificação de um grafo em seqüências é a mesma para os Problemas AVS01L, AVSOL e AVS. A decodificação de soluções, entretanto, é um pouco diferente em cada um desses casos. 
valor ou cardinalidade do corte $C$.

A demonstração de que um alinhamento ótimo 0-1-lacuna $A^{*}$ produz um corte $C_{A^{*}}$. que também é ótimo é feita contabilizando-se a pontuação do alinhamento $A_{0}$ em relação a uma matriz genérica $M$ e calculando-se a variação de pontuação que ocorre quando o alinhamento $A_{0}$ é modificado para que o alinhamento ótimo $A^{*}$ seja obtido.

Alguns fatos auxiliares para a demonstração estão a seguir.

Lema 3.7. Cada coluna de $A_{0}$ possui, no máximo, 1 caractere A.

Prova: Suponhamos que existam duas seqüências $t_{i}$ e $t_{i^{\prime}}$, com $0 \leq i, i^{\prime} \leq k-1$, que possuam um caractere A em sua $j$-ésima coluna, isto é, $t_{i}[j]=\mathrm{A}=t_{i^{\prime}}[j]$. Assim, pela definição de $t_{i}[j]=\mathrm{A}$, temos que $j=k^{7} l n+k^{7} m+r$, para algum $0 \leq n<k^{5}$, para algum $r \in\{1,2,3\}$ e para alguma aresta $e_{m}$ incidente a $v_{i}$. Por outro lado, pela definição de $t_{i^{\prime}}[j]=\mathrm{A}, j=k^{7} l n^{\prime}+k^{7} m^{\prime}+r^{\prime}$, para algum $0 \leq n^{\prime}<k^{5}$, para $r^{\prime} \in\{1,2,3\}$ e para $m^{\prime}$ tal que $e_{m^{\prime}}$ é incidente a $v_{i^{\prime}}$. Como $k$ é suficientemente grande, podemos supô-lo $k \geq 4$ e, dá́, $k^{7} l n+k^{7} m+r=k^{7} l n^{\prime}+k^{7} m^{\prime}+r^{\prime}$ implica que $r \equiv r^{\prime}(\bmod k)$, de onde segue que $r=r^{\prime}$, pois $0 \leq r<k$ e $0 \leq r^{\prime}<k$. Assim, temos que $k^{7} l n+k^{7} m=k^{7} l n^{\prime}+k^{7} m^{\prime}$, isto é, $l n+m=l n^{\prime}+m$, uma vez que $k>0$. Novamente, como $l>0$ (já que supomos que o grafo tenha arestas) e $0 \leq m<l$, temos $m \equiv m^{\prime}(\bmod l)$ e, daí, $m=m^{\prime}$. Finalmente, de $l n=l n^{\prime}$ segue que $n=n^{\prime}$.

$\mathrm{Da}$ discussão acima, podemos concluir que $v_{i}$ e $v_{i^{\prime}}$ são incidentes à mesma aresta $e_{m}$. Há duas possibilidades para $v_{i}$ e $v_{i^{\prime}}$ : serem extremos diferentes de $e_{m}$ ou serem o mesmo vértice. Como vértices diferentes incidentes a uma mesma aresta não possuem caracteres A's em uma mesma coluna de suas seqüências codificadoras (pela definição das seqüências) e o grafo $G$ é simples, segue que $v_{i}=v_{i^{\prime}}$ e, daí, $t_{i}=t_{i^{\prime}}$, ou seja, não é possível que duas seqüências diferentes possuam caracteres A's em uma mesma coluna. Logo o alinhamento $A_{0}$ possui, no máximo, um caractere A por coluna.

Lema 3.8. $O$ alinhamento $A_{0}$ possui exatamente $3 k^{5} l\left(k^{2}-1\right)$ emparelhamentos entre caracteres diferentes.

Prova: Pelo Lema 3.7, sabemos que cada coluna de $A_{0}$ contém no máximo um caractere A. Para cada aresta $e \in E$, existem $k^{5}$ trincas de A's dispostas em $A_{0}$, sendo uma para cada valor de $n$, que varia entre 0 e $k^{5}-1$. Logo, existem $3 k^{5}$ caracteres A's dispostos em $A_{0}$ por aresta, totalizando $3 k^{5} l$ caracteres A's em $A_{0}$. Como cada coluna que contém um caractere A possui $k^{2}-1$ caracteres T's, temos que cada uma dessas colunas possui $k^{2}-1$ emparelhamentos entre A's e T's. Logo, como existem $3 k^{5} l$ caracteres A's, temos que $A_{0}$ possui $3 k^{5} l\left(k^{2}-1\right)$ emparelhamentos entre caracteres diferentes, como queríamos demonstrar.

O próximo lema, que apesar de simples é muito importante, nos afirma que os blocos de A's estão sempre "bastante espaçados" no alinhamento $A_{0}$ e que pequenos deslocamentos das seqüências não são suficientes para fazer A's de blocos distintos ficarem alinhados, se $k$ for suficientemente grande.

Lema 3.9. Dois blocos de A's quaisquer e distintos em $A_{0}$ estão pelo menos à distância $\Omega\left(k^{7}\right)$.

Prova: Vamos demonstrar o lema calculando quantas são as colunas que estão entre as primeiras colunas de dois blocos quaisquer distintos. 
Sejam $j=k^{7} l n+k^{7} m+1$ e $j^{\prime}=k^{7} l n^{\prime}+k^{7} m^{\prime}+1$ as colunas de início de dois blocos distintos de A's em $A_{0}$. Para ajudar a fixar as idéias, vamos fazer a demonstração em dois casos.

Inicialmente, vejamos que se $m=m^{\prime}$ (i.e., se $j$ e $j^{\prime}$ são colunas iniciais de blocos distintos referentes a uma mesma aresta), então $\left|j-j^{\prime}\right|=\left|k^{7} l n+k^{7} m+1-k^{7} l n^{\prime}-k^{7} m^{\prime}-1\right|=$ $\left|k^{7} l\left(n-n^{\prime}\right)\right|=k^{7} l\left|n-n^{\prime}\right|$ e como $j \neq j^{\prime}$, segue que $\left|n-n^{\prime}\right| \neq 0$ e como $n$ e $n^{\prime}$ são inteiros, $\left|n-n^{\prime}\right| \geq 1$, de onde segue que $\left|j-j^{\prime}\right| \geq k^{7} l=\Omega\left(k^{7}\right)$.

Tratemos agora do caso em que os blocos referem-se a arestas diferentes do grafo e supomos que elas sejam $e_{m}$ e $e_{m^{\prime}}$, com $m \neq m^{\prime}$. Então temos que $\left|j-j^{\prime}\right|=\mid k^{7} l\left(n-n^{\prime}\right)+$ $k^{7}\left(m-m^{\prime}\right)\left|=k^{7}\right| l\left(n-n^{\prime}\right)+\left(m-m^{\prime}\right) \mid$, em que $0 \leq m, m^{\prime} \leq l-1$ e $0 \leq n, n^{\prime} \leq k^{5}-1$. Queremos mostrar que $\left|l\left(n-n^{\prime}\right)+\left(m-m^{\prime}\right)\right| \geq 1$, de onde seguirá que $\left|j-j^{\prime}\right| \geq k^{7}=\Omega\left(k^{7}\right)$.

De fato, se $n=n^{\prime}$, então $l\left(n-n^{\prime}\right)=0$ e como, por hipótese $m \neq m^{\prime}$, temos como conseqüência que $\left|l\left(n-n^{\prime}\right)+\left(m-m^{\prime}\right)\right|=\left|m-m^{\prime}\right| \geq 1$. Se, por outro lado, $n \neq n^{\prime}$, então $l\left(n-n^{\prime}\right) \leq-l$ ou $l\left(n-n^{\prime}\right) \geq l$. Ademais, como $m$ e $m^{\prime}$ variam nos inteiros restritos ao conjunto $\{0, \ldots, l-1\}$, temos que $\left|m-m^{\prime}\right| \leq l-1$, isto é, $-(l-1) \leq m-m^{\prime} \leq l-1$. Mas então, se $l\left(n-n^{\prime}\right) \leq-l$ ocorrer, temos que $l\left(n-n^{\prime}\right)+\left(m-m^{\prime}\right) \leq-l+(l-1)=-1$ e se $l\left(n-n^{\prime}\right) \geq l$ ocorrer, temos que $l\left(n-n^{\prime}\right)+\left(m-m^{\prime}\right) \geq l-(l-1)=1$.

Em outras palavras, em qualquer caso é válido que $\left|l\left(n-n^{\prime}\right)+\left(m-m^{\prime}\right)\right| \geq 1$, o que conclui a demonstração do lema.

Lema 3.10. Se três colunas consecutivas de $A_{0}$ possuem caracteres A's na configuração descrita na definição de $t_{i}$ 's e um espaço é inserido no início de uma das seqüências que tem algum A nessas colunas, então um par de A's é criado, um par de $\mathrm{T}$ 's é criado e dois pares de $\mathrm{A} e \mathrm{~T}$ 's são desfeitos.

Prova: Sejam $\mathcal{C}_{1}, \mathcal{C}_{2}$ e $\mathcal{C}_{3}$, nessa ordem, as colunas com caracteres A's. Sem perda de generalidade, podemos supor que o espaço seja inserido no início da seqüência codificadora que contém um $\mathrm{A}$ e que tem menor índice e que, portanto, o caractere $\mathrm{A}$ de $\mathcal{C}_{2}$ fique alinhado ao caractere $\mathrm{A}$ de $\mathcal{C}_{3}$ após a inserção. Caso contrário, $\mathcal{C}_{1}$ faria o papel de $\mathcal{C}_{3}$ no lema e vice-versa.

Antes da inserção, a coluna $\mathcal{C}_{2}$ possuía 1 caractere A e $k^{2}-1$ caracteres T's, o mesmo valendo para a coluna $\mathcal{C}_{3}$, ou seja, a coluna $\mathcal{C}_{2}$ possuía $\left(\begin{array}{c}k^{2}-1 \\ 2\end{array}\right)$ pares de T's, $k^{2}-1$ pares entre A's e T's e nenhum par de A's, que era a mesma situação para a coluna $\mathcal{C}_{3}$.

Após o espaço ser inserido, a coluna $\mathcal{C}_{2}$ fica apenas com caracteres T's e, portanto, com 0 par de diferentes caracteres e 0 par de A's. Note-se que $k^{2}-1$ pares de T's foram criados em $\mathcal{C}_{2}$, que substituíram os $k^{2}-1$ pares entre A's e T's que existiam nessa coluna. A coluna $\mathcal{C}_{3}$ fica com 2 caracteres A's e $k^{2}-2$ caracteres T's, isto é, ela fica com 1 par de A's, $\left(\begin{array}{c}k^{2}-2 \\ 2\end{array}\right)$ pares de T's e $2\left(k^{2}-2\right)$ pares de caracteres diferentes. A coluna $\mathcal{C}_{1}$ permanece com 1 caractere A e $k^{2}-1$ caracteres T's, não sofrendo modificações após a inserção do espaço. Logo, no total, 1 par A-A foi criado, 1 par T-T foi criado e $2\left(k^{2}-1\right)-2\left(k^{2}-2\right)=2$ pares entre A e $\mathrm{T}$ foram desfeitos após a inserção do espaço, como queríamos mostrar.

Agora, estamos prontos para provar que o Problema AVS01L é NP-difícil com a pontuação SP dada por uma matriz genérica.

Se o alinhamento $A_{0}$ consistisse apenas de T's, sua pontuação SP seria $\left(k^{12} l\right) k^{2}\left(k^{2}-\right.$ 1) $v_{T} / 2$. Entretanto, pelos argumentos dos Lemas 3.9 e 3.8 , ele possui $3 k^{5} l$ caracteres A's em colunas distintas, o que muda a pontuação SP calculada acima de $-3 k^{5} l\left(k^{2}-1\right) v_{T}+$ $3 k^{5} l\left(k^{2}-1\right) u=3 k^{5} l\left(k^{2}-1\right)\left(u-v_{T}\right)$. Note-se que essa quantia é positiva porque $u>v_{T}$. 
Logo, pode-se concluir que a pontuação SP do alinhamento $A_{0}$ é igual a

$$
\left(k^{12} l\right) k^{2}\left(k^{2}-1\right) v_{T} / 2+3 k^{5} l\left(k^{2}-1\right)\left(u-v_{T}\right) .
$$

Seja agora $A^{*}$ um alinhamento 0-1-lacuna ótimo. Se $e=\left\{v_{h}, v_{i}\right\}$ é uma aresta do grafo usado para construir as seqüências de $A^{*}$ e $v_{h}$ está em um lado diferente de $v_{i}$ na bipartição (i.e., $e$ pertence ao corte $C_{A^{*}}$ ), então exatamente uma das seqüências $t_{h}, t_{i}$ teve um espaço inserido em seu início. Pelo Lema 3.10, cada uma das $k^{5}$ trincas de A's existentes nessas duas seqüências (que representam $e$ ) tem um emparelhamento A-A feito, um emparelhamento $\mathrm{T}-\mathrm{T}$ feito e dois emparelhamentos A-T desfeitos, resultando em um total de $k^{5}$ emparelhamentos feitos entre A's, $k^{5}$ emparelhamentos feitos entre T's e $2 k^{5}$ emparelhamentos entre A's e T's desfeitos, de forma que a pontuação do alinhamento devida à aresta $e$ ser incluída no corte é $k^{5} v_{A}+k^{5} v_{T}-2 k^{5} u=k^{5}\left(v_{A}+v_{T}-2 u\right)$, que é negativa, pois $v_{A}+v_{T}-2 u<0$, pela definição de matriz genérica. Logo, cada aresta presente no corte diminui a pontuação de $A_{0}$ de $k^{5}\left(v_{A}+v_{T}-2 u\right)$. Pelo Lema 3.9, sabemos que os blocos de A's estão bastante espaçados em $A_{0}$ e que em um alinhamento 0-1-lacuna as contribuições de pontuação das arestas que aparecem no corte são duas a duas independentes, de onde segue que $c_{A^{*}}$ arestas diminuem a pontuação de $c_{A^{*}} k^{5}\left(v_{A}+v_{T}-2 u\right)=-c_{A^{*}} k^{5}\left(2 u-v_{A}-v_{T}\right)$.

Observe-se que as únicas duas colunas em um alinhamento 0-1-lacuna que podem conter espaços são a primeira e a última, de onde segue que cada uma delas possui, no máximo, $O\left(k^{4}\right)$ emparelhamentos de caracteres diferentes. Como a matriz de pontuação $M$ é fixada, a pontuação SP contribuída por cada uma dessas colunas é $O\left(k^{4}\right)$ e, portanto, a contribuição total à pontuação SP feita por colunas que contenham espaços em um alinhamento 0-1lacuna é $O\left(k^{4}\right)$.

A pontuação SP do alinhamento $A^{*}$ é, então, igual a

$$
\left(k^{12} l\right) k^{2}\left(k^{2}-1\right) v_{T} / 2+3 k^{5} l\left(k^{2}-1\right)\left(u-v_{T}\right)-c_{A} \cdot k^{5}\left(2 u-v_{A}-v_{T}\right)+O\left(k^{4}\right),
$$

isto é, a pontuação $\mathrm{SP}\left(A^{*}\right)$ é limitada superiormente por $\left(k^{12} l\right) k^{2}\left(k^{2}-1\right) v_{T} / 2+3 k^{5} l\left(k^{2}-\right.$ 1) $\left(u-v_{T}\right)-c_{A^{*}} k^{5}\left(2 u-v_{A}-v_{T}\right)+\alpha k^{4}$, para alguma constante $\alpha>0$ para todo $k \geq$ $k_{0}$. Naturalmente, como as matrizes com que trabalhamos possuem apenas valores nãonegativos, o custo das colunas que contém espaços em um alinhamento 0-1-lacuna qualquer é pelo menos 0 e, portanto, um limite inferior para o custo $\operatorname{SP}\left(A^{*}\right)$ é dado por

$$
\left(k^{12} l\right) k^{2}\left(k^{2}-1\right) v_{T} / 2+3 k^{5} l\left(k^{2}-1\right)\left(u-v_{T}\right)-c_{A^{*}} k^{5}\left(2 u-v_{A}-v_{T}\right) .
$$

Observe-se que em ambos limitantes acima o termo referente à pontuação do alinhamento $A_{0}$, dado em (3.3) é invariante para todo alinhamento, uma vez que as seqüências estejam fixadas. Por esse motivo, para estudarmos a relação de otimalidade entre um alinhamento e seu corte associado, basta estudarmos as partes $-c_{A^{*}} k^{5}\left(2 u-v_{A}-v_{T}\right)$ e $-c_{A^{*}} k^{5}\left(2 u-v_{A}-\right.$ $\left.v_{T}\right)+\alpha k^{4}$ dos limitantes do custo de $A^{*}$ e como o valor $\operatorname{SP}\left(A^{*}\right)-\left[\left(k^{12} l\right) k^{2}\left(k^{2}-1\right) v_{T} / 2+\right.$ $\left.3 k^{5} l\left(k^{2}-1\right)\left(u-v_{T}\right)\right]$ se relaciona com tais limitantes. Para facilitar a notação, definimos

$$
\mathrm{SP}^{\prime}(A)=\operatorname{SP}(A)-\left[\left(k^{12} l\right) k^{2}\left(k^{2}-1\right) v_{T} / 2+3 k^{5} l\left(k^{2}-1\right)\left(u-v_{T}\right)\right]
$$

para um alinhamento qualquer $A$. É claro que se $\operatorname{SP}(A)$ for mínimo então $\operatorname{SP}^{\prime}(A)$ também o será e vice-versa.

Além disso, como a matriz de pontuação está fixada, a quantia $\beta=2 u-v_{A}-v_{T}$ é uma constante positiva. 
Consideremos agora os intervalos $I_{k, n}$ da forma $I_{k, n}=\left[-\beta k^{5} n,-\beta k^{5} n+\alpha k^{4}\right]$. Notemos que se $k$ é suficientemente grande, então se $y \in I_{k, n}$ e $y^{\prime} \in I_{k, n+1}$, então $y>y^{\prime}$.

De fato, se $k_{0}=\alpha / \beta$, então para todo $k>k_{0}$ temos que como $y \in I_{k, n}$,

$$
\begin{aligned}
y & \geq-\beta k^{5} n=-\beta k^{5} n-\beta k^{5}+\beta k^{5}=-\beta k^{5}(n+1)+\beta k^{5}=-\beta k^{5}(n+1)+\beta k^{4} k \\
& >-\beta k^{5}(n+1)+\beta k^{4}(\alpha / \beta)=-\beta k^{5}(n+1)+\alpha k^{4} \\
& \geq y^{\prime} .
\end{aligned}
$$

Logo, os intervalos $I_{k, n}$ e $I_{k, n+1}$ são disjuntos para $k$ suficientemente grande e, além disso, todo elemento de $I_{k, n}$ é maior do que qualquer elemento de $I_{k, n+1}$.

Logo, se $A^{*}$ é um alinhamento 0-1-lacuna ótimo, seu valor $\operatorname{SP}^{\prime}\left(A^{*}\right)$ pertence ao intervalo $I_{k, c_{A^{*}}}$, onde $c_{A^{*}}$ é o tamanho do corte associado a $A^{*}$ e como todos os outros alinhamentos 01-lacuna possuem valor pelo menos igual ao de $A^{*}$, não é possível que haja um alinhamento $A$ cujo valor $\mathrm{SP}^{\prime}(A)$ pertença a um intervalo $I_{k, c_{A}} \operatorname{com} c_{A}>c_{A^{*}}$, porque isso violaria a otimalidade de $A^{*}$, de onde segue que o corte associado ao alinhamento $A^{*}$ é ótimo, o que conclui a demonstração do teorema. 


\section{Capítulo 4}

\section{Algoritmos de Aproximação}

"Although this may seem a paradox, all exact science is dominated by the idea of approximation." — Bertrand Russell (1872-1970)

\subsection{Introdução}

Ainda que o Problema AVS com pontuação SP seja NP-difícil seja uma "má notícia", diversos problemas dependem de alinhamentos como um ponto de partida. A esperança de encontrar um algoritmo eficiente para o problema fica reduzida (e, na verdade, se $\mathrm{P} \neq \mathrm{NP}$, é impossível encontrar um algoritmo polinomial). Existem algumas medidas-padrão tomadas em casos como esse para contornar as dificuldades.

Intuitivamente, o fato de um problema de otimização ser NP-difícil significa que não se espera encontrar um algoritmo que sempre ache uma solução ótima, para todas as instâncias e em tempo polinomial para o problema na forma em que ele foi posto. Isso não necessariamente significa que não se possa encontrar em nenhum caso algoritmos eficientes para o problema. Na realidade, aceitando-se determinados compromissos, algoritmos eficientes podem ser descobertos.

Compromissos clássicos que normalmente são feitos abrem mão de alguns dos requerimentos estritos que caracterizam o problema como NP-difícil. Por exemplo, ao sacrificar-se a generalidade da formulação do problema e ao adotar-se uma formulação mais restrita (como, por exemplo, algum caso particular de interesse prático) é possível que um algoritmo de tempo polinomial seja encontrado.

Outro método freqüentemente empregado é desenvolver algoritmos que encontrem soluções ótimas para o problema, mas que não necessariamente o façam em tempo polinomial para todas instâncias. Essa estratégia faz sentido pois podem ocorrer casos (novamente, guiados pela prática) em que um algoritmo funcione rapidamente para muitas instâncias e exiba comportamento superpolinomial apenas para alguns poucos casos, que possam ser considerados "patológicos". Um exemplo de algoritmo que tem essas características (ainda que ele não seja um algoritmo ótimo do ponto de vista de complexidade de tempo) é o Algoritmo Simplex, para resolver programas lineares.

Se soluções incorretas para o problema puderem ser admitidas com baixa probabilidade, pode ser possível encontrar um algoritmo probabilístico eficiente para resolver o problema (por exemplo, um algoritmo do tipo Monte Carlo [BS96]). 
Um outro jeito clássico usado para obter algoritmos eficientes para problemas difíceis é abrir mão do requerimento de otimalidade das soluções devolvidas pelo algoritmo, mas ainda manter a generalidade do problema e a exigência de tempo polinomial. Nesse caso, podem-se obter algoritmos heurísticos e algoritmos de aproximação.

Um algoritmo heurístico (ou uma heurística) é um algoritmo que funciona bem em casos práticos, mas para o qual não necessariamente se tem uma garantia de que a solução devolvida esteja "próxima" da ótima. Geralmente, heurísticas são fundamentadas em métodos não rigorosos, ainda que forneçam resultados satisfatórios. Já para um algoritmo de aproximação, por outro lado, há uma garantia de que todas soluções devolvidas estejam "próximas" da ótima (digamos, no máximo a 10\% da solução ótima). A garantia fornecida por um algoritmo de aproximação é chamada razão de aproximação.

O interesse nesses tipos de algoritmos que não necessariamente devolvem soluções ótimas reside no fato de que para determinadas finalidades, as soluções ótimas podem não ser indispensáveis e uma solução "boa o suficiente" pode dar resultados satisfatórios [NB94, BLP97].

Neste capítulo, tratamos de dois algoritmos de aproximação para o Problema AVS com pontuação SP.

A área de estudo e aplicação de algoritmos de aproximação é, hoje em dia, bastante extensa e muitas são as técnicas (algumas bastante sofisticadas) em uso. Bons tratamentos da teoria para um estudo aprofundado de técnicas gerais de desenvolvimento de algoritmos de aproximação e de aspectos de complexidade de problemas em termos de aproximabilidade podem ser encontrados em [FMCF01, GJ79, Vaz01].

\subsection{Junção de Alinhamentos}

Um método padrão usado tanto em algoritmos de aproximação quanto em heurísticas para o Problema AVS é a junção de alinhamentos. A idéia básica do método é de "colar" dois. ou mais alinhamentos para obter um alinhamento maior composto por todas as seqüências dos alinhamentos menores. Esse método é usado nos dois algoritmos de aproximação que descrevemos neste capítulo.

Definição 4.1 (Alinhamentos Compatíveis). Dados um alinhamento $A$ das seqüências $s_{1}, \ldots, s_{k}$ e um alinhamento $A^{\prime}$ de um subconjunto das $k$ seqüências, dizemos que $A$ é compativel com $A^{\prime}$ se as seqüências de $A^{\prime}$ estão alinhadas em $A$ da mesma forma que em $A^{\prime}$.

Em outras palavras, um alinhamento $A$ é compatível com um alinhamento $A^{\prime}$ se $A^{\prime}$ for alguma projeção de $A$.

Um fato pertencente ao folclore do estudo de alinhamentos e descrito em um clássico artigo de Feng e Doolittle [FD87] é que, dada uma árvore qualquer onde cada nó é rotulado por uma seqüência e cada aresta tem um alinhamento associado (não necessariamente ótimo) que envolve as seqüências que rotulam os extremos da aresta, existe um alinhamento de todas as seqüências e que é compatível com cada um dos alinhamentos de pares de seqüências determinados pelas arestas das árvores.

Essencialmente, o método para junção de alinhamentos funciona tomando alinhamentos $A_{1}, \ldots, A_{r}$ em que exatamente uma das seqüências de entrada, digamos $s$, seja comum a cada par de alinhamentos (e, como conseqüência, seja comum a todos os alinhamentos) e, usando $s$ como orientação, o método constrói um alinhamento $A$ de todas as sequiências. A seqüência $s$, comum a todos os alinhamentos, é chamada seqüência guia. 
O Algoritmo JunTA, que implementa o método, supõe, sem perda de generalidade que a seqüência guia $s$ esteja na primeira linha de cada alinhamento. Supõe-se que a seqüência $s=s[1] \cdots s[n]$ possua comprimento $n$ e que o alinhamento $A_{i}$ possua $k_{i}$ seqüências e comprimento $l_{i}$, para $i=1, \ldots, r$.

Fixado $i$, seja $p_{i, j}$ a posição (coluna) do $j$-ésimo caractere de $s$ no alinhamento $A_{i}$ para todo $j=1, \ldots, n$ e definamos $p_{i, 0}=0$ e $p_{i, n+1}=l_{i}+1$. Seja $z_{i, j}=p_{i, j}-p_{i, j-1}-1$, para todo $j=1, \ldots, n+1$ e para todo $i=1, \ldots, r$. A interpretação para $z_{i, j}$ de acordo com a definição é que $z_{i, j}$ é o número de espaços que ocorrem imediatamente antes de $s[j]$ no alinhamento $A_{i}$ (a interpretação para o caso $j=n+1$ é de que $z_{i, n+1}$ é o número de espaços após o último caractere de $s$ em $A_{i}$ ). Naturalmente, fixado $i$, a soma de todos $z_{i, j}$ 's é igual ao número de espaços intercalados a $s$ em $A_{i}$, isto é, $\sum_{j=1}^{n+1} z_{i, j}=l_{i}-n$.

Agora, definimos $z_{j}^{*}=\max _{i}\left\{z_{i, j}\right\}$, para todo $j=1, \ldots, n+1$ (intuitivamente, $z_{j}^{*}$ é o maior número de espaços que ocorrem imediatamente antes de $s[j]$ em qualquer um dos alinhamentos $A_{i}$ ).

Para cada alinhamento $A_{i}$, se fizermos com que existam $z_{j}^{*}$ caracteres $\lrcorner^{\prime}$ s imediatamente antes de $s[j]$ (possivelmente adicionando a $A_{i}$ colunas inteiras em branco no início das $z_{i, j}$ colunas já existentes em $A_{i}$ para obter, assim, um alinhamento $A_{i}^{\prime}$ ), então os caracteres de $s$ ficarão espaçados da mesma maneira em cada um dos alinhamentos $A_{i}^{\prime}$. Como conseqüência, todos os alinhamentos $A_{i}^{\prime}$ terão o mesmo comprimento.

Um alinhamento $A$ entre todas as seqüências presentes nos $r$ alinhamentos $A_{i}^{\prime}$ pode ser obtido reunindo-se todas linhas de cada $A_{i}^{\prime}$ em $A$ (removendo-se, naturalmente, as $r-1$ duplicações da linha que contém $s$ ).

Observe-se que o alinhamento $A$ construído pelo procedimento descrito é compatível com cada um dos alinhamentos $A_{i}$, pois a projeção de $A$ na direção das seqüências que aparecem em $A_{i}$ é o alinhamento $A_{i}^{\prime}$ e o passo de adicionar colunas em branco aos alinhamentos $A_{i}$ para obter $A_{i}^{\prime}$ não muda a forma como os caracteres das colunas originais de $A_{i}$ estavam alinhados.

É interessante comparar o procedimento descrito aqui com a última parte da demonstração dada para a Proposição 1.2 do Capítulo 1, que diz que a distância de edição satisfaz à desigualdade triangular.

\subsubsection{O Algoritmo JUNTA}

O pseudo-código que descreve o Algoritmo JunTA está listado a seguir. Para maior clareza na análise do algoritmo, os laços do pseudo-código foram divididos em laços com corpos pequenos e uma implementação do algoritmo provavelmente faria as operações em ordens diferentes. Essa divisão, todavia, não modifica a complexidade de tempo do Algoritmo JUNTA.

\subsubsection{Análise de Complexidade}

Para o $i$-ésimo dos $r$ alinhamentos de entrada, o corpo do primeiro laço do Algoritmo JUNTA pode ser executado em tempo $O\left(l_{i}\right)$. Logo, o primeiro laço do algoritmo toma tempo $O\left(\sum_{i} l_{i}\right)$.

Por um argumento semelhante, o laço em que os valores $z_{i, j}$ são determinados também toma tempo $O\left(\sum_{i} l_{i}\right)$, uma vez que $n \leq l_{i}$.

A determinação de cada valor $z_{j}^{*}$ é feita em tempo $O(r)$ e $n+1$ desses valores são determinados, de forma que todos valores podem ser calculados em tempo $O(r n)$. Como 


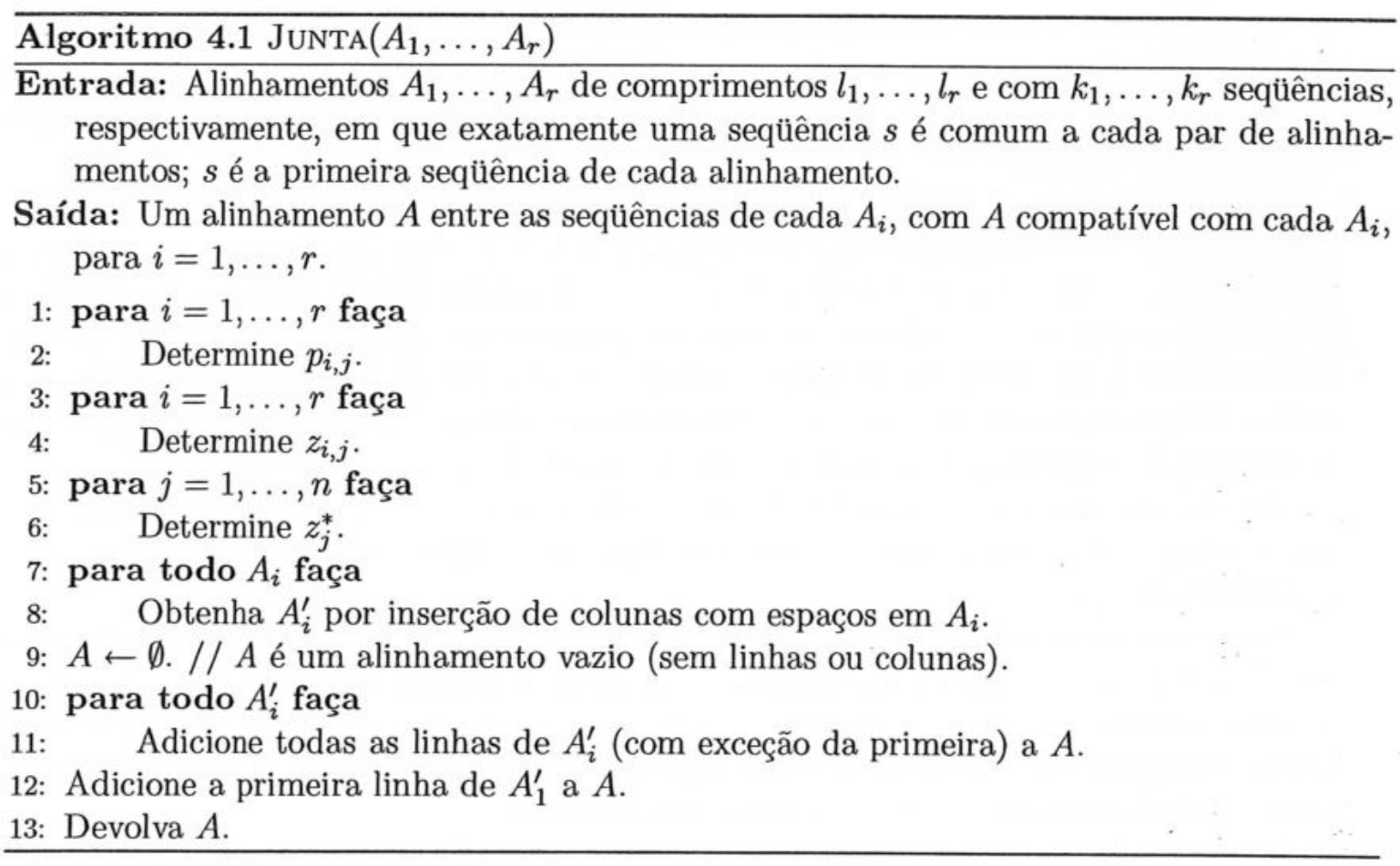

$r n=\sum_{i} n \leq \sum_{i} l_{i}$, o terceiro laço do algoritmo também toma tempo $O\left(\sum_{i} l_{i}\right)$.

Cada alinhamento $A_{i}^{\prime}$ possui, após a inserção das colunas em branco, no máximo $\sum_{i} l_{i}$ colunas e possui exatamente $k_{i}$ linhas. Como a determinação de cada caractere de $A_{i}^{\prime}$ (visto como uma matriz) pode ser feita em tempo constante, o tempo para obter o alinhamento $A_{i}^{\prime}$ a partir de $A_{i}$ é igual a $O\left(k_{i} \sum_{j} l_{j}\right)$. Logo, o tempo total para executar o quarto laço do algoritmo é $O\left(\left(\sum_{i} k_{i}\right)\left(\sum_{i} l_{i}\right)\right)$.

O trecho do algoritmo das linhas 9-12 trata, basicamente, de uma cópia de caracteres entre duas matrizes. Isso toma também tempo $O\left(\left(\sum_{i} k_{i}\right)\left(\sum_{i} l_{i}\right)\right)$.

Observe-se que $\sum_{i} k_{i}=k+(r-1) \leq 2 k$, onde $k$ é o número de linhas do alinhamento final $A$. Fazendo $l=\max _{i}\left\{l_{i}\right\}$, temos que $\sum_{i} l_{i} \leq \sum_{i} l=r l$. Logo, a complexidade de tempo do algoritmo é $O(r l)+O(r l)+O(k r l)+O(k r l)=O(r k l)$.

\subsubsection{Comentários Gerais}

Um fato interessante a ser observado no Algoritmo JunTa é que se dois caracteres consecutivos em alguma seqüência de algum $A_{i}$ estão separados por espaços em $A_{i}$, então eles continuam separados por espaços no alinhamento $A_{i}^{\prime}$ e, por conseqüência, também ficam separados no alinhamento $A$ devolvido por $\operatorname{Junta}\left(A_{1}, \ldots, A_{r}\right)$. Nas clássicas palavras de Feng e Doolittle, "once a gap, always a gap" [FD87]. O Algoritmo JUNTA é usado, além dos algoritmos de aproximação vistos neste capítulo, pelos Métodos de Alinhamento Progressivo que incorporam idéias propostas por Feng e Doolittle [FD87].

No caso em que uma árvore é dada com cada um de seus nós rotulado por uma sequiência e um alinhamento (ótimo ou não) entre os extremos de cada aresta associado à aresta, um alinhamento $A$ compatível com cada um dos alinhamentos de pares de seqüências pode ser obtido por aplicações sucessivas do Algoritmo JUNTA, usando para combinar alinhamentos de arestas adjacentes a seqüência que rotula o vértice em que todas as arestas incidem como seqüência guia. 
Exemplo 4.1. Considere o caso em que a árvore é o grafo $G=(V, E) \operatorname{com} V=\{1, \ldots, 5\}$ e $E=\{12,23,24,45\}$, com uma seqüência $s_{i}$ associada ao vértice $i \in V$. Uma primeira chamada ao Algoritmo JunTA poderia ser feita entre os alinhamentos associados às arestas 12,23 e 24, usando-se a seqüência $s_{2}$ como seqüência guia. Após essa chamada, um alinhamento $A^{\prime}$, compatível com cada um dos alinhamentos dados, é devolvido e, obviamente, $A^{\prime}$ inclui a seqüência $s_{4}$. Esse alinhamento pode ser observado como um alinhamento entre $s_{4}$ e uma "seqüência fictícia" composta por todas as outras seqüências e, assim, com mais uma chamada ao Algoritmo JUNTA, agora com o alinhamento $A^{\prime}$ e com o alinhamento associado à aresta 45 , um alinhamento $A$ entre todas as seqüências que rotulam os vértices da árvore é encontrado. Naturalmente, $A$ é compatível com os alinhamentos entre pares de seqüências dados pela árvore.

Por causa da ordem em que os alinhamentos associados a partes da árvore podem ser unidos, pode ser possível que operações de junção de alinhamentos produzam alinhamentos diferentes. Isso significa, em particular, que mais de um alinhamento pode ser compatível com um dado conjunto de alinhamentos ou, em outras palavras, que um alinhamento compatível com vários outros alinhamentos pode não ser único.

\subsection{Algoritmo de Aproximação de Gusfield}

Hoje sabemos que o Problema AVS com pontuação SP é NP-difícil e que as possibilidades de um algoritmo de tempo polinomial ser encontrado são menores por isso. Os métodos para resolução exata do problema giram em torno do método de programação dinâmica (às vezes fazendo uso de estratégias adicionais como a de Carrillo-Lipman) e, de uma forma geral, consomem muito tempo e espaço, mesmo para quantidades modestas de seqüências de aminoácidos com tamanho usual [Kec95].

Por conta desse fato, apesar de uma demonstração formal da NP-dificuldade ter aparecido somente em 1994 [WJ94], algoritmos de aproximação já haviam sido propostos para o problema logo no início da década de 1990.

O primeiro algoritmo de aproximação para o Problema AVS foi proposto por Gusfield [Gus93] e possui uma razão de aproximação de $2-2 / k$. Nos anos subseqüentes, generalizações do algoritmo de Gusfield foram propostas, como a $(2-3 / k)$-aproximação de Pevzner [Pev92] e a $(2-l / k)$-aproximação de Bafna, Lawler e Pevzner [BLP97], para um inteiro $l<k$.

Um fato importante a respeito desses algoritmos é que é essencial para sua corretude que a matriz de pontuação usada seja uma métrica, já que eles fazem uso extensivo de propriedades como a desigualdade triangular para garantir suas razões de aproximação. Naturalmente, nesses casos o Problema AVS é tratado como um problema de minimização.

Um outro algoritmo de aproximação, proposto por Korostensky e Gonnet [KG99], funciona para uma formulação alternativa do problema de alinhamento em que a função objetivo deve ser maximizada. Esta função, todavia, é diferente da pontuação SP. O algoritmo de Korostensky e Gonnet possui razão de aproximação de $(k-1) / k$ e é inspirado no Problema do Caixeiro Viajante.

O algoritmo proposto por Gusfield é conceitualmente simples. A idéia básica do algoritmo é usar alinhamentos ótimos de pares de sequiências para obter um "bom" alinhamento de várias seqüências. Para isso, dadas seqüências $s_{1}, \ldots, s_{k}$, o algoritmo de Gusfield opera fixando uma seqüência $s_{c}$ dentre as $k$ seqüências de entrada (chamada seqüência central) e computando alinhamentos ótimos (de pares) entre $s_{c}$ e cada uma das $k-1$ seqüências de 
$\left\{s_{1}, \ldots, s_{k}\right\} \backslash\left\{s_{c}\right\}$. Após os alinhamentos estarem prontos, ele usa o Algoritmo JunTA que vimos na seção anterior com $s_{c}$ como seqüência guia para encontrar um alinhamento entre todas as $k$ seqüências.

Para a seqüência $s_{c}$ fixada, definimos $M(c)=\sum_{j \neq c} d\left(s_{c}, s_{j}\right)$, onde $d\left(s_{c}, s_{j}\right)$ é a distância entre $s_{c}$ e $s_{j}$ segundo alguma matriz de pontuação pré-estabelecida. O processo é repetido usando-se cada uma das seqüências como seqüência central e, para cada uma delas, computando-se o valor de $M$ correspondente. O alinhamento com valor de $M$ mínimo dentre os $k$ alinhamentos computados é devolvido como resposta.

Por causa de o algoritmo de Gusfield funcionar fixando uma seqüência $s_{c}$ e alinhando as demais seqüências a $s_{c}$, ele é também chamado algoritmo de estrelas (ou algoritmo de estrelas centrais), porque o alinhamento com a seqüência $s_{c}$ fixada pode ser representado por um grafo $G_{c}=\left(V, E_{c}\right)$ em que o conjunto dos vértices é $V=\left\{s_{1}, \ldots, s_{k}\right\}$, em que as arestas de $G_{c}$ são da forma $\left\{s_{c}, s_{j}\right\}$, para $j \neq c$ e um alinhamento ótimo entre $s_{c}$ e $s_{j}$ está associado à aresta $\left\{s_{c}, s_{j}\right\}$. Esse é o motivo por que a seqüência $s_{c}$ é chamada seqüência central.

É ilustrativo comparar o grafo $G_{c}$ com uma situação como a descrita na Seção 4.2.3. Note-se que, nesse caso, o grafo $G_{c}$ é uma estrela e, é claro, um tipo muito particular de árvore (de altura 1). O alinhamento devolvido pelo algoritmo de Gusfield é obviamente compatível com os alinhamentos de pares de seqüências que estão associados às arestas de $G_{c}$.

O pseudo-código do Algoritmo Estrela, que implementa o algoritmo de Gusfield, está descrito a seguir.

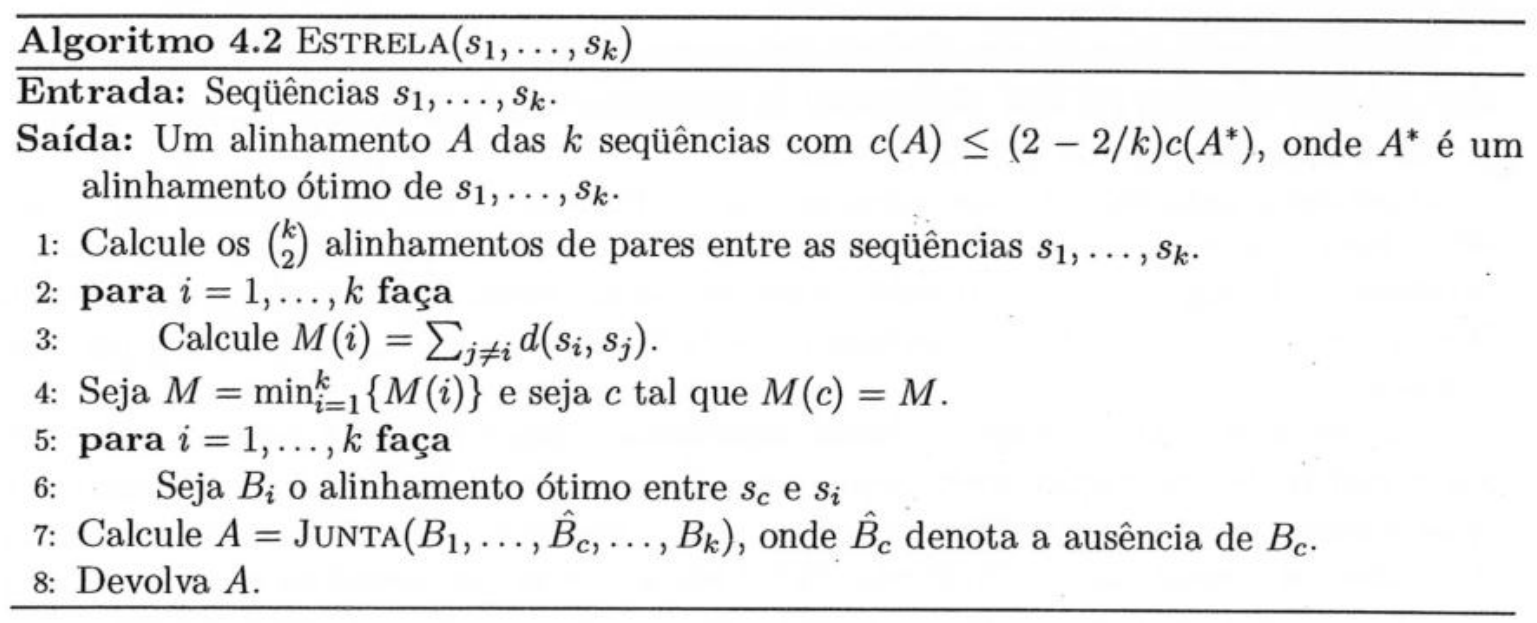

O Algoritmo Estrela é eficiente em comparação com o Algoritmo DisT-AVS. Supondose que as $k$ sequiências possuam comprimento $n$, a primeira linha leva tempo $O\left(\left(\begin{array}{l}k \\ 2\end{array}\right) n^{2}\right)=$ $O\left(k^{2} n^{2}\right)$. O cálculo de cada $M(i)$ leva tempo $O(k)$ e como $M(i)$ é calculado para cada valor de $i$, segue que as linhas 2 e 3 do algoritmo podem ser completadas em tempo $O\left(k^{2}\right)$. A determinação de $M$ e de $c$ pode ser feita em tempo $O(k)$. Na linha 7 , o alinhamento $A$ é calculado em tempo $O((k-1) k n)=O\left(k^{2} n\right)$. Portanto, para $k$ seqüências $s_{1}, \ldots, s_{k}$ de tamanho $n$ cada, o Algoritmo Estrela $\left(s_{1}, \ldots, s_{k}\right)$ devolve um alinhamento $A$ em tempo $O\left(k^{2} n^{2}\right)$. 


\subsubsection{Razão de Aproximação}

Prosseguimos agora com a demonstração de que o Algoritmo Estrela é uma $(2-2 / k)$ aproximação para o Problema AVS, isto é, que o alinhamento $A$ devolvido por Estrela é tal que $c(A) \leq(2-2 / k) c\left(A^{*}\right)$, onde $A^{*}$ é um alinhamento ótimo das seqüências de entrada.

Seja $A$ o alinhamento devolvido por Estrela $\left(s_{1}, \ldots, s_{k}\right)$ e seja $c(A)$ seu custo SP para alguma matriz de pontuação fixada, isto é, $c(A)=\sum_{i<j} c\left(A_{\mid i, j}\right)$, em que $c\left(A_{\mid i, j}\right)$ denota a projeção de $A$ na direção das seqüências $s_{i}$ e $s_{j}$. Desejamos mostrar que $c(A) \leq(2-$ $2 / k) c\left(A^{*}\right)$, onde $A^{*}$ é um alinhamento ótimo de $s_{1}, \ldots, s_{k}$, que significa que o Algoritmo Estrela é uma $(2-2 / k)$-aproximação (polinomial) para o Problema AVS com pontuação SP.

Para facilitar a notação, denotamos aqui por $D\left(s_{i}, s_{j}\right)$ o valor $c\left(A_{\mid i, j}\right)$ e, da mesma maneira, por $D^{*}\left(s_{i}, s_{j}\right)$, o valor $c\left(A_{\mid i, j}^{*}\right)$, para algum alinhamento ótimo $A^{*}$ fixado.

Na demonstração da razão de aproximação, usamos o resultado do lema a seguir.

Lema 4.1 (Desigualdade Triangular para $D$ ). Para todas trincas de seqüências $x, y, z \in$ $\left\{s_{1}, \ldots, s_{k}\right\}$, temos que $D(x, z) \leq D(x, y)+D(y, z)$.

Prova: No alinhamento $A$, fixemos a projeção $A_{\mid x, y, z}$ e seja $q$ uma coluna qualquer de $A_{\mid x, y, z}$. Denotemos por $x^{\prime}, y^{\prime}$ e $z^{\prime}$ respectivamente as seqüencias $x, y$ e $z$ como elas aparecem em $A_{\mid x, y, z}$ (com os espaços inseridos). Como por hipótese a função de pontuação usada satisfaz à desigualdade triangular, para a $q$-ésima coluna de $A_{\mid x, y, z}$, é válido que $c\left(x^{\prime}[q], z^{\prime}[q]\right) \leq c\left(x^{\prime}[q], y^{\prime}[q]\right)+c\left(y^{\prime}[q], z^{\prime}[q]\right)$. Como a coluna tomada é arbitrária, a desigualdade vale para todas colunas e, somando-se as desigualdades de todas colunas membro a membro, segue o resultado do lema ${ }^{1}$.

Agora podemos provar o resultado principal de Gusfield.

Teorema 4.2 (Gusfield, 1993). O Algoritmo Estrela é uma $(2-2 / k)$-aproximação para o Problema AVS.

Prova: Seja $A$ o alinhamento devolvido pelo Algoritmo Estrela e $A^{*}$ um alinhamento ótimo para as seqüências $s_{1}, \ldots, s_{k}$.

Pela definição de $c(A)$ e pela desigualdade triangular satisfeita por $D$, conforme o Lema 4.1, temos que

$$
\begin{aligned}
c(A) & =\sum_{i=1}^{k} \sum_{j=1}^{i-1} D\left(s_{i}, s_{j}\right) \leq \sum_{i=1}^{k} \sum_{j=1}^{i-1}\left[D\left(s_{i}, s_{c}\right)+D\left(s_{c}, s_{j}\right)\right] \\
& =\sum_{i=1}^{k} \sum_{j=1}^{i-1} D\left(s_{i}, s_{c}\right)+\sum_{i=1}^{k} \sum_{j=1}^{i-1} D\left(s_{c}, s_{j}\right),
\end{aligned}
$$

onde $s_{c}$ é o centro que o algoritmo escolheu.

Mas para $i^{\prime}$ fixado, o termo $D\left(s_{c}, s_{i^{\prime}}\right)$ aparece $i^{\prime}-1$ vezes no primeiro somatório de (4.1) (quando $i=i^{\prime}$ e, aí, o somatório possui $i^{\prime}-1$ termos $D\left(s_{i^{\prime}}, s_{c}\right)=D\left(s_{c}, s_{i^{\prime}}\right)$ ) e $k-i^{\prime}$ vezes no segundo somatório (nos somatórios internos ao segundo somatório, $D\left(s_{c}, s_{i^{\prime}}\right)$ aparece somente quando $i>i^{\prime}$ - ou seja, para $k-i^{\prime}$ valores de $i$ - e exatamente uma vez para cada um desses valores). Assim, para cada $i^{\prime}$ entre 1 e $k$, o termo $D\left(s_{c}, s_{i^{\prime}}\right)$ aparece $k-1$ vezes em (4.1).

\footnotetext{
${ }^{1} \mathrm{O}$ lema é válido também para outras funções definidas da mesma forma que $D$, como, por exemplo, $D^{*}$.
} 
Logo, $c(A) \leq(k-1) \sum_{i=1}^{k} D\left(s_{i}, s_{c}\right)$. Como a projeção de $A$ na direção das sequiências $s_{c}$ e $s_{i}$ é um alinhamento ótimo pela forma como $A$ é construído, temos que $D\left(s_{i}, s_{c}\right)=d\left(s_{i}, s_{c}\right)$ para todo $i$, de onde pode-se concluir que

$$
c(A) \leq(k-1) \sum_{i=1}^{k} d\left(s_{c}, s_{i}\right)=(k-1) M(c)=(k-1) M,
$$

em que $M$ é o valor computado pelo Algoritmo Estrela.

Por outro lado, $c\left(A^{*}\right)=\sum_{i=1}^{k} \sum_{j=1}^{i-1} D^{*}\left(s_{i}, s_{j}\right)=\frac{1}{2} \sum_{i=1}^{k} \sum_{j=1}^{k} D^{*}\left(s_{i}, s_{j}\right)$. Mas como $D^{*}\left(s_{i}, s_{j}\right) \geq d\left(s_{i}, s_{j}\right)$, então

$$
\begin{aligned}
c\left(A^{*}\right) & \geq \frac{1}{2} \sum_{i=1}^{k} \sum_{j=1}^{k} d\left(s_{i}, s_{j}\right)=\frac{1}{2} \sum_{i=1}^{k} M(i) \\
& \geq \frac{1}{2} \sum_{i=1}^{k} M(c)=\frac{1}{2} k M(c)=\frac{1}{2} k M,
\end{aligned}
$$

onde a última desigualdade segue do fato de que $s_{c}$ é escolhida de forma que o valor $M(c)$ seja mínimo.

Acoplando as desigualdades (4.2) e (4.3), temos que

$$
c(A) \leq(k-1) M \leq(k-1) \frac{2}{k} c\left(A^{*}\right)=\left(2-\frac{2}{k}\right) c\left(A^{*}\right),
$$

de onde segue que o Algoritmo Estrela é uma $(2-2 / k)$-aproximação polinomial para o Problema AVS com pontuação SP.

\subsubsection{Comentários Gerais}

O artigo de Gusfield [Gus93] apresenta ainda uma curta e interessante análise de uma versão probabilística do Algoritmo Estrela. Nessa versão, em vez de $k$ estrelas serem construídas (cada uma correspondendo a uma seqüência tomada como centro) e a de menor valor $M$ ser devolvida, o algoritmo probabilístico constrói apenas $p \leq k$ estrelas e escolhe a de menor valor associado.

Isso pode permitir que nem todos os $\left(\begin{array}{c}k \\ 2\end{array}\right)$ alinhamento entre as seqüências $s_{1}, \ldots, s_{k}$ sejam computados, dando margem a uma possível economia de tempo em relação à versão determinística do algoritmo. Nesse caso, em vez de computar alinhamentos ótimos entre cada par de seqüências, uma seqüência $s_{i}$ pode ser escolhida para ser o centro de uma estrela e $k-1$ alinhamentos ótimos (um com cada uma das outras seqüências) serem computados. Se $p$ centros são escolhidos, então é suficiente calcular $(k-1) p$ alinhamentos, o que pode representar uma vantagem se $p$ for pequeno em relação a $k$.

Para essa variante do algoritmo, é possível mostrar [Gus93] que o alinhamento gerado possui, com grande probabilidade, pontuação SP que não é muito maior do que a pontuação ótima. Mais especificamente, é possível mostrar [Gus93] que se $r>1$ e se $E(r)$ é o número esperado de estrelas a serem construídas até que o melhor alinhamento conseguido tenha pontuação a $2+1 /(r-1)$ do ótimo, então $E(r) \leq r$ ou, posto de outra maneira, para $r>1$, construindo-se $p$ alinhamentos com centros escolhidos aleatoriamente e escolhendo-se o alinhamento que possui o menor valor associado, a solução terá valor que está a $2+1 /(r-1)$ do ótimo com probabilidade pelo menos $1-[(r-1) / r]^{p}$. 
O método de Carrillo-Lipman necessita de um limite superior $U$ no custo $c\left(A^{*}\right)$ do alinhamento ótimo $A^{*}$ para delimitar a região de busca no reticulado de programação dinâmica. O algoritmo de estrelas de Gusfield pode ser utilizado para obter (rapidamente) um alinhamento $A$ com valor relativamente próximo ao do ótimo do Problema AVS e, assim, uma limitação superior no valor $c\left(A^{*}\right)$ do alinhamento ótimo.

Alternativamente, uma observação do raciocínio do Teorema 4.2 nos revela que, na notação usada na Seção $2.5, L=\frac{1}{2} \sum_{i=1}^{k} \sum_{j=1}^{k} d\left(s_{i}, s_{j}\right)=\frac{1}{2} \sum_{i=1}^{k} M(i)$ e que como o centro $c$ é escolhido de forma a minimizar a função $M, L \geq \frac{1}{2} \sum_{i=1}^{k} M(c)=\frac{k}{2} M(c)$, isto é, $M(c) \leq \frac{2}{k} L$ e, em conjunto com a desigualdade (4.2), segue que $c\left(A^{*}\right) \leq c(A) \leq(2-2 / k) L$. Disso segue que, adotando como limite superior no custo de um alinhamento ótimo o valor $U=(2-2 / k) L$, a constante de Carrillo-Lipman fica $C=U-L=(1-2 / k) L$, o que significa que uma estimativa para a constante de Carrillo-Lipman pode ser feita apenas com o conhecimento das seqüências a serem alinhadas, sem a necessidade de pré-computar um alinhamento inicial para referência (para usar seu valor como $U$ ). Naturalmente, nesse caso a constante de Carrillo-Lipman usada poderá ser maior do que se um alinhamento for calculado pelo algoritmo de aproximação e, portanto, possivelmente um número menor de nós do reticulado poderá ser eliminado da computação.

Ainda assim é interessante constatar que a análise do Teorema 4.2 pode fornecer um limite superior não trivial ao custo de um alinhamento ótimo.

A análise da razão de aproximação dada pelo Teorema 4.2 é uma análise de pior caso e, para várias situações, o alinhamento devolvido pelo Algoritmo Estrela pode ter valor bem mais próximo do valor ótimo do que o teorema prevê para o pior caso. Em seu artigo, Gusfield faz uma análise empírica dos resultados obtidos pelo Algoritmo Estrela e nota que os alinhamentos devolvidos para seus testes possuem valor no máximo $16 \%$ piores do que o valor ótimo [Gus93].

\subsection{Algoritmo de l-Estrelas}

O algoritmo de Gusfield é conceitualmente simples em sua tentativa de agregar vários "pequenos" alinhamentos ótimos para obter um alinhamento "grande", com várias seqüências. Essa idéia básica foi generalizada para obter outros algoritmos de aproximação.

Em 1992, Pevzner publicou um artigo [Pev92] cuja idéia central é juntar alinhamentos ótimos de trincas de seqüências (em vez de pares de seqüências como no algoritmo de Gusfield) para obter uma $(2-3 / k)$-aproximação para o Problema AVS de $k$ seqüências com pontuação SP.

No artigo, Pevzner relaciona a garantia de aproximação do algoritmo com o custo de comunicação normalizado de um grafo associado às seqüências (de maneira semelhante ao uso de estrelas feito por Gusfield).

Por observação das garantias de aproximação conseguidas com alinhamentos ótimos de pares e de trincas de seqüências, Pevzner conjecturou ainda que seria possível obter uma $(2-l / k)$-aproximação para o Problema AVS com pontuação SP se (após uma escolha adequada) alinhamentos ótimos de $l$ seqüências fossem agregados.

A conjectura foi confirmada positivamente por um artigo em 1997 em que Bafna, Lawler e Pevzner [BLP97] mostraram um algoritmo de aproximação aos moldes dos de Gusfield e de Pevzner que dá garantia de erro de $(2-l / k)$, para um inteiro arbitrário $l$ que seja $2 \leq l<k$. Esse é o algoritmo que passamos a descrever em linhas gerais a partir de agora. 


\subsubsection{Definições}

O conceito central em que o algoritmo de Bafna, Lawler e Pevzner está apoiado é uma classe especial de grafos chamados $l$-estrelas.

Definição 4.2 (Clique). Dado um grafo $G=(V, E)$ um clique $\Omega$ de $G$ é um subgrafo completo e maximal de $G$. O tamanho do clique $\Omega$ é definido como o número de vértices de $\Omega$ e é denotado por $|\Omega|$.

Definição 4.3 (l-Estrela). Seja $G=(V, E)$ um grafo com $|V|=k$ vértices e seja $l \geq 2$ um inteiro tal que $l-1 \mid k-1$. Se $G$ possui $r=(k-1) /(l-1)$ cliques $\Omega_{1}, \ldots, \Omega_{r}$ com $\left|\Omega_{1}\right|=\cdots=\left|\Omega_{r}\right|=l$ e existe um vértice $c \in V$ tal que $\Omega_{i} \cap \Omega_{j}=\{c\}$, para todo par $i, j=1, \ldots, r$ com $i \neq j$, então $G$ é dito ser uma $l$-estrela. O vértice $c$ é chamado vértice central ou centro da $l$-estrela $G$. Uma aresta de $G$ que liga $c$ a um outro vértice qualquer é chamada aresta central.

A definição acima generaliza o conceito de estrelas empregado no algoritmo de Gusfield. De acordo com a definição de $l$-estrelas, uma estrela usual é uma 2-estrela (caso em que os cliques têm tamanho 2 e são as arestas do grafo).

A Figura 4.1 mostra uma 4-estrela com 10 vértices.

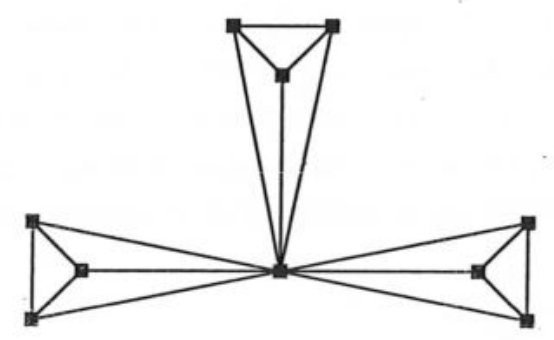

Figura 4.1: Uma 4-estrela com 10 vértices. Cada clique do grafo possui $l \doteq 4$ vértices e há um total de $r=3$ cliques na estrela.

Se uma $l$-estrela $G$ com $k$ vértices possui cada um de seus vértices rotulado por uma seqüência distinta dentre $k$ seqüências $s_{1}, \ldots, s_{k}$ e, além disso, $r$ alinhamentos $A_{1}, \ldots, A_{r}$ são dados de maneira que $A_{i}$ seja um alinhamento entre as seqüências do clique $\Omega_{i}$ de $G$, então é simples de ver que existe um alinhamento $A$ que é compatível com cada um dos alinhamentos $A_{i}$, já que $A$ pode ser obtido por meio de aplicações do Algoritmo JunTA. Isso é possível porque os cliques $\Omega_{i}$ possuem precisamente um vértice em comum (o vértice central $c$ ) e a seqüência que rotula $c$ pode ser usada como seqüência guia.

Uma decorrência trivial da discussão acima (mas importante para o algoritmo de aproximação) é a seguinte:

Lema 4.3. No caso em que cada $A_{i}$ é um alinhamento ótimo das seqüências que rotulam os vértices de $\Omega_{i}$, existe um alinhamento que é compativel com cada alinhamento ótimo de seqüências que rotulam os vértices dos cliques. Ademais, um tal alinhamento pode ser determinado em tempo $O\left(r^{2} k n\right)=O\left(k^{3} n\right)$ pelo Algoritmo JUNTA se as seqüências possuírem tamanho $O(n)$ e se os alinhamentos $A_{i}$ forem dados.

Para simplificar a linguagem, quando não houver risco de ambigüidade não faremos distinção entre os vértices de uma $l$-estrela e as seqüências que rotulam esses vértices. 


\subsubsection{Custo de Comunicação de Grafos e l-Estrelas}

Lembremos que, dado um alinhamento $A$ de $k$ seqüências, seu custo SP é definido como $\mathrm{SP}(A)=\sum_{1 \leq i<j \leq k} \mathrm{SP}\left(A_{\mid i, j}\right)$. Se definirmos a matriz $S(A)$ de dimensões $k \times k$ como $S(A)=\left(\operatorname{SP}\left(A_{\mid i, j}\right)\right)$ e a matriz $U=\left(U_{i j}\right)$, também de dimensões $k \times k$, de forma que $U_{i j}=0$ para $i=j$ e $U_{i j}=1$ para $i \neq j$, então o produto escalar de $U$ por $S(A)$ será $U \cdot S(A)=2 \mathrm{SP}(A)$. Para simplificar a discussão, vamos trabalhar no restante do capítulo com $U \cdot S(A)$ em vez de $(U \cdot S(A)) / 2$.

$\mathrm{O}$ caso mais geral em que a pontuação SP é ponderada (ou seja, na situação em que $\left.\mathrm{SP}_{W}(A)=\sum_{i<j} W_{i j} \mathrm{SP}\left(A_{\mid i j}\right)\right)$ para escalares $W_{i j}$ pode também ser representado como um produto escalar de uma matriz simétrica de pesos $W=\left(W_{i j}\right)$ pela matriz $S(A)$ porque $W \cdot S(A)=2 \mathrm{SP}_{W}(A)$. Para nossas intenções, supomos que matrizes de pesos usadas para ponderar pontuações de alinhamentos sejam sempre matrizes simétricas.

Conforme vimos no Capítulo 2, o problema geral de calcular um alinhamento ótimo com pontuação SP ponderada pode também ser resolvido pelo algoritmo de programação dinâmica em tempo $O\left(k^{2} 2^{k} n^{k}\right)$.

Dada uma $l$-estrela $G$ de $k$ vértices com centro $c$, definimos a matriz $W_{G}=\left(W_{i j}\right)$ de dimensões $k \times k$ por

$$
W_{i j}= \begin{cases}k-l+1, & \text { se } i \neq j \text { e }(i=c \text { ou } j=c) \\ 1, & \text { se } i \neq c \text { e } j \neq c \text { e } i, j \text { pertencem a um mesmo clique de } G \\ 0, & \text { caso contrário. }\end{cases}
$$

Observe-se que definimos como 0 o peso das "arestas inexistentes" de G. É importante também notar que

$$
W_{G} \cdot U=2\left[(k-l+1)(k-1)+r\left(\begin{array}{c}
l-1 \\
2
\end{array}\right)\right]=2\left(\begin{array}{l}
k \\
2
\end{array}\right)\left(2-\frac{l}{k}\right) .
$$

Existe uma interpretação "geométrica" tanto para os pesos $W_{i j}$ que definem a matriz $W_{G}$ quanto para a quantia $W_{G} \cdot U$.

Definição 4.4 (Distância entre vértices). Se $G=(V, E)$ é um grafo qualquer conexo e não-dirigido, definimos para cada par de vértices $x, y \in V$ a distância $d(x, y)$ entre os vértices $x$ e $y$ como o número de arestas de um caminho $\gamma(x, y)$ de menor comprimento que liga o vértice $x$ ao vértice $y$.

Para simplificar, supomos que os vértices de G sejam $V=\{1, \ldots, k\}$.

Definição 4.5 (Custo de Comunicação). O custo de comunicação de $G$ é definido como $c(G)=\sum_{x<y} d(x, y)$.

Observe-se que como $x \neq y \Rightarrow d(x, y) \geq 1$, então fixado um número de vértices $k$, o grafo completo $H_{k}$ de $k$ vértices é o grafo com menor custo de comunicação dentre os grafos com $k$ vértices e seu custo de comunicação é $c\left(H_{k}\right)=\sum_{x<y} d(x, y)=\sum_{x<y} 1=\left(\begin{array}{l}k \\ 2\end{array}\right)$.

Definição 4.6 (Custo de comunicação normalizado). Define-se o custo de comunicação normalizado $b(G)$ do grafo $G$ de $k$ vértices como a relação entre o custo de comunicação de $G$ e o custo de comunicação de $H_{k}$, de modo que $b(G)=c(G) / c\left(H_{k}\right)=c(G) /\left(\begin{array}{c}k \\ 2\end{array}\right)$. 
Fixemos uma família $\Gamma(G)=\{\gamma(x, y): x, y \in V\}$ de caminhos de menor comprimento para cada par de vértices $x, y \in V$, de maneira que $\Gamma(G)$ contenha exatamente 1 caminho entre cada par de vértices de $G$. Se $\Gamma_{e}(G)=\{\gamma \in \Gamma(G): e \in \gamma\}$, é simples de constatar que o custo $c(G)=\sum_{e \in E}\left|\Gamma_{e}(G)\right|$, onde naturalmente $\left|\Gamma_{e}(G)\right|$ é o número de caminhos da família $\Gamma(G)$ que contém a aresta $e$.

No caso particular em que $G$ é uma $l$-estrela, há apenas uma família $\Gamma(G)$ de caminhos de menor comprimento de $G$ e os pesos $W_{x y}$ que definimos acima na matriz $W_{G}$ são tais que $W_{x y}=\left|\Gamma_{x y}(G)\right|$. Isso significa que $U \cdot W_{G}$ e os custos $b(G)$ e $c(G)$ relacionam-se por $U \cdot W_{G}=2 c(G)=2 c\left(H_{k}\right) b(G)$ e que, portanto, o custo de comunicação normalizado de uma $l$-estrela de $k$ vértices é $b(G)=2-l / k$.

Um resultado que é importante para provar a garantia do algoritmo de aproximação de Bafna, Lawler e Pevzner é o lema que apresentamos a seguir.

Lema 4.4 (Delimitação superior para $U \cdot S(A)$ ). Se $A$ é um alinhamento qualquer entre as seqüências $s_{1}, \ldots, s_{k}$ e $G$ é uma l-estrela com $|V|=k$ cujos vértices são rotulados pelas seqüências de $A$, então $U \cdot S(A) \leq W_{G} \cdot S(A)$.

Prova: Seja $H_{k}$ o grafo completo com $k$ vértices e para cada aresta $e \in E\left(H_{k}\right)$, definimos o peso de $e$ como 1 . Nessa situação, a matriz $U$ pode ser interpretada como uma matriz de pesos $W_{H_{k}}$ de $H_{k}$ da maneira definida pela equação (4.4) onde os valores da diagonal principal de $W_{H_{k}}$ são definidos como 0 e, trivialmente, $U \cdot S(A)=W_{H_{k}} \cdot S(A)$. Isso ocorre porque o grafo $H_{k}$ é trivialmente um clique de tamanho $l=k$ e qualquer um de seus vértices pode ser escolhido como o vértice central (esta escolha arbitrária ocorre pela simetria existente entre os vértices) e a definição dada de $W_{G}$ para uma $l$-estrela $G$ também se aplica para este caso.

Para o resultado, vamos descrever uma seqüência de operações que definem uma seqüência de grafos (com pesos nas arestas) $G_{0}, G_{1}, \ldots, G_{m}$ de modo que $G_{0}=H_{k}, G_{m}=G$ e tal que $W_{G_{i}} \cdot S(A) \leq W_{G_{i+1}} \cdot S(A)$, para $i=0, \ldots, m-1$. Na seqüência, $m=(k-l)(k-1) / 2$. Em outras palavras, a seqüência de operações define uma seqüência de grafos de custo de comunicação não-decrescente com o primeiro grafo sendo o grafo completo e o último grafo sendo a $l$-estrela $G$.

O processo é o seguinte. Seja $x y$ uma aresta de $G_{i}$ que tenha peso positivo e que não esteja presente na $l$-estrela $G$ (isto é, $x$ e $y$ pertencem a cliques diferentes de $G$ ). Definamos $G_{i+1}$ como sendo o grafo igual a $G_{i}$ com a aresta $x y$ com peso igual a 0 e com as arestas $x c$ e $c y$ ( $c$ é o vértice central de $G$ ) com peso incrementado de 1 unidade em relação ao peso que elas tinham em $G_{i}$. Todas as outras arestas e seus pesos permanecem inalterados de $G_{i}$ para $G_{i+1}$. Neste processo, podemos imaginar que as arestas de $G_{i}$ com peso nulo estão "removidas" em relação ao grafo completo $H_{k}$.

Com isso, $W_{G_{i+1}} \cdot S(A)-W_{G_{i}} \cdot S(A)=\left(W_{G_{i+1}}-W_{G_{i}}\right) \cdot S(A)=2\left(S\left(A_{\mid x, c}\right)+S\left(A_{\mid c, y}\right)-\right.$ $\left.S\left(A_{\mid x, y}\right)\right) \geq 0$ pois $S\left(A_{\mid x, y}\right) \leq S\left(A_{\mid x, c}\right)+S\left(A_{\mid c, y}\right)$, pela desigualdade triangular mostrada no Lema 4.1. Logo, para dois grafos consecutivos $G_{i}$ e $G_{i+1}$ na seqüência, vale que $W_{G_{i}} \cdot S(A) \leq$ $W_{G_{i}} \cdot S(A)$. O processo é repetido até que o grafo $G$ seja obtido pela "remoção" de arestas.

Dessa forma, observando que $W_{x y}=\left|\Gamma_{x y}(G)\right|$ para cada aresta $x y$ presente em $G$ e $W_{x y}=0$ para os outros casos, temos que $W_{G_{0}}=U$ e $W_{G_{m}}=W_{G}$, de onde segue que $U \cdot S(A) \leq W_{G} \cdot S(A)$ e, assim, o resultado está provado.

Os Lemas 4.3 e 4.4 possuem uma conexão, conforme diz o próximo lema:

Lema 4.5 (Alinhamento ótimo baseado em uma l-estrela). Seja $G$ uma l-estrela com cada um de seus vértices rotulado por uma seqüência única dentre $s_{1}, \ldots, s_{k}$ e seja 
$W_{G}$ a matriz de pesos de $G$. Sejam $W_{1}, \ldots, W_{r}$ as submatrizes de $W_{G}$ correspondentes aos cliques $\Omega_{1}, \ldots, \Omega_{r}$ e sejam $A_{1}^{*}, \ldots, A_{r}^{*}$ alinhamentos ótimos das seqüências dos cliques $\Omega_{1}, \ldots, \Omega_{r}$ ponderados por $W_{1}, \ldots, W_{r}$, respectivamente. Então, o alinhamento $A$ construído por $\operatorname{JUNTA}\left(A_{1}^{*}, \ldots, A_{r}^{*}\right)$ é um alinhamento ótimo em relação à pontuação SP ponderada por $W_{G}$.

Prova: Para provar o resultado, vejamos inicialmente que a pontuação SP ponderada por $W_{G}$ de $A$ é

$$
\begin{aligned}
W_{G} \cdot S(A) & =2 \sum_{x y \in E} W_{x y} S\left(A_{\mid x y}\right)=2 \sum_{i=1}^{r} \sum_{x y \in E\left(\Omega_{i}\right)} W_{x y} S\left(A_{\mid x y}\right) \\
& =\sum_{i=1}^{r}\left(2 \sum_{x y \in E\left(\Omega_{i}\right)} W_{x y} S\left(A_{\mid x y}\right)\right)
\end{aligned}
$$

Mas como o alinhamento $A$ é compatível com cada $A_{i}^{*}$, tem-se que, para todo $i=1, \ldots, r$,

$$
2 \sum_{x y \in E\left(\Omega_{i}\right)} W_{x y} S\left(A_{\mid x y}\right)=2 \sum_{x y \in E\left(\Omega_{i}\right)} W_{x y} S\left(A_{i \mid x y}^{*}\right)=W_{i} \cdot S\left(A_{i}^{*}\right) .
$$

Logo,

$$
W_{G} \cdot S(A)=\sum_{i=1}^{r} W_{i} \cdot S\left(A_{i}^{*}\right) .
$$

Como por hipótese sabemos que $A_{i}^{*}$ é um alinhamento ótimo, então para qualquer alinhamento $A^{\prime}$ das $k$ seqüências temos que a projeção $A_{\mid \Omega_{i}}^{\prime}$ de $A^{\prime}$ na direção de $\Omega_{i}$ satisfaz $W_{i} \cdot S\left(A_{i}^{*}\right) \leq W_{i} \cdot S\left(A_{\mid \Omega_{i}}^{\prime}\right)$ e, como conseqüência,

$$
\begin{aligned}
W_{G} \cdot S(A) & =\sum_{i=1}^{r} W_{i} \cdot S\left(A_{i}^{*}\right) \leq \sum_{i=1}^{r} W_{i} \cdot S\left(A_{\mid \Omega_{i}}^{\prime}\right) \\
& =W_{G} \cdot S\left(A^{\prime}\right),
\end{aligned}
$$

em que a última igualdade justifica-se por (4.6) ser válida para um alinhamento qualquer e não apenas para o resultado de JUNTA, uma vez que nenhuma propriedade intrínseca de tal alinhamento é necessária, de forma que (4.6) vale também para $A^{\prime}$.

Como $A^{\prime}$ é arbitrário, o alinhamento $A$ devolvido pelo Algoritmo JunTa é ótimo em relação à pontuação SP ponderada por $W_{G}$, como desejávamos mostrar.

Para facilitar a memorização, vamos denotar daqui em diante o alinhamento ótimo em relação aos pesos $W_{G}$ por $A_{G}$.

É claro que, após as seqüências $s_{1}, \ldots, s_{k}$ estarem associadas a vértices de uma $l$-estrela $G$, cada alinhamento $A_{i}^{*}$ pode ser calculado em tempo $O\left(l^{2} 2^{l} n^{l}\right)$ e $A_{G}$ pode ser calculado em tempo $r O\left(l^{2} 2^{l} n^{l}\right)+O\left(r^{2} k n\right)$.

Definição 4.7 (Conjunto Balanceado de $l$-Estrelas). Seja $\mathcal{G}$ um conjunto de $l$-estrelas sobre o conjunto de vértices $V=\{1, \ldots, k\}$. Dizemos que $\mathcal{G}$ é um conjunto balanceado se $\sum_{G \in \mathcal{G}} W_{G}=p U$, para algum escalar $p$. 
Intuitivamente, um conjunto balanceado de $l$-estrelas é um conjunto que possui $l$-estrelas em disposições suficientes para que, quando uma bijeção entre as seqüências $s_{1}, \ldots, s_{k}$ e o conjunto $V=\{1, \ldots, k\}$ fica fixada, haja alinhamentos suficientes da forma descrita pelo Lema 4.5. Em outras palavras, um conjunto balanceado não tem excesso de algum determinado tipo de $l$-estrelas (digamos, conter apenas estrelas que tenham um dado vértice fixado como centro) em detrimento de outros tipos: todos tipos são representados eqüitativamente.

Assim, se houver uma bijeção entre as seqüências $s_{1}, \ldots, s_{k}$ e os vértices $V=\{1, \ldots, k\}$, um conjunto de $l$-estrelas balanceado sobre $V$ representará alinhamentos entre várias das diferentes disposições dadas pelos alinhamentos ótimos.

Teorema 4.6. Se $\mathcal{G}$ é um conjunto balanceado de l-estrelas, então

$$
\min _{G \in \mathcal{G}} W_{G} \cdot S\left(A_{G}\right) \leq \frac{p}{|\mathcal{G}|} \min _{A} U \cdot S(A)
$$

onde $A$ varia no conjunto de alinhamentos de $s_{1}, \ldots, s_{k}$.

Prova: O argumento usado para a demonstração é baseado no fato de que a média de uma coleção de números é pelo menos igual ao menor dos números.

Com isso em mente, $\min _{G \in \mathcal{G}} W_{G} \cdot S\left(A_{G}\right) \leq \frac{1}{|\mathcal{G}|} \sum_{G \in \mathcal{G}} W_{G} \cdot S\left(A_{G}\right)$. Mas como $A_{G}$ é ótimo em relação aos pesos $W_{G}$ pelo Lema 4.5 , segue que $\frac{1}{|\mathcal{G}|} \sum_{G \in \mathcal{G}} W_{G} \cdot S\left(A_{G}\right) \leq \frac{1}{|\mathcal{G}|} \sum_{G \in \mathcal{G}} W_{G} \cdot$ $S(A)$, para um alinhamento $A$ fixado qualquer. Mas o segundo membro da desigualdade pode ser reescrito como $\frac{1}{|\mathcal{G}|} \sum_{G \in \mathcal{G}} W_{G} \cdot S(A)=\frac{1}{|\mathcal{G}|}\left(\sum_{G \in \mathcal{G}} W_{G}\right) \cdot S(A)=\frac{p}{|\mathcal{G}|} U \cdot S(A)$. Disso conclui-se que $\min _{G \in \mathcal{G}} W_{G} \cdot S\left(A_{G}\right) \leq \frac{p}{|\mathcal{G}|} U \cdot S(A)$.

Como o alinhamento $A$ é arbitrário, a afirmação anterior é válida, em particular, para o alinhamento ótimo $A^{*}$ das seqüências $s_{1}, \ldots, s_{k}$ com função objetivo igual à pontuação SP simples (não-ponderada). Isso significa que $\min _{G \in \mathcal{G}} W_{G} \cdot S\left(A_{G}\right) \leq \frac{p}{|\mathcal{G}|} \min _{A} U \cdot S(A)=$ $\frac{p}{|\mathcal{G}|} U \cdot S\left(A^{*}\right)$, o que prova o resultado.

O teorema anterior é um resultado bastante importante pois ele fornece uma relação entre o custo de um alinhamento ponderado ótimo para $l$-estrelas e o custo de um alinhamento ótimo das seqüências. O fator $p /|\mathcal{G}|$ presente na expressão é o foco do lema a seguir:

Lema 4.7. Se $\mathcal{G}$ é um conjunto balanceado de l-estrelas, então $\frac{p}{|\mathcal{G}|}=(2-l / k)$.

Prova: Como $\mathcal{G}$ é um conjunto balanceado de $l$-estrelas, sabemos que $\sum_{G \in \mathcal{G}} W_{G}=p U$ de onde decorre que $\sum_{G \in \mathcal{G}} W_{G} \cdot U=p U \cdot U$. Por argumentos anteriores, sabemos que $W_{G} \cdot U=2\left(\begin{array}{c}k \\ 2\end{array}\right)(2-l / k)$ para todo $G \in \mathcal{G}$. Naturalmente, $U \cdot U=2\left(\begin{array}{c}k \\ 2\end{array}\right)$. Como conseqüência, $2\left(\begin{array}{c}k \\ 2\end{array}\right)(2-l / k)|\mathcal{G}|=2\left(\begin{array}{c}k \\ 2\end{array}\right) p$ e, daí,

$$
\frac{p}{|\mathcal{G}|}=\left(2-\frac{l}{k}\right)
$$

O Teorema 4.6 e o Lema 4.7 nos dão os recursos necessários para demonstrar o seguinte corolário:

Corolário 4.8 (Bafna, Lawler e Pevzner, 1997). Se $\mathcal{G}$ é um conjunto balanceado de l-estrelas, $G^{*}$ é uma l-estrela que minimiza a quantia $W_{G} \cdot S\left(A_{G^{*}}\right)$ e $A^{*}$ é um alinhamento ótimo das seqüências em relação à pontuação SP não-ponderada, então $U \cdot S\left(A_{G^{*}}\right) \leq(2-$ $l / k) U \cdot S\left(A^{*}\right)$. 
Prova: Pelo Lema 4.4, sabemos que $G^{*}$ é tal que $U \cdot S\left(A_{G^{*}}\right) \leq W_{G^{*}} \cdot S\left(A_{G^{*}}\right)$. Além disso, pelo Teorema 4.6 e pelo Lema 4.7 , temos que $W_{G^{*}} \cdot S\left(A_{G^{*}}\right) \leq(2-l / k) U \cdot S\left(A^{*}\right)$ e o resultado segue dessas duas desigualdades.

Todo o raciocínio do que foi provado até agora sugere o algoritmo de aproximação descrito a seguir para o Problema AVS com pontuação SP.

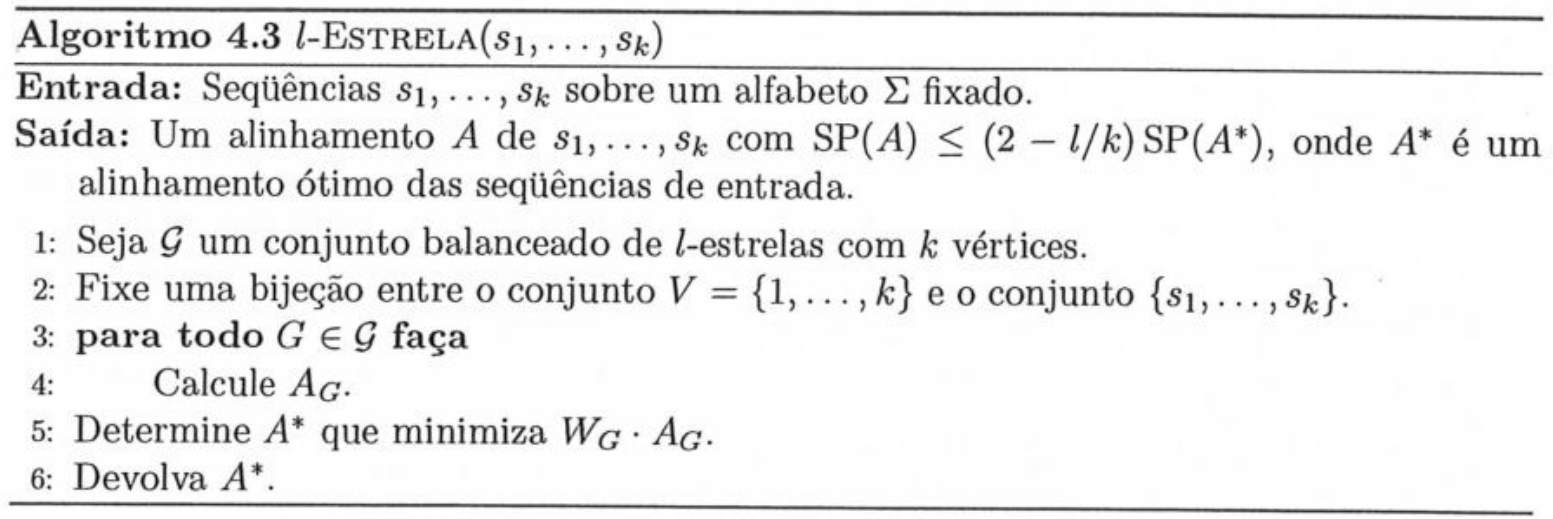

O Algoritmo $l$-Estrela possui razão de aproximação $2-l / k$, de acordo com o Corolário 4.8. Mas há um problema com ele, que é o passo de número 1: a enumeração do conjunto $\mathcal{G}$ pode ser demorada porque $\mathcal{G}$ pode ser muito grande. Na realidade, o conjunto $\mathcal{G}$ pode ser de tamanho exponencial em relação aos dados de entrada, dependendo de como sua escolha é feita.

Um exemplo disso é o caso em que $\mathcal{G}$ é tomado como o conjunto de todas as possíveis $l$-estrelas. Esse conjunto é um conjunto balanceado, por simetria, mas, dependendo dos parâmetros $l$ e $k$, ele pode ser muito grande. O número de possíveis $l$-estrelas de tamanho $k$ (com $r$ cliques) e fixado o centro $c$ é igual a

$$
\frac{\left(\begin{array}{l}
k-1 \\
l-1
\end{array}\right)\left(\begin{array}{c}
k-l \\
l-1
\end{array}\right)\left(\begin{array}{c}
k-2 l+1 \\
l-1
\end{array}\right) \cdots\left(\begin{array}{l}
l-1 \\
l-1
\end{array}\right)}{r !}=\frac{(k-1) !}{[(l-1) !]^{r} r !} .
$$

Como existem $k$ possibilidades para o centro $c$ e para cada uma dessas possibilidades há o mesmo número de $l$-estrelas (e as possibilidades para cada um dos centros são diferentes se $l<k$ ), segue que, dados $l$ e $k \operatorname{com} l<k$, existem $\frac{k !}{\left[(l-1) ! !{ }^{r} r !\right.}$ possíveis $l$-estrelas com $k$ vértices.

Se $l=k$, a $l$-estrela é um grafo completo e para qualquer escolha de centro, as $l$-estrelas possíveis são sempre as mesmas e em número igual a $(k-1) ! /\left[(k-1) !^{1} 1 !\right]=1$.

\subsubsection{O Algoritmo $l$-Estrela no Caso $l=2$}

Da mesma forma que o Algoritmo l-Estrela, o algoritmo de Gusfield restringe suas buscas a uma classe de grafos $\mathcal{G}$. No caso particular do algoritmo de Gusfield, os cliques dos grafos considerados (i.e., os grafos de $\mathcal{G}$ ) possuem tamanho $l=2$ e toda aresta é uma aresta central. Dessa forma, se $G$ é uma 2-estrela, a matriz de pesos $W_{G}$ tem entradas da forma:

$$
W_{i j}= \begin{cases}k-l+1=k-1, & \text { se } i j \in E(G) \\ 0, & \text { caso contrário. }\end{cases}
$$

Intuitivamente, dado um vértice $x \neq c$, a aresta $x c$ pertence ao caminho mínimo de $x$ a $c$ (que possui tamanho 1) e de $x$ a $y$, para todo $y \in V \backslash\{x, c\}$, isto é, $x c$ pertence a 
$k-1$ caminhos mínimos de $G$. Como toda aresta de $G$ tèm a forma $x c$ e a afirmação acima vale para qualquer uma das arestas, vemos que a matriz de pesos $W_{G}$ realmente reflete os números de caminhos mínimos a que as arestas de $G$ pertencem.

Observe-se que para cada $c \in V$, existe apenas uma 2-estrela $G_{c}$ que tem $c$ como centro. O conjunto usado pelo Algoritmo Estrela de Gusfield é $\mathcal{G}=\left\{G_{c}: c \in V\right\}$, que contém todas as $k$ diferentes $l$-estrelas e é balanceado. Para ver isso, seja $W_{c, i j}$ a entrada $i, j$ da matriz de pesos de $G_{c}$ e vamos definir $\mathcal{W}=\left(\mathcal{W}_{i j}\right)$ como a matriz soma de pesos $\mathcal{W}=\sum_{G \in \mathcal{G}} W_{G}$. Então a entrada $\mathcal{W}_{i j}=\sum_{c \in V} W_{c, i j}=0=2(k-1) U_{i j}$, se $i=j$. Por outro lado, se $i \neq j$, então $\mathcal{W}_{i j}=\sum_{c \in V} W_{c, i j}=W_{i, i j}+W_{j, i j}=2(k-1)=2(k-1) U_{i j}$. Isso deixa claro que o conjunto de todas as 2-estrelas usado pelo Algoritmo de Gusfield é balanceado e que o Algoritmo Estrela é um caso particular do Algoritmo $l$-Estrela.

Naturalmente, para o caso geral deseja-se que o conjunto $\mathcal{G}$ que o algoritmo usa seja o menor possível para que o tempo de execução seja pequeno.

A situação de encontrar um algoritmo de aproximação com a razão de aproximação desejada reduz-se, então, a encontrar conjuntos balanceados pequenos. Determinar conjuntos balanceados pequenos parece ser uma tarefa difícil a menos de para valores particulares de $l$ e $k$ [BLP97].

Um contorno para essa dificuldade consiste em considerar uma família $\mathcal{G}$ de $l$-estrelas que seja balanceada e de tamanho exponencial, mas em que uma $l$-estrela ótima (que minimize $W_{G} \cdot S\left(A_{G}\right)$ ) possa ser determinada em tempo polinomial ${ }^{2}$. Esse é o assunto da próxima seção.

\subsubsection{Conjuntos Balanceados de $(2 l-1)$-Estrelas}

Seja $G$ uma $l$-estrela de $k$ vértices com $r$ cliques. Vamos supor momentaneamente que $2(l-1) \mid(k-1)$. Uma configuração $G^{\prime}$ da $l$-estrela $G$ é qualquer grafo obtido de $G$ pareandose os cliques de $G$ e, para cada tal emparelhamento de cliques de $G$, adicionando-se todas as possíveis arestas entre os vértices de cliques pareados a fim de que dois cliques de $G$ formem. um só clique de $G^{\prime}$. Naturalmente, os cliques de $G^{\prime}$ possuem tamanho $2 l-1$. A Figura 4.2 mostra o procedimento de obter uma configuração $G^{\prime}$ a partir de uma $l$-estrela $G$. Veja que uma configuração $G^{\prime}$ possui o mesmo centro que a $l$-estrela de que a configuração é derivada.
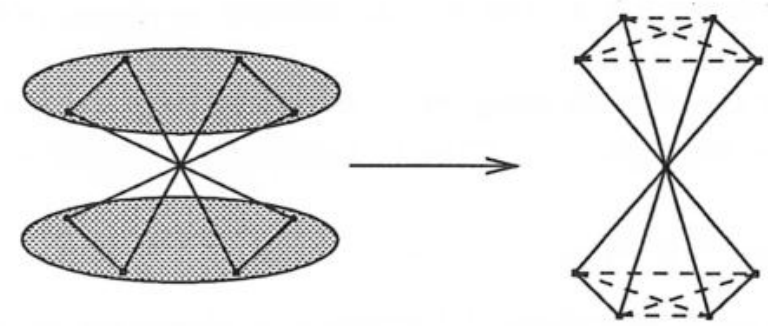

Figura 4.2: Uma 3-estrela de 9 vértices e uma configuração obtida a partir da 3-estrela. As elipses indicam quais cliques foram pareados para construir a configuração. As arestas tracejadas no grafo à direita foram as adicionadas. Note-se que a configuração é uma 5estrela de 9 vértices e que o centro é o mesmo para ambos os grafos.

Dada uma configuração $G^{\prime}$ obtida de uma $l$-estrela $G$ com centro $c$, definimos a matriz

\footnotetext{
${ }^{2}$ Naturalmente, sem fazer a enumeração explícita da família $\mathcal{G}$, para garantir o tempo polinomial.
} 
de pesos $W_{G^{\prime}}=\left(W_{i j}\right)$ de $G^{\prime}$ por:

$W_{i j}= \begin{cases}k-l+1 / 2, & \text { se } i \neq j \text { e }(i=c \text { ou } j=c) \\ 1, & \text { se } i, j \text { estão no mesmo clique de } G^{\prime}, \text { mas em cliques distintos de } G \\ 0, & \text { caso contrário. }\end{cases}$

O Lema 4.4 vale também para a matriz $W_{G^{\prime}}$ de uma configuração e esse é o assunto que passamos a tratar.

Lema 4.9 (Delimitação superior para $U \cdot S(A)$, para configurações). Seja $G$ uma $l$-estrela de $k$ vértices com centro $c$ e seja $G^{\prime}$ uma configuração de $G$. Então $U \cdot S(A) \leq$ $W_{G^{\prime}} \cdot S(A)$, para um alinhamento $A$ arbitrário.

Prova: De maneira parecida com a demonstração do mesmo resultado para $l$-estrelas, a estratégia é construir uma seqüência de grafos com pesos nas arestas.

Seja $H_{k}$ o grafo completo de $k$ vértices cujas arestas possuem todas peso 1 . Naturalmente, a matriz $U$ é a matriz de pesos de $H_{k}$ (a "aresta" $i$ tem peso 0 para $i=1, \ldots, k$ ). Vamos descrever um algoritmo que define uma seqüência de grafos $H_{k}=G_{0}, G_{1}, \ldots, G_{m}$ com pesos nas arestas de forma que $W_{G_{i}} \cdot S(A) \leq W_{G_{i+1}} \cdot S(A)$, para todo $i=0, \ldots, m-1$. Há uma sutileza desse caso, que não está presente para a situação mais simples em que só há $l$-estrelas: a matriz final obtida pelo algoritmo não será igual à matriz de pesos da configuração $G^{\prime}$.

$\mathrm{O}$ algoritmo funciona como no caso de $l$-estrelas: seja $G_{i}$ o grafo com pesos nas arestas dados pela matriz $W_{G_{i}}$ na $i$-ésima iteração e seja $x y$ uma aresta com peso positivo de $G_{i}$ que não esteja presente em $G^{\prime}$ ou uma aresta com peso positivo de $G_{i}$ cujos extremos pertençam a um mesmo clique da $l$-estrela $G$. O grafo $G_{i+1}$ é definido com a aresta $x y$ tendo peso igual a 0 e com as arestas $x c$ e $c y$ com pesos incrementados de uma unidade em relação aos pesos que essas arestas possuíam em $G_{i}$. Os pesos das demais arestas permanecem inalterados de $G_{i}$ para $G_{i+1}$. O algoritmo termina quando todas arestas de $H_{k}$ que não forem arestas de $G^{\prime}$ tiverem peso igual a 0 e todas arestas de $H_{k}$ que não forem central, mas que forem internas a um clique de $G$ tiverem peso 0 .

Intuitivamente, as arestas com peso 0 podem ser interpretadas como arestas que foram "removidas" em relação ao grafo $H_{k}$ e cada passo do algoritmo pode ser interpretado com a remoção de uma aresta. Observe-se que, ao longo do algoritmo, apenas as arestas que ligam o centro $c$ a outros vértices é que podem ter peso maior que 1 . É claro que apenas arestas com peso 1 podem passar a ter peso 0 .

Se $G_{i}$ e $G_{i+1}$ são grafos consecutivos na seqüência construída pelo algoritmo e $W_{G_{i}}$ e $W_{G_{i+1}}$ são suas respectivas matrizes de pesos, então a diferença $W_{G_{i+1}} \cdot S(A)-W_{G_{i}} \cdot S(A)=$ $2\left(\mathrm{SP}\left(A_{\mid x c}\right)+\mathrm{SP}\left(A_{\mid c y}\right)-\mathrm{SP}\left(A_{\mid x y}\right)\right) \geq 0$ pela desigualdade triangular $\operatorname{SP}\left(A_{\mid x y}\right) \leq \operatorname{SP}\left(A_{\mid x c}\right)+$ $\mathrm{SP}\left(A_{\mid c y}\right)$. Isso significa que a pontuação do alinhamento $A$ ponderada pelas matrizes de pesos dos grafos construídos pelo algoritmo é não-decrescente.

A matriz $W_{G_{m}}$ de pesos do último grafo obtido pelo algoritmo possui zeros nas mesmas entradas que a matriz $W_{G^{\prime}}$ : todo par $x y \operatorname{com} x=y$ ou com $x$ e $y$ que não sejam extremos de uma aresta de $G^{\prime}$ ou que sejam extremos de uma aresta não-central de um clique de $G$ tem valores correspondentes iguais a 0 em ambas matrizes. Se $x y$ é uma aresta de $G^{\prime}$ de forma que $x$ e $y$ pertençam a cliques diferentes de $G$, então suas entradas correspondentes têm valor igual a 1 tanto na matriz $W_{G^{\prime}}$ quanto na matriz $W_{G_{m}}$.

Resta, finalmente, comparar os pesos que uma aresta central possui em $W_{G_{m}}$ e em $W_{G^{\prime}}$. Seja $x c$ uma aresta central arbitrária de $G^{\prime}$. No grafo completo $H_{k}$, o vértice $x$ 
possuía $k-1$ vértices adjacentes. Já no grafo $G_{m}$, o vértice $x$ é adjacente ao vértice $c$ e a outros $l-1$ vértices que juntos de $c$ compõem o clique a que o clique que contém $x$ foi pareado ${ }^{3}$. Assim, o algoritmo atribuiu peso 0 a $(k-1)-l$ arestas adjacentes a $x$ e incrementou o peso da aresta $x c$ (que originalmente era 1 na matriz $W_{H_{k}}$ ) um total de $k-l-1$ vezes, de modo o peso final da aresta $x c$ no grafo $G_{m}$ seja $k-l$. Mas, pela definição de $W_{G^{\prime}}$, a entrada correspondente à aresta $x c$ vale $W_{G^{\prime}, x c}=k-l+1 / 2=W_{G_{m}, x c}+1 / 2$. Como a aresta $x c$ é arbitrária, a afirmação é válida para toda aresta central. Assim, as matrizes $W_{G_{m}}$ e $W_{G^{\prime}}$ diferem apenas nas entradas correspondentes às arestas centrais e $\left(W_{G^{\prime}}-W_{G_{m}}\right) \cdot S(A)=2\left(\sum_{x \in V} \frac{1}{2} \mathrm{SP}\left(A_{\mid x c}\right)\right)=\sum_{x \in V} \mathrm{SP}\left(A_{\mid x c}\right) \geq 0$, pois $\operatorname{SP}\left(A_{\mid x y}\right)$ é sempre não-negativo, para quaisquer que sejam $x, y \in V$.

Isso mostra que $U \cdot S(A)=W_{H_{k}} \cdot S(A) \leq W_{G_{m}} \cdot S(A) \leq W_{G^{\prime}} \cdot S(A)$, o que prova o resultado também para matrizes de pesos de configurações.

Trivialmente, o Lema 4.5 também é válido para configurações e ele nos garante que um alinhamento ótimo ponderado pela matriz $W_{G^{\prime}}$ pode ser obtido pela junção de alinhamentos associados a cliques de $G^{\prime}$ e que sua pontuação é igual à soma das pontuações dos alinhamentos dos cliques.

Bem como para a matriz de pesos de uma $l$-estrela, a matriz de pesos de uma configuração $G^{\prime}$ tem a soma de suas entradas satisfazendo

$$
W_{G^{\prime}} \cdot U=2\left[\left(k-l+\frac{1}{2}\right)(k-1)+\frac{(k-1)}{2(l-1)}(l-1)^{2}\right]=2\left(\begin{array}{l}
k \\
2
\end{array}\right)\left(2-\frac{l}{k}\right),
$$

independentemente de qual seja a configuração $G^{\prime}$.

Seja $G$ uma $l$-estrela com centro $c$ e sejam $x, y \in V(G)$ vértices distintos e pertencentes a cliques diferentes de $G$. Seja $q$ o número de vezes que a aresta $x y$ aparece no conjunto de configurações de $G$. Por simetria, todas as arestas com extremos em cliques diferentes de $G$ aparecem o mesmo número $q$ de vezes no conjunto de configurações de $G$ (isto é, cada uma dessas arestas aparece em $q$ configurações de $G$ ).

É relativamente simples observar que o mesmo número $q$ vale para $l$-estrelas que possuem centros diferentes. Sejam $G$ e $H$ duas $l$-estrelas com mesmo número de vértices, mas centros diferentes. Então $G$ e $H$ são grafos isomorfos e digamos que $\varphi$ seja o isomorfismo que mapeia $G$ em $H$. Suponhamos que $x$ e $y$ estejam em cliques diferentes de $G$ e que a aresta $x y$ apareça em $q$ configurações de $G$. Naturalmente, como $\varphi$ é um isomorfismo, $\varphi(x)$ e $\varphi(y)$ pertencem a cliques diferentes de $H$. Mas a aresta $\varphi(x) \varphi(y)$ pertence a uma configuração $H^{\prime}$ de $H$ se e somente $\operatorname{se}^{-1}\left(H^{\prime}\right)$ possui a aresta $x y$. Logo, o mesmo número $q$ vale para $l$-estrelas com centros diferentes.

Deixamos em destaque esse resultado para sua posterior referência:

Lema 4.10 (Número de configurações com xy). Existe um inteiro q tal que, para todo par de vértices $x$ e $y$ de uma l-estrela $G$ de $k$ vértices que tenha $x$ e y em cliques diferentes, $q$ é o número de configurações de $G$ que contém a aresta xy. O número $q$ independe da aresta considerada e de qual é a l-estrela com $k$ vértices.

Sejam agora $G_{1}, \ldots, G_{k} l$-estrelas arbitrárias, cada uma com centro diferente das demais. Sem perda de generalidade, podemos supor que, para todo $i$, a estrela $G_{i}$ tenha $i$ como vértice central. Para cada $G_{i}$, considere o conjunto $\mathcal{G}_{i}$ de todas as configurações de $G_{i}$. O conjunto $\mathcal{G}$ obtido pela união de todos os conjuntos $\mathcal{G}_{i}$ 's mais $q$ cópias de cada uma das $l$-estrelas $G_{i}$ é um conjunto importante, conforme atesta a seguinte proposição:

\footnotetext{
${ }^{3}$ Estamos considerando aqui adjacência em um grafo determinada por arestas que possuam peso positivo.
} 
Proposição 4.11 ( $\mathcal{G}$ é balanceado). Seja $\mathcal{G}=\left(\bigcup_{i=1}^{k} \mathcal{G}_{i}\right) \cup\left(\bigcup_{i=1}^{k} C_{G_{i}}\right)$, onde $C_{G_{i}}=$ $\{\overbrace{G_{i}, \ldots, G_{i}}^{\text {qcópias }}\}$. Então o (multi) conjunto $\mathcal{G}$ é balanceado.

Prova: Para demonstrar a proposição, vamos verificar que se $W=\sum_{G \in \mathcal{G}} W_{G}$, então sua entrada $W_{i j}$ independe de $i, j$, se $i \neq j$. Naturalmente, quando $i=j, W_{G, i j}=0$ quer $G$ seja uma $l$-estrela, quer $G$ seja uma configuração, o que significa que a diagonal de $W$ possui apenas zeros.

Vamos agora ao caso em que $i \neq j$. Note-se que para qualquer $i \in V$, o vértice $i$ é centro das configurações presentes em $\mathcal{G}_{i}$. Além disso, $\left|\mathcal{G}_{i}\right|=\left|\mathcal{G}_{j}\right|$ para quaisquer $i, j=$ $1, \ldots, k$ porque as $l$-estrelas $G_{i}$ e $G_{j}$ são isomorfas (observadas como grafos) e aplicando-se o isomorfismo $\varphi$ que mapeia $G_{i}$ em $G_{j}$ a cada elemento de $\mathcal{G}_{i}$ obtemos o conjunto $\mathcal{G}_{j}$. Para simplificar, vamos fazer $L=\left|\mathcal{G}_{i}\right|$.

Há basicamente quatro casos que precisam ser analisados: o caso em que $W_{G, i j}=$ $k-l+1 / 2$, o caso em que $W_{G, i j}=k-l+1$, o caso em que $W_{G, i j}=1$ para configurações e o caso em que $W_{G, i j}=1$ para $l$-estrelas. Em todos outros casos, $W_{G, i j}=0$.

Pela definição de $W_{G}, W_{G, i j}=k-l+1 / 2$ para configurações em que $i$ é o vértice central ou em que $j$ é o vértice central. Para cada uma das $L$ configurações $G \in \mathcal{G}_{i}$, $W_{G, i j}=k-l+1 / 2$, o mesmo valendo para as configurações que têm $j$ como centro e disto decorre que, fixados $i, j \in V$, com $i \neq j, W_{G, i j}=k-l+1 / 2$ exatamente em $2 / k$ das configurações de $\mathcal{G}$, isto é, $2 L$ vezes.

Pelo mesmo raciocínio, $W_{G, i j}=k-l+1$ para todas as $q$ cópias de $G_{i}$ e para todas as $q$ cópias de $G_{j}$, totalizando $2 q$ vezes.

Vamos agora analisar o número de vezes em que $W_{G, i j}=1$ para um grafo $G \in \mathcal{G}$.

Se $i$ ou $j$ é centro de uma $l$-estrela ou de uma configuração, é claro então que $W_{G, i j} \neq 1$, pela maneira como as matrizes de peso são definidas.

Seja $G_{m}$ alguma das $l$-estrelas fixadas $G_{1}, \ldots, G_{k}$ e suponhamos que $i$ e $j$ sejam vértices em cliques diferentes de $G_{m}$. Pelos argumentos acima, sabemos que $q$ configurações de $G_{m}$ possuem a aresta $i j$ e que para cada uma dessas configurações a entrada $i, j$ da matriz de pesos vale 1 , de que se conclui que $\sum_{G \in \mathcal{G}_{m}} W_{G, i j}=q$. Pela definição da matriz de pesos para $l$-estrelas, segue trivialmente que $\sum_{G \in C_{G_{m}}} W_{G, i j}=0$.

Se $i$ e $j$ estão em um mesmo clique de $G_{m}$ (mas são ambos diferentes de $m$ ), então $\sum_{G \in \mathcal{G}_{m}} W_{G, i j}=0$. Por outro lado, para as cópias de $G_{m}$ em $C_{G_{m}}, \sum_{G \in C_{G_{m}}} W_{G, i j}=q$.

Então, se $G_{m}$ é uma $l$-estrela qualquer dentre $G_{1}, \ldots, G_{k}$ e $i, j \in V \backslash^{\prime}\{m\}$, com $i \neq$ $j$, então $\sum_{G \in \mathcal{G}_{m}} W_{G, i j}=q$ para as configurações de $G_{m}$, independentemente do fato de $i$ e $j$ estarem ou não em um mesmo clique de $G_{m}$. Esse também é o caso para as $q$ cópias de $G_{m}$, resultando em $\sum_{G \in C_{G_{m}}} W_{G, i j}=q$. Ou seja, se $i$ e $j$ são vértices distintos e $i, j \neq m, \sum_{G \in \mathcal{G}_{m} \vee G \in C_{G_{m}}} W_{G, i j}=2 q$. Como $i$ e $j$ são centros apenas das $l$-estrelas $G_{i}$ e $G_{j}$, respectivamente, os resultados que deduzimos são válidos para $k-2$ das estrelas $G_{1}, \ldots, G_{k}$.

Disso segue que $\sum_{G \in \mathcal{G}} W_{G, i j}=2 q(k-2)$ para vértices $i \neq j$.

Resumindo, se $i$ e $j$ são vértices distintos quaisquer, $W_{G, i j}=1$ para exatamente $2 q(k-2)$ dos grafos de $\mathcal{G}$.

Logo, o valor de uma entrada qualquer ${ }^{4}$ de $W=\sum_{G \in \mathcal{G}} W_{G}$ vale $2 L(k-l+1 / 2)+2 q(k-$ $l+1)+2 q(k-2)$, independentemente da entrada. Logo, a matriz $W$ pode ser observada como

\footnotetext{
${ }^{4} \mathrm{~A}$ menos da diagonal principal, onde as entradas são todas iguais a zero. É claro que, como tanto a diagonal de $W$ quanto a diagonal de $U$ são ambas nulas, a diagonal de $W$ é também múltipla da diagonal de $U$ com o escalar $p$.
} 
$W=p U$, para algum escalar $p$, de onde segue o fato de que $\mathcal{G}$ é um conjunto balanceado.

$\mathrm{O}$ resultado demonstrado acima significa que, de maneira semelhante ao caso de conjuntos balanceados que continham só $l$-estrelas, para o conjunto $\mathcal{G}$ que reúne tanto configurações quanto $l$-estrelas, $p=\frac{\left(\sum_{G \in \mathcal{G}} W_{G}\right) \cdot U}{U \cdot U}$ e como $W_{G} \cdot U=2\left(\begin{array}{c}k \\ 2\end{array}\right)(2-l / k)$ para qualquer $G \in \mathcal{G}, p /|\mathcal{G}|=(2-l / k)$, que é exatamente o mesmo valor calculado antes para conjuntos balanceados que tinham só $l$-estrelas.

Como o Algoritmo $l$-Estrela requer um conjunto balanceado em seu primeiro passo, o conjunto $\mathcal{G}$ da Proposição 4.11 pode ser usado pelo algoritmo. O conjunto $\mathcal{G}$ pode não ser pequeno, mas sua estrutura permite que o alinhamento $A$ devolvido seja determinado sem que os elementos de $\mathcal{G}$ sejam explicitamente enumerados, o que alivia as necessidades de construir conjuntos balanceados pequenos e de realizar uma busca exaustiva dos elementos desse conjunto. Mostramos agora uma ligeira modificação do Algoritmo l-Estrela para utilizar o conjunto $\mathcal{G}$ da Proposição 4.11 de maneira implícita.

Considere as $k$-estrelas $G_{1}, \ldots, G_{k}$, como anteriormente. Para a $l$-estrela $G_{i}$, que possui $r$ cliques, construa o grafo completo $H_{r}$. A idéia da construção é que cada um dos vértices de $H_{r}$ representa um dos cliques de $G_{i}$. Atribua à aresta $x y \in E\left(H_{r}\right)$ o valor de um alinhamento ótimo das seqüências dos cliques que $x$ e $y$ representam, de forma que o alinhamento seja ponderado em relação aos custos que os cliques teriam se estivessem unidos em uma configuração de $G_{i}$.

Observe-se que cada configuração de $G_{i}$ descreve um emparelhamento perfeito de $H_{r}$. Reciprocamente, um emparelhamento em $H_{r}$ descreve uma configuração de $G_{i}$. Mais do que isso, pelo Lema 4.5 (que pode ser aplicado tanto para $l$-estrelas quanto para configurações), o custo ponderado de um alinhamento dado por uma configuração de $G_{i}$ é igual à soma dos custos dos alinhamentos associados a cada clique da configuração de $G_{i}$, isto é, o custo do alinhamento é igual ao custo do emparelhamento de $H_{r}$. Em particular, um alinhamento de custo mínimo pode ser determinado por um emparelhamento perfeito de custo mínimo de $H_{r}$. Isso determina um alinhamento de custo mínimo dentre os determinados pelos grafos de $\mathcal{G}_{i}$.

É interessante notar que o cálculo de um emparelhamento perfeito de custo mínimo equivale a uma "busca simultânea" em $\mathcal{G}_{i}$ para encontrar uma configuração ótima ${ }^{5}$ de $G_{i}$. Essa busca "abreviada" é que elimina a necessidade de realizar uma enumeração explícita dos elementos de $\mathcal{G}_{i}$.

Para encontrar um alinhamento de custo mínimo dentre aqueles determinados pelos grafos do conjunto balanceado $\mathcal{G}$, basta realizar o procedimento descrito acima para todo $i=1, \ldots, k$ e calcular um alinhamento ótimo segundo cada $l$-estrela $G_{i}$ (ponderado com pesos $W_{G_{i}}$ ) e escolher o alinhamento $A$ de menor pesos dentre todos os alinhamentos calculados. Por argumentos como os do Corolário 4.8, o custo SP do alinhamento $A$ é limitado superiormente por $(2-l / k) \operatorname{SP}\left(A^{*}\right)$, onde $A^{*}$ é um alinhamento ótimo das $k$ seqüências.

Seja $g(l, n)$ o tempo usado pelo algoritmo de programação dinâmica para encontrar um alinhamento ótimo (ponderado ou não) de $l$ seqüências de comprimento $n$ cada. Pelo Capítulo 2 sabemos que $g(l, n)=O\left(l^{2} 2^{l} n^{l}\right)$. Dada uma $l$-estrela $G$ de $k$ vértices, o alinhamento $A_{G}$ pode ser determinado em tempo $r g(l, n)=O(k g(l, n))$ (para construir os $r$ alinhamentos ótimos correspondentes aos cliques) mais tempo $O(r k l n)=O\left(k^{2} n\right)$ (para juntar os $r$ alinhamentos). Como para os casos de interesse $g(l, n)$ é muito maior que $O\left(k^{2} n\right)$, o termo $k g(l, n)$ é dominante no tempo gasto para computar $A_{G}$ [BLP97].

\footnotetext{
${ }^{5}$ Ou seja, uma configuração $G_{i}^{\prime}$ que determine um alinhamento $A_{G_{i}^{\prime}}$ que minimize $W_{G_{i}^{\prime}} \cdot S\left(A_{G_{i}^{\prime}}\right)$.
} 
Para cada centro $c \in V$, o grafo completo $H_{r}$ pode ter o peso de cada aresta determinado em tempo $g(2 l-1, n)$ e como há $\left(\begin{array}{l}r \\ 2\end{array}\right)$ arestas, tempo $O\left(r^{2} g(2 l-1, n)\right)$ é suficiente para calcular todos os pesos.

Um emparelhamento perfeito de peso mínimo em um grafo de $r$ vértices pode ser determinado em tempo $O\left(r^{4}\right)$ ou, usando técnicas mais sofisticadas, em tempo $O\left(r^{3}\right)$ [Law76].

A escolha do alinhamento ótimo deve ser feita para toda configuração com cada centro $c \in V$ e isso pode ser feito em tempo $O\left(k\left(r^{3}+r^{2} g(2 l-1, n)\right)\right)=O\left(k^{4}+k^{3} g(2 l-1, n)\right)$.

O Algoritmo $l$-Estrela em sua versão modificada deve examinar ainda os $k$ alinhamentos determinados pelas $l$-estrelas $G_{1}, \ldots, G_{k}$ e o alinhamento associado a cada um desses grafos pode ser calculado em tempo $O(k g(l, n))$, conforme já argumentamos. Assim, o Algoritmo $l$-Estrela pode ser executado como um todo em tempo $O\left(k^{4}+k^{3} g(2 l-1, n)+\right.$ $\left.k^{2} g(l, n)\right)=O\left(k^{4}+k^{3} g(2 l-1, n)\right)$ se $2(l-1) \mid(k-1)$. Isso significa que para $l$ fixado satisfazendo $2(l-1) \mid(k-1)$, o Algoritmo $l$-Estrela encontra em tempo polinomial em $k$ e $n$ um alinhamento entre as seqüências $s_{1}, \ldots, s_{k}$ com fator de aproximação $2-l / k$.

\subsubsection{Caso em que $2(l-1) \chi(k-1)$}

Vamos agora analisar o caso em que $l$ não satisfaz $2(l-1) \mid(k-1)$.

Inicialmente, definimos uma generalização do conceito de $l$-estrela. Uma $l$-estrela, conforme definimos antes é um grafo em que cada clique possui tamanho $l$ e tal que todos os cliques possuem um mesmo vértice em comum. Dizemos que um grafo $G$ é uma l-estrela híbrida se os cliques de $G$ possuem tamanho $l$ ou $l+1$ e se seus cliques têm um vértice em comum, o vértice central.

Observe-se que para $k$ suficientemente grande, sempre é possível encontrar uma $l$-estrela híbrida com $k$ vértices e com um número par de cliques.

Primeiramente, vejamos que sempre há uma $l$-estrela híbrida de $k$ vértices. Para isso, basta observar que $k-1$ pode ser escrito na forma $k-1=a l+b(l-1)$, com $a$ e $b$ inteiros não-negativos. Isso equivale a repartir os $k-1$ vértices diferentes do centro em $a$ cliques de tamanho $l+1$ e em $b$ cliques de tamanho $l$.

De fato, se $k-1 \geq(2 l-1)(l-1)$, então pelo Algoritmo de Divisão de Euclides podem ser encontrados inteiros $a^{\prime}$ e $b^{\prime}$ tais que $k-1=a^{\prime} l+b^{\prime}$, com $0 \leq b^{\prime} \leq l-1$. Definido $a=a^{\prime}+b^{\prime}+1-l$ e $b=l-b^{\prime}$ temos inteiros desejados e não-negativos, conforme passamos a verificar. É imediato ver que $a l+b(l-1)=a^{\prime} l+b^{\prime}=k-1$. Além disso, como $0 \leq b^{\prime} \leq l-1$, temos que $l \geq l-b^{\prime} \geq 1$, isto é, $l \geq b \geq 1$, de onde segue trivialmente que $b$ é não-negativo. Para ver que $a \geq 0$, consideremos que $a=[(k-1)-b(l-1)] / l$ e que como $k-1 \geq(2 l-1)(l-1)$ e $-b \geq-l$, segue que $a \geq[(2 l-1)(l-1)-l(l-1)] / l=(l-1)^{2} / l=l-2+1 / l$. Mas como $a$ é um inteiro e $l \geq 2$, temos que $a \geq l-2+1 / l$ significa que $a \geq l-1$, de onde podemos ver que $a$ é não-negativo, conforme desejado.

É relativamente simples de ver que, fixado $k$, a escrita de $k-1$ na forma $a l+b(l-1)$ não necessariamente é única. Essa observação é útil para dividir os $k$ vértices em um número par de cliques (isto é, para obtermos $a+b$ como um número par), se $k$ é suficientemente grande.

Se $a+b$ obtidos de acordo com o processo acima for par, então o problema está resolvido. Caso contrário, se $a$, que é o número de cliques de tamanho $l+1$ for tal que $a \geq l-1$ (que é uma hipótese satisfeita, conforme já vimos), então podemos escolher $l-1$ cliques dentre os $a$ cliques de tamanho $l+1$, retirar um vértice (diferente do centro) de cada um desses $l-1$ cliques selecionados e formar um novo clique de tamanho $l$ a partir desses vértices retirados (e do vértice central). É claro que os cliques de que os vértices foram retirados ficam menores 
após um de seus vértices ser removido. Assim, os vértices podem ser divididos em $a-(l-1)$ cliques de tamanho $l+1$ e $b+(l-1)+1$ cliques de tamanho $l$, de onde segue que o novo número de cliques é 1 a mais do que o número antigo e, portanto, par.

Disso tudo vemos que se o número de vértices for suficientemente grande, podemos sempre encontrar uma $l$-estrela híbrida de $k$ vértices com número par de cliques. Isso torna possível tentar aplicar o que já mostramos para $l$-estrelas e suas configurações para o caso de $l$-estrelas híbridas e configurações obtidas por pareamento de cliques (que, neste caso, pode resultar em cliques de tamanho $2 l-1,2 l$ ou $2 l+1$ ).

Definimos a matriz de pesos de uma $l$-estrela híbrida da exata mesma maneira que para $l$-estrelas (com os exatos mesmos valores). Da mesma forma, se $G^{\prime}$ é uma configuração de uma $l$-estrela híbrida, usamos exatamente a mesma definição para a matriz de pesos de $G^{\prime}$.

É simples de observar que a versão do Lema 4.5 para $l$-estrelas híbridas e suas configurações também é válida, o que nos permite encontrar alinhamentos ponderados ótimos da mesma forma que antes.

Menos trivial é a validade do Lema 4.4 também para $l$-estrelas híbridas e para suas configurações. A verificação desse fato é trabalhosa e pode ser feita usando-se mais uma vez os argumentos presentes nos Lemas 4.4 e 4.9. Nessa verificação, o importante é observar que o processo de remover uma aresta que liga dois vértices (i.e., colocar seu peso como sendo 0 ) e aumentar o peso das arestas que ligam esses vértices ao vértice central continua não diminuindo o valor de $S(A)$ ponderado pela matriz de pesos dos respectivos grafos. Ademais, para $l$-estrelas híbridas e configurações de $l$-estrelas híbridas, é possível que a matriz do último grafo obtido pelo algoritmo não seja igual à matriz de pesos do grafo que se deseja, mas ela fornece um limite inferior para esse peso (como no Lema 4.9).

Da mesma maneira que antes, se $G$ é uma $l$-estrela híbrida e $x$ e $y$ pertencem a cliques diferentes de $G$, digamos $\Omega$ e $\Omega^{\prime}$, então a aresta $x y$ está presente nas configurações de $G$ em que $\Omega$ é pareado com $\Omega^{\prime}$, não importando como os demais cliques de $G$ são pareados para obter uma configuração. Como o número de pareamentos de cliques com um par de cliques fixado não depende de qual par foi fixado, o número de vezes que qualquer aresta que liga dois vértices em cliques diferentes aparece no conjunto de configurações é o mesmo para todas a arestas, digamos $q$.

Da mesma maneira como antes, queremos $k l$-estrelas híbridas com centros diferentes (uma com cada centro $c \in V$ ). Se outras $k-1 l$-estrelas híbridas forem obtidas de $G$ trocando-se o centro com algum outro vértice (para manter a forma da $l$-estrela), então todos comentários acima permanecem válidos, inclusive o mesmo número $q$ valendo para configurações das várias $l$-estrelas.

Assim, fixadas $k l$-estrelas híbridas da forma descrita acima, o conjunto $\mathcal{G}$ obtido pela união de todas configurações das $k l$-estrelas mais $q$ cópias de cada $l$-estrela é um conjunto balanceado.

Como fizemos antes, observemos que se $G \in \mathcal{G}$ é uma $l$-estrela híbrida, então

$$
W_{G} \cdot U \leq 2\left[(k-1)(k-l+1)+\frac{k-1}{l-1}\left(\begin{array}{l}
l \\
2
\end{array}\right)\right]=2\left(\begin{array}{l}
k \\
2
\end{array}\right)\left(2-\frac{l-1}{k}\right) .
$$

Se $G \in \mathcal{G}$ é uma configuração de uma $l$-estrela híbrida, então

$$
W_{G} \cdot U \leq 2\left[(k-1)(k-l+1 / 2)+\frac{k-1}{2(l-1)} l^{2}\right] \leq 2\left(\begin{array}{l}
k \\
2
\end{array}\right)\left(2-\frac{l-3}{k}\right) .
$$


Em qualquer caso, então, para todo $G \in \mathcal{G}$,

$$
W_{G} \cdot U \leq 2\left(\begin{array}{l}
k \\
2
\end{array}\right)\left(2-\frac{l-3}{k}\right) .
$$

Isso significa que $p /|\mathcal{G}| \leq 2-(l-3) / k$ e usando os argumentos anteriores temos que uma configuração ótima para cada centro $c \in V$ pode ser encontrada em tempo $O\left(k^{2} g(2 l+1, n)\right)$. Como o tempo usado para encontrar um alinhamento para cada $l$-estrela é menor que o tempo usado para as configurações dessa $l$-estrela, segue que o Algoritmo $l$-Estrela para esse caso generalizado calcula um alinhamento ótimo ponderado em tempo $O\left(k^{3} g(2 l+1, n)\right)$ com garantia de aproximação $2-(l-3) / k$. Para $l^{\prime}=l-3$, isso significa que o algoritmo roda em tempo $O\left(k^{3} g\left(2 l^{\prime}+7, n\right)\right)$ e tem uma garantia de aproximação $2-l^{\prime} / k$, o que termina a demonstração de que o Algoritmo $l$-Estrela (com escolha adequada de um conjunto balanceado) é uma $(2-l / k)$-aproximação polinomial para o Problema AVS com pontuação SP não-ponderada.

O método apresentado acima, a menos de alguns detalhes, é o método dado no artigo de Bafna, Lawler e Pevzner [BLP97]. Para garantir a polinomialidade do algoritmo, o valor de $l$ é considerado fixo. Perceba-se que o algoritmo requer também que $(2 l-1)(l-1) \leq k-1$, isto é, que $2 l^{2}-3 l+2 \leq k$. Mas, por outro lado, se o valor de $k$ for tal que $2 l^{2}-3 l+2>k$, então o valor $2 l^{2}$ é um limitante superior no valor de $k$. Neste caso, podemos obter a solução exata empregando-se o algoritmo de programação dinâmica básico para as $k$ seqüências da entrada (vide Capítulo 2), em tempo $g(k, n)=O\left(g\left(2 l^{2}, n\right)\right)=O\left(l^{4} 2^{2 l^{2}} n^{2 l^{2}}\right)$, que é polinomial em $n$ considerando-se $l$ fixo. Em outras palavras, instâncias com "poucas" seqüências ( $k$ "pequeno" em relação a $l$ ) podem ser resolvidas diretamente pelo algoritmo exato de programação dinâmica, enquanto instâncias com mais seqüências podem ser resolvidas pelo Algoritmo de Bafna, Lawler e Pevzner para obter uma $(2-l / k)$-aproximação em tempo polinomial para o Problema AVS com pontuação SP não-ponderada para qualquer $l$ fixo.

A versão modificada do Algoritmo $l$-EsTRELA para usar emparelhamentos perfeitos tem bom potencial para ser paralelizável, porque pelo menos a parte da atribuição de custos às arestas do grafo $H_{r}$ pode ser feita em uma ordem qualquer e cada um desses custos pode ser calculado de forma independentemente dos demais (naturalmente, $\left(\begin{array}{l}r \\ 2\end{array}\right)=O\left(r^{2}\right)$ tais custos precisam ser calculados, cada um deles, por exemplo, com uma chamada à função DisT-AVS). 


\title{
Capítulo 5
}

\section{Modelos de Markov de Estados Ocultos}

\author{
"If your experiment needs statistics, you ought to have done a better experiment."
}

- Ernest Rutherford (1871-1937)

\subsection{Introdução}

Os algoritmos e argumentos que usamos até agora são principalmente combinatórios e (com exceção daquilo discutido na Seção 1.8.4) não fazem uso direto de probabilidades. É possível, inclusive, para muitos casos (e.g., para alinhamentos globais de seqüências) fazer uma descrição dos problemas e algoritmos completamente em termos de distâncias, sem levar em consideração aspectos estatísticos que os problemas tenham.

Por outro lado, conforme vimos também no fim do Capítulo 1, similaridades (em vez de distâncias) são mais usadas na prática por serem mais naturais do ponto de vista biológico e por darem uma possível interpretação estatística às pontuações dos alinhamentos, se as matrizes de substituição de resíduos forem construídas usando log da razão de probabilidades (log-odd scores), relacionando um modelo de mutação ao modelo de pareamento de caracteres ao acaso.

A decisão de como pontuar alinhamentos de várias seqüências não é tão evidente (como discutimos no Capítulo 2). A pontuação mais popular para várias seqüências, a somade-pares (SP), possui a desvantagem de não permitir uma interpretação evolutiva simples como a que pode ser feita para pares de seqüências, porque o fato de a pontuação SP ser igual à soma das pontuações de cada seqüência comparada com as $k-1$ outras seqüências significa essencialmente que cada uma das seqüências é tratada como descendente das demais seqüências [KG99, DEKM98].

Sob esse aspecto, a situação ideal para a pontuação de colunas no algoritmo de programação dinâmica seria o uso de uma árvore filogenética que fosse "correta" do ponto de vista biológico. Dessa maneira, cada seqüência seria comparada apenas com as sequiências de que ela descende e não haveria excesso no peso/contagem de cada uma das pontuações ${ }^{1}$. Mas,

\footnotetext{
${ }^{1}$ Apesar disso, o uso de pontuação SP ponderada pode mitigar até certo limite o excesso ou a falta de alguma pontuação no todo da pontuação SP.
} 
geralmente, a árvore filogenética das seqüências em questão é desconhecida e o alinhamento das seqüências é o primeiro dos passos da construção da árvore filogenética (vários métodos populares de inferência de árvores filogenéticas usam alinhamentos como pontos de partida).

Uma outra limitação dos métodos de programação dinâmica ${ }^{2}$ é que uma mesma função de pontuação é igualmente usada para analisar todas as colunas do alinhamento. Isso significa que o mesmo "rigor" é usado para todas as colunas. Mas, do ponto de vista evolutivo, isso pode não ser desejável, já que posições diferentes de uma dada seqüência podem evoluir com taxas diferentes dependendo de sua importância para o organismo (por meio de uma complexa interação de fatores, que incluem, possivelmente, o meio em que o organismo está).

Regiões de moléculas cujas composições sejam importantes para a forma e para a função dessas moléculas tendem a ser mais conservadas do que regiões que não determinem diretamente as formas das moléculas, o que significa que regiões mais importantes sofrem mutação mais lentamente. Um exemplo é o caso dos exons e dos introns em genes/moléculas de DNA. Os exons, que se expressam para codificar proteínas, são mais fortemente conservados do que os introns, que separam os exons em um gene e que não codificam partes de proteínas. Uma situação parecida ocorre com proteínas. Em particular, para as hemoglobinas, os sítios de ligação de oxigênio são mais conservados do que outras partes da proteína, porque mudanças em sua composição levariam potencialmente a uma perda da função da molécula.

Assim, os resíduos de uma seqüência são, em geral, conservados de modo diferente e seqüências de uma mesma família têm partes que ficam mais preservadas durante a evolução (e que, portanto, tendem a possuir similaridade relativamente alta) enquanto outras partes (possivelmente de menor importância) divergem mais rapidamente (e tendem a possuir menor similaridade). Informalmente, isso significa que regiões diferentes de uma molécula evoluem com "velocidades diferentes"3. Pode também ocorrer a situação de que moléculas de uma mesma família evoluam e acabem adquirindo estruturas diferentes. Nesse caso, as regiões que divergiram passam a ser biologicamente incomparáveis e tentativas de alinhá-las podem ter sucesso limitado [DEKM98].

Isso significa que é conveniente que algoritmos para alinhar seqüências levem em consideração as taxas de conservação de resíduos, específicas para cada posição das moléculas e a situação mais desejada talvez fosse incorporar, de alguma maneira, um procedimento de comparação mais estrito para regiões bem conservadas entre as sequiências e um procedimento mais permissivo para comparar as regiões potencialmente divergidas há muito tempo.

Um modelo que pode ser usado para comparar seqüências e leva em parte os problemas descritos acima em consideração é o modelo de Markov de Estados Ocultos, que é uma variante dos modelos estocásticos clássicos chamados cadeias de Markov. Com um modelo de Markov de Estados Ocultos, é possível penalizar os eventos de mutações, remoções e inserções de resíduos de forma diferente para cada posição das seqüências. Desse modo é possível penalizar abertura de lacunas de formas diferentes dependendo da posição no alinhamento (por exemplo, diminuindo o custo em partes do alinhamento em que elas sejam

\footnotetext{
${ }^{2}$ Pelo menos em sua forma mais básica de implementação, como a do Capítulo 2.

${ }^{3}$ Isso indica que uma boa estratégia para buscar alinhamentos globais ótimos de seqüências talvez fosse utilizar diferentes matrizes de pontuação/substituição de resíduos conforme os trechos das seqüências tivessem que ser comparados (dependendo se eles estejam mais ou menos distantes do ponto de vista evolutivo). Mais uma vez, entretanto, um tipo de tarefa como essa fica dificultado porque geralmente não se conhece quais regiões das seqüências são homólogas e construir um alinhamento é justamente uma maneira de inferir as regiões das moléculas e suas homologias.
} 
esperadas e aumentando a penalidade em trechos em que elas normalmente não ocorram).

Este capítulo faz uma introdução básica aos modelos de Markov de Estados Ocultos para descrevermos suas aplicações à Biologia Computacional e, mais especificamente, à construção de alinhamentos de várias seqüências.

Inicialmente, damos uma descrição bastante breve de cadeias de Markov e introduzimos os modelos de Markov de Estados Ocultos como uma extensão de cadeias de Markov. Em seguida, mostramos um tipo particular de modelos de Markov de Estados Ocultos, especializado para capturar as características de seqüências biológicas e que pode ser aplicado inclusive na obtenção de alinhamentos.

\subsection{Cadeias de Markov}

Muitos processos que ocorrem na prática podem ser observados como fontes que geram sinais segundo algumas regras. Em vários casos de interesse, os sinais produzidos pelas fontes podem ser descritos como uma seqüência de símbolos sobre algum alfabeto, e tal seqüência é obtida verificando-se o estado da fonte em intervalos regulares de tempo. Fontes que produzem sinais que podem ser representados como uma seqüência de elementos de um conjunto discreto (como é o caso de símbolos de um alfabeto) são ditas produtoras de sinais discretos. Caso contrário, diz-se que a fonte produz um sinal contínuo.

Em algumas situações, os sinais são também chamados seqüências de observações da fonte. Uma maneira natural de obter seqüências de observações a partir da fonte é verificar em intervalos de tempo fixados qual é o estado da fonte e tomá-los como a observação.

Esse enfoque de considerar uma fonte que gera sinais pode ser aplicado a várias situações práticas, incluindo Compressão de Dados [BCW90] e Reconhecimento de Voz [Rab89]. Da mesma maneira, podemos interpretar que seqüências biológicas de proteínas e de DNA são sinais produzidos por alguma fonte.

Em muitos casos, as fontes que produzem sinais de interesse podem ser modeladas satisfatoriamente e de maneira simples por modelos estocásticos. Um modelo estocástico de uso bastante vasto e amplamente estudado são as cadeias de Markov. Informalmente, uma cadeia de Markov modela sinais ou sistemas em que cada observação corresponde a um estado do sistema e em que cada estado depende apenas do estado anterior (o sistema muda possivelmente de estado a cada intervalo de observação, podendo inclusive ter seu estado mantido entre duas observações). Cada possível par de observações consecutivas que o modelo pode gerar é chamado de uma transição.

Vamos definir formalmente uma cadeia de Markov e, em seguida, ilustrar o conceito com um exemplo.

Definição 5.1 (Cadeia de Markov). Uma cadeia de Markov é uma trinca $\lambda=(Q, a, \pi)$, onde $Q$ é um conjunto finito chamado conjunto de estados da cadeia $\lambda, a$ é uma matriz de números reais não-negativos indexada por $Q \times Q$ de forma que para $(i, j) \in Q \times Q, a_{i j}$ denota a probabilidade de a cadeia estar no estado $j$ em um instante dado que a cadeia estava no estado $i$ no instante anterior e $\pi$ é um vetor de números reais não-negativos indexado por $Q$ de forma que $\pi(i)$ é a probabilidade de a cadeia estar no estado $i$ no início do processo de observação. A matriz a é chamada matriz de transição de $\lambda$ e o vetor $\pi$ é chamado de vetor de probabilidades iniciais de $\lambda$.

Exemplo 5.1. Um exemplo tradicional do funcionamento de cadeias de Markov é uma modelagem simplificada de mudanças do tempo ("previsão do tempo"). Para manter a 
discussão simples, vamos supor que estamos interessados nas observações de tempo de uma determinada região em que três são as possibilidades: tempo ensolarado, tempo nublado e tempo chuvoso. Vamos supor que as condições do tempo sejam observadas exatamente uma vez por dia, todos os dias. Digamos que, pela experiência prévia do tempo na região, constate-se que a probabilidade de um dia estar em algum estado dependa apenas de como o tempo estava no dia anterior. Para ficar mais cômodo, vamos denotar a condição de tempo ensolarado por $S$, a condição de tempo nublado por $N$ e a condição de tempo chuvoso por $C$. Vamos supor que as probabilidades de mudança de tempo sejam dadas de acordo com a matriz $a$ dada por

$$
a=\begin{array}{c|ccc} 
& S & N & C \\
\hline S & 1 / 5 & 3 / 5 & 1 / 5 \\
N & 1 / 4 & 1 / 2 & 1 / 4 \\
C & 1 / 4 & 1 / 4 & 1 / 2
\end{array}
$$

onde $a_{i j}=\operatorname{Pr}(j \mid i)$ denota a probabilidade de o tempo estar no estado $j$ dado que no dia anterior o tempo estava no estado $i$, para $i, j \in\{S, N, C\}$. Por exemplo, $a_{N C}=1 / 4$ é a probabilidade de o tempo ficar chuvoso dado que no dia anterior ele estava nublado. O par $(N, C)$ é uma transição do sistema e a matriz $a$ é a matriz de transições.

É normalmente costumeiro representar uma cadeia de Markov por um grafo dirigido em que o conjunto de vértices é $Q$, isto é, em que cada vértice corresponda a um estado da cadeia e em que um arco $(i, j) \in Q \times Q$ do grafo corresponde a uma transição da cadeia, com probabilidade da transição dada pela matriz $a$. Observe-se que como uma cadeia de Markov admite transições de um estado para ele mesmo, permitimos arcos da forma $(i, i)$ no grafo, para qualquer $i \in Q$. No caso do modelo de previsão do tempo, o grafo é o da Figura 5.1.

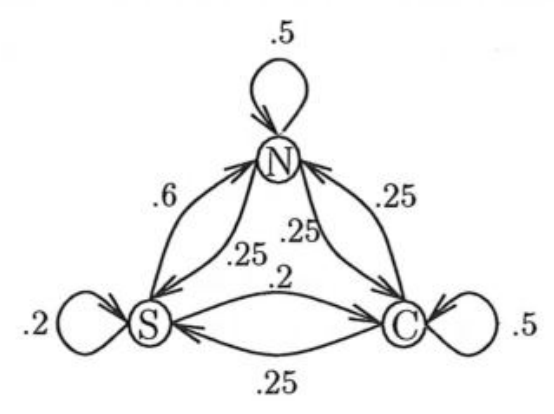

Figura 5.1: O grafo de transição da cadeia de Markov para previsão do tempo.

O grafo representado da maneira descrita é chamado grafo de transição da cadeia de Markov. Naturalmente, como o sistema sempre está em algum estado, as probabilidades associadas aos arcos que saem de um determinado estado somam 1.

Um fato importante a respeito de cadeias de Markov é que uma seqüência de observações $q=q_{1} \cdots q_{n}$ com $q_{i} \in Q$ para $i=1, \ldots, n$ determina um passeio (orientado) no grafo de transições.

Dada uma seqüência de observações $q=q_{1} \cdots q_{n}$, podemos nos perguntar qual é a probabilidade $\operatorname{Pr}(q)$ de $q$ ter ocorrido de acordo com a cadeia de Markov $\lambda$. Essa probabilidade 
é dada pela fórmula

$$
\begin{aligned}
\operatorname{Pr}\left(q_{1}, \ldots, q_{n}\right) & =\operatorname{Pr}\left(q_{n} \mid q_{1}, \ldots, q_{n-1}\right) \operatorname{Pr}\left(q_{1}, \ldots, q_{n-1}\right) \\
& =\operatorname{Pr}\left(q_{n} \mid q_{1}, \ldots, q_{n-1}\right) \operatorname{Pr}\left(q_{n-1} \mid q_{1}, \ldots, q_{n-2}\right) \operatorname{Pr}\left(q_{1}, \ldots, q_{n-2}\right)=\ldots \\
& =\operatorname{Pr}\left(q_{n} \mid q_{1}, \ldots, q_{n-1}\right) \operatorname{Pr}\left(q_{n-1} \mid q_{1}, \ldots, q_{n-2}\right) \cdots \operatorname{Pr}\left(q_{2} \mid q_{1}\right) \operatorname{Pr}\left(q_{1}\right) \\
& =\operatorname{Pr}\left(q_{1}\right) \prod_{i=1}^{n-1} \operatorname{Pr}\left(q_{i+1} \mid q_{1}, \ldots, q_{i}\right)
\end{aligned}
$$

onde para cada igualdade segue de aplicações sucessivas da definição de probabilidade condicional.

Entretanto, como a seqüência $q$ é gerada por uma cadeia de Markov, cada símbolo observado depende apenas do símbolo anterior e, portanto, $\operatorname{Pr}\left(q_{i+1} \mid q_{1}, \ldots, q_{i}\right)=\operatorname{Pr}\left(q_{i+1} \mid q_{i}\right)$, para $i=1, \ldots, n-1$. Logo, a probabilidade de a cadeia $\lambda$ gerar a observação $q$ é

$$
\operatorname{Pr}(q)=\operatorname{Pr}\left(q_{1}\right) \prod_{i=1}^{n-1} \operatorname{Pr}\left(q_{i+1} \mid q_{i}\right)=\pi\left(q_{1}\right) \prod_{i=1}^{n-1} a_{q_{i} q_{i+1}} .
$$

A partir da cadeia de Markov para previsão do tempo, podemos calcular, por exemplo, a probabilidade de que a sucessão de estados de tempo observada seja $S S N C C$, usando, para isso, a fórmula acima. Assim, $\operatorname{Pr}(S S N C C)=\pi(S) a_{S S} a_{S N} a_{N C} a_{C C}=3 \pi(S) / 200$. Supondose que o estado $S$ ocorra inicialmente com probabilidade $2 / 3$, segue que $\operatorname{Pr}(S S N C C)=$ $1 / 100$, isto é, a seqüência $S S N C C$ em particular tem probabilidade de $1 \%$ de ocorrer.

A teoria de cadeias de Markov é bastante extensa e muitos resultados sobre cadeias de Markov estão além do escopo de nossa discussão (como é o caso do importante teorema de distribuições estacionárias de probabilidades de estados para cadeias ergódicas aperiódicas ou o caso de cadeias de Markov de ordens diferentes de 1). Em todo caso, com a simples fórmula para o cálculo de probabilidade de uma seqüência de observações é possível encontrar aplicações úteis, inclusive em Biologia Molecular, como o exemplo de aplicação que descrevemos na próxima seção.

\subsubsection{Estimação de Parâmetros}

Nas seqüências de DNA, o dinucleotídeo CG ocorre com probabilidade menor do que seria de se esperar se observássemos as probabilidades dos nucleotídeos isoladamente. Por um processo chamado metilação, a base C de um dinucleotídeo CG torna-se metil-C e o metil-C tem grande probabilidade de se tornar um T e, por conseqüência, dinucleotídeos CG são relativamente raros em seqüências de DNA. Esse efeito é chamado supressão de citosina e ocorre, por exemplo, no genoma humano. Entretanto, por motivos bioquímicos importantes, em determinadas regiões de DNA, como por exemplo nas regiões promotoras de genes, o dinucleotídeo CG ocorre com freqüência maior do que no restante do DNA. Essas regiões com alta concentração de dinucleotídeos CG são chamadas ilhas ${ }^{4}$ CpG. Ilhas CpG são usadas como "pistas" para busca de regiões codificadoras de genes em uma molécula de DNA [DEKM98].

Logo, um problema de interesse biológico poderia ser o seguinte:

\footnotetext{
${ }^{4} \mathrm{~A}$ notação CpG é adotada para ressaltar que as bases C e G estão em uma mesma fita de DNA em vez de pareados em fitas separadas. A confusão poderia ocorrer porque C e $\mathrm{G}$ são bases complementares e ligam-se por pontes de hidrogênio entre as duas fitas de DNA. No caso de ilhas CpG, estamos nos referindo a nucleotídeos C e G consecutivos em uma mesma fita. A letra p indica que as bases C e G são ligadas por uma ponte fosfodiéster.
} 
Problema-Exemplo 5.2 (Identificação de Seqüências como Ilhas $\mathrm{CpG}$ ). Dado um trecho $s$ de uma seqüência de $\mathrm{DNA}^{5}$, descobrir se esse trecho é ou não uma ilha CpG.

Esse problema pode ser resolvido usando-se cadeias de Markov da seguinte maneira. Construímos uma cadeia de Markov $\lambda_{+}=\left(Q, a_{+}, \pi_{+}\right)$com 4 estados $(Q=\{\mathrm{A}, \mathrm{C}, \mathrm{G}, \mathrm{T}\})$, com matriz de transição $a_{+}$referente às probabilidades de transição para regiões que sejam ilhas Cpg e com vetor $\pi_{+}$de probabilidades iniciais de acordo. Construímos também uma cadeia $\lambda_{-}=\left(Q, a_{-}, \pi_{-}\right)$de modo similar, mas com a matriz $a_{-}$denotando as probabilidades de transição de bases para regiões de DNA que não sejam ilhas CpG e com $\pi_{-}$denotando as probabilidades iniciais de as bases iniciarem seqüências que não sejam ilhas $\mathrm{CpG}^{6}$.

Observe-se que para as cadeias $\lambda_{+}$e $\lambda_{-}$ficarem completamente especificadas é suficiente determinar apenas as matrizes de transição e os vetores de probabilidades iniciais, porque o conjunto de estados é o mesmo para ambas cadeias. O par $\theta=(a, \pi)$ de uma cadeia de Markov $\lambda=(Q, a, \pi)$ é chamado de parâmetros da cadeia $\lambda$.

A especificação dos parâmetros de $\lambda_{+}$e de $\lambda_{-}$pode ser feita usando-se seqüências de DNA pré-rotuladas (i.e., com situação pré-conhecida) da seguinte maneira: se $S_{+}$é um conjunto de trechos de DNA que são ilhas Cpg e se $S_{-}$é um conjunto de trechos de DNA que não são ilhas CpG (determinação feita, por exemplo, experimentalmente), então cada seqüência $s \in S_{+}$descreve um passeio na cadeia $\lambda_{+}$e cada cadeia $s \in S_{-}$descreve um passeio na cadeia $\lambda_{-}$. Assim, para cada arco $(i, j)$ de $\lambda_{+}$, pode-se contar o número $A_{+, i j}$ de quantas vezes a transição $(i, j)$ é usada por seqüências de $S_{+}$e definir $a_{+, i j}$ como a freqüência relativa

$$
a_{+, i j}=\frac{A_{+, i j}}{\sum_{j^{\prime}} A_{+, i j^{\prime}}} .
$$

$\mathrm{O}$ valor $\pi_{+}(i)$ pode ser definido também como a freqüência relativa de uma seqüência de $S_{+}$ser iniciada pela base $i \in Q$. É claro que os parâmetros de $\lambda_{-}$podem ser determinados segundo o mesmo procedimento, desta vez com as seqüências do conjunto $S_{-}$.

O processo de determinar valores para os parâmetros de um modelo a partir de dados observados é chamado estimação de parâmetros e os valores calculados são chamados estimativas. A forma segundo a qual os valores dos parâmetros são determinados é chamada estimador.

\subsubsection{Pseudo-Contadores}

Observe-se que nas freqüências relativas definidas acima, é possível que haja transições na cadeia de Markov para as quais as probabilidades sejam nulas, isto é, $a_{i j}=0$ para algum $\operatorname{par}(i, j) \in Q \times Q$.

Gostaríamos de evitar esse tipo de situação porque os modelos construídos podem estar muito especializados para as seqüências que foram utilizadas para estimar os parâmetros e gostaríamos de que os modelos fossem uma abstração relativamente genérica das situações que eles representam (em nosso caso, a modelagem de ilhas CpG e de regiões que não são ilhas $\mathrm{CpG}$ ).

\footnotetext{
${ }^{5}$ Para consistência com o material do restante do texto, as seqüências de observações no contexto biológico serão representadas por $s$ em vez de $q$.

${ }^{6}$ Essa forma de identificação da família a que uma seqüência pertence possui muitas aplicações práticas. Um exemplo de uso dessas estratégias é a classificação automática de mensagens eletrônicas, para separar (ou mesmo eliminar) mensagens indesejadas, também conhecidas como spams. Essa é a idéia básica usada em programas como o filtro de $e$-mails bogofilter (disponível em http://bogofilter.sf.net/).
} 
Essa especialização excessiva pode ocorrer porque os dados da entrada (isto é, as seqüências de observação contidas em $S_{+}$e em $S_{-}$) podem ser insuficientes e não representar com fidelidade ilhas $\mathrm{CpG}$, isto é, os dados de entrada podem não ser representativos daquilo que se deseja modelar. Mais concretamente, os parâmetros estimados por meio das freqüências relativas podem ser tais que, digamos, $a_{+, i j}=0$ para uma transição $(i, j)$ que ocorra com probabilidade não-nula em ilhas CpG e, portanto, pela Fórmula (5.1) uma seqüência que dependesse de $(i, j)$ teria probabilidade nula de ocorrer de acordo com o modelo de ilhas $\mathrm{CpG}$, o que claramente não desejamos.

Esse problema também presente em outras áreas em que há modelagem estatística (como em Compressão de Dados) é às vezes chamado Problema da Freqüência Zero [BCW90]. Uma maneira simples e usual de contorná-lo é adicionar às frequiências observadas valores positivos chamados pseudo-contadores. Por exemplo, no caso da estimação das probabilidades $a_{+, i j}$, valores $r_{+, i j}>0$, para todo $i, j \in Q$, poderiam ser adicionados às freqüências $A_{+, i j}$ de forma a definirmos alternativamente $a_{+, i j}$ por

$$
a_{+, i j}=\frac{A_{+, i j}+r_{+, i j}}{\sum_{j^{\prime}}\left(A_{+, i j^{\prime}}+r_{+, i j^{\prime}}\right)}
$$

e, assim, toda probabilidade de transição calculada para o modelo seja não-nula. Uma regra simples para adoção de pseudo-contadores e fazer todo pseudo-contador igual a 1, a chamada Regra de Laplace [DEKM98].

Um comentário análogo sobre pseudo-contadores pode obviamente ser feito para que todas probabilidades iniciais sejam também não-nulas.

Intuitivamente, pseudo-contadores correspondem à "adição" de dados fictícios aos dados usados para estimar os parâmetros de um modelo e, sob a perspectiva bayesiana, podem ser interpretados como parâmetros de uma distribuição a priori de Dirichlet para os parâmetros do modelo [DEKM98].

\subsubsection{Usando Cadeias de Markov para Detectar Ilhas CpG}

As cadeias $\lambda_{+}$e $\lambda_{-}$construídas podem ser usadas para resolver o Problema 5.2 de descobrir se um trecho de DNA é uma ilha Cpg ou não se compararmos as probabilidades $\operatorname{Pr}\left(s \mid \lambda_{+}\right)$e $\operatorname{Pr}\left(s \mid \lambda_{-}\right)$de $s$ ser observada dado o modelo $\lambda_{+}$e de $s$ ser observada dado o modelo $\lambda_{-}$.

Aplicando-se a Equação (5.1), que nos dá a probabilidade de uma cadeia gerar uma observação, obtemos

$$
\frac{\operatorname{Pr}\left(s \mid \lambda_{+}\right)}{\operatorname{Pr}\left(s \mid \lambda_{-}\right)}=\frac{\pi_{+}\left(s_{1}\right)}{\pi_{-}\left(s_{1}\right)} \prod_{i=1}^{n-1} \frac{a_{+, s_{i} s_{i+1}}}{a_{-, s_{i} s_{i+1}}} .
$$

Um critério, portanto, para decidir se $s$ corresponde ou não a uma ilha CpG usando as cadeias $\lambda_{+}$e $\lambda_{-}$pode ser verificar se $\operatorname{Pr}\left(s \mid \lambda_{+}\right)>\operatorname{Pr}\left(s \mid \lambda_{-}\right)$ou, equivalentemente, se $\log \frac{\operatorname{Pr}\left(s \mid \lambda_{+}\right)}{\operatorname{Pr}\left(s \mid \lambda_{-}\right)}>0$, no caso de usarmos pseudo-contadores (porque não há problemas de o denominador ser 0 ). Denotando-se por $b_{i j}$ o valor $b_{i j}=\log \left(a_{+, i j} / a_{-, i j}\right)$ e por $c_{i j}=\log \pi_{+}(i) / \pi_{-}(j)$, para todo $i, j \in Q$, segue que

$$
\log \frac{\operatorname{Pr}\left(s \mid \lambda_{+}\right)}{\operatorname{Pr}\left(s \mid \lambda_{-}\right)}=c_{s_{1} s_{1}}+\sum_{i=1}^{n-1} b_{s_{i}, s_{i+1}},
$$

que pode ser manipulado mais facilmente do que a quantia $\operatorname{Pr}\left(s \mid \lambda_{+}\right) / \operatorname{Pr}\left(s \mid \lambda_{-}\right)$(que é a divisão de dois produtos de vários números menores ou iguais a 1), pois o uso do loga- 
ritmo diminui a necessidade de trabalhar com números muito pequenos que não possam ser representados pelo computador ("underflow").

$\mathrm{Na}$ realidade, pode-se argumentar que o interesse seria comparar $\operatorname{Pr}\left(\lambda_{+} \mid s\right)$ e $\operatorname{Pr}\left(\lambda_{-} \mid s\right)$, isto é, comparar as probabilidades de o modelo $\lambda_{+}$ser o "modelo correto" dada a observação $s$ com a probabilidade de o modelo $\lambda_{-}$ser o "modelo correto" dada $s$.

Mas, pela definição de probabilidade condicional e pelo Teorema de Bayes, temos que

$$
\frac{\operatorname{Pr}\left(\lambda_{+} \mid s\right)}{\operatorname{Pr}\left(\lambda_{-} \mid s\right)}=\frac{\frac{\operatorname{Pr}\left(s \mid \lambda_{+}\right) \operatorname{Pr}\left(\lambda_{+}\right)}{\operatorname{Pr}(s)}}{\frac{\operatorname{Pr}\left(s \mid \lambda_{-}\right) \operatorname{Pr}\left(\lambda_{-}\right)}{\operatorname{Pr}(s)}}=\frac{\operatorname{Pr}\left(s \mid \lambda_{+}\right) \operatorname{Pr}\left(\lambda_{+}\right)}{\operatorname{Pr}\left(s \mid \lambda_{-}\right) \operatorname{Pr}\left(\lambda_{-}\right)} .
$$

Se soubermos as probabilidades de ocorrências de ilhas Cpg e de regiões que não sejam ilhas CpG ou se supusermos uma distribuição uniforme para os modelos (que, em um enfoque bayesiano corresponderia a não dispor de informações sobre a distribuição a priori dos modelos), então para calcularmos $\operatorname{Pr}\left(\lambda_{+} \mid s\right) / \operatorname{Pr}\left(\lambda_{-} \mid s\right)$ bastaria calcular $\operatorname{Pr}\left(s \mid \lambda_{+}\right) / \operatorname{Pr}\left(s \mid \lambda_{-}\right)$ da forma feita na Equação (5.2), possivelmente corrigindo por um fator multiplicativo (no caso de levar em conta as probabilidades de ocorrência de ilhas $\mathrm{CpG}$ ).

\subsection{Modelos de Markov de Estados Ocultos}

Nas cadeias de Markov, uma seqüência de observações $q$ tem a propriedade de cada símbolo observado estar em correspondência biunívoca com um estado da cadeia ${ }^{7}$. Os Modelos de Markov de Estados Ocultos (doravante abreviados por MMEOs) são uma generalização das cadeias de Markov.

Em um Modelo de Markov de Estados Ocultos, o símbolo produzido como observação por um estado não necessariamente é único, ao contrário do que ocorre com as cadeias de Markov. Cada estado de um MMEO gera como observação um símbolo pertencente a um alfabeto $\Sigma$. As observações produzidas por um estado são geradas aleatoriamente de acordo com uma distribuição de probabilidades (que pode não ser a mesma para todos os estados) sobre $o$ alfabeto $\Sigma$.

Conforme ilustrado nos exemplos abaixo, a propriedade de não haver uma relação biunívoca entre o estado que produz uma observação e o símbolo produzido é que justifica a nomenclatura dada aos MMEOs.

Os MMEOs são modelos estocásticos que tiveram suas primeiras bases teóricas estabelecidas no final da década de 1960 e no início da década de 1970 e uma importante aplicação dessa época foi o uso para Reconhecimento de Voz [Rab89]. Por serem modelos genéricos e relativamente simples, foram aplicados a diversas outras áreas, dentre as quais a Biologia Computacional (a partir da década de 1990) [DEKM98]. Em Biologia Computacional, MMEOs são utilizados para várias tarefas como modelagem de famílias de proteínas, buscas em bancos de dados e construção de alinhamentos, dentre outras.

Nossa discussão a respeito de MMEOs faz uma descrição breve dos aspectos mais básicos da teoria geral sobre estes modelos para, em seguida, mostrar uma classe particular de MMEOs de interesse para Biologia Computacional.

Definição 5.2 (Modelo de Markov de Estados Ocultos). Um Modelo de Markov de Estados Ocultos é uma quíntupla $\lambda=(Q, \Sigma, a, e, \pi)$, onde $Q$ é um conjunto finito, chamado conjunto de estados de $\lambda ; \Sigma$ é um conjunto finito, chamado alfabeto de $\lambda$; $a$ é uma matriz

\footnotetext{
${ }^{7}$ Intuitivamente, pode-se dizer que a observação é o estado.
} 
de números reais não-negativos indexada por $Q \times Q$, de forma que $a_{i j}$ denota, para cada par $(i, j) \in Q \times Q$, a probabilidade de transição para o estado $j$ dado que o estado anterior do modelo era $i$; e é uma matriz de números reais não-negativos indexada por $Q \times \Sigma$ tal que, para cada par $(i, \sigma) \in Q \times \Sigma, e_{i \sigma}$ denota a probabilidade de o símbolo $\sigma$ ser gerado no estado $i$; $\pi$ é um vetor indexado por $Q$ de forma que $\pi(i)$ denota a probabilidade de $\lambda$ estar no estado $i \in Q$ no início da geração de uma seqüência de observações.

A matriz $a$ e o vetor $\pi$ são chamados, da mesma forma que no caso de cadeias de Markov, matriz de transição e vetor de probabilidades iniciais, respectivamente. A matriz $e$ é chamada matriz de probabilidades de emissão de símbolos ou, resumidamente, matriz de emissão. Naturalmente, por se tratarem de distribuições de probabilidades, as matrizes $a$ e $e$ e o vetor $\pi$ são tais que $\sum_{j \in Q} a_{i j}=1, \sum_{i} \pi(i)=1$ e $\sum_{\sigma \in \Sigma} e_{i \sigma}=1$, para todo $i \in Q$.

Dependendo da ocasião, é bom tratar a matriz $e$ de emissão de símbolos como uma coleção de diversos vetores (ou funções) de emissão de símbolos, sendo um vetor para cada estado de $\lambda$. Assim, como abuso de notação, escrevemos livremente $e_{i}(\sigma)$ em vez de $e_{i \sigma}$ para destacar a distribuição referente ao estado $i$.

É fácil de ver que MMEOs generalizam cadeias de Markov, porque a cadeia $\lambda=$ $\left(Q_{c}, a_{c}, \pi_{c}\right)$ pode ser representada pelo MMEO $\lambda^{\prime}=(Q, \Sigma, a, e, \pi)$ em que $Q=Q_{c}, \Sigma=Q_{c}$, $a=a_{c}, \pi=\pi_{c}$ e $e=I$ (a matriz identidade).

De forma parecida com o caso de cadeias de Markov, definimos $\theta=(a, e, \pi)$ como os parâmetros do MMEO $\lambda=(Q, \Sigma, a, e, \pi)$. Quando for conveniente, vamos supor que o conjunto $Q$ de estados de $\lambda$ seja $Q=\{1, \ldots, N\}$, onde $N=|Q|$, e que o alfabeto $\Sigma$ seja $\Sigma=\left\{\sigma_{1}, \ldots, \sigma_{M}\right\}, \operatorname{com} M=|\Sigma|$.

Analogamente ao caso de cadeias de Markov, tratamos os MMEOs como modelos que geram sinais (seqüências de observações). A diferença entre eles é que, no caso de MMEOs, um símbolo produzido por um estado não necessariamente é único (e, de fato, dependendo da distribuição de probabilidades $e_{i}$ para $i \in Q$, qualquer símbolo de $\Sigma$ pode ser gerado em $i$ ). É necessário, então, distinguir entre a seqüência de observações e a seqüência de estados que produziu as observações.

Um MMEO pode também ser representado por um grafo dirigido, à semelhança do que é feito para cadeias de Markov. A diferença é que para $i \in Q$, a função $e_{i}(\cdot)$ deve ser especificada. É claro que uma seqüência de estados que gera uma observação descreve um passeio orientado no grafo de transições de $\lambda$. Como a seqüência de observações e a sequiência de estados (passeio) são objetos distintos em um MMEO, vamos denotar a seqüência de símbolos observada por $s=s_{1} s_{2} \cdots s_{n}$ e por $q=q_{1} q_{2} \cdots q_{n}$ a seqüência de estados que gerou $s$. Intuitivamente, a seqüência $s$ pode ser interpretada como um "rastro" deixado pela seqüência $q$.

Uma vez que $s$ e $q$ sejam conhecidos, é possível calcular a probabilidade conjunta $\operatorname{Pr}(s, q \mid \lambda)$ de que o passeio $q$ tenha gerado $s$. Lembrando que cada observação $s_{i}$ de $s$ depende só do estado $q_{i}$ em que $s_{i}$ é gerada e que cada estado do modelo $\lambda$ depende só do estado anterior, temos que:

$$
\begin{aligned}
\operatorname{Pr}(s, q \mid \lambda) & =\pi\left(q_{1}\right) e_{q_{1}}\left(s_{1}\right) a_{q_{1} q_{2}} e_{q_{2}}\left(s_{2}\right) \cdots e_{q_{n-1}}\left(s_{n-1}\right) a_{q_{n-1} q_{n}} e_{q_{n}}\left(s_{n}\right) \\
& =\pi\left(q_{1}\right)\left[\prod_{i=1}^{n-1} e_{q_{i}}\left(s_{i}\right) a_{q_{i} q_{i+1}}\right] e_{q_{n}}\left(s_{n}\right) .
\end{aligned}
$$

Em diversas situações em que MMEOs são empregados, apenas o sinal $s$ é conhecido e o passeio $q$ não está disponível. Em outras palavras, em um MMEO a seqüência de estados 
que gera uma observação é geralmente desconhecida e este é o motivo de estes modelos serem ditos de estados ocultos. O seguinte exemplo ilustra os conceitos definidos.

\subsubsection{Cassino Ocasionalmente Desonesto}

Suponhamos que um cassino possua dois dados a serem lançados para apostas ${ }^{8}$. Os dados possuem seis faces cada. Um dos dados é honesto, de forma que cada uma de suas faces possui probabilidade 1/6 de aparecer em um lançamento, e o outro é viciado de tal maneira que a face 6 possui probabilidade $1 / 2$ de aparecer e as demais faces possuem probabilidade 1/10 cada. Os dados são lançados pelo cassino para realização de apostas, com um dado lançado por vez. Os dados são trocados de vez em quando pelo cassino para fazer lançamentos. Se o dado honesto é usado para um lance, ele é trocado pelo dado viciado para o próximo lance com probabilidade $5 / 100$ e mantido com probabilidade 95/100. Já se o viciado estiver em uso, ele é trocado pelo dado honesto com probabilidade 10/100 e mantido com probabilidade $90 / 100$.

Naturalmente, o cassino não revela qual dado foi utilizado para os lançamentos (nem sequer que eles usam dados viciados e muito menos quais são suas probabilidades) e tudo o que os apostadores vêem é a seqüência de resultados. Os lançamentos sempre são iniciados com o dado honesto.

A situação do cassino pode ser modelada por um MMEO. O conjunto $Q$ de estados do modelo contém dois elementos, $d_{1}$ e $d_{2}$, que denotam, respectivamente, o dado honesto e o dado viciado. O alfabeto é $\Sigma=\{1,2, \ldots, 6\}$, onde constam todas as possíveis observações. A matriz de transição é

$$
a=\begin{array}{c|cc} 
& d_{1} & d_{2} \\
\hline d_{1} & 95 / 100 & 5 / 100 \\
d_{2} & 10 / 100 & 90 / 100
\end{array}
$$

a matriz de emissão de símbolos é dada por

$e=$\begin{tabular}{c|cccccc} 
& 1 & 2 & 3 & 4 & 5 & 6 \\
\hline$d_{1}$ & $1 / 6$ & $1 / 6$ & $1 / 6$ & $1 / 6$ & $1 / 6$ & $1 / 6$ \\
$d_{2}$ & $1 / 10$ & $1 / 10$ & $1 / 10$ & $1 / 10$ & $1 / 10$ & $1 / 2$
\end{tabular}

e o vetor de probabilidades iniciais é $\pi=(1,0)$. O grafo dirigido que representa este modelo está mostrado na Figura 5.2.

Todas as observações geradas pelo modelo são seqüências de números (as faces dos dados) e apenas olhando para essas faces não é possível dizer qual foi o dado que gerou um dado lance, de forma que não sabemos qual foi o passeio percorrido no grafo do modelo.

É claro que caso uma grande seqüência de 6's consecutivos fosse observada, poderíamos suspeitar que um dado viciado estivesse sendo empregado, embora um dado honesto também possa gerar uma tal seqüência (com baixa probabilidade, entretanto).

De maneira geral, pouco pode ser dito a respeito de qual sequiência de estados gerou uma seqüência de observações. Tratamos desse assunto com mais detalhes adiante.

\subsection{Problemas Básicos de MMEOs}

O estudo sobre MMEOs é feito tradicionalmente resolvendo-se três problemas fundamentais [Rab89]. A solução desses problemas é importante, dentre outras coisas, para a

\footnotetext{
${ }^{8} \mathrm{O}$ exemplo que apresentamos nesta seção é originalmente de [DEKM98].
} 


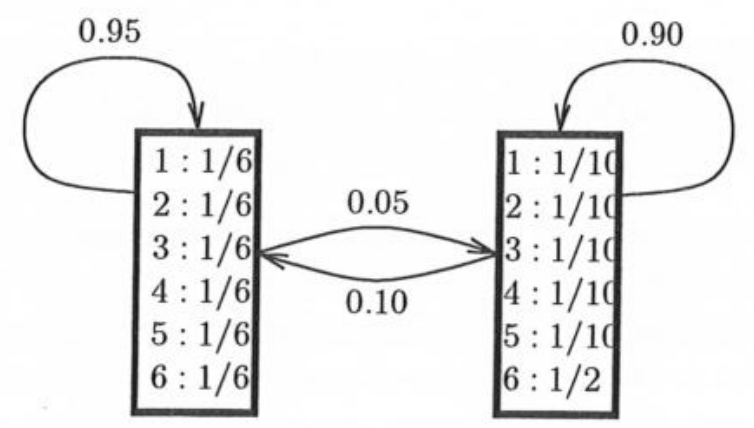

Figura 5.2: O grafo de transições para o MMEO que modela como o cassino lança os dados. Nos vértices do grafo estão anotadas as probabilidades de emissão de símbolos. $\mathrm{O}$ vértice da esquerda representa o dado honesto e o da direita, o viciado.

construção de modelos adequados a fenômenos práticos e para a simulação e o estudo desses fenômenos.

Conforme dissemos, em geral, a única coisa que se sabe a respeito de um MMEO é a seqüência de observações que ele gerou. A respeito da seqüência, duas perguntas podem ser feitas. A primeira, é de determinar qual é a probabilidade de um modelo dado ter gerado as observações. A segunda é mais imprecisa. Idealmente, gostaríamos de conhecer qual foi a seqüência de estados que gerou as observações, mas como já vimos, mais de uma seqüência de estados pode ter gerado as observações. Como a pergunta é muito imprecisa para poder ser respondida, é necessário restringir seu escopo e admitir apenas respostas (isto é, seqüências de estados) que "melhor expliquem" como a seqüência de observações pode ter sido obtida. Com esta formulação, mais de um critério pode ser adotado para "melhor explicar" as observações a partir de passeios no grafo do modelo e a escolha do critério depende da aplicação desejada.

Um terceiro problema importante sobre MMEOs refere-se à construção do modelo para fenômenos práticos, uma vez que alguma observação seja conhecida. Este problema, na verdade, possui duas partes distintas. A primeira é a decisão de qual é o conjunto de estados $Q$ e o alfabeto $\Sigma$ do modelo a ser construído. Em geral, heurísticas e alguns conhecimentos prévios sobre a fonte que gera os sinais são usados para decidir quais são $Q$ e $\Sigma$.

Para efeito de ilustração, isso equivaleria, no exemplo do cassino desonesto, a decidir quantos são os dados usados pelo cassino (e quantas são suas faces) com base apenas nos resultados dos lançamentos dos dados.

A segunda parte do problema é, decididos $Q$ e $\Sigma$, inferir os parâmetros do modelo. Para esta segunda parte do problema há fundamentos teóricos mais bem estudados do que para a primeira e vamos tratar neste texto apenas de um método para o problema de ajustar os parâmetros. Para determinar $Q$ e $\Sigma$ no caso de interesse (para alinhamentos) usaremos uma heurística muito simples.

Os três problemas citados acima estão formalizados a seguir:

Problema 5.1 (Problema da Avaliação). Dados um MMEO $\lambda=(Q, \Sigma, a, e, \pi)$ e uma seqüência de observações $s=s_{1} \cdots s_{n}$, calcular a probabilidade $\operatorname{Pr}(s \mid \lambda)$ de a seqüência ter sido gerada pelo modelo.

Problema 5.2 (Problema da Decodificação). Dados um MMEO $\lambda=(Q, \Sigma, a, e, \pi)$ e uma seqüência de observações $s=s_{1} \cdots s_{n}$, encontrar uma seqüência de estados $q^{*}=$ $q_{1}^{*} \cdots q_{n}^{*}$ que "melhor explique" (segundo algum critério preciso) a geração de $s$. 
Problema 5.3 (Problema do Treinamento). Dado um MMEO em que apenas o conjunto de estados $Q$ e o alfabeto $\Sigma$ sejam conhecidos e dada uma seqüência de observações $s$, estimar os parâmetros a, e e $\pi$ do modelo a partir de $s$.

O Problema 5.3 é denominado Problema de Treinamento porque interpretamos o ajuste de parâmetros do modelo como um "processo de aprendizado" para gerar a seqüência de observações $s$. A seqüência $s$ é também chamada seqüência de treinamento do modelo.

Para ilustrar como os três problemas acima podem ser usados na construção e aplicação de MMEOs a situações práticas, citamos um exemplo simplificado de Reconhecimento de Voz [Rab89]. Nessas aplicações, o sinal de interesse é alguma representação (geralmente discretizada) de uma onda sonora que contém uma palavra ou frase a ser reconhecida. Uma representação de uma tal onda sonora é uma seqüência de inteiros de modo geral e, para nossos fins, estes inteiros são interpretados como símbolos do alfabeto.

Suponhamos que temos um vocabulário (uma lista) de palavras isoladas (isto é, que não estão em uma frase) que desejamos reconhecer (essas palavras podem representar comandos de voz como "pare" ou "ande"). Vamos supor também que um MMEO será construído para modelar cada palavra. Com base em um número (de preferência, grande) de observações de cada palavra do vocabulário (por exemplo, pronunciadas por várias pessoas e com velocidades diferentes), um MMEO é criado para cada palavra por meio da solução do Problema 5.3. Em seguida, os modelos criados são analisados usando a solução do Problema 5.2 para cada seqüência de treinamento. Isso permite analisar quais estados do modelo ficam associados a quais símbolos para que modificações e refinamentos (por exemplo, mudanças no número de estados) sejam feitos a fim de que o modelo represente com fidelidade palavras faladas.

Finalmente, para um sinal que representa uma palavra que deve ser reconhecida, a solução do Problema 5.1 é usada para ordenar os modelos de forma a descobrir a qual modelo o sinal observado melhor se ajusta. A classificação dos modelos e a seleção do melhor são feitas usando como parâmetros ou pontuações as probabilidades de o sinal ter. sido gerado por cada modelo. A palavra cujo modelo possui maior pontuação é usada como resultado do reconhecimento.

Esse exemplo mostra que um dos usos do Problema 5.1 é o de comparar uma coleção de modelos para a escolha daquele que melhor poderia ter gerado uma observação desconhecida.

Vamos agora estudar soluções algorítmicas a cada um dos três problemas básicos de MMEOs.

\subsubsection{Problema 1: Problema de Avaliação}

A probabilidade $\operatorname{Pr}(s \mid \lambda)$ de uma observação $s$ ser gerada por um modelo $\lambda$ pode ser calculada em função das probabilidades conjuntas de $s$ ser gerada por $\lambda$ para cada possível passeio $q$ de tamanho $n=|s|$ em $\lambda$ pela fórmula

$$
\operatorname{Pr}(s \mid \lambda)=\sum_{q \in Q^{n}} \operatorname{Pr}(s, q \mid \lambda)
$$

e cada uma das probabilidades conjuntas $\operatorname{Pr}(s, q \mid \lambda)$ pode ser calculada pela Fórmula (5.3). Infelizmente, a Fórmula (5.4) tem um número de termos que cresce exponencialmente com $n$, o que torna inviável sob o aspecto computacional a aplicação direta da fórmula. Uma maneira alternativa e muito mais eficiente de calcular $\operatorname{Pr}(s \mid \lambda)$ e que não faz uma enumeração explícita de todos os passeios no grafo de $\lambda$ pode ser feita por programação dinâmica, através de um algoritmo chamado de Algoritmo Progressivo. 


\subsubsection{Algoritmo Progressivo}

O cálculo de $\operatorname{Pr}(s \mid \lambda)$ pode ser acelerado com a seguinte observação: um passeio (parcial) que gera as observações $s_{1} s_{2} \cdots s_{i}$ e que gera o símbolo $s_{i}$ no estado $j$ pode ser obtido a partir de um passeio qualquer que gere $s_{1} s_{2} \cdots s_{i-1}$ e que termine no estado $j$ por meio de uma transição de um estado $j^{\prime}$ para $j$ e de uma emissão de $s_{i}$ no estado $j$. Assim, para gerar a seqüência $s_{1} s_{2} \cdots s_{i}$, com $s_{i}$ gerado no estado $j$, basta considerar todas as possibilidades de gerar $s_{1} s_{2} \cdots s_{i-1}$ com $s_{i-1}$ gerado no estado $j^{\prime}$, para todo $j^{\prime} \in Q$, e considerar as transições de $j^{\prime}$ a $j$ seguidas por emissões de $s_{i}$ em $j$ para cada uma das possibilidades.

É importante ver que, para $i \geq 2$, para gerar $s_{1} \cdots s_{i}$ e atingir o estado $j$, as possibilidades de estar no estado $j^{\prime} \in Q$ no momento de geração de $s_{i-1}$ são, naturalmente, duas a duas disjuntas. Além disso, é claro que essas são todas as possibilidades para um passeio em $\lambda$ de comprimento $i$ que termina em $j$.

Podemos reescrever essas observações em termos de probabilidades de uma maneira simples.

Se denotarmos pela variável $\alpha(i, j)$ a probabilidade $\alpha(i, j)=\operatorname{Pr}\left(s_{1} \cdots s_{i}, q_{i}=j \mid \lambda\right)$ de um passeio (parcial) de tamanho $i$ e que termina no estado $j$ gerar a seqüência (também parcial) de observações $s_{1}, \ldots, s_{i}$, pelos motivos acima é simples de ver que há uma relação de recorrência dada por $\alpha(i+1, j)=\sum_{j^{\prime} \in Q} \alpha\left(i, j^{\prime}\right) a_{j^{\prime} j} e_{j}\left(s_{i+1}\right)=e_{j}\left(s_{i+1}\right)\left[\sum_{j^{\prime} \in Q} \alpha\left(i, j^{\prime}\right) a_{j^{\prime} j}\right]$, para todo $i=1, \ldots, n-1$ e para todo $j=1, \ldots, N$, onde $N=|Q|$. As bases da relação de recorrência ficam definidas como $\alpha(1, j)=\pi(j) e_{j}\left(s_{1}\right)$, para todo $j$. A probabilidade $\operatorname{Pr}(s \mid \lambda)$ pode ser calculada então por

$$
\operatorname{Pr}(s \mid \lambda)=\sum_{j \in Q} \alpha(n, j) .
$$

O resumo de nossa discussão está no pseudo-código do Algoritmo Progressivo, listado a seguir.

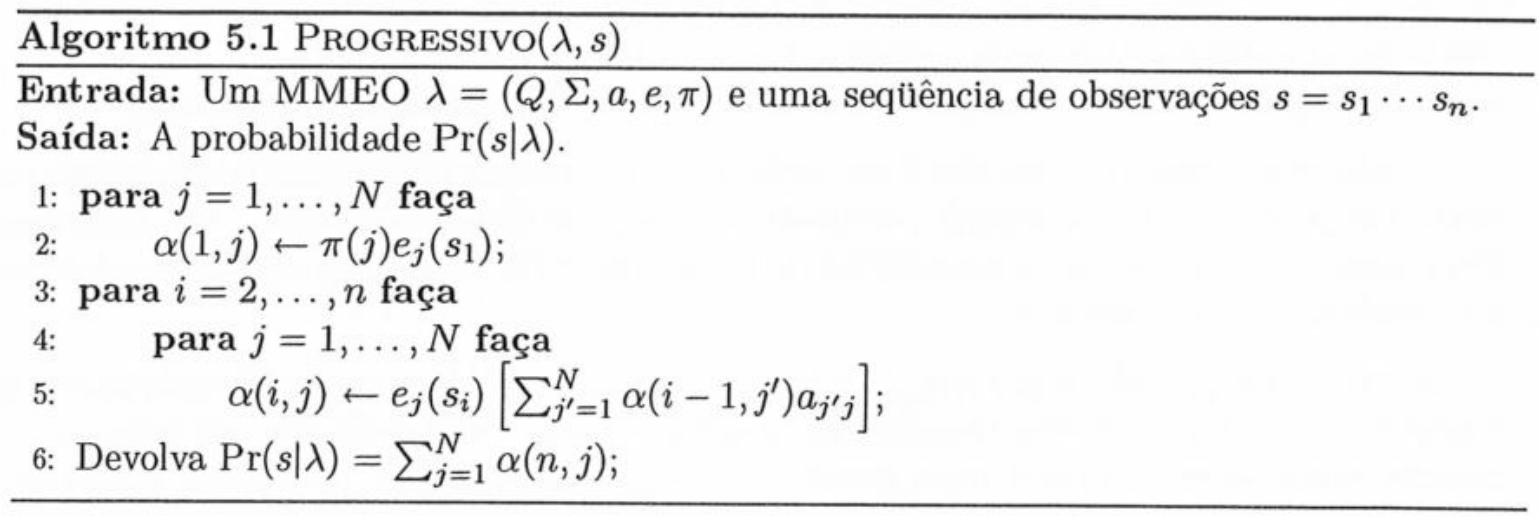

5.4.1.1.1 Análise de Complexidade A inicialização do algoritmo, que consiste no cálculo das probabilidades $\operatorname{Pr}\left(s_{1}, q_{1}=j \mid \lambda\right)$, para $j \in Q$, é feita em tempo $O(|Q|)$. $\mathrm{O}$ cálculo restante da matriz $\alpha$ de programação dinâmica é feito em $(|s|-1)|Q|$ iterações e cada uma dessas iterações leva tempo $O(|Q|)$, totalizando tempo $O\left(|s||Q|^{2}\right)$ para esta etapa. Finalmente, a probabilidade $\operatorname{Pr}(s \mid \lambda)$ é calculada com uma soma em tempo $O(|Q|)$. Assim, o algoritmo como um todo leva tempo $O(|Q|)+O\left(|s||Q|^{2}\right)+O(|Q|)=O\left(|s||Q|^{2}\right)$.

Observe-se que uma aplicação direta da Fórmula (5.4) tomaria tempo $O(|s|)$ para que cada uma das probabilidades conjuntas $\operatorname{Pr}(s, q \mid \lambda)$ fosse calculada e, como existem $|Q|^{|s|}$ 
tais termos, o cálculo tomaria tempo $O\left(|s||Q|^{|s|}\right)$, que é assintoticamente muito maior que $O\left(|s||Q|^{2}\right)$.

O espaço usado pelo algoritmo é, a menos do modelo $\lambda$ e da seqüência $s$, que fazem parte da entrada e das variáveis de controle do algoritmo (que totalizam espaço $O(1)$ ), o espaço usado pela matriz $\alpha$, que possui dimensões $|s| \times|Q|$, o que significa que o Algoritmo Progressivo usa espaço $O(|s||Q|)$.

Uma análise ligeiramente mais cuidadosa nos convence de que para calcular as entradas da linha $i$ da matriz $\alpha$ são usadas apenas entradas da linha $i-1$, para $i=2, \ldots, n$. Assim, o algoritmo pode ser implementado mantendo-se apenas duas linhas de $\alpha$ em vez de manter a matriz inteira em memória, isto é, usando apenas espaço $O(|Q|)$.

Se estivermos interessados apenas na resposta ao Problema de Avaliação, espaço $O(|Q|)$ é suficiente para calcular $\operatorname{Pr}(s \mid \lambda)$. Entretanto, conforme veremos, a matriz $\alpha$ é útil também para a solução de outros problemas, de modo que é bom dispor de uma versão do Algoritmo Progressivo que use espaço $O(1)$ e devolva a matriz $\alpha$ inteira para uso posterior.

\subsubsection{Algoritmo Regressivo}

Embora o Algoritmo Progressivo resolva completamente o Problema de Avaliação, é ilustrativo observar uma solução diferente para o problema. Essa solução, também de programação dinâmica, é obtida através do Algoritmo REgREssivo que, informalmente, realiza os cálculos na "direção contrária" da usada pelo Algoritmo Progressivo: enquanto o Algoritmo Progressivo calcula probabilidades de que prefixos de $s$ sejam gerados por passeios que terminem em um estado fixado, o Algoritmo Regressivo calcula probabilidades de que sufixos de $s$ sejam gerados a partir de um determinado estado de $\lambda$. Essas formas de operação claramente justificam os nomes Progressivo e REgressivo.

O Algoritmo Regressivo não é necessário para a solução do Problema de Avaliação, conforme já vimos, mas a matriz calculada por ele (e também a matriz $\alpha$ do Algoritmo Progressivo) é usada para uma solução do Problema de Decodificação e para uma solução do Problema de Treinamento.

Se $\beta(i, j)$ é a probabilidade $\beta(i, j)=\operatorname{Pr}\left(s_{i+1} \cdots s_{n} \mid q_{i}=j, \lambda\right)$, isto é, a probabilidade de o modelo $\lambda$ gerar a seqüência (parcial) de observações $s_{i+1} \cdots s_{n}$ dado que no instante $i$ o modelo estava no estado $j$ e já tinha gerado $s_{i}$, então as variáveis $\beta(i, j)$ também satisfazem a uma relação de recorrência.

De fato, para gerar a seqüência $s_{i} s_{i+1} \cdots s_{n}$ dado que no instante $i-1$ o estado era $j$, as possibilidades são realizar uma transição de $j$ para um estado $j^{\prime} \in Q$, gerar o símbolo $s_{i}$ (já que agora o instante é $i$ ) e prosseguir com a geração da seqüência de $s_{i+1}$ até $s_{n}$ dado que no instante $i$ o modelo está em $j^{\prime}$, para $j^{\prime} \in Q$. Em termos das probabilidades $\beta(i, j)$, essa observação significa que $\beta(i-1, j)=\sum_{j^{\prime} \in Q} a_{j j^{\prime}} e_{j^{\prime}}\left(s_{i}\right) \beta\left(i, j^{\prime}\right)$, para todo $i=1, \ldots, n$ e para todo $j \in Q$. Para $i=n$, temos que $\beta(n, j)=\operatorname{Pr}\left(s_{n+1} \cdots s_{n} \mid q_{n}=j, \lambda\right)=\operatorname{Pr}\left(\varepsilon \mid q_{n}=j, \lambda\right)$, ou seja $\beta(n, j)$ é a probabilidade de $\lambda$ gerar a seqüência vazia dado que o estado $q_{n}$ é $j$ e que $s_{n}$ já foi gerado, isto é, $\beta(n, j)$ é a probabilidade de o modelo gerar a seqüência vazia uma vez que a geração de símbolos terminou. Assim, $\beta(n, j)=1$ para todo $j \in Q$. 
Com base no significado das variáveis $\beta(i, j)$, segue que

$$
\begin{aligned}
\operatorname{Pr}(s \mid \lambda) & =\operatorname{Pr}\left(s_{1} \cdots s_{n} \mid \lambda\right)=\sum_{j \in Q} \operatorname{Pr}\left(s_{1} \cdots s_{n}, q_{1}=j \mid \lambda\right) \\
& =\sum_{j \in Q} \operatorname{Pr}\left(s_{2} \cdots s_{n} \mid s_{1}, q_{1}=j, \lambda\right) \operatorname{Pr}\left(s_{1}, q_{1}=j \mid \lambda\right) \\
& =\sum_{j \in Q} \pi(j) e_{j}\left(s_{1}\right) \beta(1, j) .
\end{aligned}
$$

Esses cálculos fornecem-nos uma maneira alternativa de calcular $\operatorname{Pr}(s \mid \lambda)$, chamada Algoritmo REgRESSIVO, cujo pseudo-código está listado a seguir.

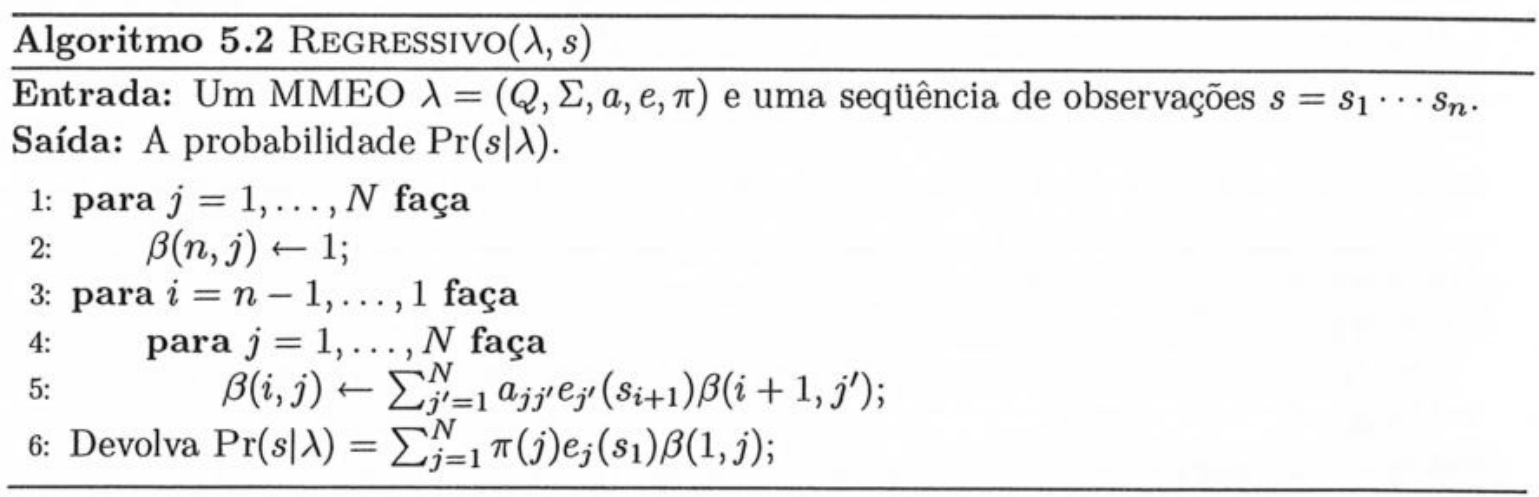

5.4.1.2.1 Análise de Complexidade O Algoritmo Regressivo é bastante similar ao Algoritmo Progressivo e isso vale também para as complexidades de espaço e de tempo.

O primeiro laço do Algoritmo Regressivo (inicialização) leva tempo $O(|Q|$ ). Os dois laços encaixados, onde está o cerne do algoritmo, preenchem a matriz $\beta \mathrm{em}$ um total de $(|s|-1)|Q|$ iterações, sendo que cada iteração toma tempo $O(|Q|)$. O último passo calcula $\operatorname{Pr}(s \mid \lambda)$ em tempo $O(|Q|)$. Logo, o algoritmo é executado em tempo $O\left(|s||Q|^{2}\right)$.

Em relação ao espaço, o algoritmo usa, excetuando os dados de entrada e as variáveis de controle, apenas o espaço para a matriz $\beta$, que tem tamanho $O(|s||Q|)$. Por uma observação parecida à feita para o Algoritmo Progressivo (a $i$-ésima linha de $\beta$ depende apenas da linha $i+1$ ), o espaço suficiente para o Algoritmo REgRESsivo pode ser reduzido para $O(|Q|)$, apesar de as matrizes $\alpha$ e $\beta$ serem ambas usadas em outras ocasiões.

\subsubsection{Problema 2: Problema de Decodificação}

A idéia por trás do Problema de Decodificação é, intuitivamente falando, descobrir, dada a sequiência $s$, qual foi o passeio de $\lambda$ que gerou $s$. Já vimos que, em princípio, qualquer passeio de $\lambda$ pode gerar uma seqüência de observações fixada e que algum critério deve ser adotado para obter uma seqüência de estados (dentre as várias em potencial) que "melhor explique" as observações. Um critério adotado é tratar o problema como um problema de otimização para funções objetivo de interesse. Mostramos aqui duas possíveis soluções para o problema com enfoques diferentes: uma que procura soluções boas que sejam "locais" e outra que procura boas soluções "globais". 


\subsubsection{Decodificação Posterior}

Um critério para resolver o Problema da Decodificação é tentar saber qual, dentre os estados de $\lambda$, foi o mais provável de ter gerado o símbolo $s_{i}$, para todo $i=1, \ldots, n$, isto é, saber, dada a seqüência $s$, qual foi, para cada $i$, o estado $q_{i}^{*}$ mais provável, ou seja, descobrir $q_{i}^{*}$ que maximiza $\operatorname{Pr}\left(q_{i}^{*} \mid s\right)$, para todo $i$. O passeio $q^{*}$ dado como solução para o problema com esse critério é, então, $q^{*}=q_{1}^{*} \cdots q_{n}^{*}$. Esse método de cálculo de um passeio é chamado Decodificação Posterior de $s$.

Notando que $\operatorname{Pr}\left(s, q_{i}=j\right)=\operatorname{Pr}\left(s_{i+1} \ldots s_{n} \mid s_{1} \cdots s_{i}, q_{i}=j\right) \operatorname{Pr}\left(s_{1} \cdots s_{i}, q_{i}=j\right)$ e que, como a geração de $s_{i+1} \cdots s_{n}$ não depende dos símbolos gerados anteriormente, mas apenas do estado $q_{i}$, então $\operatorname{Pr}\left(s_{i+1} \cdots s_{n} \mid s_{1} \cdots s_{i}, q_{i}=j\right)=\operatorname{Pr}\left(s_{i+1} \cdots s_{n} \mid q_{i}=j\right)$ e, daí, a probabilidade fica $\operatorname{Pr}\left(s, q_{i}=j\right)=\operatorname{Pr}\left(s_{i+1} \cdots s_{n} \mid q_{i}=j\right) \operatorname{Pr}\left(s_{1} \cdots s_{i}, q_{i}=j\right)=\alpha(i, j) \beta(i, j)$, onde $\alpha$ e $\beta$ são as matrizes calculadas pelos Algoritmos Progressivo e REgREssivo, respectivamente.

Definindo $\gamma(i, j)=\operatorname{Pr}\left(q_{i}=j \mid s\right)=\operatorname{Pr}\left(s, q_{i}=j\right) / \operatorname{Pr}(s)$, temos que o estado $q_{i}^{*}$ procurado é $q_{i}^{*}=\operatorname{argmax}_{j \in Q} \gamma(i, j)=\operatorname{argmax}_{j \in Q} \alpha(i, j) \beta(i, j) / \operatorname{Pr}(s) \doteq \operatorname{argmax}_{j \in Q} \alpha(i, j) \beta(i, j)$, uma vez que maximizar $\alpha(i, j) \beta(i, j) / \operatorname{Pr}(s)$ é o mesmo que maximizar $\alpha(i, j) \beta(i, j)$, porque $\operatorname{Pr}(s)$ independe de $i$ e de $j$. O Algoritmo de Decodificação Posterior está listado a seguir.

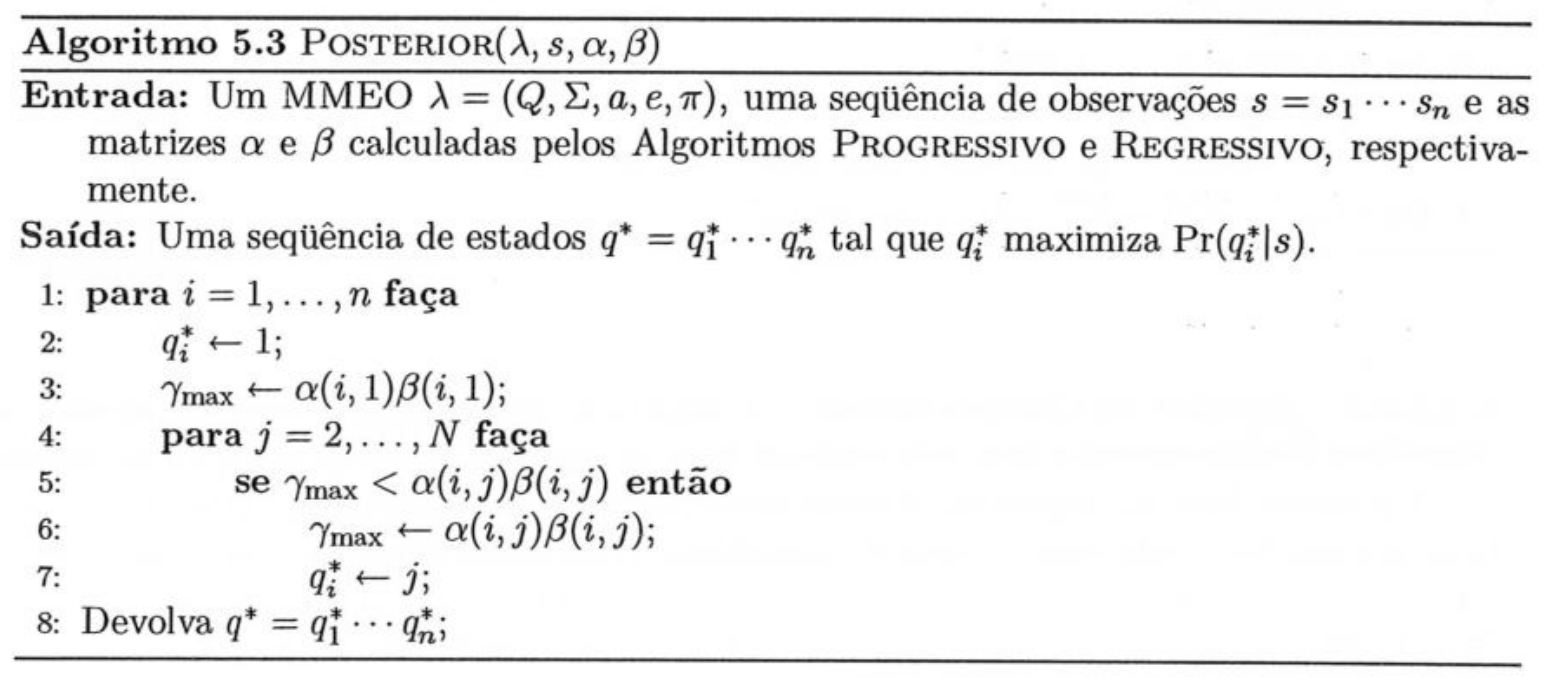

5.4.2.1.1 Análise de Complexidade O Algoritmo Posterior tem seu laço externo executado $|s|$ vezes (cada vez determina um estado de $q^{*}$ ). Para cada valor de $i$, o corpo do laço examina cada estado de $Q$ em tempo $O(1)$ e, assim, para cada $i$, o corpo do laço é executado em tempo $O(|Q|)$. Logo, o Algoritmo Posterior pode ser executado em tempo $O(|s||Q|)$.

Em relação ao espaço, além dos dados de entrada (que incluem as duas matrizes $\alpha$ e $\beta$ ) e das variáveis de controle, o algoritmo usa apenas um vetor de tamanho $n=|s|$ para devolver o passeio calculado, o que significa que sua resposta ocupa espaço $O(|s|)$ e que sua complexidade de espaço é $O(1)$.

Perceba-se que a descrição dada do Algoritmo Posterior supõe que as matrizes $\alpha$ e $\beta$ sejam dadas. Se isso não for verdade, então cálculos dessas matrizes devem ser feitos pelo algoritmo e sua complexidade fica maior (complexidade de tempo de $O\left(|s||Q|^{2}\right.$ ) e complexidade de espaço de $O(|s||Q|)$ ), já que essas partes tornam-se as mais custosas do algoritmo. 


\subsubsection{Decodificação de Viterbi}

Apesar de o Algoritmo Posterior devolver uma seqüência de estados no grafo de $\lambda$ em que cada estado é aquele que possui a maior probabilidade de ter gerado a observação correspondente, o critério usado leva em consideração os estados de forma isolada dos demais, preocupando-se apenas com cada estado para cada símbolo da seqüência de observações, que é um critério "local" para encontrar $q^{*}$.

Um possível problema com a resposta dada pelo Algoritmo Posterior é que a seqüência $q^{*}$ devolvida pode não ser um passeio válido no grafo de $\lambda$. Isto aconteceria, por exemplo, quando o passeio devolvido fosse tal que dois estados consecutivos, digamos, $j$ e $j^{\prime} \in Q$, fossem tais que $a_{j j^{\prime}}=0$, ou seja, haja probabilidade 0 de transição entre dois estados consecutivos no passeio determinado. Apesar disso, algumas aplicações podem ainda ter interesse na seqüência $q^{*}$ sem necessariamente interpretá-la como um passeio de $\lambda$, mas observar localmente quais estados têm maior verossimilhança.

Uma outra estratégia, em um certo sentido "oposta" à estratégia do método de Decodificação Posterior, seria tentar restringir as buscas a seqüências $q=q_{1} \cdots q_{n} \in Q^{n}$ de estados de $\lambda$ que formam passeios válidos de $\lambda$ (aqueles em que nenhuma probabilidade de transição seja nula) e procurar dentre elas uma seqüência $q^{*}=q_{1}^{*} \cdots q_{n}^{*}$ tal que $\operatorname{Pr}\left(q^{*} \mid s\right)$ seja máxima. Note-se que este novo critério de otimização é "global", no sentido de que ele procura seqüências inteiras de estados, ao contrário do critério anterior ("local") para o Problema da Decodificação.

Mais uma vez, há um algoritmo eficiente para o problema com a nova estratégia de otimização. O algoritmo aqui é também um algoritmo de programação dinâmica, chamado Algoritmo de Viterbi. Conforme veremos, o Algoritmo de Viterbi possui muita similaridade com o Algoritmo Progressivo e, de fato, um pode ser visto como uma ligeira modificação do outro.

A observação fundamental para o algoritmo é que, fixado um estado final, digamos $j$, para um passeio, existem $|Q|$ possibilidades para o penúltimo estado do passeio. Além disso, um passeio de maior probabilidade conjunta ( $\operatorname{com} s$ ) e que termine em um estado $j$ é obtido como um passeio de maior probabilidade conjunta (com $s[1 \ldots n-1]$ ) que termine em um estado $j^{\prime}$ seguido de uma transição de $j^{\prime}$ a $j$, considerando para isso todas as possibilidades para $j^{\prime}$. Após a transição para o estado $j$, o símbolo $s_{n}$ é gerado.

É fácil de ver que o problema possui a propriedade das subsoluções ótimas, no sentido de que um passeio ótimo que termine em $j$ e que tenha $j^{\prime}$ como penúltimo símbolo tem o subpasseio com fim em $j^{\prime}$ também ótimo. Se isso não fosse verdade, ou seja, se houvesse um outro passeio com fim em $j^{\prime}$ cuja probabilidade conjunta com $s[1 \ldots n-1]$ fosse maior do que a do primeiro subpasseio, então poderíamos construir um novo passeio com fim em $j$ simplesmente justapondo $j$ ao fim do subpasseio melhor e obtendo, desta forma, um passeio com probabilidade conjunta ( $\operatorname{com} s$ ) maior do que a do passeio original, o que contrariaria a otimalidade deste.

Vamos então denotar por $\delta(i, j)$ a probabilidade $\delta(i, j)=\max _{q_{1}, \ldots q_{i-1}} \operatorname{Pr}\left(q_{1} \cdots q_{i-1}, q_{i}=\right.$ $\left.j, s_{1} \cdots s_{i} \mid \lambda\right)$, ou seja, $\delta(i, j)$ é a probabilidade de um melhor passeio em $\lambda$ que produz as observações $s_{1} \cdots s_{i}$ e que tem $j$ como último estado.

Por observações já feitas, temos que $\delta(i, j)$ satisfaz à seguinte relação de recorrência

$$
\delta(i+1, j)=\left[\max _{j^{\prime} \in Q} \delta\left(i, j^{\prime}\right) a_{j^{\prime} j}\right] e_{j}\left(s_{i+1}\right)
$$


para todo $i \geq 1$ e para todo $j \in Q$. As condições iniciais da recorrência são dadas por

$$
\delta(1, j)=\pi(j) e_{j}\left(s_{1}\right)
$$

para todo $j \in Q$.

Naturalmente, um passeio de maior probabilidade é obtido escolhendo-se um passeio com valor $\delta(n, j)$ máximo, dentre todos valores de $j$.

Observe-se que $\operatorname{Pr}\left(s, q^{*}\right)=\max _{j \in Q} \delta(n, j)$, onde $q^{*}$ é uma seqüência ótima de estados que gera $s$ como observações. Como a seqüência $s$ está fixada e $\operatorname{Pr}\left(s, q^{*}\right)=\operatorname{Pr}\left(q^{*} \mid s\right) / \operatorname{Pr}(s)$, a seqüência $q^{*}$ de estados calculada pelo Algoritmo de Viterbi é realmente o passeio desejado no segundo critério do Problema de Decodificação ${ }^{9}$.

Todos esses cálculos determinam apenas a probabilidade de um passeio ótimo que gera $s$. Para determinar também o passeio (ou um tal passeio, no caso de haver vários), podemos usar uma variável $\psi(i, j)$ para cada valor $\delta(i, j)$ que indique qual foi o estado $j^{\prime}$ para o qual o produto $\delta\left(i-1, j^{\prime}\right) a_{j^{\prime} j}$ atingiu valor máximo. Vamos denotar isso por $\psi(i, j)=$ $\operatorname{argmax}_{j^{\prime} \in Q} \delta\left(i-1, j^{\prime}\right) a_{j^{\prime} j}$. Essas variáveis nos permitem calcular os estados de um passeio ótimo se fizermos $q_{n}^{*}=\operatorname{argmax}_{j \in Q} \delta(n, j)$ e usarmos as variáveis $\psi(i, j)$ (que funcionam como apontadores) para restaurar o restante do passeio (os outros $n-1$ estados). Apenas por completude, podemos fazer para todo $j \in Q, \psi(1, j)=0$ para indicar que nenhum estado precede o estado $j$ no passeio ótimo que gera $s_{1}$.

O pseudo-código do Algoritmo de Viterbi está listado a seguir.

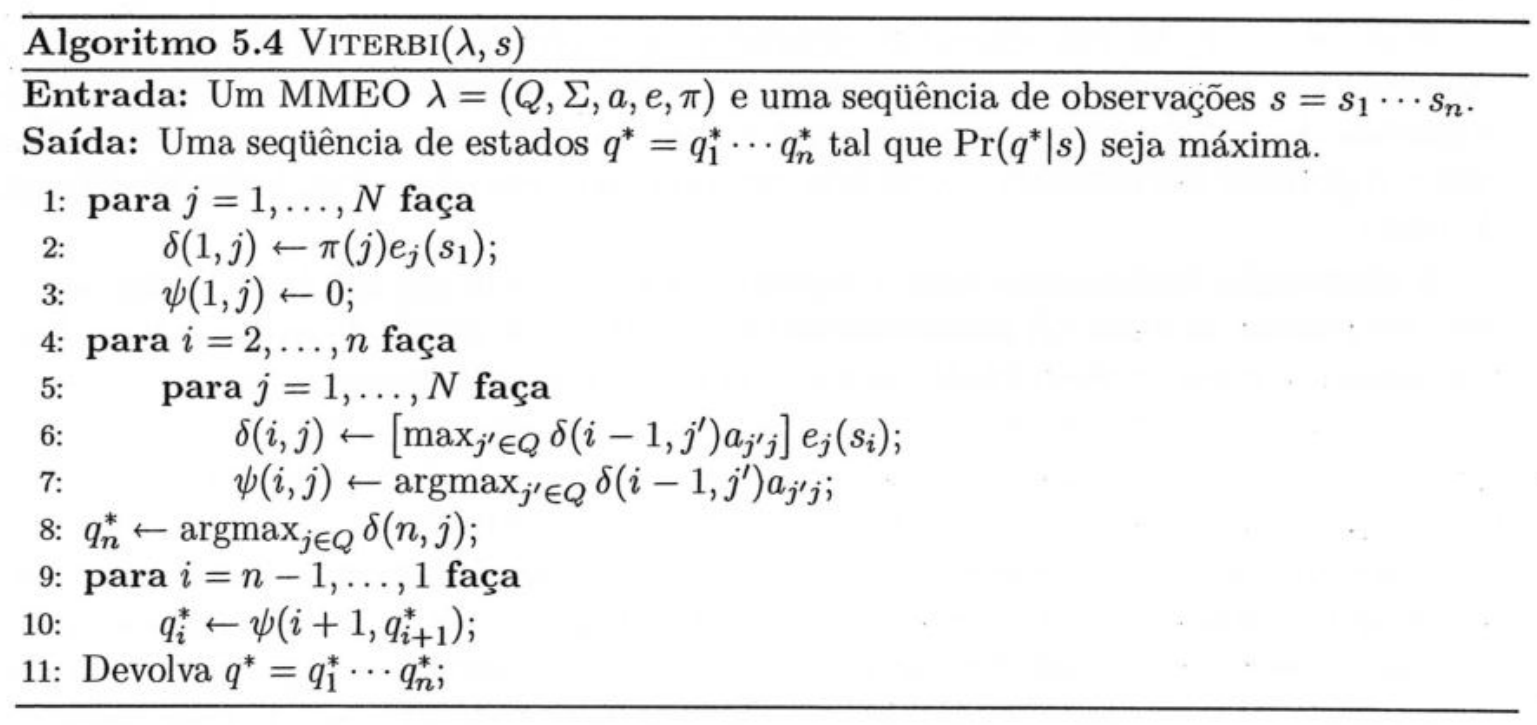

A propósito, é interessante destacar a similaridade da relação de recorrência das variáveis $\delta$ do Algoritmo Viterbi e das variáveis $\alpha$ do Algoritmo Progressivo: o Algoritmo Viterbi pode ser obtido a partir do Algoritmo Progressivo (a menos da determinação do passeio $q^{*}$ ) pela simples substituição de somas pelo cálculo de máximo.

5.4.2.2.1 Análise de Complexidade No começo do Algoritmo Viterbi, a primeira linha de cada uma das matrizes $\delta$ e $\psi$ (ambas matrizes de dimensões $|s| \times|Q|$ ) é inicializada em tempo $O(|Q|)$.

\footnotetext{
${ }^{9} \mathrm{~A}$ observação é relevante porque o que o Algoritmo de Viterbi calcula é a probabilidade conjunta de $s$ de do passeio ótimo, enquanto o foco do Problema da Decodificação está na probabilidade condicional de passeios, dadas as seqüências de observações.
} 
A parte principal do algoritmo consiste de dois laços encaixados. A parte mais interna do laço contém um cálculo de máximo sobre os estados de $\lambda$ (além da determinação do estado em que o máximo é atingido) e ela pode ser realizada em tempo $O(|Q|)$. Como os laços encaixados executam um total de $O(|s||Q|)$ iterações, o tempo para esta parte do algoritmo é de $O\left(|s||Q|^{2}\right)$.

O cálculo de $q_{n}^{*}$ leva tempo $O(|Q|)$. Finalmente, a determinação dos demais estados $q_{i}^{*}$ é feita em tempo $O(|s|)$.

Isso tudo significa que o Algoritmo VITERBI pode ser executado em tempo $O(|Q|)+$ $O\left(|s||Q|^{2}\right)+O(|Q|)+O(|s|)=O\left(|s||Q|^{2}\right)$, a mesma complexidade de tempo dos Algoritmos Progressivo e Regressivo.

Quanto ao espaço, além dos dados de entrada e das variáveis de controle, o Algoritmo VITERBI usa apenas as matrizes $\delta$ e $\psi$ (ambas com $|s|$ linhas por $|Q|$ colunas) e um vetor para devolver a seqüência $q^{*}$ (que possui tamanho $|s|$ ). Logo, o consumo de espaço do algoritmo é $O(|s \| Q|)$. Argumentos similares aos que já usamos para os Algoritmos Progressivo e REGRESSIVO podem nos convencer de que o Algoritmo VITERBI pode ser implementado de maneira que o espaço usado seja $O(|Q|)$, se apenas a probabilidade $\operatorname{Pr}\left(q^{*} \mid s\right)$ for desejada.

5.4.2.2.2 Comentários Gerais Uma observação trivial, mas importante em relação ao Problema da Decodificação é que um passeio $q^{*}$ pode ser interpretado como uma rotulação das observações de $s$ : com esta interpretação, o símbolo $s_{i}$ da seqüência de observações é rotulado com o valor $q_{i}^{*}$ (ou com o valor de uma função de $q_{i}^{*}$ ), para cada $i$.

Por exemplo, no caso do cassino desonesto, se tivéssemos quatro dados sendo lançados com dois deles sendo honestos e os outros dois, viciados, poderíamos estar interessados em saber se, dada uma seqüência $s$ de lançamentos, o $i$-ésimo resultado provém (com grande probabilidade) de um dado honesto ou de um dado viciado, sem importar qual dado produziu o resultado.

Esse tipo de tratamento de um passeio em um MMEO como uma rotulação da seqüência de observações é útil para várias aplicações, incluindo a construção de alinhamentos de seqüências biológicas.

Outro ponto a ressaltar sobre os algoritmos apresentados até aqui é que eles geralmente trabalham com um grande número de produtos de fatores de pequena magnitude (probabilidades). Isso fica bastante claro ao observar-se, por exemplo, o pseudo-código do Algoritmo Viterbi. Nesses casos, há riscos de que os números em questão fiquem tão pequenos a ponto de não poderem ser representados em computadores convencionais (ocorrência de "underflow").

Tal problema pode ser aliviado pelo uso de logaritmos das probabilidades para que se lide com números de magnitudes maiores do que aquelas que surgiriam se as probabilidades fossem usadas diretamente. Essa transformação também apresenta o desejável efeito colateral de converter as multiplicações em adições (que normalmente podem ser executadas em menos tempo do que multiplicações nos computadores convencionais).

Por exemplo, para o Algoritmo VITERBI, a modificação é bastante direta ao usarmos logaritmos de probabilidades. Já para os Algoritmos Progressivo e Regressivo, as transformações para uso de logaritmos não são tão imediatas quanto no caso anterior, mas ainda assim são possíveis [DEKM98].

A idéia básica é observar que $\log (x+y)=\log x+\log (1+y / x)$, se $x \neq 0$. Fazendo $z=y / x$ e supondo-se $y \leq x$, temos que $z \leq 1$. Daí, o termo $\log (1+z)$ pode ser facilmente calculado a partir de sua série de Taylor (possivelmente via alguma implementação em biblioteca), 
de interpolações lineares de uma tabela de $\log (1+z)$ para valores de $z$ entre 0 e 1 ou de alguma mescla de técnicas que sejam adequadas.

Outros métodos podem ainda serem usados para evitar trabalhar com números muito pequenos [DEKM98].

\subsubsection{Problema 3: Problema de Treinamento}

O problema básico a respeito de MMEOs que talvez seja o mais difícil é o problema de construir modelos com base em observações. Conforme já sabemos, a construção de um modelo pode ser observada como resultado de duas subtarefas: a determinação do número de estados do modelo, sua topologia (forma de seu grafo) e o alfabeto a ser utilizado; a outra tarefa consiste de, determinados os itens anteriores, estimar os parâmetros $\theta=(a, e, \pi)$ do modelo a ser construído, com base apenas em observações.

Para o caso de seqüências biológicas, freqüentemente o alfabeto será o conjunto de aminoácidos ou o conjunto de bases nitrogenadas, dependendo do tipo de seqüência em estudo. $\mathrm{O}$ número de estados (ou mesmo os estados em si) usado para o modelo pode, às vezes, possuir alguma interpretação física para o fenômeno prático que se deseja modelar; no caso do cassino desonesto, os estados do MMEO representavam, cada um, um dado do cassino. A decisão de quantos são os estados usados pode depender de informações adicionais do problema e heurísticas de refinamentos sucessivos podem ser usadas para construir um MMEO adequado para a aplicação.

No texto, não vamos tratar de tais métodos, exceto ao discutirmos uma classe especial de MMEOs, quando usaremos uma heurística muito simples para decidir qual conjunto $Q$ usar.

Vamos supor então que temos um MMEO $\lambda$ com $Q$ e $\Sigma$ determinados e, dadas seqüências de observações $s^{1}, \ldots, s^{k}$, com $\left|s^{j}\right|=n_{j}$, para $j=1, \ldots, k$, desejamos ajustar os parâmetros $a, e$ e $\pi$ de $\lambda$ de acordo com as observações. Supomos que as sequiências $s^{1}, \ldots, s^{k}$ sejam independentes e que, portanto, $\operatorname{Pr}\left(s^{1}, \ldots, s^{k} \mid \theta\right)=\prod_{j} \operatorname{Pr}\left(s^{j} \mid \theta\right)$, para um conjunto de parâmetros $\theta$ fixado. Nosso interesse é encontrar $\hat{\theta}=(\hat{a}, \hat{e}, \hat{\pi})$ de maneira que $\operatorname{Pr}\left(s^{1}, \ldots, s^{k} \mid \hat{\theta}\right)$ seja máxima.

Freqüentemente, trabalhamos com log das probabilidades e isso significa que queremos maximizar $\log \operatorname{Pr}\left(s^{1}, \ldots, s^{k} \mid \theta\right)=\log \prod_{j} \operatorname{Pr}\left(s^{j} \mid \theta\right)=\sum_{j} \log \operatorname{Pr}\left(s^{j} \mid \theta\right)$, já que as seqüências são independentes.

A estimação dos parâmetros do modelo, dadas as seqüências de observações, pode ser feita de duas maneiras, dependendo se os passeios $q^{1}, \ldots, q^{k}$ em $\lambda$ que geraram $s^{1}, \ldots, s^{k}$ forem conhecidos ou não. Vamos mostrar a estimação de parâmetros primeiro para o caso mais simples, em que os passeios são conhecidos para fixar as idéias e, em seguida, mostrar o Algoritmo de Baum-Welch para o caso em que os passeios (i.e., seqüências de estados) que geraram as seqüências de observações não estão disponíveis.

\subsubsection{Caso 1: Passeios Conhecidos}

Se o passeio $q^{j}$ que gerou a seqüência $s^{j}$ for conhecido para cada uma das seqüências, o processo de estimação de parâmetros fica simplificado. Neste contexto, as seqüências de observações são também chamadas seqüências de treinamento.

Esse caso pode parecer artificial ao leitor à primeira vista, mas ele pode ocorrer, por exemplo, em situações em que se deseje construir um modelo para algum fenômeno prático. Para a construção, é necessário supor que um MMEO seja o tipo de modelo adequado, 
dispor de seqüências de observações do fenômeno e, por algum meio (talvez indireto), ter as sequiências já rotuladas com estados do modelo.

Por exemplo, podemos ter uma coleção de sequiências de DNA que já estejam anotadas, de forma que se saiba, para cada seqüência, quais trechos fazem parte de ilhas CpG e quais trechos não fazem. Essa rotulação pode ser determinada, digamos, por algum método empírico ou por inspeção manual [DEKM98]. Poderíamos, então, estar interessados em construir um MMEO para sistematizar a rotulação de outras seqüências de DNA em relação a ilhas CpG usando as seqüências já anotadas no treinamento dos parâmetros do MMEO.

Uma vez que o modelo esteja totalmente especificado, ele pode ser usado para rotular uma nova seqüência de DNA cuja estrutura ainda não seja conhecida. Em outras palavras, ele pode ser usado para encontrar uma seqüência $q^{*}$ de estados do MMEO para a seqüência de observações $s$, por meio de alguma solução ao Problema da Decodificação (e.g., Algoritmo VITERBi).

Supomos então que, para cada $j=1, \ldots, k$, tenhamos um $\operatorname{par}\left(s^{j}, q^{j}\right)$.

Um algoritmo para estimar as probabilidades de transição do modelo $\lambda$, fixados $Q$ e $\Sigma$ e conhecidos $s^{1}, \ldots, s^{k}$ e $q^{1}, \ldots, q^{k}$ pode ser percorrer o grafo do modelo $\lambda$ para cada um dos passeios $q^{j}$, contar quantas vezes cada transição do modelo foi usada e adotar como probabilidade daquela transição a sua freqüência relativa (em relação às transições com mesmo estado de origem).

Mais precisamente, seja $A_{x y}^{j}$ o número de vezes que a transição do estado $x$ ao estado $y$ foi usada no passeio $q^{j}$. Com essa definição, segue que $A_{x y}=\sum_{j=1}^{k} A_{x y}^{j}$ é o número de vezes que a transição de $x$ a $y$ foi usada por todos os passeios e, além disso, a probabilidade $a_{x y}$ da transição de $x$ a $y$ pode assim ser estimada por

$$
a_{x y}=\frac{A_{x y}}{\sum_{y^{\prime} \in Q} A_{x y^{\prime}}},
$$

para cada transição $(x, y)$ do modelo. Estes são os estimadores de máxima verossimilhança para as probabilidades de transição [DEKM98].

De maneira parecida, as probabilidades de emissão de símbolos podem ser estimadas também como frequiências relativas de quanto a emissão de um dado símbolo foi gerada em um dado estado. Mais formalmente, seja $E_{x}^{j}(b)$ a quantidade de vezes que o símbolo $b$ foi gerado no estado $x$ pelo passeio $q^{j}$, para todo $b \in \Sigma, x \in Q$ e $j=1, \ldots, k$. Para cada símbolo $b$ e para cada estado $x$, seja $E_{x}(b)=\sum_{j=1}^{k} E_{x}^{j}(b)$. A freqüência relativa

$$
\frac{E_{x}(b)}{\sum_{b^{\prime} \in \Sigma} E_{x}\left(b^{\prime}\right)}
$$

pode ser usada para estimar a probabilidade $e_{x}(b)$ e, neste caso, a freqüência relativa é também um estimador de máxima verossimilhança para as probabilidades de emissão de símbolos [DEKM98].

Finalmente, a mesma estratégia pode ser usada para estimar as probabilidades iniciais $\pi$. Seja $\Pi^{j}(x)=1$ se $q^{j}[1]=x$ ou $\Pi^{j}(x)=0$ se $q^{j}[1] \neq x$. Definamos $\Pi(x)=\sum_{j=1}^{k} \Pi^{j}(x)$, isto é, o número de vezes que o estado $x \in Q$ é o início de um passeio no modelo que gerou as $k$ observações.

Com esta notação, para cada $x \in Q$, a freqüência relativa

$$
\frac{\Pi(x)}{\sum_{x \in Q} \Pi(x)}=\frac{\Pi(x)}{k}
$$


é o estimador de máxima verossimilhança para a probabilidade $\pi(x)$ de que $x$ inicie um passeio no modelo $\lambda$ [DEKM98].

Conforme deve ficar claro, a estimação dos parâmetros do modelo (supondo-se que o modelo de fato represente o fenômeno em estudo) é tão melhor quanto maior for a quantidade disponível de dados para treinamento. Infelizmente, entretanto, o método de uso de estimadores de máxima verossimilhança possui a deficiência de que, digamos, se uma transição $(x, y)$ tiver probabilidade muito baixa (mas não-nula) pode acontecer que nenhum dos dados de treinamento (no caso de transições, os passeios no grafo de $\lambda$ ) apresente uma ocorrência de $(x, y)$ e que, desta forma, $A_{x y}=0$, de onde segue que a probabilidade estimada $a_{x y}$ para a transição $(x, y)$ seja 0 , o que não é desejado (pois queremos que os modelos estimados atribuam, para cada passeio válido no modelo, uma probabilidade diferente de zero para as seqüências de observações que puderem ser geradas por tais passeios).

Tal situação é a mesma que vimos para a estimação de parâmetros de Cadeias de Markov e também para o presente caso usam-se pseudo-contadores, sendo que uma das estratégias é a Regra de Laplace (isto é, adicionar 1's como pseudo-contadores de cada parâmetro do modelo). Evita-se, desta forma, o Problema da Probabilidade Zero e, também, qualquer possibilidade de ocorrência de zero nos denominadores dos cálculos das freqüências relativas. Também como no caso das Cadeias de Markov, as quantias adicionadas podem refletir algum conhecimento prévio de como as probabilidades do modelo devem ser (por outro lado, a Regra de Laplace pode ser usada quando nenhuma informação a mais é conhecida a respeito daquilo que se deseja modelar).

O pseudo-código para o Algoritmo EstimaPC, que implementa o método, está adiante. Nele, as contagens de uso de transições, emissões de símbolos e de estados iniciais estão acumuladas diretamente nas matrizes $A, E$ e $\Pi$, sem fazer uso das contagens em separado para cada passeio (isto é, sem usar $A^{j}, E^{j}$ ou $\Pi^{j}$ ).

5.4.3.1.1 Análise de Complexidade A inicialização das matrizes $A, E$ e $\Pi$ com 0's ou com pseudo-contadores é feita em tempo $O\left(|Q|^{2}\right)+O(|Q||\Sigma|)+O(|Q|)=O\left(|Q|^{2}+|Q||\Sigma|\right)$.

As contagens das frequiências de transições, de emissões e de início de geração são feita pelo laço principal do algoritmo em tempo $O(1)$ para cada caractere das seqüências de treinamento, isto é, em tempo total $O\left(\sum_{j} n_{j}\right)$, onde $n_{j}=\left|s^{j}\right|$. Denotando por $n$ o $\max \left\{n_{j}\right\}$, segue que essa parte do algoritmo pode ser executada em tempo $O(k n)$.

$\mathrm{O}$ cálculo das freqüências relativas é feito em três partes. Para a primeira, referente às probabilidades de transições, o algoritmo leva tempo $O\left(|Q|^{2}\right)$. Para a segunda, em que as probabilidades de emissão são estimadas, o tempo usado é $O(|Q \| \Sigma|)$. Para a terceira, onde as probabilidades iniciais são estimadas, o tempo é $O(|Q|)$. Logo, o tempo gasto por estes cálculos é $O\left(|Q|^{2}+|Q \|| \Sigma \mid\right)$, o mesmo tempo (assintoticamente falando) usado na inicialização de $A, E$ e $\Pi$.

O algoritmo leva, portanto, tempo $O\left(|Q|^{2}+|Q||\Sigma|+k n\right)$ para ser executado. Em casos de interesse, a quantidade de dados de treinamento é grande e o termo $k n$ é dominante na complexidade de tempo.

Para contabilizar o espaço, basta observar que, excetuando-se as variáveis de controle dos laços, as variáveis $A^{\prime}, E^{\prime}$ e $\Pi^{\prime}$ e as matrizes $a, e$ e $\pi$ de saída, apenas as matrizes $A, E$ e $\Pi$ são utilizadas, que possuem tamanho total $O\left(|Q|^{2}+|Q \| \Sigma|+|Q|\right)=O\left(|Q|^{2}+|Q \|| \Sigma \mid\right)$. Naturalmente, as matrizes $a, e$ e $\pi$ possuem, respectivamente, os mesmos tamanhos ${ }^{10}$ que

\footnotetext{
${ }^{10} \mathrm{Em}$ uma implementação real do Algoritmo EstimaPC, as matrizes $a, e$ e $\pi$ podem ser as mesmas que $A, E$ e $\Pi$, de forma que não é necessário usar espaço em separado para o cálculo das freqüências e das
} 


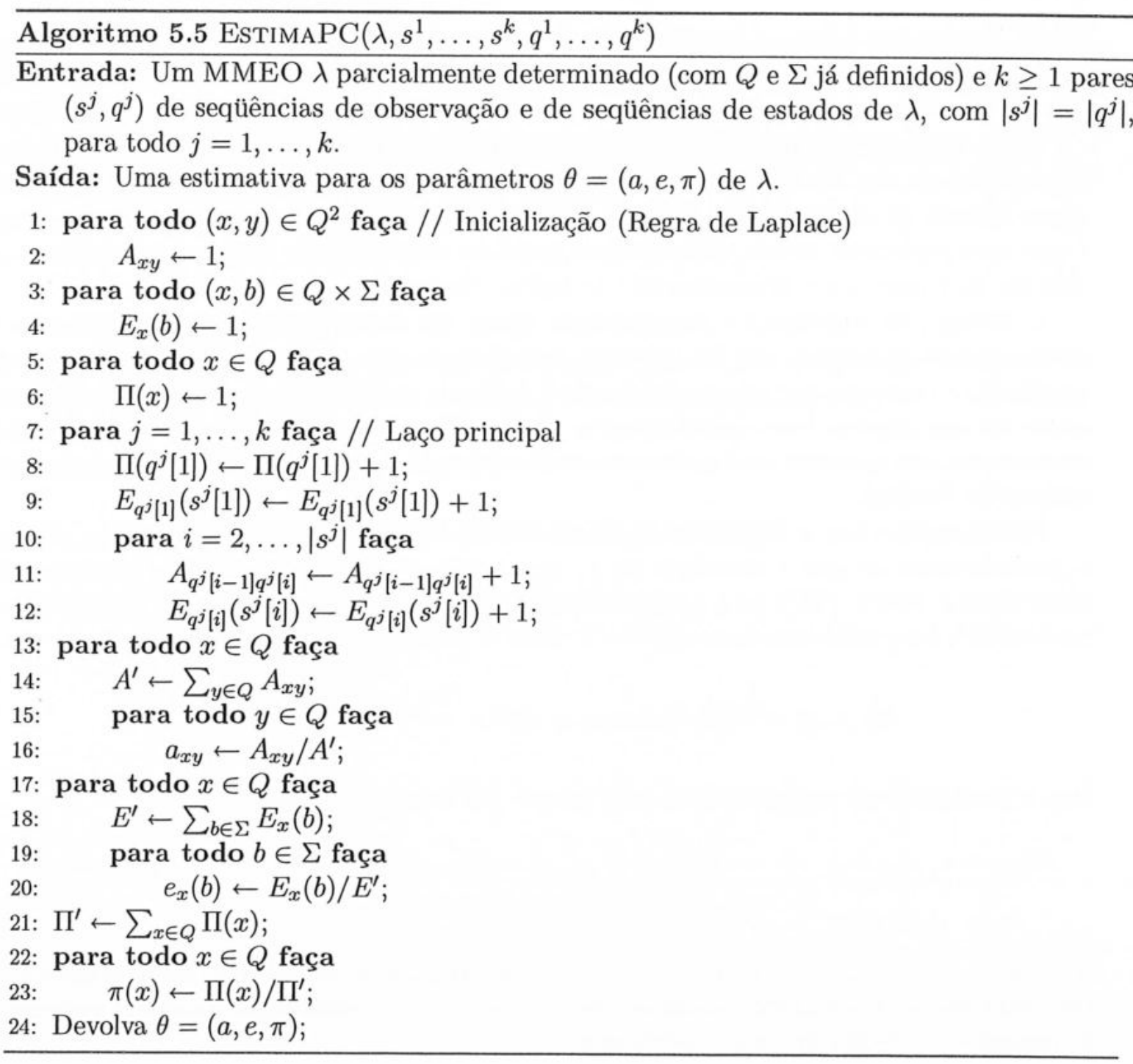

$A, E$ е П.

\subsubsection{Caso 2: Passeios Desconhecidos}

Ao contrário do caso anterior, em que os passeios que geraram as sequiências de observações eram conhecidos, para o caso em que os passeios são desconhecidos não há formulas fechadas que sirvam para estimar os parâmetros do modelo de forma que a probabilidade de uma dada observação seja máxima [Rab89, DEKM98]. Nesse caso, técnicas de otimização contínua podem ser usadas para encontrar pontos de máximo da função de verossimilhança, isto é, para encontrar um ponto $\theta^{*}=\left(a^{*}, e^{*}, \pi^{*}\right)$ para o qual $\operatorname{Pr}\left(s^{1}, \ldots, s^{k} \mid \theta^{*}\right)$ seja máxima. Por exemplo, técnicas de gradiente como o Método de Multiplicadores de Lagrange, para otimizar uma função de várias variáveis com restrição de domínio, podem ser utilizadas [Rab89].

Por causa da falta de métodos analíticos conhecidos para resolver o problema de maneira

freqüências relativas, o que significa que o Algoritmo EstimaPC pode ser implementado com complexidade de espaço $O(1)$ em vez de $O\left(|Q|^{2}+|Q \| \Sigma|\right)$. 
exata, geralmente usam-se métodos iterativos (numéricos) para encontrar soluções para o problema. Um problema com os métodos de otimização de maneira geral é que eles garantem apenas que algum máximo local seja encontrado e não que o máximo global seja encontrado.

Neste texto, mostramos o método iterativo mais amplamente divulgado para encontrar parâmetros de um MMEO a partir de seqüências de observação. O método é conhecido como Método de Baum-Welch. Pode-se mostrar [DEKM98] que o Método de Baum-Welch é um caso particular de um método mais geral de otimização de funções conhecido como Método da Esperança e Maximização (do inglês, Expectation-Maximization Method).

O Método da Esperança e Maximização opera, em linhas gerais, com uma alternância de dois passos principais: um em que uma aproximação para os parâmetros do modelo é determinada e outro em que esta aproximação é utilizada para calcular o valor da função a otimizar até que alguma convergência ocorra (ou que algum número máximo pré-estabelecido de iterações seja atingido sem que se encontre convergência dos pontos candidatos a pontos críticos da função).

Para descrevermos o Algoritmo de Baum-Welch, vamos definir a variável $\xi(i, x, y)$ como a probabilidade de que a transição $(x, y)$ seja usada no momento $i$ dada a seqüência de observação $s$, isto é, $\xi(i, x, y)$ é a probabilidade de que o estado $x$ seja usado no momento $i$ e o estado $y$ seja usado no momento $i+1$, dada a seqüência $s$. Formalmente,

$$
\xi(i, x, y)=\operatorname{Pr}\left(q_{i}=x, q_{i+1}=y \mid s\right)=\frac{\operatorname{Pr}\left(s, q_{i}=x, q_{i+1}=y\right)}{\operatorname{Pr}(s)} .
$$

Mas a probabilidade conjunta de $q_{i}=x, q_{i+1}=y$ e $s$ é simplesmente

$$
\begin{aligned}
\operatorname{Pr}\left(q_{i}=x, q_{i+1}=y, s\right) & =\operatorname{Pr}\left(s_{1}, \ldots, s_{i}, q_{i}=x\right) a_{x y} e_{y}\left(s_{i+1}\right) \operatorname{Pr}\left(s_{i+2}, \ldots, s_{n} \mid q_{i+1}=y\right) \\
& =\alpha(i, x) a_{x y} e_{y}\left(s_{i+1}\right) \beta(i+1, y),
\end{aligned}
$$

em que $n$ é o comprimento de $s$ e $\alpha$ e $\beta$ são os valores calculados pelos Algoritmos Progressivo e Regressivo vistos em seções anteriores. Substituindo esta nova expressão na equação que define $\xi(i, x, y)$, temos que

$$
\xi(i, x, y)=\frac{\alpha(i, x) a_{x y} e_{y}\left(s_{i+1}\right) \beta(i+1, y)}{\operatorname{Pr}(s)},
$$

onde $\operatorname{Pr}(s)$ pode também ser calculada por um dos Algoritmos Progressivo ou Regressivo.

Observe-se que, para $i$ fixado, $i<n$,

$$
\begin{aligned}
\sum_{(x, y) \in Q^{2}} \operatorname{Pr}\left(q_{i}=x, q_{i+1}=y, s\right) & =\sum_{x \in Q} \alpha(i, x) \sum_{y \in Q} a_{x y} e_{y}\left(s_{i+1}\right) \beta(i+1, y) \\
& =\sum_{x \in Q} \alpha(i, x) \beta(i, x) \\
& =\operatorname{Pr}(s),
\end{aligned}
$$

conforme esperado.

Observe-se que, para $i$ fixado, $i<n$, temos que, intuitivamente, a soma das probabilidades de uma transição $(x, y)$ ocorrer, no instante $i$, dada $s$, somando-se sobre todos os possíveis destinos $y$ nos dá a probabilidade de o estado no instante $i$ ser $x$, dada a seqüência $s$, isto é, esta quantia é $\gamma(i, x)$, conforme definida para o método de decodificação posterior. 
De fato ${ }^{11}$, se $i<n$,

$$
\begin{aligned}
\sum_{y \in Q} \xi(i, x, y) & =\sum_{y \in Q} \frac{\alpha(i, x) a_{x y} e_{y}\left(s_{i+1}\right) \beta(i+1, y)}{\operatorname{Pr}(s)}=\frac{\alpha(i, x)}{\operatorname{Pr}(s)} \sum_{y \in Q} a_{x y} e_{y}\left(s_{i+1}\right) \beta(i+1, y) \\
& =\frac{\alpha(i, x) \beta(i, x)}{\operatorname{Pr}(s)}=\gamma(i, x),
\end{aligned}
$$

que nos fornece uma relação entre as quantias $\gamma(i, x)$ já conhecidas e as quantias $\xi(i, x, y)$ recém-definidas.

Observe-se que, ao somarmos $\xi(i, x, y)$ sobre $i$, com $i$ variando de 1 a $n-1$, obtemos o número esperado de vezes que a transição $(x, y)$ foi usada pela seqüência de observação $s$.

Isto pode ser justificado notando-se que, para $i=1, \ldots, n-1$, se $X_{i}$ é uma variável aleatória com distribuição de Bernoulli em que o sucesso é o uso da transição $(x, y)$ no instante $i$ e o fracasso é o uso de alguma outra transição neste instante, então a esperança $E\left[X_{i}\right]$ vale $E\left[X_{i}\right]=0 \cdot(1-\xi(i, x, y))+1 \cdot \xi(i, x, y)=\xi(i, x, y)$.

Além disso, seja $X$ a variável aleatória definida por $X=\sum_{i=1}^{n-1} X_{i}$. A variável $X$ nos dá o número de usos da transição $(x, y)$ pela seqüência de observação $s$ e seu valor esperado $E[X]$ é igual a $\sum_{i=1}^{n-1} E\left[X_{i}\right]=\sum_{i=1}^{n-1} \xi(i, x, y)$, ou seja, $\sum_{i=1}^{n-1} \xi(i, x, y)$ é, de fato, o número esperado de vezes que a transição $(x, y)$ foi usada pela seqüência de observação $s$. Naturalmente, os argumentos são válidos para uma transição $(x, y) \in Q^{2}$ qualquer, pois $(x, y)$ é genérica.

Pelo mesmo argumento, é possível ver que $\sum_{i=1}^{n-1} \gamma(i, x)=\sum_{i=1}^{n-1} \sum_{y \in Q} \xi(i, x, y)$ é o número esperado de transições feitas a partir do estado $x$ durante a geração de $s$. Além disso, $\sum_{i=1}^{n} \gamma(i, x)$ é o número esperado de vezes em que o estado $x$ é visitado durante a geração de $s$. Em particular, $\gamma(1, x)$ é o número esperado de vezes em que o estado $x$ é visitado no início da geração de $s$.

De maneira análoga, se considerarmos os instantes em que o modelo está no estado $x$ e um símbolo $b$ fixado é gerado como observação, temos que $\sum_{i=1 \wedge s_{i}=b}^{n} \gamma(i, x)$ nos dá o número esperado de vezes em que $b$ é gerado no estado $x$ para a seqüência $s$.

O Algoritmo de Baum-Welch parte de um chute inicial $\theta^{0}=\left(a^{0}, e^{0}, \pi^{0}\right)$ para os parâmetros do modelo e usa-o para obter, iterativamente, estimativas melhores para os parâmetros de $\lambda$, da forma como passamos a descrever.

Para uma seqüência de observações $s$, o Algoritmo de Baum-Welch define a matriz $A$ de forma que $A_{x y}$ seja o número esperado de vezes em que a transição do estado $x$ ao estado $y$ ocorreu ao gerar $s$, isto é, $A_{x y}=\sum_{i=1}^{n-1} \xi(i, x, y)$. É ilustrativo comparar esta definição com a definição da matriz $A$ no caso em que os passeios são conhecidos. A matriz $E$ é definida de forma que $E_{x}(b)$ seja o número esperado de vezes em que o modelo esteve no estado $x$ e o símbolo $b$ foi gerado, isto é, $E_{x}(b)=\sum_{i=1 \wedge s_{i} \equiv b}^{n} \gamma(i, x)$. A matriz $\Pi$, da mesma forma, é definida de maneira que $\Pi(x)$ seja igual ao número esperado de vezes em que o modelo iniciou no estado $x$ a geração da seqüência $s$, ou seja, o número esperado de vezes em que o estado inicial da geração de $s$ foi o estado $x$, isto é, $\Pi(x)=\gamma(1, x)$.

O Algoritmo de Baum-Welch define $a_{x y}=A_{x y} / \sum_{y^{\prime} \in Q} A_{x y^{\prime}}$, para todo $(x, y) \in Q^{2}$, $e_{x}(b)=E_{x}(b) / \sum_{b^{\prime} \in \Sigma} E_{x}\left(b^{\prime}\right)$, para todo $(x, b) \in Q \times \Sigma \mathrm{e} \pi(x)=\Pi(x)$, para todo $x \in Q$. Esses valores calculados de $a, e$ e $\pi$ compõem a nova estimativa $\theta$ para os parâmetros de $\lambda$. O processo de estimação pode ser repetido com os valores de $\theta$ no lugar de $\theta^{0}$ para

\footnotetext{
${ }^{11}$ A restrição $i<n$ é feita porque obviamente não há nenhuma transição a fazer a partir do estado que gerou o último símbolo de $s$.
} 
obter uma nova estimativa. É possível mostrar [Rab89, DEKM98] que a verossimilhança do modelo determinado pelo Algoritmo de Baum-Welch aumenta a cada iteração até que um ponto de máximo local seja encontrado. Em outras palavras, uma das duas afirmações abaixo é verdadeira para o Algoritmo de Baum-Welch:

- $\operatorname{Pr}(s \mid \theta)>\operatorname{Pr}\left(s \mid \theta^{0}\right)$;

- $\operatorname{Pr}(s \mid \theta)=\operatorname{Pr}\left(s \mid \theta^{0}\right)$ significa que $\theta$ é um máximo local da função de verossimilhança.

O pseudo-código do Algoritmo BAUM-WeLCH, que implementa o Algoritmo de BaumWelch está listado a seguir.

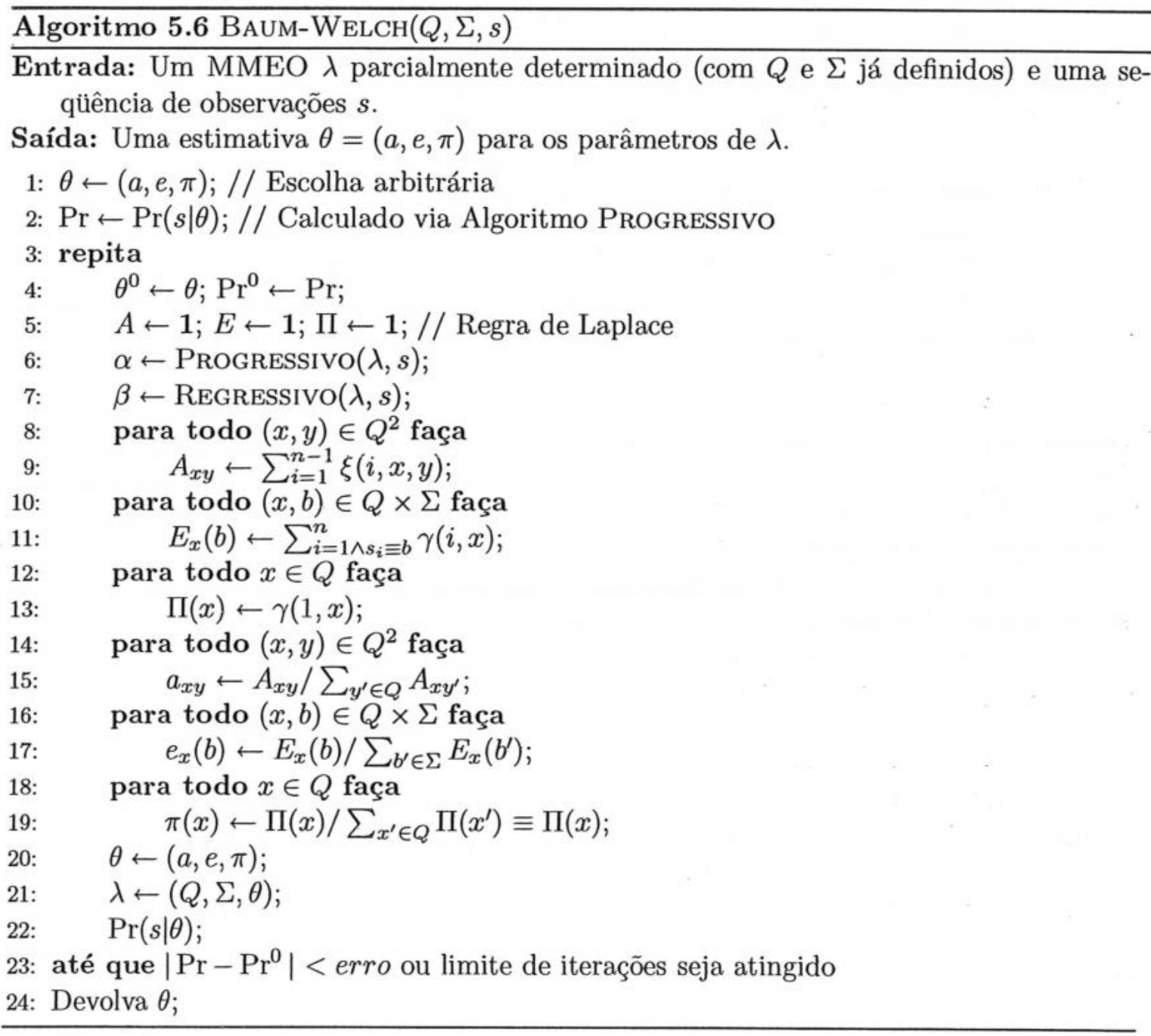

Observe-se que, para efeito de implementação desta versão do algoritmo de Baum-Welch para uma seqüência apenas, as variáveis $A_{x y}$ não necessariamente precisam ser definidas como somas de $\xi(i, x, y)$, porque o denominador $\operatorname{Pr}(s)$ está presente em cada um dos termos $\xi(i, x, y)$ (vide fórmula da definição de $\xi(i, x, y))$ e os termos $A_{x y}$ são usados para calcular a razão $a_{x y}=A_{x y} / \sum_{y^{\prime} \in Q} A_{x y^{\prime}}$, de modo que os fatores $\operatorname{Pr}(s)$ do numerador e denominador da razão se cancelam. Um comentário parecido aplica-se para os valores $E_{x}(b)$.

Além disso, em termos de implementação, as chamadas ao Algoritmo Progressivo para o cálculo de Pr e para o cálculo de $\alpha$ podem ser aglutinadas de maneira que apenas 
uma chamada seja feita por iteração pelo algoritmo.

Para o caso de várias seqüências de observações $s^{1}, \ldots, s^{k}$, definimos $A_{x y}^{j}$ como o número esperado de vezes que a transição $(x, y)$ é usada na geração da seqüência $s^{j}, E_{x}^{j}(b)$ como o número esperado de vezes que o símbolo $b$ é gerado no estado $x$ na geração de $s^{j}$ e $\Pi^{j}(x)$ como o número esperado de vezes em que $x$ é o estado inicial na geração de $s^{j}$. Esses valores podem ser calculados pelas fórmulas dadas para o caso de uma seqüência se no cálculo de $A^{j}, E^{j}$ e $\Pi^{j}$ forem usados os valores $\alpha^{j}$ e $\beta^{j}$ devolvidos, respectivamente, pelos Algoritmos Progressivo e REgressivo para a seqüência $s^{j}$.

Para estimar os valores dos parâmetros de $\lambda$, definimos $A=\sum_{j=1}^{k} A^{j}, E=\sum_{j=1}^{k} E^{j} \mathrm{e}$ $\Pi=\sum_{j=1}^{k} \Pi^{k}$ e definimos $a$, e e $\pi$ como anteriormente. O pseudo-código para o Algoritmo de Baum-Welch para $k$ seqüências independentes $s^{1}, \ldots, s^{k}$ está listado abaixo.

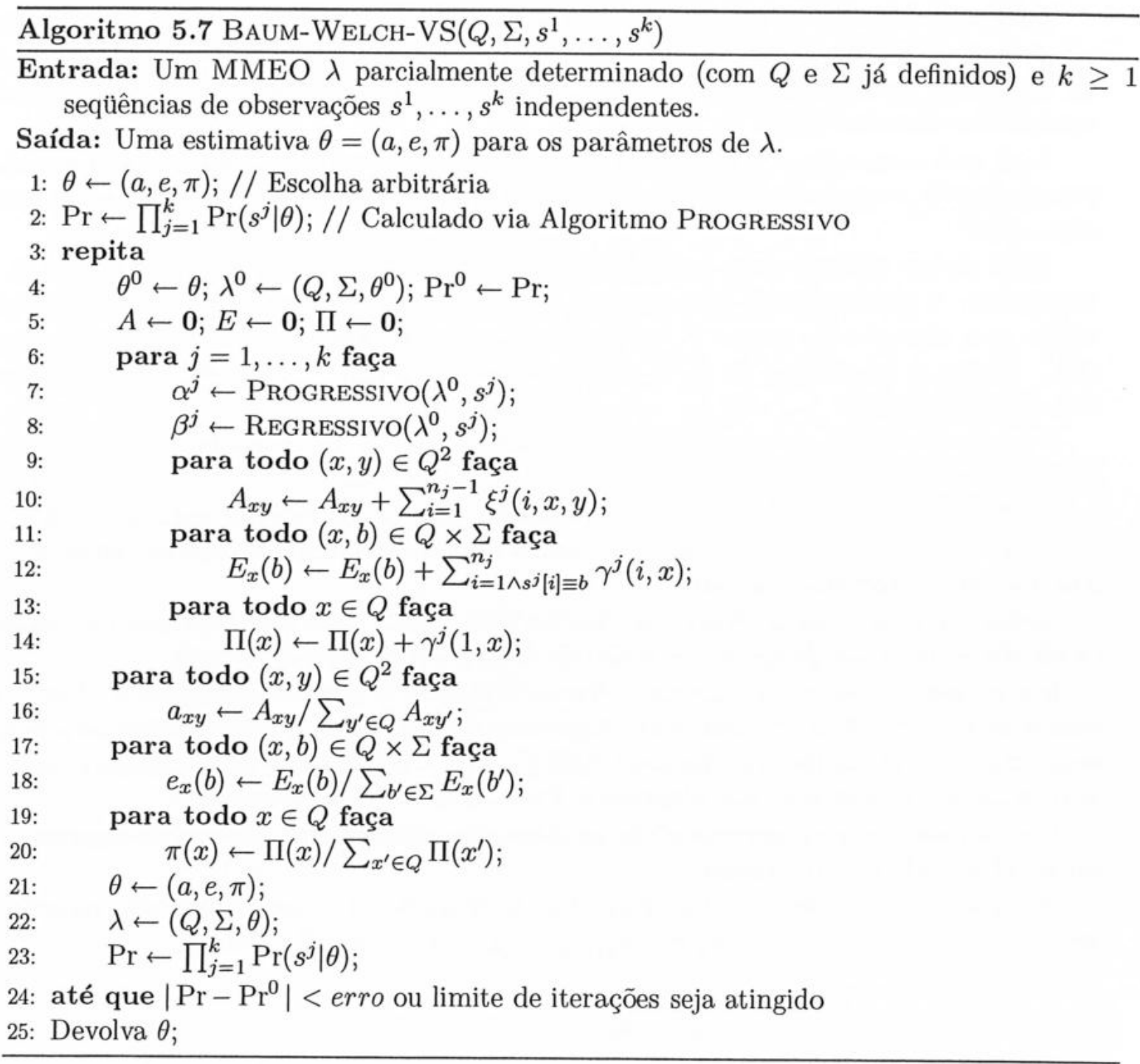

Os mesmos comentários feitos a respeito de implementação para o Algoritmo de BaumWelch para uma seqüência aplicam-se a várias seqüências. Em particular, os cálculos de $\alpha^{j}$ e o cálculo da probabilidade Pr.

É importante perceber que, no momento de a probabilidade Pr ser calculada ao fim de uma iteração do algoritmo, as matrizes $\alpha^{j}$ e $\beta^{j}$ não são mais necessárias e podem ser 
reutilizadas para guardar os próximos valores de $\alpha^{j}$ e $\beta^{j}$, usados para a iteração seguinte.

5.4.3.2.1 Análise de Complexidade Como o Algoritmo de Baum-Welch é um método iterativo, sua convergência (e, portanto, seu tempo de execução) depende de quantas iterações são realizadas e também de quão boa é a aproximação inicial para os parâmetros do modelo. Aqui, faremos uma breve análise de complexidade do tempo e do espaço necessários para uma iteração do método de várias seqüências.

Naturalmente, o tempo para uma escolha arbitrária dos parâmetros iniciais depende de como é feita tal escolha, mas alguns tipos de parâmetros (como, por exemplo, os equiprováveis) podem ser escolhidos em tempo $O(|Q|(|Q|+|\Sigma|))$. O cálculo da probabilidade $\operatorname{Pr}$ pode ser feito em tempo $O\left(|Q|^{2} \sum_{j}\left|s^{j}\right|\right)$.

Para cada iteração, as matrizes $A, E$ e $\Pi$ são inicializadas com zeros (ou com pseudocontadores, conforme a necessidade) em tempo $O(|Q|(|Q|+|\Sigma|))$. Durante a execução do algoritmo, as contagens das contribuições de $A^{j}, E^{j}$ e $\Pi^{j}$ de cada seqüência $s^{j}$ são acumuladas diretamente em $A, E$ e $\Pi$.

Para cada sequiência $s^{j}$, o Algoritmo BAUM-WELCH-VS faz uma chamada ao Algoritmo Progressivo e outra ao Algoritmo Regressivo, usando tempo $O\left(\left|s^{j} \| Q\right|^{2}\right)$ para estas chamadas $^{12}$.

Além desses cálculos, para cada seqüência $s^{j}$, cada entrada das matrizes $A, E$ e $\Pi$ é atualizada. A atualização de uma entrada de $A$ é feita em tempo $O\left(\left|s^{j}\right|\right)$, o mesmo sendo válido para entradas da matriz $E$. A atualização de uma entrada de $\Pi$ é feita em tempo $O(1)$. Assim, a atualização de $A, E$ e $\Pi$ para uma seqüência $s^{j}$ pode ser feita em tempo $O\left(\left|s^{j}\right||Q|(|Q|+|\Sigma|)\right)$.

O tempo total para as $k$ iterações do laço mais interno do Algoritmo BAUM-WELCH-VS é, portanto, $O\left(\sum_{j}\left(\left|s^{j}\right||Q|^{2}+\left|s^{j}\right||Q|(|Q|+|\Sigma|)\right)\right)=O(k n|Q|(|Q|+|\Sigma|))$, onde $n=\max \left\{\left|s^{j}\right|\right\}$.

Ao fim de cada iteração do algoritmo, o cálculo das estimativas dos parâmetros de $\lambda$ é feito a partir das matrizes $A, E$ e $\Pi$ em tempo $O(|Q|(|Q|+|\Sigma|))$, da mesma forma como descrita para o algoritmo EstimaPC.

Assim, cada iteração do Algoritmo BAUM-WELCH-VS pode ser executada em tempo $O(|Q|(|Q|+|\Sigma|)+k n|Q|(|Q|+|\Sigma|)+|Q|(|Q|+|\Sigma|))=O(k n|Q|(|Q|+|\Sigma|))$.

Em relação ao espaço, o Algoritmo BAUM-WELCH-VS utiliza as matrizes $A, E$ e $\Pi$ e duas matrizes $\alpha^{j}$ e $\beta^{j}$ devolvidas pelos Algoritmo Progressivo e Regressivo para cada seqüência $s^{j}$. Isso significa que espaço $O\left(|Q| \sum_{j}\left|s^{j}\right|\right)=O(k n|Q|)$ é suficiente para conter os resultados das chamadas aos Algoritmos Progressivo e Regressivo.

Para armazenar os parâmetros $\theta^{0}$ (e também para armazenar a resposta do algoritmo), espaço $O(|Q|(|Q|+|\Sigma|))$ é usado.

O espaço total usado pelo Algoritmo BAUM-WELCH-VS é, então, limitado superiormente por $O(|Q|(|Q|+|\Sigma|)+k n|Q|+|Q|(|Q|+|\Sigma|))=O(|Q|(|Q|+k n+|\Sigma|))$.

5.4.3.2.2 Comentários Gerais Um ponto importante a respeito do Método de BaumWelch é que caso um determinado parâmetro do modelo seja 0 em alguma estimativa, então o valor daquele parâmetro permanecerá sendo 0 em todas as estimativas futuras (incluindo, é claro, a solução devolvida pelo algoritmo).

\footnotetext{
${ }^{12}$ Não há diferença do ponto de vista de complexidade se as chamadas ao Algoritmo Progressivo forem economizadas por decorrência das chamadas já feitas para calcular a probabilidade Pr, porque os Algoritmos Progressivo e REgressivo possuem a mesma complexidade.
} 
Para ver isso, basta notar que, na fórmula utilizada para atualizar o valor $a_{x y}$ é usado o valor $A_{x y}$ e ele é definido como soma de termos (no caso mais geral de várias sequiências), onde cada termo é da forma $\xi^{j}(i, x, y)=\alpha^{j}(i, x) a_{x y} e_{x}\left(s^{j}[i+1]\right) \beta^{j}(i+1, y) / \operatorname{Pr}\left(s^{j}\right)$ e, se $a_{x y}$, cada um dos termos $\xi^{j}(i, x, y)$ de $A_{x y}$ vale 0 , de onde segue que as novas estimativas para $a_{x y}$ prosseguirão com valor 0 .

Um raciocínio parecido pode ser feito para observar que se $e_{x}(b)=0$ para algum par $(x, b) \in Q \times \Sigma$, então as próximas estimativas de $e_{x}(b)$ serão também todas nulas, porque $E_{x}(b)$ é definido como somas de valores $\xi^{j}(i, x, y)$ e tais termos incluem $e_{x}(b)=0$, resultando em 0 para o valor de $E_{x}(b)$ e, portanto, para o próximo valor de $e_{x}(b)$ calculado pelo algoritmo.

Idem para $\pi(x)$, cuja definição depende de $\gamma^{j}(1, x)$, que inclui o fator $\pi(x)$.

Essa propriedade pode ser explorada, por exemplo, em casos em que se saiba que uma determinada transição nunca ocorre e queira-se usar uma estimativa inicial escolhida de acordo, para sempre garantir que o algoritmo estime a probabilidade da transição como 0 .

Um método de treinamento de modelos alternativo ao Algoritmo de Baum-Welch é o Treinamento de Viterbi [DEKM98]. Nesse método, o Algoritmo de Viterbi é usado para cada uma das seqüências $s^{1}, \ldots, s^{k}$ para obter os passeios mais prováveis $q^{1}, \ldots, q^{k}$ no grafo de $\lambda$. Assim, passeios ficam conhecidos para as seqüências de observações e o método de estimação de parâmetros quando os passeios são conhecidos pode ser usado para obter uma nova estimativa para os parâmetros do modelo. O método prossegue com as iterações até que os parâmetros não sofram modificações em duas iterações consecutivas [DEKM98]. Apesar de este método não maximizar a função de verossimilhança, ele é usado amplamente [DEKM98] e, para algumas situações, ele pode ser preferível [DEKM98] em relação ao método de estimação de Baum-Welch.

5.4.3.2.3 Estados Mudos Para concluir a discussão dos problemas fundamentais de MMEOs, gostaríamos de comentar a respeito de um último tópico.

Em algumas situações, pode ser conveniente considerar MMEOs que possuam estados que não gerem símbolos ou observações. Tais estados são chamados estados mudos.

Por exemplo, uma situação em que pode ser conveniente utilizar estados mudos é na uniformização dos estados de um modelo para evitar a necessidade de ter um vetor de probabilidades iniciais para cada estado. Para isso, pode-se criar um estado adicional para o modelo, chamado estado inicial, que seja mudo, pelo qual toda geração de observações seja iniciada (isto é, ele é escolhido como estado inicial com probabilidade 1), tal que a probabilidade de transição deste estado a um estado $x \in Q$ seja $\pi(x)$ e tal que nenhum estado possua transição para o estado inicial.

Em algumas ocasiões, pode também ser vantajoso utilizar um outro estado mudo adicional a partir do qual não emanem transições, mas para o qual todo estado (possivelmente incluindo o estado inicial) possua uma transição. Um tal estado é chamado estado final.

Nesses casos, é possível que os algoritmos para os modelos fiquem com menos casos especiais e, portanto, mais simples.

Outra situação em que é desejável o uso de estados mudos é no caso em que se tenha um MMEO que seja composto essencialmente de uma longa seqüência de estados que estejam topologicamente ordenados (i.e., o modelo possa ter seus estados numerados de forma que um estado $i \in Q$ tenha apenas transições para estados $j \in Q$ com $i<j$ ). Veremos exemplos dessa situação nas próximas seções. 


\subsection{MMEOs de Perfil de Seqüências}

No estudo de seqüências biológicas e suas funções é comum explorar quais são as características de seqüências que pertençam a uma família. Por exemplo, em um estudo de globinas, é razoável que mais de uma globina (inclusive globinas de várias espécies) sejam estudadas em conjunto para verificar características que sejam comuns a todas as sequiências da família, uma vez que os estudos freqüentemente são comparativos.

Ainda que as seqüências de uma família tenham composições diferentes, elas geralmente possuem formas parecidas por causa de suas funções; tal fato é válido até mesmo para seqüências que sejam homólogas mais remotas às outras da família. Isso acontece porque determinadas partes das seqüências são importantes para a função das moléculas e, por causa disso, pouca ou quase nenhuma mutação pode ocorrer para a molécula continuar desempenhando sua função. Conforme dissemos na introdução, em uma família de hemoglobinas, é de se esperar que as regiões que se ligam a átomos de oxigênio estejam bastante conservadas em todas as seqüências da família a despeito de suas histórias evolutivas diferentes. Esse é também o caso de determinadas regiões de moléculas que funcionam como enzimas, uma vez que se grandes alterações acontecem em suas regiões mais importantes, as moléculas podem deixar de formar ligação com seu substrato específico, perdendo, assim, sua função.

Por outro lado, partes das moléculas que não sejam determinantes para sua forma ou função podem sofrer maior quantidade de mutações e terem baixa conservação, mesmo que as moléculas da família sejam homólogas. Esse fato, que varia em ocorrência ao longo das moléculas, deve também ser levado em consideração em um estudo estrutural das moléculas.

Evidentemente, o estudo das estruturas gerais das moléculas é melhor quando feito levando-se em consideração características das famílias de moléculas em vez das características de moléculas isoladas. Ao se conhecer características gerais das seqüências de uma família é possível, por exemplo, decidir com maior precisão se uma outra seqüência (possivelmente com estrutura desconhecida) faz ou não parte da família já conhecida e como é sua relação (i.e., partes homólogas) com as demais seqüências.

Vem à tona, deste modo, o problema de conseguir representar as características importantes de uma família de seqüências e de descartar características que não sejam fundamentais. Diversas estratégias podem ser adotadas para essa finalidade e uma delas, que descrevemos nesta seção, é construir um tipo especial de MMEO para representar a família de moléculas. Um tal modelo é denominado Modelo de Markov de Estados Ocultos de Perfil de Seqüências, doravante indicado por MMEO de perfil de seqüências ou, simplesmente, $p$ MMEO .

Intuitivamente, um pMMEO é uma descrição estatística de uma família de moléculas e de suas características e inclui um registro de quais são as regiões em que há maior conservação de resíduos e quais são as regiões menos conservadas nas moléculas da família.

Um MMEO de perfil de seqüências, como veremos, pode ser usado para construir um alinhamento de uma seqüência com a família de seqüências que foi usada para construir o pMMEO e este alinhamento construído, diferentemente de um alinhamento produzido pelos algoritmos usuais de programação dinâmica, não possui uma pontuação fixa usada para alinhar os caracteres de uma coluna, mas sim uma pontuação variável de acordo com a região das seqüências que está sendo alinhada (se a região é altamente conservada ou se ela possui muitas mutações).

O método que descrevemos pode também, com uma pequena alteração, ser usado para, a partir de um conjunto de seqüências ainda não alinhadas, construir um MMEO de perfil 
dessas seqüências e usá-lo para construir um alinhamento delas, sem usar explicitamente o algoritmo de Needleman e Wunsch. Naturalmente, os alinhamentos construídos são melhores se as sequiências pertencem à mesma família (mas isso não é suposto pelo algoritmo).

Os MMEOs de perfil de seqüências herdam dos MMEOs a sua flexibilidade e são ferramentas que possuem diversas aplicações. Uma de suas outras aplicações (talvez, inclusive, a mais popular delas) é o uso de um MMEO de perfil para busca de seqüências em bancos de dados, a fim de encontrar mais membros da família representada pelo MMEO. Essa é a função desempenhada pelo programa hmmsearch do pacote HMMER [Edd03].

Nossa atenção, entretanto, é ao uso de MMEOs de perfil de seqüências para construção de alinhamentos.

O método mais simples para construção de um MMEO para uma família de seqüências usa como ponto de partida um alinhamento dessas seqüências e, a partir deste, determina os estados necessários para o modelo.

Nossa descrição da construção de um pMMEO é bastante informal e mostra em etapas qual é a estrutura básica do modelo derivado a partir de um alinhamento. Na próxima seção, mostramos como um pMMEO pode ser construído empiricamente a partir de seqüências sem precisar de um alinhamento como entrada.

\subsubsection{Blocos de Alinhamentos e pMMEOs}

Vamos inicialmente considerar uma situação simplificada de construção de um pMMEO a partir de um alinhamento de várias seqüências e, incrementalmente, mostrar alterações a este modelo que o tornem mais geral.

Definição 5.3 (Bloco de um Alinhamento). Dado um alinhamento $A$ de várias seqüências, dizemos que um segmento $A^{\prime}$ de $A$ é um bloco de $A$ se $A^{\prime}$ não possui espaços, se $A^{\prime}$ é um segmento maximal com esta propriedade e se $A^{\prime}$ é não vazio.

Um pMMEO pode ser construído de maneira simples para um bloco $A^{\prime}$ de $n$ colunas de um alinhamento $A$. A cada coluna de $A^{\prime}$ um estado do modelo é associado. Os estados do modelo que representam as colunas do bloco $A^{\prime}$ são denotados por $M_{i}$, para $i=1, \ldots, n$, de forma que o estado $M_{i}$ represente a $i$-ésima coluna de $A^{\prime}$. O alfabeto $\Sigma$ usado para o MMEO é o alfabeto sobre o qual as seqüências do alinhamento são definidas, sem o caractere espaço. Por exemplo, no caso de seqüências de proteínas, $\Sigma$ é tomado como o conjunto dos possíveis aminoácidos; no caso de seqüências de DNA, $\Sigma$ é o conjunto de bases nitrogenadas.

Se desejássemos criar um MMEO $\lambda$ que modelasse seqüências cujo comprimento fosse exatamente $n$ e tal que a distribuição de probabilidades para o $i$-ésimo caractere fosse igual à probabilidade de o caractere aparecer na $i$-ésima coluna de $A^{\prime}$, poderíamos construir o modelo de maneira que as únicas transições possíveis (i.e., aquelas cuja probabilidade é diferente de 0 ) fossem apenas as transições de $M_{i}$ a $M_{i+1}$, para $i=1, \ldots, n-1$, cada uma com probabilidade 1 de forma que a probabilidade $e_{M_{i}}(b)$ de emissão de um símbolo $b$ no estado $M_{i}$ fosse igual à probabilidade de $b$ aparecer na coluna $i$ de $A^{\prime}$ e de modo que o estado $M_{1}$ tivesse probabilidade 1 de ser o estado inicial (e, naturalmente, os outros estados tivessem probabilidade 0 ).

Essa é uma maneira de criar um modelo estocástico que captura as características das partes das sequiências que estão alinhadas no bloco $A^{\prime}$, com as inter-relações entre as seqüências ditadas pelo bloco. Esse é, aliás, o motivo pelo qual supõe-se que o alinhamento 
base usado para a construção do MMEO seja biologicamente "correto" e, de fato, estabeleça as relações evolutivas reais entre posições homólogas das seqüências constantes no alinhamento.

Um modelo que seja derivado de um bloco através do esquema acima gera seqüências sempre a partir do estado $M_{1}$, emitindo um símbolo e prosseguindo para o estado $M_{2}$, emitindo um novo símbolo e prosseguindo para o estado $M_{3}$ e assim por diante, até que o último símbolo seja gerado no estado $M_{n}$ e o processo termine, totalizando uma seqüência de $n$ observações. Observe-se que as transições efetivas deste modelo (aquelas que possuem probabilidade diferente de 0) sempre ocorrem com a origem em um estado com índice menor do que o do estado de destino, isto é, se o grafo do modelo for representado com $M_{i}$ à esquerda de $M_{i+1}$, o processo de geração de uma seqüência ocorre de forma que uma vez que $M_{i}$ seja visitado, nenhum estado $M_{i^{\prime}}$, com $i^{\prime}<i$, é visitado para a geração de futuros símbolos. Um modelo com esta propriedade é chamado modelo esquerda-direita na literatura (o grafo do modelo é topologicamente ordenado).

Na Figura 5.3, há um alinhamento entre seqüências, um bloco deste alinhamento e um MMEO construído para o bloco do alinhamento de acordo com a forma descrita acima.

$$
A=\begin{array}{l|l|l}
\mathrm{ACA} & \mathrm{ATG} \\
\mathrm{A}_{\sqcup \mathrm{A}} & \mathrm{GTG} \\
\mathrm{AC}_{\sqcup} & \mathrm{GTC}
\end{array} \rightarrow M_{1} \rightarrow M_{2} \rightarrow M_{3}
$$

Figura 5.3: À esquerda, um alinhamento de três seqüências de DNA, com um bloco em destaque. À direita, um MMEO que modela o bloco em destaque no alinhamento. As probabilidades de emissão de símbolos não estão representadas. O estado inicial do modelo é $M_{1}$. As transições representadas são aquelas com probabilidades não-nulas.

\subsubsection{Tratamento de Inserções e de Remoções de Caracteres}

Infelizmente, os modelos criados da forma acima possuem utilidade limitada, porque mesmo seqüências ou trechos homólogos podem ter alguma inserção ou remoção de resíduos $^{13}$ de tal maneira que blocos que possuam longo comprimento sejam relativamente raros (a menos de, por exemplo, domínios em proteínas que sejam muito fortemente conservados entre seqüências). Para englobar estes casos, é necessária alguma maneira de fazer uma "ligação" entre vários blocos ou de flexibilizar o MMEO de um bloco para que seqüências inteiras (e não apenas trechos altamente conservados) possam ser modelados. A estratégia que vamos adotar daqui em diante é a segunda.

Um fato importante a observar é que um modelo construído como acima é, na realidade, um modelo para a seqüência consenso das seqüências representadas no alinhamento ${ }^{14}$.

Vamos supor que $\left|A^{\prime}\right|=n$. Para generalizar o modelo, ele deve ser modificado de maneira que seqüências de comprimentos menores e seqüências maiores do que $n$ possam ser geradas. Estes dois casos são tratados de maneira diferente. No caso em que uma sequiência $s$ tem comprimento $|s|>n$, dizemos que $s$ possui inserção de caracteres em relação ao modelo.

\footnotetext{
${ }^{13}$ Principalmente se a família das moléculas em estudo tiver representantes que estejam evolutivamente remotos dos demais.

${ }^{14} \mathrm{~A}$ seqüência consenso de um alinhamento é uma seqüência que possui o mesmo comprimento que o alinhamento e cujo $i$-ésimo caractere é o caractere de maior probabilidade (ou um caractere de maior probabilidade, no caso de não haver um caractere único) da $i$-ésima coluna do alinhamento.
} 
No caso em que $s$ tem comprimento $|s|<n$, dizemos que $s$ possui remoção de caracteres em relação ao modelo.

Os modelos em sua forma final consistirão de estados de três tipos, a saber:

- estados de emparelhamento, denotados por $M_{i}$ (já vistos);

- estados de inserção, denotados por $I_{i}$;

- estados de remoção, denotados por $D_{i}$.

Vamos tratar agora do caso de inserção de caracteres.

Para o MMEO conseguir modelar seqüências que tenham mais símbolos do que o MMEO tem estados de emparelhamento, é necessário que a possibilidade de símbolos serem gerados fora dos estados $M_{i}$ esteja prevista. Uma maneira de lidar com essa possibilidade é inserir um estado adicional $I_{i}$ após cada estado $M_{i}$ e antes de $M_{i+1}$ para tratar de uma inserção de símbolos entre estes estados (o estado $I_{i}$ é destino de uma transição proveniente de $M_{i}$ e é origem de uma transição com destino em $M_{i+1}$ ). Como trechos de tamanhos arbitrários podem ser inseridos entre os caracteres gerados por $M_{i}$ e $M_{i+1}$, o estado $I_{i}$ possui uma transição em forma de laço (i.e., uma transição de $I_{i}$ para $I_{i}$ ). Isso dá conta das inserções de símbolos entre símbolos gerados pelos estados de emparelhamento. Para que uma seqüência de observações possa ter símbolos inseridos antes de qualquer símbolo gerado por um estado de emparelhamento, basta adicionar um estado de inserção $I_{0}$ como estado inicial do modelo. $\mathrm{O}$ estado $I_{n}$ trata do caso de inserção de símbolos após símbolos gerados pelo último estado de emparelhamento.

Mas, uma vez que os estados de inserção geram símbolos como observações, eles precisam gerar símbolos de acordo com uma distribuição de probabilidades. Como um símbolo inserido é um símbolo "não previsto" pelo modelo do bloco de alinhamento, é natural adotar como a distribuição de probabilidades para o símbolo gerado em um estado de inserção a freqüência relativa dos símbolos das seqüências do alinhamento (possivelmente com uso de pseudo-contadores para evitar o Problema da Probabilidade Zero).

As únicas transições de probabilidade não-nula referentes ao estado de inserção $I_{i}$ neste modelo com estados de inserção são as transições de $M_{i}$ a $I_{i}$, de $I_{i}$ a $I_{i}$ e de $I_{i}$ a $M_{i+1}$, para $i=1, \ldots, n-1$. Para $i=0$, as transições referentes a $I_{0}$ são apenas as transições de $I_{0}$ a $I_{0}$ e de $I_{0}$ a $M_{1}$. Para $i=n$, a única transição referente a $I_{n}$ é a transição de $M_{n}$ a $I_{n}$.

Em aplicações de interesse, as probabilidades de inserção de símbolos, bem como as probabilidades de transição são estimadas por algum algoritmo de treinamento de modelos, como o Algoritmo EstimaPC ou o Algoritmo de Baum-Welch, após o modelo estar com todos os estados determinados.

Com esta alteração do modelo, é simples de mostrar que o custo de uma inserção de $h$ símbolos, para $h \geq 1$, dado em log da razão de probabilidades de um modelo em relação ao modelo nulo, é igual ao custo afim de uma lacuna de $h$ caracteres, da maneira definida como para algoritmos de programação dinâmica básicos (vide Capítulo 1).

Tratamos agora do último tipo de estados, de remoção de caracteres.

Para tratar de seqüências que apresentam remoções de caracteres, o modelo poderia ter transições diretas de um estado $M_{i}$ a todos os estados $M_{i^{\prime}}$, com $i<i^{\prime}$, para que uma transição, por exemplo, de $M_{i}$ fosse diretamente a $M_{i+2}$, evitando que o símbolo de $M_{i+1}$ fosse gerado ("removendo-o"). Essa solução, apesar de bastante geral, deixa o modelo com muitas transições ${ }^{15} \mathrm{e}$, assim, com um grande número de parâmetros a serem estimados. Com

\footnotetext{
${ }^{15}$ Mais especificamente, um número quadrático de transições no número de estados de emparelhamento.
} 
tal topologia, o modelo precisaria de uma grande quantidade de dados para o treinamento e o problema de existência de vários máximos locais para a função de verossimilhança também seria maior [DEKM98].

Uma solução que perde um pouco da generalidade da adição das várias transições, mas que simplifica tanto a descrição do modelo quanto seu treinamento é adicionar estados de remoção $D_{i}$ que sejam mudos (i.e., que não produzam símbolos como observação) e que sejam conectados com transições de $M_{i-1}$ a $D_{i}$, de $D_{i}$ a $M_{i+1}$, de $I_{i-1}$ a $D_{i}$ e de $D_{i}$ a $I_{i+1}$.

Um tal estado $D_{i}$ é responsável pela "remoção" de um símbolo que seria emitido no modelo. Por exemplo, um símbolo poderia ser emitido por $M_{i-1}$, uma transição poderia ser feita de $M_{i-1}$ a $D_{i}$, nenhuma emissão seria feita em $D_{i}$ (pois $D_{i}$ é mudo), uma transição de $D_{i}$ a $M_{i+1}$ seria feita e uma nova geração de símbolos ocorreria em $M_{i+1}$. Em outras palavras, isso significa que o símbolo que seria emitido por $M_{i}$ é "omitido" da geração por causa de o passeio no grafo do modelo passar por $D_{i}$. Com a existência dos estados de remoção, o modelo passa a permitir a geração de seqüências que tenham menos símbolos do que o modelo tem de estados de emparelhamento.

É conveniente também permitir que transições possam ser feitas diretamente entre estados de remoção (i.e., permitir transições da forma $I_{i} \rightarrow I_{i+1}$ ) pois assim o modelo pode realizar várias transições entre estados de remoção, o que significa informalmente que uma seqüência de vários símbolos consecutivos seria removida em relação ao modelo. É claro também que, conforme descrito, o modelo pode admitir remoções e inserções consecutivas (em qualquer ordem, inclusive em alternância), conforme esperado do ponto de vista biológico (ainda que, talvez, com baixa probabilidade).

Para acomodar a existência de estados mudos, os algoritmos básicos para MMEOs devem sofrer modificações. Ilustramos mais adiante o caso de alguns algoritmos com versões especializadas para MMEOs de perfil de seqüências.

Apesar de não ser estritamente necessário, é conveniente adicionar ao modelo dois estados extras, mudos. Um estado, o estado inicial, é o estado por que a geração de símbolos sempre é iniciada e que possui transições para os estados $I_{0}, M_{1}$ e $D_{1}$. Este estado, apesar de ser mudo, é denotado por $M_{0}$. O outro estado, o estado final, é o estado em que a geração de símbolos pelo modelo é finalizada (i.e., nenhuma transiçã̃o parte do estado final) e que possui transições oriundas dos estados $D_{n}, I_{n}$ e $M_{n}$. O estado final, que é mudo, é denotado por $M_{n+1}$. A Figura 5.4 ilustra a forma final do modelo. Repare-se que o número de estados do modelo é $3 n+3$, onde $n$ é o número de estados de emparelhamento não-mudos do modelo. Para a implementação de algoritmos sobre pMMEOs (e.g., Algoritmo de Viterbi ou Progressivo) pode ainda ser vantajoso adicionar mais um estado fictício, o estado $D_{0}$, com transições apenas para os estados $I_{0}, M_{1}$ e $D_{1}$, com probabilidade de transição igual a 0 para cada uma dessas transições. Esta medida serve para eliminar os casos especiais e uniformizar o tratamento dado aos estados do modelo nos algoritmos. Em determinadas circunstâncias, pode também ser de interesse adicionar, de maneira análoga, estados $D_{n+1}$ e $I_{n+1}$ com transições de probabilidade 0 . O modelo, em sua versão final, fica com um total de $3 n+6$ estados, onde novamente $n$ é o número de estados de emparelhamento não-mudos do modelo.

A construção de um pMMEO a partir de um alinhamento é, como nos outros casos de construções de MMEOs, dividida em duas etapas: a determinação do número de estados do modelo e a estimação de seus parâmetros. Já notamos que o alfabeto do modelo fica automaticamente determinado pelo alfabeto em que as seqüências do alinhamento foram definidas. Além disso, o número de estados do modelo é automaticamente determinado pela quantidade de estados de emparelhamento do modelo. A determinação, a partir de um 


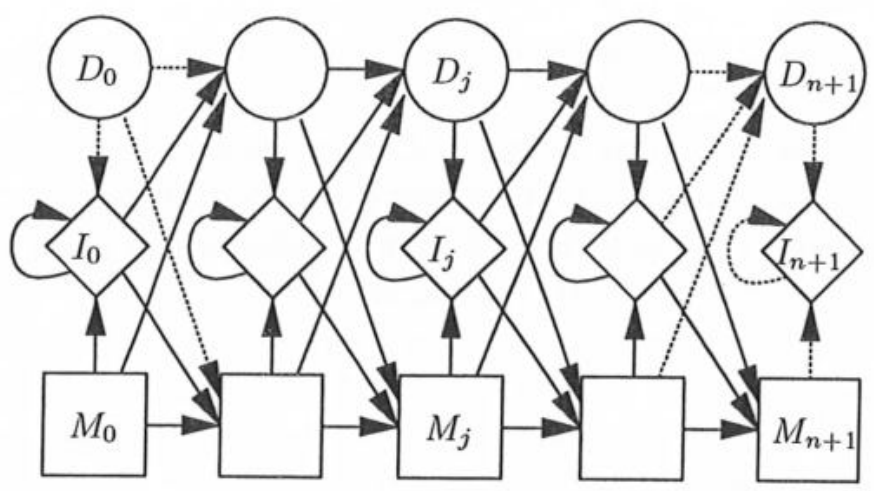

Figura 5.4: $\mathrm{O}$ esquema geral de um pMMEO. Na figura, estão incluídos os estados $M_{0}$ (inicial), $I_{0}, D_{0}, M_{n+1}, I_{n+1}$ e $D_{n+1}$. As transições pontilhadas possuem probabilidade 0 .

alinhamento, de quantos (e quais) estados do modelo serão estados de emparelhamento nãomudos resume-se a escolher quais colunas do alinhamento serão associadas a tais estados.

Intuitivamente, as colunas de um alinhamento que possuem resíduos bastante conservados são as colunas que devem ser associadas a estados de emparelhamento a fim de representar bem a família de seqüências. Como essa decisão pode ser difícil e pode requerer conhecimento prévio adicional, é comum o uso de heurísticas para decidir quais colunas do alinhamento ficam associadas a estados de emparelhamento. No início da seção, por simplicidade, havíamos escolhido para construir o modelo apenas as colunas que não tinham espaços, mas para modelos mais gerais é melhor adotar regras mais flexíveis.

Uma regra simples para decidir quais colunas ficam representadas por estados de emparelhamento é observar a freqüência de espaços na coluna do alinhamento e "marcá-la" para ser representada se a frequiência de espaços for menor do que 1/2 [DEKM98].

Com essa escolha de colunas, o modelo fica completamente definido a menos de seus parâmetros.

A escolha de colunas também determina um passeio no grafo do modelo para cada uma das seqüências do alinhamento de maneira simples:

- se uma seqüência possui um caractere em uma coluna do alinhamento que foi marcada para ser representada por um estado de emparelhamento $M_{i}$, então o estado $M_{i}$ é trivialmente escolhido como o estado que gerou o símbolo da seqüência;

- se o caractere está em uma coluna que não é representada como um estado de emparelhamento, o caractere é considerado como uma inserção e emitido pelo estado de inserção $I_{i}$ que for imediatamente sucessor ao último estado de emparelhamento $M_{i}$ usado para emitir um símbolo da seqüência (o estado $I_{0}$ é usado se nenhum estado de emparelhamento foi usado na seqüência, conforme esperado já que se trata de uma inserção de caracteres antes de caracteres modelados pelo MMEO em construção);

- finalmente, se a seqüência não possui um caractere em uma posição de alinhamento associada a um estado $M_{i}$ (isto é, a posição na seqüência possui um espaço), considerase que a seqüência possui um símbolo removido em relação ao modelo e o passeio descrito pela seqüência no grafo do modelo passa pelo estado $D_{i}$ que sucede o último estado de emparelhamento usado, $M_{i-1}$ (o estado $D_{1}$ é usado caso nenhum estado de emparelhamento tenha sido usado para rotular símbolos da seqüência). 
Note-se que o modelo construído considera a hipótese simplificadora de que cada coluna é independente das demais.

Um interessante caso ocorre na situação degenerada em que o alinhamento dado como entrada consiste de uma só seqüência, digamos $t$, com comprimento $n$. Naturalmente, este alinhamento não possui espaços e cada coluna do alinhamento (ou seja, um símbolo de t) é modelada por um estado de emparelhamento do pMMEO. Neste caso, é possível reescrever uma versão especializada do Algoritmo de Viterbi que recebe uma seqüência $s$ e que, essencialmente, simula as operações realizadas pelos algoritmos de programação dinâmica (Needleman e Wunsch) durante a inferência de um passeio que gere $s$ no grafo do modelo derivado a partir do "alinhamento" $t$ [DEKM98].

Uma vez que o modelo esteja com os estados definidos e que as seqüências do alinhamento estejam com os passeios no grafo do modelo determinados, um algoritmo como o Algoritmo EsTimAPC pode ser usado para finalizar a construção do pMMEO. Naturalmente, não há probabilidades de emissões de símbolos a serem estimadas para os estados de remoção (mudos). É claro ainda que alguma estratégia pode ser usada para lidar com o Problema da Freqüência Zero.

As versões dos algoritmos para MMEOs ficam ligeiramente modificadas quando um modelo possui estados mudos. Tal é o caso dos pMMEOs da presente seção. Embora as modificações sejam relativamente simples para acomodar os estados mudos, ainda assim é elucidativo descrever os principais algoritmos (Progressivo, REgressivo, de Viterbi e de Baum-Welch) para ilustrar as diferenças existentes; isto serve também para mostrar versões específicas dos algoritmos para pMMEOs ${ }^{16}$.

As principais diferenças aqui são o tratamento dos estados de um modelo de acordo com seus três tipos possíveis e o preenchimento de três matrizes de programação dinâmica (em vez de uma só no caso dos MMEOs genéricos).

Em particular, para o Algoritmo Progressivo-pMMEO, três matrizes, $\alpha_{M}, \alpha_{I}$ e $\alpha_{D}$, são preenchidas e possuem as seguintes interpretações:

- $\alpha_{M}(i, j)$ é a probabilidade conjunta de o prefixo $s[1 \ldots i]$ ser gerado por um passeio cujo último estado é $M_{j}$, ou seja, $\alpha_{M}(i, j)=\operatorname{Pr}\left(s[1 \ldots i], M_{j}\right)$;

- $\alpha_{I}(i, j)$ é a probabilidade conjunta de o prefixo $s[1 \ldots i]$ ser gerado por um passeio cujo último estado é $I_{j}$, ou seja, $\alpha_{I}(i, j)=\operatorname{Pr}\left(s[1 \ldots i], I_{j}\right)$;

- $\alpha_{D}(i, j)$ é a probabilidade conjunta de o prefixo $s[1 \ldots i]$ ser gerado por um passeio cujo último estado é $D_{j}$, ou seja, $\alpha_{D}(i, j)=\operatorname{Pr}\left(s[1 \ldots i], D_{j}\right)$.

As relações de recorrência satisfeitas pelas matrizes $\alpha_{M}, \alpha_{I}$ e $\alpha_{D}$ são as seguintes:

$$
\begin{aligned}
\alpha_{M}(i, j)= & e_{M_{j}}(s[i]) \\
& {\left[\alpha_{M}(i-1, j-1) a_{M_{j-1} M_{j}}+\alpha_{I}(i-1, j-1) a_{I_{j-1} M_{j}}+\alpha_{D}(i-1, j-1) a_{D_{j-1} M_{j}}\right] } \\
\alpha_{I}(i, j)= & e_{I_{j}}(s[i])\left[\alpha_{M}(i-1, j) a_{M_{j} I_{j}}+\alpha_{I}(i-1, j) a_{I_{j} I_{j}}+\alpha_{D}(i-1, j) a_{D_{j} I_{j}}\right] \\
\alpha_{D}(i, j)= & \alpha_{M}(i, j-1) a_{M_{j-1} D_{j}}+\alpha_{I}(i, j-1) a_{I_{j-1} D_{j}}+\alpha_{D}(i, j-1) a_{D_{j-1} D_{j}}
\end{aligned}
$$

A inicialização das matrizes é feita para as células que tenham $i=0$ ou $j=0$. Analisemos primeiro o caso $i=0$. Como $M_{0}$ é o estado inicial, temos que $\alpha_{M}(0,0)=1, \alpha_{I}(0,0)=0$ e $\alpha_{D}(0,0)=0$. Além disso, para todo $j \geq 1$, temos que $\alpha_{M}(0, j)=0$ e, da mesma forma,

\footnotetext{
${ }^{16} \mathrm{Na}$ forma apresentada, os principais objetivos dos algoritmos são a inteligibilidade e a didática; certamente, versões mais eficientes podem ser desenvolvidas.
} 
$\alpha_{I}(0, j)=0$, porque os estados de emparelhamento e os estados de inserção são geradores de símbolos para $j \geq 1$ e não é possível estar em um desses estados e ter gerado apenas a sequiência vazia. Já para $j \geq 1, \alpha_{D}(0, j)$ é a probabilidade de o modelo não ter gerado nenhum símbolo e de estar no estado $D_{j}$, o que pode não ter probabilidade 0 por causa dos estados mudos (é possível atingir $D_{j}$ com uma seqüência de várias transições entre estados de remoção após a transição de $M_{0}$ a $D_{1}$ ).

Aplicando-se a relação de recorrência, é simples de ver que $\alpha_{D}(0,1)=a_{M_{0} D_{1}}$ e $\alpha_{D}(0, j)=$ $\alpha_{D}(0, j-1) a_{D_{j-1} D_{j}}$, para $j \geq 2$, que corresponde à interpretação intuitiva de que é possível o modelo estar em $D_{j}$ sem gerar símbolos (apenas com transições entre estados de remoção, com exceção da primeira transição).

Para o caso $j=0$, é simples de ver que $\alpha_{M}(i, 0)=0$, para todo $i \geq 1$. Da mesma forma, $\alpha_{D}(i, 0)=0$, para $i \geq 1$. Entretanto, é possível que $\alpha_{I}(i, 0)$ seja não-nula, porque o modelo pode gerar $i$ símbolos no estado $I_{0}$, o que corresponde a inserções de caracteres antes do início do modelo. Pela relação de recorrência, segue que $\alpha_{I}(1,0)=a_{M_{0} I_{0}} e_{I_{0}}(s[1])$ e $\alpha_{I}(i, 0)=\alpha_{I}(i-1,0) a_{I_{0} I_{0}} e_{I_{0}}(s[i])$ para $i \geq 2$ (i.e., a geração de símbolos em $I_{0}$ por meio de uma transição de $M_{0}$ a $I_{0}$ e por transições de $I_{0}$ a $I_{0}$ com respectivas gerações de símbolos).

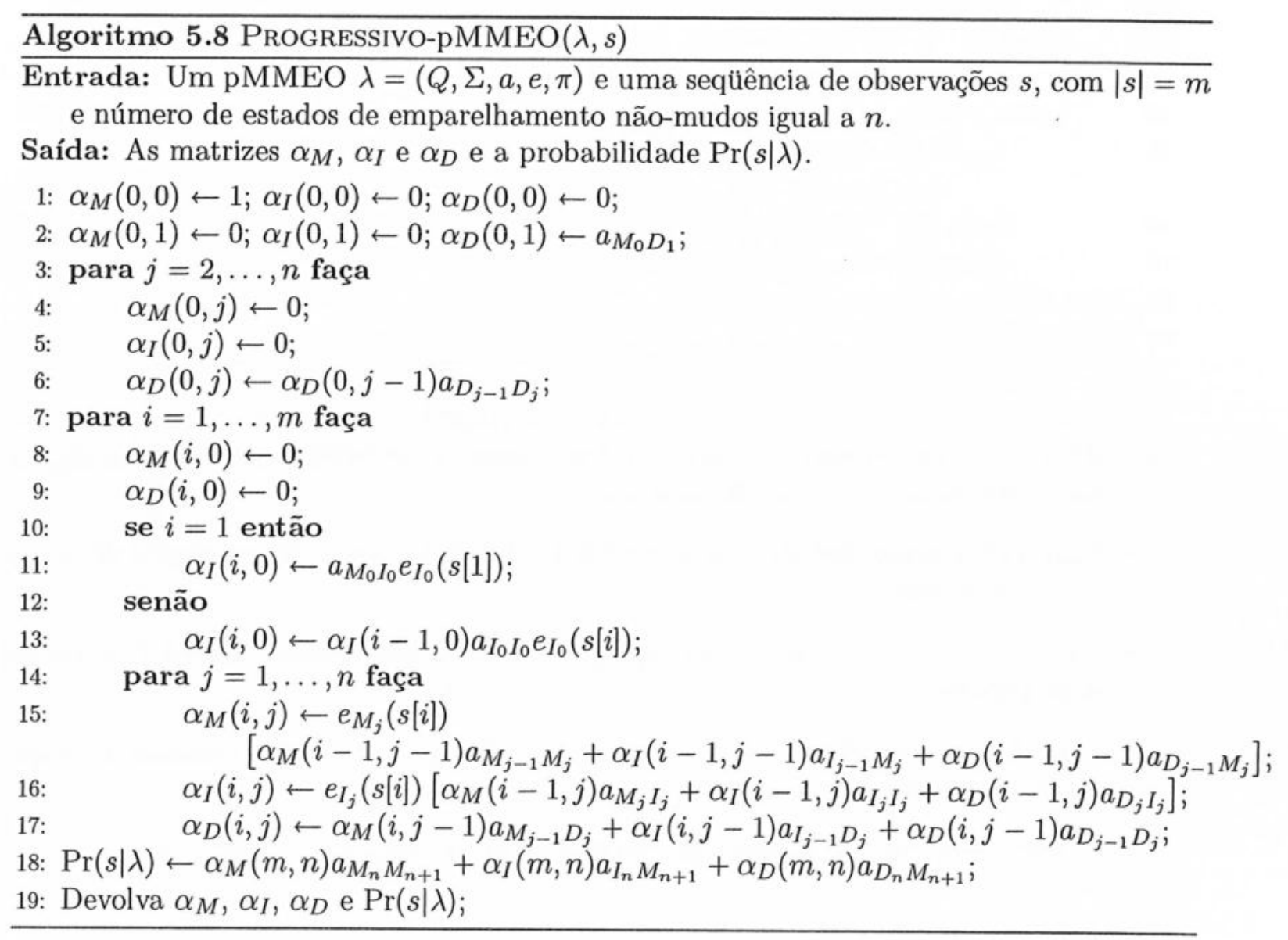

Conforme esperado, uma versão especial do Algoritmo de Viterbi para pMMEOs pode ser obtida a partir do Algoritmo Progressivo-pMMEO através de uma simples troca de somas por cálculos de máximos. Nessa versão especial, as matrizes preenchidas são $\delta_{M}$, $\delta_{I}$ e $\delta_{D}$, análogas às matrizes $\alpha_{M}, \alpha_{I}$ e $\alpha_{D}$. Apresentamos aqui uma versão simplificada do algoritmo, mas o pseudo-código pode ser modificado para devolver também um passeio 
ótimo, como foi feito para MMEOs sem estados mudos.

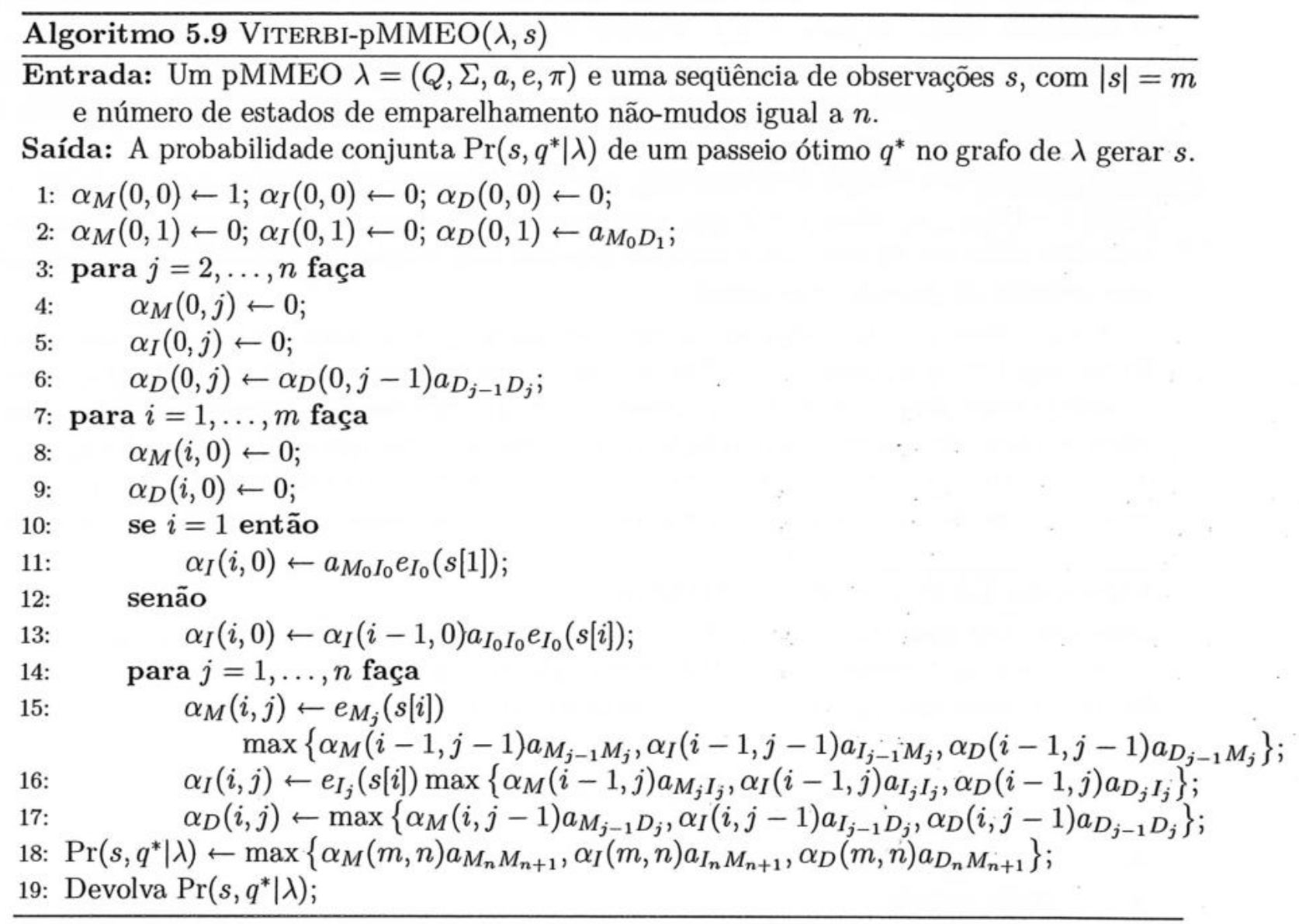

De maneira parecida, o Algoritmo REgressivo-pMMEO também pode ser escrito para um pMMEO. Como no caso do Algoritmo Progressivo-pMMEO, três matrizes, $\beta_{M}, \beta_{I}$. e $\beta_{D}$, são preenchidas e seus significados são:

- $\beta_{M}(i, j)$ é a probabilidade de gerar $s[i+1 \ldots m]$ dado que o estado atual é $M_{j}$ e que $s[i]$ já foi gerado;

- $\beta_{I}(i, j)$ é a probabilidade de gerar $s[i+1 \ldots m]$ dado que o estado atual é $I_{j}$ e que $s[i]$ já foi gerado;

- $\beta_{D}(i, j)$ é a probabilidade de gerar $s[i+1 \ldots m]$ dado que o estado atual é $D_{j}$ e que $s[i]$ já foi gerado.

Com essas definições, as relações de recorrência ficam, para $i \geq 1$ e para todo $j$ :

$$
\begin{aligned}
\beta_{M}(i-1, j)= & a_{M_{j} M_{j+1}} e_{M_{j+1}}(s[i]) \beta_{M}(i, j+1)+ \\
& a_{M_{j} I_{j}} e_{I_{j}}(s[i]) \beta_{I}(i, j)+a_{M_{j} D_{j+1}} \beta_{D}(i-1, j+1) \\
\beta_{I}(i-1, j)= & a_{I_{j} M_{j+1}} e_{M_{j+1}}(s[i]) \beta_{M}(i, j+1)+ \\
& a_{I_{j} I_{j}} e_{I_{j}}(s[i]) \beta_{I}(i, j)+a_{I_{j} D_{j+1}} \beta_{D}(i-1, j+1) \\
\beta_{D}(i-1, j)= & a_{D_{j} M_{j+1}} e_{M_{j+1}}(s[i]) \beta_{M}(i, j+1)+ \\
& a_{D_{j} I_{j}} e_{I_{j}}(s[i]) \beta_{I}(i, j)+a_{D_{j} D_{j+1}} \beta_{D}(i-1, j+1)
\end{aligned}
$$


As condições iniciais são dadas por:

$$
\begin{aligned}
& \beta_{M}(m, n+1)=\operatorname{Pr}\left(\varepsilon \mid M_{n+1}\right)=1 \\
& \beta_{M}(m, j)=\operatorname{Pr}\left(\varepsilon \mid M_{j}\right)= \begin{cases}a_{M_{j} M_{j+1}}, & \text { se } j=n \\
a_{M_{j} D_{j+1}} \beta_{D}(m, j+1), & \text { se } j<n\end{cases} \\
& \beta_{I}(m, n+1)=\operatorname{Pr}\left(\varepsilon \mid I_{n+1}\right)=1 \\
& \beta_{I}(m, j)=\operatorname{Pr}\left(\varepsilon \mid I_{j}\right)= \begin{cases}a_{I_{j} M_{j+1}}, & \text { se } j=n \\
a_{I_{j} D_{j+1}} \beta_{D}(m, j+1), & \text { se } j<n\end{cases} \\
& \beta_{D}(m, n+1)=\operatorname{Pr}\left(\varepsilon \mid D_{n+1}\right)=1 \\
& \beta_{D}(m, j)=\operatorname{Pr}\left(\varepsilon \mid D_{j}\right)= \begin{cases}a_{D_{j} M_{j+1}}, & \text { se } j=n \\
a_{D_{j} D_{j+1}} \beta_{D}(m, j+1), & \text { se } j<n\end{cases}
\end{aligned}
$$

Finalmente, o Algoritmo de Baum-Welch para pMMEOs funciona de maneira muito parecida com o caso de MMEOs sem estados mudos, com as matrizes $A$ e $E$ definidas de forma parecida como antes (no que está abaixo, $X_{j}$ denota $M_{j}, I_{j}$ e $D_{j}$ ):

$$
\begin{aligned}
A_{X_{j} M_{j+1}} & =\frac{1}{\operatorname{Pr}(s)} \sum_{i=1}^{m-1} \alpha_{X}(i, j) a_{X_{j} M_{j+1}} e_{M_{j+1}}(s[i+1]) \beta_{M}(i+1, j+1) \\
A_{X_{j} I_{j}} & =\frac{1}{\operatorname{Pr}(s)} \sum_{i=1}^{m-1} \alpha_{X}(i, j) a_{X_{j} I_{j}} e_{I_{j}}(s[i+1]) \beta_{I}(i+1, j) \\
A_{X_{j} D_{j+1}} & =\frac{1}{\operatorname{Pr}(s)} \sum_{i=1}^{m} \alpha_{X}(i, j) a_{X_{j} D_{j+1}} \beta_{D}(i, j+1) \\
E_{M_{j}}(b) & =\frac{1}{\operatorname{Pr}(s)} \sum_{i=0}^{m+1} \alpha_{M}(i, j) \beta_{M}(i, j) \\
E_{I_{j}}(b) & =\frac{1}{\operatorname{Pr}(s)} \sum_{i=0}^{m+1} \alpha_{I}(i, j) \beta_{I}(i, j)
\end{aligned}
$$

Assim como observamos nos comentários gerais do Algoritmo de Baum-Welch para MMEOs genéricos, se um dado parâmetro é igual a 0, então as futuras estimativas feitas pelo Algoritmo de Baum-Welch para este parâmetro também o serão.

\subsection{Alinhamento de Seqüências e MMEOs}

Conforme dissemos na introdução da seção sobre pMMEOs, um dos usos principais destas ferramentas é em buscas de seqüências em bancos de dados [DEKM98]. Outro uso dos pMMEOs é a adição de uma seqüência a um alinhamento que tenha sido usado como base para o modelo. Antes de tratarmos do principal tópico desta seção, que é uma breve discussão do uso de pMMEOs para construir um alinhamento de várias seqüências que estejam previamente não-alinhadas, vamos descrever rapidamente como uma seqüência pode ser adicionada a um alinhamento que tenha sido usado para construir um pMMEO.

Se um alinhamento entre seqüências de uma família está disponível e foi usado para construir um pMMEO dela, é relativamente simples usá-lo para adicionar uma nova seqüência ao alinhamento. O Algoritmo de Viterbi pode ser empregado para encontrar uma 
seqüência de estados no modelo (um passeio) para a seqüência $s$ que se deseje adicionar ao alinhamento. Esse passeio, por outro lado, pode ser interpretado como um alinhamento entre $s$ e a seqüência consenso do alinhamento, de maneira parecida com a interpretação de que um alinhamento induz um passeio no grafo para cada seqüência do alinhamento (vide seção anterior).

É importante frisar que, como um pMMEO possui estados que não produzem símbolos como observação, um passeio inferido pelo Algoritmo de Viterbi que gere $s$ pode ter mais estados do que $s$ tem símbolos, isto é, se $q^{*}$ é o passeio inferido pelo Algoritmo de Viterbi para a sequiência $s$, então $\left|q^{*}\right| \geq|s|$. Logo, perde-se a correspondência entre o tamanho do passeio e o tamanho da seqüência nos casos em que o MMEO possui estados mudos.

A informação do passeio pode ser usada para agregar a seqüência $s$ ao alinhamento já existente com as outras seqüências. No caso de um símbolo de $s$ ter um estado de emparelhamento $M_{j}$ associado pelo passeio, o caractere de $s$ pode simplesmente ser alinhado aos demais caracteres na coluna do alinhamento que deu origem a $M_{j}$. No caso de um símbolo de $s$ estar associado a um estado de inserção $I_{j}$, este símbolo poderá ser colocado em uma coluna que contenha só espaços nas linhas relativas às outras seqüências do alinhamento e que esteja imediatamente após a coluna associada a $M_{j}\left(\text { mas antes da associada a } M_{j+1}\right)^{17}$. Finalmente, no caso de o passeio associado à seqüência $s$ conter um estado de remoção $D_{j}$ (que, evidentemente, não fica associado a nenhum símbolo por ser mudo), um espaço na linha correspondente a $s$ deve ser inserido na coluna referente ao estado $M_{j}$.

Exemplo 5.3. No caso do MMEO obtido a partir do alinhamento $A$ da Figura 5.5 em que as colunas escolhidas para estados de emparelhamento estão marcadas com $*$, um passeio hipotético que gera a seqüência $s=$ ACATG é $q=M_{1} I_{1} I_{1} D_{2} M_{3} M_{4}$ e o alinhamento original com a sequiência $s$ anexada de acordo com o passeio $q$ é o alinhamento $A^{\prime}$. Ainda na figura, as colunas que continham espaços em posições complementares foram agregadas para obter $A^{\prime \prime}$.

$$
\begin{aligned}
& \text { ACAATG } \\
& \begin{aligned}
& A= \mathrm{A}_{\sqcup} \mathrm{AGTG} \\
& \mathrm{AC} \sqcup \mathrm{GTC} \\
& * \quad * * *
\end{aligned} \\
& A^{\prime}=\begin{array}{l}
\mathrm{A}_{\sqcup \sqcup \mathrm{CAATG}} \\
\mathrm{A}_{\sqcup \sqcup \sqcup \mathrm{AGTG}} \\
\mathrm{A}_{\sqcup \sqcup \mathrm{C}_{\sqcup \mathrm{GTC}}} \\
\mathrm{ACA}_{\sqcup \sqcup \sqcup \mathrm{TG}}
\end{array} \\
& A^{\prime \prime}=\begin{array}{l}
\mathrm{A}_{\sqcup} \mathrm{AGTG} \\
\mathrm{AC}_{\sqcup} \mathrm{GTC}
\end{array} \\
& \mathrm{ACA}_{\sqcup} \mathrm{TG}
\end{aligned}
$$

Figura 5.5: Um alinhamento $A$ a que a seqüência $s=$ ACATG foi adicionada para obter $A^{\prime}$. Após a inclusão de $s$, as colunas $2,3,4$ e 5 de $A^{\prime}$ foram agregadas ( 2 com 4 e 3 com 5 ) para obter o alinhamento $A^{\prime \prime}$.

Conforme dissemos, pode ser vantajoso agregar colunas que contenham espaços em posições complementares. Uma estratégia para isso é acomodar as inserções de todas as seqüências de forma conjunta, sem grandes cuidados ou preocupações em fazer um bom alinhamento nestas regiões, visto que um alinhamento entre elas é possivelmente pouco informativo, pois espera-se que, em tais trechos, as seqüências divirjam por causa de sua história evolutiva (i.e., as partes que supunham-se bem conservadas na família já foram escolhidas como estados de emparelhamento do modelo e, nas outras regiões, não é esperada grande similaridade ou conservação de resíduos entre as seqüências [DEKM98, pp. 150-

\footnotetext{
${ }^{17}$ Pode ser vantajoso, dependendo do caso, agregar duas colunas adjacentes que não estejam associadas a estados de emparelhamento se elas contiverem espaços e caracteres em posições complementares.
} 
151]). Esta, aliás, pode-se argumentar que é uma característica positiva dos MMEOs em contraste com os métodos mais tradicionais de alinhamento.

A descrição que fizemos mostra como "alinhar" uma sequência a um modelo que representa um alinhamento com o auxílio da rotulação que um passeio no modelo induz sobre uma seqüência de observações qualquer. Essas idéias podem ser usadas para criar um alinhamento via um MMEO construído a partir de seqüências não alinhadas seguindo a estratégia abaixo:

1. Escolher o comprimento do MMEO (número de estados de emparelhamento);

2. Através de algum método de treinamento como, por exemplo, o Método de BaumWelch para pMMEOs, estimar os parâmetros do modelo;

3. Uma vez que o modelo esteja completamente especificado, inferir passeios no grafo do modelo para cada uma das seqüências, através de um algoritmo como o Algoritmo de Viterbi;

4. Usando os passeios para cada seqüência, construir um alinhamento de todas elas.

Observe-se que o último passo da estratégia pode ser interpretado como a construção de um alinhamento tendo-se vários alinhamentos entre as seqüências da entrada e uma seqüência referencial (a seqüência consenso do alinhamento, que é o que o MMEO acaba representando na verdade) por meio do método de junção de alinhamentos usando a seqüência consenso como guia (vide Capítulo 4).

A escolha inicial do formato do modelo resume-se à decisão de quantos estados serão de emparelhamento. Uma regra usada comumente [DEKM98] é adotar como comprimento do modelo o tamanho médio das seqüências de treinamento, quando informações prévias não estão disponíveis. Inspeção do modelo, ajustes por meio de heurísticas e reconstruções em várias iterações podem ser convenientes para fazer um "ajuste fino" do modelo para aplicações de interesse [Rab89, DEKM98].

Em relação ao Método de Baum-Welch, como o que se encontra é um máximo local (e não global) da função de verossimilhança, a inicialização deve ser feita com cautela a partir de estimativas "razoáveis" para os parâmetros do modelo. Uma vasta lista de técnicas [DEKM98] pode ser usada para tentar contornar o problema de ótimos locais, incluindo o uso de várias estimativas iniciais, injeção de ruído e "simulated annealing".

Há ainda extensões dos modelos que apresentamos aqui, que podem ser usadas para alinhar localmente seqüências a tais pMMEOs estendidos, com uma de suas principais utilidades sendo a busca de seqüências em bancos de dados.

É interessante notar que a partir de cada conjunto $\left\{M_{j}, I_{j}, D_{j}\right\}$ de estados do modelo há 9 transições possíveis, sendo 3 transições possíveis a partir de cada estado do conjunto (a menos dos estados do final do modelo). Em determinados contextos [Edd03], cada um destes conjuntos é chamado um nó do modelo.

Por causa do número de transições, esse tipo de modelo é também chamado "Plan 9"18. Há, entretanto, variantes desse modelo. Uma delas é obtida quando transições de um estado de inserção a um estado de remoção ou de um estado de remoção a um estado de inserção não são permitidas. Com isso, a partir de cada nó do modelo partem apenas 7 transições. Essa é (com alguns outros estados adicionais) a estrutura básica do modelo "Plan 7", usado

\footnotetext{
${ }^{18} \mathrm{Em}$ uma humorosa homenagem feita ao famoso filme de ficção científica chamado "Plan 9 from Outer Space".
} 
nos modelos dos programas do pacote HMMER a partir da versão 2 (que também podem ser usados para buscas locais). 


\section{Referências Bibliográficas}

[AHU74] A. V. Aho, J. E. Hopcroft, and J. D. Ullman, The design and analysis of computer algorithms, Addison-Wesley, 1974.

[AMO93] R. K. Ahuja, T. L. Magnanti, and J. B. Orlin, Network flows: Theory, algorithms, and applications, 1st ed., Prentice Hall, 1993.

[BCW90] T. C. Bell, J. G. Cleary, and I. H. Witten, Text compression, Prentice Hall, 1990.

[Ben00] J. Bentley, Programming pearls, 2nd ed., Addison-Wesley, Inc., 2000.

[BLP97] V. Bafna, E. L. Lawler, and P. A. Pevzner, Approximation algorithms for multiple sequence alignment, Theoretical Computer Science 182 (1997), 233-244.

[BS96] E. Bach and J. Shallit, Algorithmic number theory - volume 1: Efficient algorithms, 1st ed., The MIT Press, 1996.

[BV01] P. Bonizzoni and G. D. Vedova, The complexity of multiple sequence alignment with SP-score that is a metric, Theoretical Computer Science 259 (2001), 63-79.

[CK00] P. Crescenzi and V. Kann, A compendium of NP optimization problems, World Wide Web, http://www.nada.kth.se/ viggo/problemlist/, March 2000.

[CL88] H. Carrillo and D. Lipman, The multiple sequence alignment problem in biology, SIAM Journal of Applied Math 48 (1988), no. 5, 1073-1082.

[CLR90] T. H. Cormen, C. E. Leiserson, and R. L. Rivest, Introduction to algorithms, 1st ed., The MIT Press, 1990.

[CLZU02] M. Crochemore, G. M. Landau, and Michal Ziv-Ukelson, A sub-quadratic sequence alignment algorithm for unrestricted cost matrices, SODA'2002, 2002, pp. 679-688.

[DEKM98] R. Durbin, S. R. Eddy, A. Krogh, and G.J. Mitchison, Biological sequence analysis: Probabilistic models of proteins and nucleic acids, Cambridge, 1998.

[Edd03] S. R. Eddy, HMMER: Profile hidden Markov models for biological sequence analysis, World Wide Web, http://hmmer.wust1.edu/, May 2003.

[FD87] D. Feng and R. F. Doolittle, Progressive sequence alignment as a prerequisite to correct phylogenetic trees, Journal of Molecular Evolution 25 (1987), 351-360. 
[FMCF01] C. G. Fernandes, F. K. Miyazawa, M. Cerioli, and P. Feofiloff (eds.), Uma introdução sucinta a algoritmos de aproximação, Publicações Matemáticas do IMPA, 2001.

[Fue97] G. Fuellen, Multiple alignment, Complexity International 4 (1997).

[GJ79] M. R. Garey and D. S. Johnson, Computers and intractability: A guide to the theory of NP-completeness, 1st ed., W. H. Freeman and Company, 1979.

[GK99] G. Gonnet and C. Korostensky, Optimal scoring matrices for estimating distances between aligned sequences, http://www.inf.ethz.ch/personal/gonnet/, July 1999.

[GKS95] S. K. Gupta, J. D. Kececioglu, and A. A. Schäffer, Improving the practical space and time efficiency of the shortest-paths approach to sum-of-pairs multiple sequence alignment, Journal of Computational Biology 2 (1995), no. 3, 459-472.

[GL99] D. Graur and Wen-Hsiung Li, Fundamentals of molecular evolution, 2nd ed., Sinauer Associates, Inc., 1999.

[Gui89] H. L. Guidorizzi, Um curso de cálculo, 2nd ed., vol. 1, Livros Técnicos e Científicos Editora, 1989.

[Gus93] D. Gusfield, Efficient methods for multiple sequence alignment with guaranteed error bounds, Bulletin of Mathematical Biology 55 (1993), no. 1, 141-154.

[Gus97] _ _ Algorithms on strings, trees and sequences: Computer science and computational biology, Cambrige Press, 1997.

[Ham80] R. W. Hamming, Coding and information theory, 1st ed., Prentice-Hall, Inc., 1980.

[Hir75] D. S. Hirschberg, A linear space algorithm for computing maximal common subsequences, Communications of the ACM 18 (1975), 341-343.

[Hir97] — Serial computations of Levenshtein distances, Pattern Matching Algorithms (A. Apostolico and Z. Galil, eds.), Oxford University Press, 1997, pp. 123-141.

[HSP00] R. E. Hickson, C. Simon, and S. W. Perrey, The performance of several multiplesequence alignment programs in relation to secondary-structure features for an rRNA sequence, Molecular Biology and Evolution 17 (2000), no. 4, 530-539.

[Jus01] W. Just, Computational complexity of multiple sequence alignment with SPscore, World Wide Web, http://www.math.ohiou.edu/ just/, 2001.

[Jus02] — Comunicação pessoal, Maio 2002.

[Kec95] J. Kececioglu, The MSA algorithm, Transcrição de Discussão via Conferência Eletrônica, World Wide Web, http://www.techfak.uni-bielefeld.de/bcd/ Lectures/, 1995.

[KG99] C. Korostensky and G. H. Gonnet, Near optimal multiple sequence alignments using a traveling salesman problem approach, SPIRE'99, 1999. 
[Law76] E. L. Lawler, Combinatorial optimization: Networks and matroids, Holt, Rinehart and Winston, 1976.

$\left[\mathrm{LKM}^{+} 02\right]$ A. P. Lago, C. A. Kulikowski, I. Muchnik, G. Fuks, E. W. Linton, V. Llaca, and J. Messing, Simultaneous identification of conserved regions and inversions through global optimization, May 2002.

[Mat01] S. R. Matioli, Biologia molecular e evolução, Holos Editora, 2001.

[MM88] E. W. Myers and W. Miller, Optimal alignments in linear space, Computer Applications in the Biosciences 4 (1988), no. 1, 11-17.

[MP80] W. J. Masek and M. S. Paterson, A faster algorithm computing string edit distances, Journal of Computer and System Sciences 20 (1980), no. 1, 18-31.

[NB94] D. Naor and D. L. Brutlag, On near-optimal alignments of biological sequences, Journal of Computational Biology 1 (1994), no. 4, 349-366.

[NW70] S. B. Needleman and C. D. Wunsch, A general method applicable to the search for similarities in the amino acid sequence of two proteins, Journal of Molecular Biology 48 (1970), 443-453.

[Pap94] C. H. Papadimitriou, Computational complexity, 1st ed., Addison-Wesley, Inc., 1994.

[Pev92] P. A. Pevzner, Multiple alignment, communication cost, and graph matching, SIAM Journal of Applied Math 52 (1992), no. 6, 1763-1779.

[Rab89] L. R. Rabiner, A tutorial on hidden Markov models and selected applications in speech recognition, Proceedings of the IEEE 77 (1989), no. 2, 257-286.

[SM97] J. Setubal and J. Meidanis, Introduction to computational molecular biology, PWS Publishing Company, 1997.

[Sto98] J. Stoye, Multiple sequence alignment with the divide-and-conquer method, Gene 211 (1998), 45-56.

[SW81] T. F. Smith and M. S. Waterman, Identification of common molecular subsequences, Journal of Molecular Biology 147 (1981), 195-197.

[Ukk83] E. Ukkonen, On approximate string matching, Proceedings of the 24th IEEE Annual Symposium on Foundations of Computer Science, 1983, pp. 487-495.

[Ukk85] — Algorithms for approximate string matching, Information and Control 64 (1985), 100-118.

[Vaz01] V. V. Vazirani, Approximation algorithms, Springer-Verlag, 2001.

[Wat95] M. S. Waterman, Introduction to computational biology: Maps, sequences and genomes, Chapman and Hall, 1995.

[WJ94] L. Wang and T. Jiang, On the complexity of multiple sequence alignment, Journal of Computational Biology 1 (1994), 337-348. 


\section{Índice Remissivo}

árvore filogenética, 45

\author{
alfabeto, 2,122 \\ genético estendido IUPAC, 3 \\ algoritmo \\ aproximação, 92 \\ exponencial, 72 \\ heurístico, 92 \\ polinomial, 72 \\ alinhamento, 3, 46 \\ ótimo, 6, 48 \\ 0-1-lacuna, 81 \\ 0-lacuna, 81 \\ bloco, 145 \\ compatível, 92 \\ concatenação, 5 \\ conjunto, 3 \\ corte, 28 \\ corte associado, 85 \\ global, 38 \\ induzido, 49 \\ junção, 92 \\ livre de colunas em branco, 9 \\ pontuação, 5 \\ projeção, 49 \\ $k$-projeção, 49 \\ semiglobal, 38 \\ seqüências não-alinhadas, 85
}

busca exaustiva, 9-12

cadeia de Markov, 116, 117

parâmetros, 120

caractere, 2

alinhado, 3

branco, 2

espaço, 2

ч, 2

inserção, 4, 146

remoção, 4, 147 substituição, 4

clique, 99

tamanho, 99

coluna

custo, 47

linear, 15

desmembramento, 76

conjunto balanceado, 103

conjunto de estados, 117, 122

constante de Carrillo-Lipman, 64

custo de comunicação, 101

normalizado, 101

decodificação

de Viterbi, 131

posterior, 130

diagonal principal, 60

distância, 6

de edição, 7

de Hamming, 8

de Levenshtein, 7

generalizada, 37

simples, 37

divisão e conquista, 22

edição

estado

operações, 7

de emparelhamento, 147

de inserção, 147

de remoção, 147

final, 143

inicial, 143

mudo, 143

estrela

aresta central, 100

centro, 100

configuração, 106

l-estrela, 100

vértice central, 100 
filogenia, 45

função afim, 81

gap, veja lacuna

grafo

corte, 83

cardinalidade, 86

induzido, 83

valor, 86

de edição, 51

pesos, 51

de transição, 118

distância entre vértices, 101

heurística, 92

IUPAC, veja alfabeto

l-estrela

híbrida, 111

lacuna, 3

custo linear, 15

MMEO, 45, 116, 122

pMMEO, 144

de Perfil de Seqüências, 144

nó, 155

parâmetros, 123

máquina de Turing

de entrada e saída, 16

método

de Baum-Welch, 138

de Esperança e Maximização, 138

de programação dinâmica, veja programação dinâmica

dos Quatro Russos, 29

métrica, 6

matriz

de emissão, 123

de pesos, 106

de transição, 117, 123

genérica, 82

Modelo de Markov de Estados Ocultos, veja MMEO

modelo esquerda-direita, 146

modelo nulo, 41

mutação aceita, 42

NP, 72
NP-completo, 72

ordem lexicográfica, 56

parâmetros, 120, 123

estimação, 120

estimador, 120

estimativas, 120

ponteiro de volta, 67

pontuação, 5

SP, $47-48$

ponderada, 48

aditividade, 6

função, 5,47

métrica, 6

matriz, 5

posição

dependência, 50

Problema

APS, 8

APS-SiM, 36

AVS, 48

AVSOL, 81

AVS01L, 81

Cortemáx $(B), 83$

SC-MÁx, 36

SC-MíN, 74

Alinhamento Local, 39

Alinhamento Semiglobal, 39

aparentemente intratável, 73

da Avaliação, 125

da Decodificação, 125

decodificação de Viterbi, 131

decodificação posterior, 130

da Freqüência Zero, 121

difícil, 72

do Treinamento, 126

fácil, 72

intratável, 72

solução eficiente, 72

programa

HMMER, 145, 156

hmmsearch, 145

diff, 37

patch, 37

bogofilter, 120

Clustal W, 46, 72

programação dinâmica, 12-13 
Needleman-Wunsch, 13

propriedade subproblemas comuns, 13

subsoluções ótimas, 12

Smith-Waterman, 40

pseudo-contadores, 121

razão de aproximação, 92

razão de probabilidades, 41

redução, 72

polinomial, 73

Regra de Laplace, 121

símbolo, 2

segmento, 2

seqüência, 2

central, 95

comprimento, 2

conjunto de, 2

consenso, 146

de observações, 117

de treinamento, 126

distância, 6

guia, 92

inversão, 4

reversão, 4

segmento, 2

subseqüência, 2

superseqüência, 2

treinamento, 46, 134

vazia, 2

similaridade, 35

local, 40

sinal, 117

contínuo, 117

discreto, 117

fonte de, 117

subseqüência, 2

superseqüência, 2,74

$t$-bloco, 29

canônico, 33

transcrição de edição, 51

transição, 117

treinamento

de Baum-Welch, 138

de Viterbi, 143

unidade taxonômica operacional, 45 vértice

central, 111

relevante, 65

vetor

de diferença, 32

de probabilidades iniciais, 117,123 